\title{
Evaluation of dietary intake and nutritional supplement use of elite and sub-elite Dutch athletes
}

Dutch Sport Nutrition and Supplement Study

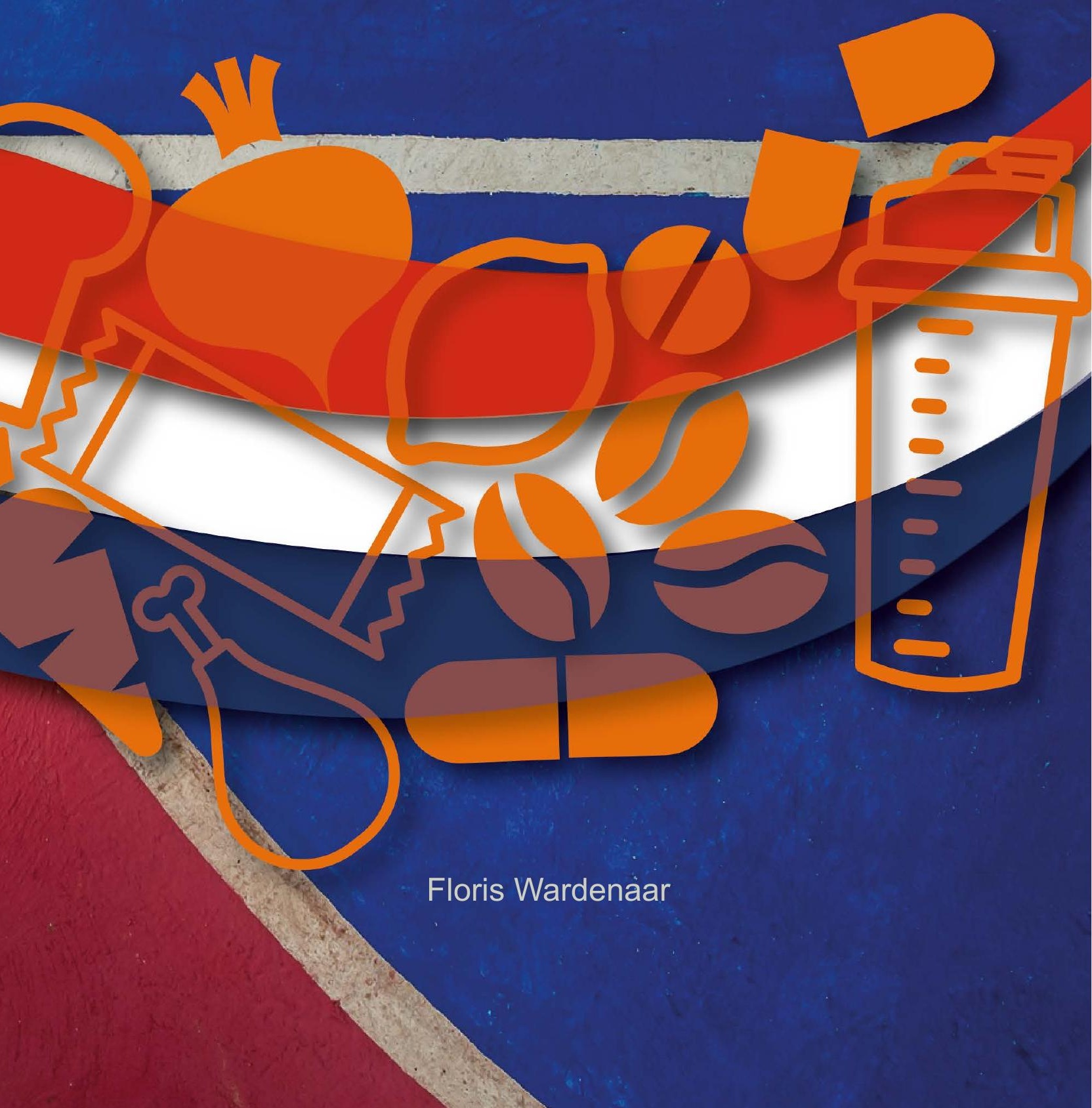




\section{Thesis committee}

Promotor

Prof. dr. R.F. Witkamp

Professor of Nutrition and Pharmacology

Wageningen University, the Netherlands

\section{Co-promotors}

Dr M. Mensink

Assistant Professor, Division of Human Nutrition

Wageningen University

Dr J.H.M. de Vries

Assistant Professor, Division of Human Nutrition

Wageningen University

\section{Other members}

Prof. Dr A.H. Kersten, Wageningen University

Prof. Dr R.J. Maughan, Loughborough University, Loughborough, United-Kingdom

Dr J. Wouters, NIZO research, Ede/ Sportcentrum Papendal, Arnhem, the Netherlands

Dr M.A.E. de van der Schueren, VU University Medical Center, Amsterdam/ HAN University of Applied Sciences, Nijmegen, the Netherlands

This research was conducted under the auspices of the Graduate School VLAG (Advanced studies in Food Technology, Agrobiotechnology, Nutrition and Health Sciences) 


\section{Evaluation of dietary intake and nutritional supplement use of elite and sub-elite Dutch athletes \\ Dutch Sport Nutrition and Supplement Study}

Floris C. Wardenaar

Thesis

submitted in fulfillment of the requirements for the degree of doctor

at Wageningen University

by the authority of the Rector Magnificus

Prof. dr. A.P.J Mol,

in the presence of the

Thesis Committee appointed by the Academic Board

to be defended in public

on Friday 3 February 2017

at 01.30 p.m. in the Aula. 
Floris C. Wardenaar

Evaluation of dietary intake and nutritional supplement use of elite and sub-elite Dutch athletes Dutch Sport Nutrition and Supplement Study

190 pages

PhD thesis, Wageningen University, Wageningen, the Netherlands (2017)

With references, with summary in English and Dutch.

ISBN 978-94-6343-032-6

DOI: http://dx.doi.org/10.18174/399863 


\section{Table of contents}

Chapter 1 Introduction

1.1 The importance of nutrition for athletes 11

1.2 Current sports nutrition guidelines, on what are they based? 12

1.3.1 Sports nutrition recommendations for daily intake 13

1.3.2 Sports nutrition recommendations before, during or after exercise 14

1.4 Gaps in dietary exposure assessment in sports nutrition research 15

1.5 Assessment of intake and dietary quality in athletes, are improvements needed?

$\begin{array}{ll}1.6 & \text { Aims and outline of this thesis. } \\ \end{array}$

\section{Original Research}

Chapter 2 Validation of web-based, multiple 24-h recalls combined with nutritional supplement intake questionnaires against nitrogen excretions to determine protein intake in Dutch elite athletes British Journal of Nutrition 2015;114:2083-92.

Chapter 3A Macronutrient intakes in 553 Dutch elite and sub-elite endurance, team and strength athletes: Does intake differ between sport disciplines?

submitted.

Chapter 3B Micronutrient intakes in 553 Dutch elite and sub-elite athletes: prevalence of low and high intakes in users and non-users of nutritional supplements

Submitted.

Chapter 4 Nutrient intake by ultramarathon runners: can they meet recommendations?

International Journal of Sport Nutrition and Exercise Metabolism. 2015;25:375-86.

Chapter 5 Self-reported use and reasons among the general population for using sports nutrition products and dietary supplements Sports 2016, 4(2), 33 
Chapter 6 Nutritional supplement use by Dutch elite and sub-elite athletes:

Does receiving dietary counselling make a difference?

Int J Sport Nutr Exerc Metab. 2016 Sep 6:1-25.

Chapter 7 General discussion

7.1 General outcomes

146

7.2 Methodological considerations

7.3 Dietary intake

150

7.4 General conclusions and directions for further research

Summary

Nederlandse samenvatting en praktijkadviezen

Acknowledgments

List of publications

About the author 


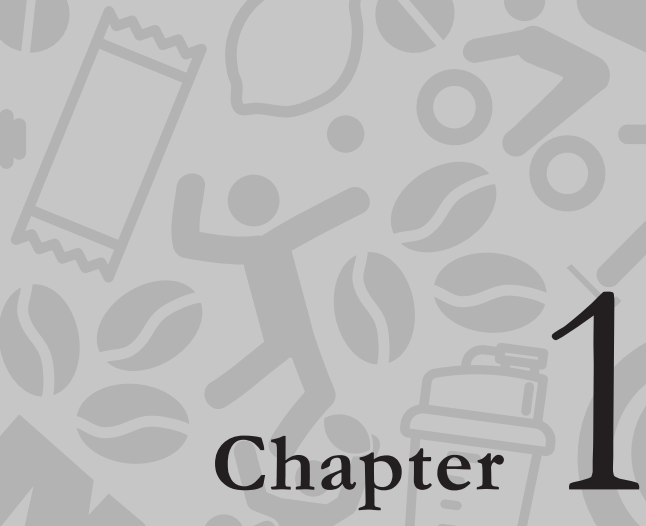




\section{Introduction}

$-$ 



\subsection{The importance of nutrition for athletes}

High level athletes differ from the general population in being considerably more physically active and by other lifestyle characteristics including intensive training routines and periodisation. ${ }^{1}$ Hence, adequate intake (Al) of energy and nutrients is of great importance for this population to ensure optimal performance, adaptation and recovery during training or competition, and also to minimize health risks. ${ }^{2,3}$ To meet these demands, specific recommendations have been formulated for nutritional intake during and after training or competition. ${ }^{2}$ However, the recommended habitual dietary intake can be difficult to reach as part of the athlete's personal available energy budget. ${ }^{4} \mathrm{~A}$ large variation is seen in dietary intake by athletes. ${ }^{1}$ An obvious reason is that sports differ with respect to their nutritional demands, in particular when it comes to macronutrients and total energy intake. Additionally, some sport disciplines do not allow, or make it difficult for the athlete to always consume the right quantity and type of foods at the right time. For example, during competition this could be due to the intensity of exercise, or because of the rules applicable to the field of sport. ${ }^{1}$ Planning dietary intake before, during and after exercise can be quite demanding. ${ }^{3}$ Also physiological limitations such as gastrointestinal (GI) distress can interfere with recommended dietary intake related to exercise. ${ }^{5,6}$ Last but not least, having a strong winners' mentality and personality in common, top-athletes belong to a small and elite group of individuals displaying inter-individual heterogeneity both physically and psychologically. Looking for ways to improve their performance, some may be tempted to follow certain food hypes or take products that promise benefits. Commercial pressure may play a role as well. Suppliers consider top-athletes an interesting target group to promote sales of their products and they sometimes sponsor teams or individual athletes. Taken together, sports nutrition presents specific challenges for sports dieticians, coaches and not the least the athletes themselves. It is therefore also understandable that several athletes experience difficulties in meeting the recommendations or their personal goals dietary goals.

A three level pyramid is often used to illustrate the different categories of foods and products used by athletes to meet their dietary requirements (Figure 1). The basis for this model is that athletes should focus on making proper basal nutrition choices first. If needed, sport specific nutrition can be added to their personal diet, for example when basic foods are not convenient or not available. The top of the pyramid represents the use of dietary supplements. The idea behind this model is to educate athletes about making proper choices. 


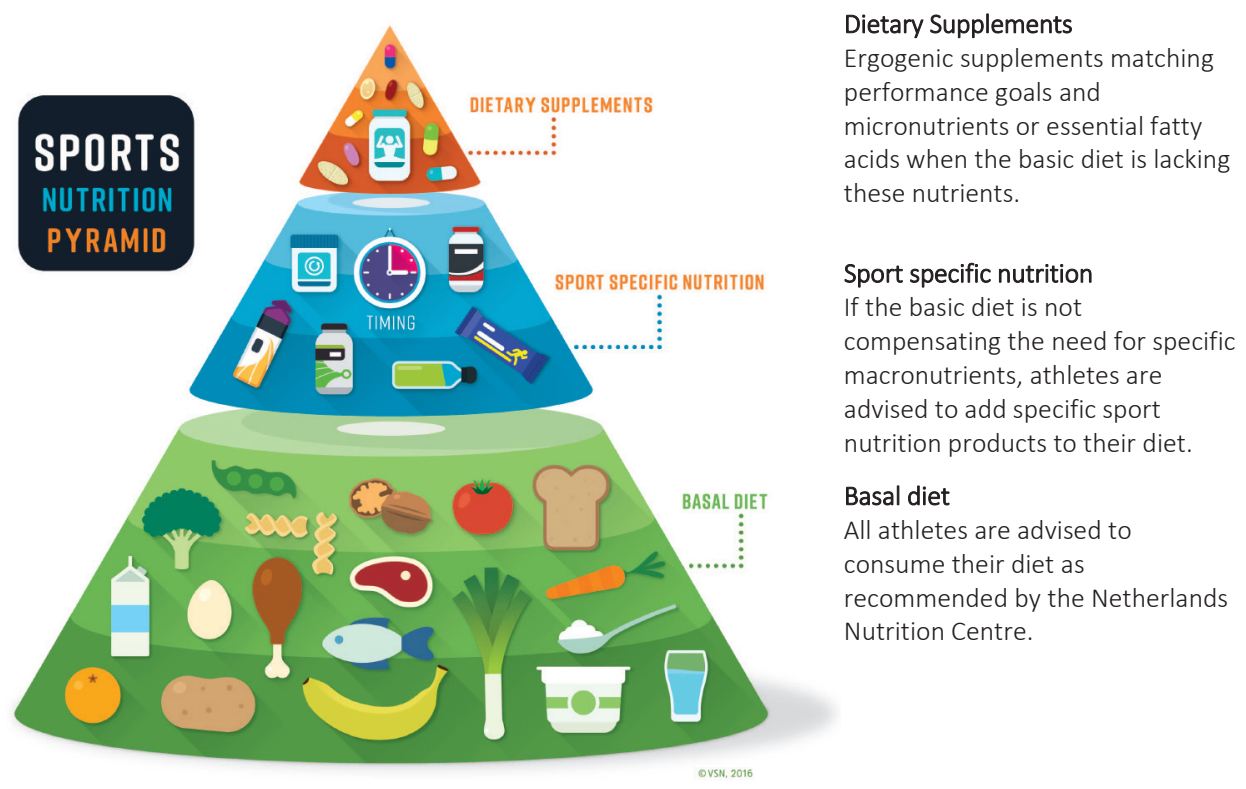

Figure 1. Sports nutrition pyramid (adapted from the Dutch Association of Sports Dietetics, VSN).

\subsection{Current sports nutrition guidelines, on what are they based?}

In view of the specific challenges described above, and the often limited research data on the relationship between nutrition and top-level performance, sports nutrition guidelines are based on expert opinion and consensus using the best available scientific evidence. Hence, these recommendations consist of a mix of practical experience and expertise, data from observational studies, physiological knowledge and experimental data from laboratory studies and, if available, intervention studies. 2, 3, 7 Like the recommended dietary intakes (RDIs) set for the general population, sports nutrition guidelines apply to population level. At the same time, it is commonly acknowledged that these general recommendations should be fine-tuned in consideration of the individual's total energy requirements, specific training needs, and feedback from training or competing performance. $^{8}$

Sports nutrition guidelines differ from regular RDIs, which are based on data from observational and intervention studies used to estimate nutrient requirements for micronutrients and to establish recommendations for optimal ranges of macronutrient intakes based on randomized clinical trials (RCTs) where possible. ${ }^{9}$

As RDIs are intended for the general population, and not for groups or individuals with specific conditions affecting their nutrient requirements, ${ }^{9}$ sports nutrition guidelines can be seen as a valuable addition. These guidelines focus on quantity, structure and timing of food intake of single nutrients ${ }^{2}$ and also include advice for types or cate- 
gories of exercise, i.e. for endurance, team and strength sports. ${ }^{10-12}$ Sports nutrition recommendations are given to ensure that athletes train more effectively, increase performance and reduce the risk of injury and illness.

\subsubsection{Sports nutrition recommendations for daily intake}

Maintenance of energy balance is important in people who are physically active. ${ }^{2}$ Athletes need to consume enough energy to refuel their body and to maintain an appropriate body weight and body composition. ${ }^{3}$ The fat requirements of athletes are similar or somewhat higher than those recommended for the general population. ${ }^{2}$ Fat is a necessary component of a healthy diet, providing energy, essential elements of cell membranes and other biochemical processes, and facilitating the absorption of fat soluble vitamins. General recommendations focus on the proportion $(<10 \%)$ of energy from saturated fats and include sources of essential fatty acids (i.e. linoleic acid [C18:2 n-6] and $\alpha$-linoleic acid [C18:3 n-3]) to meet adequate intake recommendations. ${ }^{13}$ Intake of fat by athletes should be in accordance with public health guidelines. ${ }^{14}$ If athletes choose to excessively restrict their fat intake, for example in an effort to lose bodyweight or improve body composition, they should be discouraged from chronic implementation of fat intakes below $20 \%$ of energy intake. A reduction this large has frequently been associated with a lower intake of fat-soluble vitamins and essential fatty acids, mainly n-3 fatty acids. When such a specific dietary restriction is considered necessary, the advice should be to limit this to more or less acute scenarios, for example temporarily weight reduction, during carbohydrate-loading or to prevent gastrointestinal discomfort. In recent years there has been a renewed interest in the use of- and chronic adaptation to low-carbohydrate high-fat, (LCHF) diets. Current evidence suggests that at moderate intensities an enhanced rate of fat oxidation could equal the energy delivered by carbohydrates. However, current evidence also underlines that during high-intensity exercise, performance would be impaired when carbohydrate intake is low as is the case with LCHF diets. This is mainly due to a down-regulation of carbohydrate metabolism even when glycogen is available. Therefore, the main focus of this thesis is on carbohydrate and protein intake in relation to sport nutrition recommendations. $^{14}$

Regular carbohydrate intake is essential for physically active individuals and should be timed according to training sessions to ensure optimal pre-, during, and post-workout nutrition. ${ }^{2}$ Regarding the types of carbohydrates, the intake of products delivering complex carbohydrates with a low-moderate glycaemic index in amounts ranging from 3-12 $\mathrm{g} / \mathrm{kg}$ body mass per day is to be preferred. ${ }^{8}$ Additionally, nutrient-dense sources of carbohydrates, i.e. sports nutrition products such as sports drinks and energy gels can be included when it is not possible to reach high carbohydrate requirements via conventional food products. ${ }^{2}$ Dietary protein requirements are slightly higher than those of the general population. ${ }^{13}$ In case of strength, speed and endurance training ${ }^{2}$ there is good 
rationale for recommending athletes protein intakes that are higher than the RDA. ${ }^{15}$ This results in a recommendation of absolute protein intake in the range of $1.3-1.8 \mathrm{~g} / \mathrm{kg}$ per day, consumed as 3-4 equally divided protein-rich meals, to optimize muscle protein synthesis or to prevent lean mass losses. ${ }^{15}$ Despite differences between disciplines of sports the recommendation of $5 \mathrm{~g} / \mathrm{kg} / \mathrm{bw}$ of $\mathrm{CHO}$ and $1.2 \mathrm{~g} / \mathrm{kg} / \mathrm{bw}$ PRO is a well-accepted lower level in athletes exercising 9-15 times a week over 60-90 minutes a day. ${ }^{14}$

Being well-hydrated is also an important prerequisite for optimal exercise performance. Dehydration increases the risk of severe hyperthermia, heat exhaustion and heat stroke during exercise. Therefore, in general athletes should strive for euhydration during the day. ${ }^{3}$

Vitamins and minerals are needed to ensure optimal body functions. ${ }^{3}$ In relation to exercise, it is sometimes suggested that micronutrients are performance enhancing. Nevertheless, the ergogenic effect of most micronutrients is unclear and warrants further research. ${ }^{3}$ It is well known that micronutrients display U-shaped dose-efficacy curve, which means that supra-optimal doses are not beneficial and sometimes even harmful In other words, and in contrast to what is sometimes believed by the public, there is common scientific consensus that "more" does not mean "better". Although the Health Council of the Netherlands provides a full range of recommended dietary intakes (RDIs), the Netherlands Nutrition Foundation also refers to the internationally accepted Nordic Nutrition Recommendations ${ }^{9}$ as a preferred source for recommendations when Dutch guidelines are pre 2000.

\subsubsection{Sports nutrition recommendations before, during or after exercise}

An advice to take food shortly before exercise is mainly given to pre-fuel the athlete, but should not lead to gastro-intestinal (GI) complaints during exercise. ${ }^{16}$ Based on the literature, the focus on macronutrient intake can differ slightly between training and competition. In both cases a good hydration status is seen as desirable with normal plasma electrolyte levels based on the consumption of normal meals and standard fluid intake. ${ }^{17}$ Protein, fat and dietary fiber are advised to be mainly excluded from the diet in the last 2-3 hours before competition. ${ }^{3,16}$ The necessity of this advice during a training period is not always as obvious or feasible during daily practice. In addition, some athletes, despite following these recommendations experience Gl complaints. Besides the intake of nutrients and(or) fluids before or during exercise, these complaints can also have other causes, for example physiological or mechanical. ${ }^{18}$

During exercise the main focus is on the intake of sufficient fluid and carbohydrate. ${ }^{8}$ The consumption of carbohydrate immediately before and during exercise represents an effective strategy to provide an exogenous fuel source to the muscles and central nervous system, especially during exercise lasting longer than 45 minutes. ${ }^{8,17}$ The recommendations for fluid intake range from $150-350 \mathrm{ml}$ per 15 minutes $^{17}$ and for carbohydrate intake from 30-90 grams per hour. ${ }^{8}$ These recommendations can be met by 
athletes during competition as described previously. ${ }^{5,6}$ Although there is considerable consensus on these recommendations, there is also data that questions for example the need of meeting traditional fluid recommendations (i.e. based on programmed fluid intake vs. drinking at thirst) for all athletes. ${ }^{19}$

After exercise, the nutritional goal is to replace any fluid electrolyte deficit ${ }^{17}$ up to $150 \%$ of the fluid lost during exercise ${ }^{16}$ and to promote glycogen syntheses and muscle protein syntheses for recovery and adaptation. ${ }^{8,15,17}$ If a quick recovery is desired, athletes should consume 1-4 gram of carbohydrate per kg bodyweight within the first 4 hours. ${ }^{8}$ A dose of 20-25 grams of protein appears to maximally stimulate muscle protein synthesis. ${ }^{15}$ It cannot be ruled out that this estimate may be lower for lighter athletes. ${ }^{15}$ The combined intake of an insufficient amount of carbohydrate and 10-20 grams of protein can enhance muscle glycogen by optimizing efficiency of carbohydrate uptake and therefore results in both muscle protein syntheses as muscle glycogen recovery. ${ }^{8}$

\subsection{Gaps in dietary exposure assessment in sports nutrition research}

A wide array of practical and cultural factors influence the unique set of requirements and individual goals of the athlete. ${ }^{1}$ Nutrition is an important factor as part of elite athletic performance as previously said by Professor Dr. Ron Maughan: "Good food choices will not a make a mediocre athlete into a champion, but poor food choices may prevent the potential champion from realizing his or her potential." Sport-specific nutritional requirements should be reviewed from three separate angles: the physiological requirements of training and competition; the athlete's lifestyle; and the tradition of the sport. $^{1}$

Although there is substantial insight into the energy expenditure of athletes, ${ }^{20,21}$ the individual athlete's energy needs often remain difficult to determine. Also, as sport nutrition recommendations reflect total energy requirements, ${ }^{2}$ it is difficult to evaluate real macronutrient needs, as for example previously stated for carbohydrates. ${ }^{22}$ In practice, recommendations are often further tailored to sports categories such as endurance, strength and team sports. ${ }^{10-12}$ However, considering individual differences between athletes in a specific discipline on the one hand, and advancing insights into training methods resulting in mixed training programs on the other hand, it is questionable whether there is still an evidence base for discipline-specific differences in sports recommendations. In daily practice, nutritional recommendations for different types of training and sports may be used interchangeably. At the same time, studies that looked at differences between categories ${ }^{23,24}$ did show some differences. Therefore, conducting dietary assessment studies in different groups of well-trained competitive athletes is of value to increase our knowledge and understanding of the current situation and to compare this with data collected in other, including non-European, countries. 
Food choices, dietary patterns and the use of specific nutritional supplements are part of the athletes lifestyle. ${ }^{1}$ Differences exist in dietary patterns and food choices between countries and regions. ${ }^{25,26}$ Therefore, it is often difficult to compare results of studies even within countries because of methodological differences, and it is even more complex to compare results of one country with those from other European studies. Despite the fact that over twenty studies have been published since 2000, our knowledge of dietary intake in the European top-level athletes is still incomplete. The main problem with most studies is the small numbers of subjects included and the differences in collecting data which makes it difficult to compare findings. ${ }^{27-49}$ From a Dutch perspective, data from other Western European countries in particular would be the most valuable to compare with. However, only a small number of relevant publications could be found describing athlete populations from Germany (\#3), United Kingdom (\#3) and France (\#2).

Nutritional supplements play an important role in total dietary intake of athletes and therefore their lifestyle. The intake of nutritional supplements, i.e. dietary supplements containing micronutrients or fatty acids, sport nutrition products containing fluid, carbohydrate and protein and ergogenic supplements such as creatine and caffeine by athlete's from all over the world has been well documented in a recent review paper. ${ }^{50}$ On the other hand, a proper insight into the relative contribution of these products to the average athlete's total dietary intake is still lacking. Nutritional supplements are not used by all athletes, ${ }^{51}$ and compliance varies. ${ }^{52}$ Therefore, it remains to be investigated whether the behaviour of athletes with respect to supplement use in general constitutes a sufficient contribution to achieve nutrient requirements on a population level. ${ }^{4}$

The sport's tradition and it's culture also influence the importance attributed to- and belief in the role of nutrition by athletes and their coaches. ${ }^{1}$ This can be addressed on an individual basis by a sports nutritionist if athletes receive dietary counselling, but insight into these cultural characteristics is often limited in scientific studies. Most sports also have their own practical literature, i.e. magazines and web pages, which enables sport nutritionists to provide tailored advice for individual sports. ${ }^{1}$ Athletes have always been eager to improve their performance, and are therefore prone to adopting new but not yet scientifically proven interventions. ${ }^{53}$ With this knowledge, monitoring dietary intake and nutritional supplement use as a purpose in itself is important as this provides data to those working with athletes in order to expand their reference of specific nutritional behaviour of athletes. 


\subsection{Assessment of intake and dietary quality in athletes, are improvements needed?}

In current practice food records are mostly used to describe athletes' habitual nutritional intake. ${ }^{16}$ For scientific purposes, food records and 24-hour recalls are commonly preferred to assess actual intake. On a group level, both 3-4 day or 7-day food records and multiple 24-hour recalls have been used to estimate dietary intake. ${ }^{54,55}$ These methods, however, show large differences in validity between different populations. ${ }^{56}$ All self-reported dietary assessment methods are prone to different types of errors. ${ }^{57}$ The advantage of the 24-hour recall is that the outcome is not affected by awareness and therefore does not result in an altered intake as seen with the use of a food record. ${ }^{56}$ The preferred five-step, multiple pass, 24-hour recall is highly standardized and is considered to result in a reliable estimation of dietary intake. ${ }^{58}$ At the moment it is often assumed that the quality of reporting dietary intake by athletes is the same of even better compared to the general population, but validation studies are lacking in athletes.

Sport nutrition publications also often use different methods to assess adequacy of the diet. This may have resulted in inconsistent study results. For example, differences in inadequacies found between previous studies may be caused by differences in dietary reference values used. ${ }^{59}$ The use of the estimated average requirement (EAR or AR) is preferred as reference and has been recommended for years. ${ }^{60,61}$ Thus, studies using recommended dietary intake (RDI), recommended dietary allowances (RDA), or adequate intake (Al) as dietary reference values (DRVs) instead of EAR, may have overestimated the reported inadequacy. Also, in most cases the mean intake has been used to compare with available DRVs. In these cases using the median or another approach such as the cut-off method or probability approach would be more appropriate. ${ }^{62}$

The 21st century athlete often combines intensive training and competition programs with college education. This type of lifestyle can generate additional methodological challenges. For example, dietary registration of multiple days of a large population is needed to capture the large variety in dietary intake caused by considerable differences in intensity of activities between training days and days of study, rest and recovery. In addition to this, specific sports-related factors such as the season, the day of the week and training load contribute to daily variation in intake, which may contribute to errors if not properly taken into account. ${ }^{63}$

The number of studies in athletes which compare existing methods is limited ${ }^{64}$ and also the information regarding the validity of self-reported dietary intake in elite athletes is scarce. ${ }^{21,65}$ There is a need for a properly validated dietary intake method in active competitive athletes. 


\subsection{Aims and outline of this thesis.}

Insight into current practices and quality of dietary and nutritional supplement intake of Dutch (sub)elite athletes is very limited. Therefore, the overall objective of this thesis was to get a better understanding of the current nutritional intake of (sub)elite athletes in the Netherlands and to evaluate current practices in view of the existing guidelines and developments in the field.

The following specific objectives served as starting points of this thesis:

- To evaluate nutritional intake of a diverse group of (sub)elite competitive athletes as well as evaluating the quality of reporting against a reference method.

- To obtain insight in the intake of energy and macronutrients in different categories of athletes (endurance, team and strength athletes) and to evaluate nutritional intake against current sport nutrition recommendations.

- To obtain insight in micronutrient intake in view of existing guidelines to establish potential risks for inadequate intake, including overdosing, in those using dietary supplements and sport nutrition products or not.

- To obtain insight into the intake and use of nutritional supplements, i.e. dietary supplements and sport nutrition products, by athletes and the role of dietary counselling.

- To make an inventory of the use of dietary supplements and sport nutrition products in non-athletes. This made it possible to compare the athlete's use of nutritional supplements against that of non-athletes.

These objectives are addressed in the next chapters:

Chapter 2 describes important methodological issues in dietary assessment in athletes by comparing our preferred method of multiple web-based 24 hour recalls and accompanying questionnaires with a biochemical standard reference method, i.e. multiple 24 hour urine nitrogen excretions in a subgroup of our population.

Chapters $3 a$ and chapter $3 b$ focus on the actual intake of well-trained competitive athletes. These two chapters describe the results of the Dutch Sport Nutrition and Supplement Study (DSSS) which was based on two relevant key questions: are there differences in nutritional intake between categories of athletes (endurance, strength and team sports) and are athletes using nutritional supplements at potential risk of too high or too low intake of micronutrients?

Chapter 4 focuses on the practice of dietary intake during competition. To this end we describe a study in ultramarathon runners where we investigated whether the athletes were able to meet their nutritional targets and the recommendations during a race. 
Chapter 5 describes our research on the frequency of use and reasons for using dietary supplements and sport nutrition products in the general Dutch population with the aim to compare these figures with those obtained in our athletes population and with nationwide surveys mainly focusing on the prevalence of micronutrient based dietary supplements for health purposes.

Chapter 6 completes the investigational part of this thesis by describing a study on the association between the use of nutritional supplements and the question whether or not dietary counselling was received.

Finally, the results found are discussed in chapter 7, which also discusses remaining knowledge gaps and presents suggestions for future research. 


\section{References}

1 Burke L. Practical sports nutrition. Champaign, IL: Human Kinetics, 2007.

2 Potgieter S. Sport nutrition: A review of the latest guidelines for exercise and sport nutrition from the American College of Sport Nutrition, the International Olympic Committee and the International Society for Sports Nutrition. S Afr J Clin Nutr. 2013; 26: 6-16.

3 Rodriguez NR DN, Langley S. Nutrition and athletic performance. American College of Sports Medicine. 2009.

4 van Erp-Baart AM, Saris WM, Binkhorst RA, Vos JA, Elvers JW. Nationwide survey on nutritional habits in elite athletes. Part II. Mineral and vitamin intake. Int J Sports Med. 1989; 10 Suppl 1: S11-6.

5 Pfeiffer B, Cotterill A, Grathwohl D, Stellingwerff T, Jeukendrup AE. The effect of carbohydrate gels on gastrointestinal tolerance during a 16-km run. Int J Sport Nutr Exerc Metab. 2009; 19: 485-503.

6 Pfeiffer B, Stellingwerff T, Hodgson AB, et al. Nutritional intake and gastrointestinal problems during competitive endurance events. Med Sci Sports Exerc. 2012; 44: 344-51.

7 Maughan RJ, Shirreffs SM. IOC Consensus Conference on Nutrition in Sport, 25-27 October 2010, International Olympic Committee, Lausanne, Switzerland. J Sports Sci. 2011; 29 Suppl 1: S1.

8 Burke LM, Hawley JA, Wong SH, Jeukendrup AE. Carbohydrates for training and competition. J Sports Sci. 2011; 29 Suppl 1: S17-27.

9 Nordic Council of Ministers. Nordic Nutrition Recommendations 2012: Integrating nutrition and physical activity. 2012.

10 Jeukendrup AE. Nutrition for endurance sports: marathon, triathlon, and road cycling. J Sports Sci. 2011; 29 Suppl 1: S91-9.

11 Holway FE, Spriet LL. Sport-specific nutrition: practical strategies for team sports. J Sports Sci. $2011 ; 29$ Suppl 1: S115-25.

12 Stellingwerff T, Maughan RJ, Burke LM. Nutrition for power sports: middle-distance running, track cycling, rowing, canoeing/kayaking, and swimming. J Sports Sci. 2011; 29 Suppl 1: S79-89.

13 Health Council of the Netherlands. Dietary Reference Intakes: energy, proteins, fats and digestible carbohydrates. The Hague, the Netherlands: Health Council of the Netherlands, , 2001.

14 Thomas DT, Erdman KA, Burke LM. Position of the Academy of Nutrition and Dietetics, Dietitians of Canada, and the American College of Sports Medicine: Nutrition and Athletic Performance. J Acad Nutr Diet. 2016; 116: 501-28.

15 Phillips SM, Van Loon LJ. Dietary protein for athletes: from requirements to optimum adaptation. J Sports Sci. 2011; 29 Suppl 1: S29-38.

16 Wardenaar FC, Maas T, Danen S, Pannekoek S. Richtlijn Wedstrijdsport. Dieetbehandelingsrichtlijnen. Rotterdam: 2010 uitgevers, 2013.

17 American College of Sports M, Sawka MN, Burke LM, et al. American College of Sports Medicine position stand. Exercise and fluid replacement. Med Sci Sports Exerc. 2007; 39: 377-90.

18 Stuempfle KJ, Hoffman MD, Hew-Butler T. Association of gastrointestinal distress in ultramarathoners with race diet. Int J Sport Nutr Exerc Metab. 2013; 23: 103-9.

19 Dion T, Savoie FA, Asselin A, Gariepy C, Goulet ED. Half-marathon running performance is not improved by a rate of fluid intake above that dictated by thirst sensation in trained distance runners. Eur J Appl Physiol. 2013; 113: 3011-20.

20 Westerterp KR. Physical activity and physical activity induced energy expenditure in humans: measurement, determinants, and effects. Front Physiol. 2013; 4: 90.

21 Westerterp KR, Saris WH, van Es M, ten Hoor F. Use of the doubly labeled water technique in humans during heavy sustained exercise. J Appl Physiol (1985). 1986; 61: 2162-7.

22 Jeukendrup A. A step towards personalized sports nutrition: carbohydrate intake during exercise. Sports Med. 2014; 44 Suppl 1: S25-33.

23 de Sousa EF, Da Costa TH, Nogueira JA, Vivaldi L. Assessment of nutrient and water intake among adolescents from sports federations in the Federal District, Brazil. Br J Nutr. 2008; 99: 1275-83. 
24 Burke LM, Slater G, Broad EM, Haukka J, Modulon S, Hopkins WG. Eating patterns and meal frequency of elite Australian athletes. Int J Sport Nutr Exerc Metab. 2003; 13: 521-38.

25 Mensink GB, Fletcher R, Gurinovic M, et al. Mapping low intake of micronutrients across Europe. Br J Nutr. 2013; 110: 755-73.

26 Giannopoulou I, Noutsos K, Apostolidis N, Bayios I, Nassis GP. Performance level affects the dietary supplement intake of both individual and team sports athletes. J Sports Sci Med. 2013; 12: 190-6.

27 Aerenhouts D, Hebbelinck M, Poortmans JR, Clarys P. Nutritional habits of Flemish adolescent sprint athletes. Int J Sport Nutr Exerc Metab. 2008; 18: 509-23.

28 Bettonviel AE, Brinkmans NY, Russcher K, Wardenaar FC, Witard OC. Nutritional Status and Daytime Pattern of Protein Intake on Match, Post-Match, Rest and Training Days in Senior Professional and Youth Elite Soccer Players. Int J Sport Nutr Exerc Metab. 2015.

29 Carlsohn A, Cassel M, Linne K, Mayer F. How much is too much? A case report of nutritional supplement use of a high-performance athlete. Br J Nutr. 2011; 105: 1724-8.

30 Cupisti A, D'Alessandro C, Castrogiovanni S, Barale A, Morelli E. Nutrition knowledge and dietary composition in Italian adolescent female athletes and non-athletes. Int J Sport Nutr Exerc Metab. 2002; 12: 207-19.

31 Farajian P, Kavouras SA, Yannakoulia M, Sidossis LS. Dietary intake and nutritional practices of elite Greek aquatic athletes. Int J Sport Nutr Exerc Metab. 2004; 14: 574-85.

32 Garcia-Roves PM, Fernandez S, Rodriguez M, Perez-Landaluce J, Patterson AM. Eating pattern and nutritional status of international elite flatwater paddlers. Int J Sport Nutr Exerc Metab. 2000; 10: 182-98.

33 Garcia-Roves PM, Garcia-Zapico P, Patterson AM, Iglesias-Gutierrez E. Nutrient intake and food habits of soccer players: analyzing the correlates of eating practice. Nutrients. 2014; 6: 2697-717.

34 Garcia-Roves PM, Terrados N, Fernandez S, Patterson AM. Comparison of dietary intake and eating behavior of professional road cyclists during training and competition. Int J Sport Nutr Exerc Metab. 2000; 10: 82-98.

35 Garcin M, Doussot L, Mille-Hamard L, Billat V. Athletes' dietary intake was closer to French RDA's than those of young sedentary counterparts. Nutr Res. 2009; 29: 736-42.

36 Hassapidou MN, Manstrantoni A. Dietary intakes of elite female athletes in Greece. $J$ Hum Nutr Diet. 2001; 14: 391-6.

37 Hermans JD, Z. Voedingsinname van topatleten (in Dutch). BOK-verslag. Arnhem: NOC*NSF, 2006.

38 Julian-Almarcegui C, Gomez-Cabello A, Gonzalez-Aguero A, et al. The nutritional status in adolescent Spanish cyclists. Nutr Hosp. 2013; 28: 1184-9.

39 Leblanc J, Le Gall F, Grandjean V, Verger P. Nutritional intake of French soccer players at the clairefontaine training center. Int J Sport Nutr Exerc Metab. 2002; 12: 268-80.

40 Maughan RJ, Shirreffs SM. Nutrition for soccer players. Curr Sports Med Rep. 2007; 6: 279-80.

41 Mielgo-Ayuso J, Maroto-Sanchez B, Luzardo-Socorro R, et al. Evaluation of nutritional status and energy expenditure in athletes. Nutr Hosp. 2015; 31 Suppl 3: 227-36.

42 Molina-Lopez J, Molina JM, Chirosa LJ, et al. Implementation of a nutrition education program in a handball team; consequences on nutritional status. Nutr Hosp. 2013; 28: 1065-76.

43 Nikic M, Jakovljevic S, Pedisic Z, Venus D, Satalic Z. Adequacy of nutrient intakes in elite junior basketball players. Int J Sport Nutr Exerc Metab. 2014; 24: 516-23.

44 Ruiz F, Irazusta A, Gil S, Irazusta J, Casis L, Gil J. Nutritional intake in soccer players of different ages. J Sports Sci. 2005; 23: 235-42.

45 Soric M, Misigoj-Durakovic M, Pedisic Z. Dietary intake and body composition of prepubescent female aesthetic athletes. Int J Sport Nutr Exerc Metab. 2008; 18: 343-54.

46 Vogt S, Heinrich L, Schumacher YO, et al. Energy intake and energy expenditure of elite cyclists during preseason training. Int J Sports Med. 2005; 26: 701-6.

47 Weimann E. Gender-related differences in elite gymnasts: the female athlete triad. J Appl Physiol (1985). 2002; 92: 2146-52.

48 Wierniuk A, Wlodarek D. Estimation of energy and nutritional intake of young men practicing aerobic sports. Rocz Panstw Zakl Hig. 2013; 64: 143-8. 


\section{Chapter 1}

49 Zapolska J, Witczak K, Manczuk A, Ostrowska L. Assessment of nutrition, supplementation and body composition parameters on the example of professional volleyball players. Rocz Panstw Zakl Hig. 2014; 65: 235-42.

50 Knapik JJ, Steelman RA, Hoedebecke SS, Austin KG, Farina EK, Lieberman HR. Prevalence of Dietary Supplement Use by Athletes: Systematic Review and Meta-Analysis. Sports Med. 2016; 46: 103-23.

51 Wardenaar FC, Dijkhuizen R, Ceelen IJ, et al. Nutrient Intake by Ultramarathon Runners: Can They Meet Recommendations? Int J Sport Nutr Exerc Metab. 2015.

52 Herbold NH, Visconti BK, Frates S, Bandini L. Traditional and nontraditional supplement use by collegiate female varsity athletes. Int J Sport Nutr Exerc Metab. 2004; 14: 586-93.

53 Williams MH. Ergogenic aids in sport. Champaign, IL: Human Kinetics Publishers, 1983.

54 Magkos F, Yannakoulia M. Methodology of dietary assessment in athletes: concepts and pitfalls. Curr Opin Clin Nutr Metab Care. 2003; 6: 539-49.

55 Chaouachi A, Chamari K, Roky R, et al. Lipid profiles of judo athletes during Ramadan. Int J Sports Med. 2008; 29: 282-8.

56 Willett W. Nutritional Epidemiology. 3rd edn. New York, NY: Oxford University Press USA, 2012.

57 Bingham SA. The use of 24-h urine samples and energy expenditure to validate dietary assessments. Am J Clin Nutr. 1994; 59: 227S-31S.

58 Moshfegh AJ, Rhodes DG, Baer DJ, et al. The US Department of Agriculture Automated Multiple-Pass Method reduces bias in the collection of energy intakes. Am J Clin Nutr. 2008; 88: 324-32.

59 Heaney S, O'Connor H, Gifford J, Naughton G. Comparison of strategies for assessing nutritional adequacy in elite female athletes' dietary intake. Int J Sport Nutr Exerc Metab. 2010; 20: 245-56.

60 Barr SI, Murphy SP, Poos MI. Interpreting and using the dietary references intakes in dietary assessment of individuals and groups. J Am Diet Assoc. 2002; 102: 780-8.

61 Murphy SP, Barr SI, Poos MI. Using the new dietary reference intakes to assess diets: a map to the maze. Nutr Rev. 2002; 60: 267-75.

62 DRI Dietary Reference Intakes: Applications in Dietary Assessment. Washington (DC)2000.

63 Van Staveren WA, Ocké, M.C. \& De Vries, J.H.M., editor Estimation of dietary intake Unkown: WileyBlackwell, 2012.

64 Baker LB, Heaton LE, Stein KW, Nuccio RP, Jeukendrup AE. Validity and relative validity of a novel digital approach for 24-h dietary recall in athletes. Nutr J. 2014; 13: 41.

65 Rehrer NJ, Hellemans IJ, Rolleston AK, Rush E, Miller BF. Energy intake and expenditure during a 6-day cycling stage race. Scand J Med Sci Sports. 2010; 20: 609-18. 



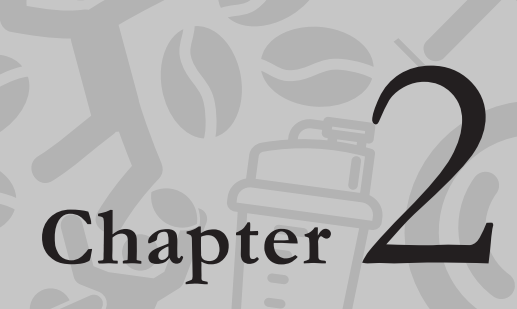




\section{Validation of web-based,}

multiple 24-h recalls combined with nutritional supplement intake questionnaires against nitrogen excretions to determine protein intake in Dutch elite athletes

Floris C. Wardenaar, Jora Steennis, Ingrid J.M. Ceelen, Marco Mensink, Renger F. Witkamp, Jeanne H.M. de Vries.

British Journal of Nutrition 2015;114:2083-92. 


\begin{abstract}
Aim: Information on dietary composition is vitally important for elite athletes to optimise their performance and recovery, which requires valid tools. The aim of the present study was to investigate the validity multiple 24-hour recalls and accompanying questionnaires.

Methods: Forty-seven Dutch elite top athletes, both disabled and non-disabled, aged 18-35 years, with a BMI of $17.5-31 \mathrm{~kg} / \mathrm{m}^{2}$, exercising $>12$ hours a week were recruited to assess protein intake. Three Web-based 24-hour recalls and questionnaires were compared with three urinary nitrogen excretions on the same day for mean intake, ranking based on correlation between both methods and visual inspection of a BlandAltman plot to evaluate agreement of the protein intake between recalls and urinary excretions in individuals.
\end{abstract}

Results: Estimated mean dietary protein intake was $109.6 \pm 33.0 \mathrm{~g} / \mathrm{d}$ by recalls and questionnaires versus $141.3 \pm 38.2 \mathrm{~g} / \mathrm{d}$ based on nitrogen excretions in urine; the difference was $25.5 \pm 21.3 \%$ between methods $(p<0.05)$. We found a reasonably good association between methods for protein intake of 0.65 (95\% Cl: 0.45; 0.79). On an individual level, underreporting was larger with higher protein intakes than with lower intakes. No significant differences were found in reporting absolute differences between subcategories (gender, under reporting, BMI, collection of recalls within a certain amount of time and using protein supplements or not).

Conclusions: Combined, multiple, 24-hour recalls and questionnaires underestimated protein intake in these young elite athletes more than reported for non-athlete populations. The method proved to be suitable for ranking athletes according to their protein intake as needed in epidemiological studies. On an individual level the magnitude of underestimation was about equal for all athletes except for those with a very high protein intake. 


\section{Introduction}

Dietary composition and timing of food intake are vitally important for elite athletes to optimise their performance and recovery. ${ }^{1-3}$ Protein requirements, in particular, differ between elite athletes and physically less active people. Recommendations for protein intake are between 1.2 and $2.0 \mathrm{~g} / \mathrm{kg} /$ day and are frequently tailored to individual needs. ${ }^{4,5}$ This demands for adequate tools to advise and monitor the intake of athletes.

Food records and 24-hour recalls are commonly used to assess current intake or intake of the recent past. To assess dietary intake by athletes at a group level both, 3-4 day or 7-day food records and multiple 24-hour recalls have been used. ${ }^{6,7}$ These methods, however, show large differences in validity between different populations. ${ }^{8}$

The 21st century athlete, often combining intensive training and competition programmes with college education, demands practical dietary assessment methods like Web-based 24-hour recalls. The advantage of the 24-hour recall is that the outcome is not affected by awareness and consequently an altered -desirable - intake as seen with the use of a food record. ${ }^{8}$ Also by using Web-based recalls athletes can report their intake, within certain limits, at their own convenience. The preferred five-step, multiple pass, 24-hour recall is highly standardised and is considered to result in a reliable estimation of dietary intake. ${ }^{9}$

At the same time, all dietary assessment methods based on self-reporting are prone to different types of errors. ${ }^{10}$ In addition to this, specific sports-related factors such as season, day of the week and training load contribute to daily variation in intake, which may contribute to errors if not taken into account properly. Total intake of energy and macronutrients, such as protein, normally display less random or day-to-day variation than other nutrients such as retinol or marine fatty acids. ${ }^{11}$ Systematic errors i.e. overor underreporting of intake are often due to social desirable reporting, omitting foods, and underestimating of portion sizes. ${ }^{12}$

Validation studies are important for identifying the magnitude and type of measurement error of a specific method. For validation purposes, 24-hour urinary nitrogen is considered the best available biomarker to estimate dietary protein intake. ${ }^{13-18}$ The method was first proposed by Isaksson ${ }^{19}$ and further developed by Bingham and Cummings. ${ }^{15}$ When corrected for faecal and skin losses of nitrogen, the method correlated well $(r=0.99)$ with protein intake estimated by 28 days of duplicate portions. ${ }^{15,19}$

Information about the validity of self-reported dietary intake in elite athletes is scarce. $^{20,21}$ Their active lifestyle with intensive training programmes generates methodological problems. For example, dietary registration of multiple days is needed to capture the large variety in dietary intake caused by differences in intensity of activities between training days and days of rest and recovery.

To our knowledge, no validation studies have been undertaken to estimate the accuracy of multiple 24-hour recalls to assess protein intake in athletes. Therefore, the aim of this study was to investigate the validity of assessing protein intake by three 24 - 
hour recalls plus day questionnaires on dietary supplement intake compared with analysis of urinary nitrogen excretion using three different 24-hour samples in elite athletes.

\section{Methods}

\section{Study design}

The study was performed between March and July 2013. In the general information letter for candidate subjects it was explained that the collection of 24-hour urine served to determine the nitrogen content of the consumed diet. After including subjects, no additional information was given about the intended use of the 24-urine collections or the timing of the 24-hour urine collection in relation to the 24-hour recalls.

After inclusion, subjects were asked to complete three unannounced Web-based non-consecutive, 24-hour dietary recalls and questionnaires about dietary supplements and sport nutrition products, in combination with a 24-hour urine collection covering the same day. The measurements were scheduled during a 2-4 week period on three separate days, selected by the researchers, and collection days were at least four days apart. If the collection (24-hour recall plus daily questionnaire and/or 24-hour urine collection) was not complete, additional days were scheduled at the end of the 2-4 week period. This gave athletes four opportunities to deliver at least two 24-hour recalls, questionnaires and 24-hour urine excretions.

\section{Study population}

Forty-eight subjects, both disabled and non-disabled Dutch elite athletes, aged 18-35 years, with a BMI of $17.5-31 \mathrm{~kg} / \mathrm{m}^{2}$ and a minimum exercise duration $>12$ hours a week were recruited. They had an elite top athlete status of the Dutch Olympic Committee (NOC*NSF) and/ or, had participated in a European or World Championship, or had proven to be part of the national top level in their discipline or age group. Subjects were recruited from different national elite teams for athletics (middle distance and sprint), cycling (track sprint, BMX cyclists and Paralympics), archery, speed skating and shorttrack skating. Before the start of the study all coaches confirmed that the training programme during the period of the study ( 3 to 5 weeks) was part of a stable condition training phase. The majority of the subjects did not focus specifically on building muscle mass or breaking down body fat as a possible interfering factor when assessing nitrogen balance. Only four athletes intended to lose weight during this period. None of the subjects was diagnosed with a disease or used medication. Written informed consent to participate was provided by all subjects after attending a presentation meeting about the study. Subjects received a financial incentive if they delivered at least two complete datasets out of three, consisting of a 24-hour urine collection, a 24-hour recall plus a 
questionnaire on dietary supplement and sport nutrition product intake and exercise. The survey was conducted according to the Declaration of Helsinki and approved by the Medical Ethics Committee of Wageningen University.

\section{4-hour recalls}

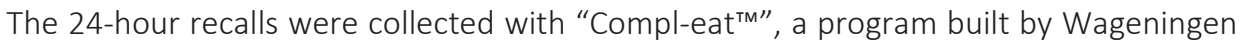
University that guides participants to report accurately report all foods and drinks consumed the previous day, and were to be reported within 36 hours. It is designed based on the Multiple-Pass approach. ${ }^{9,22}$ Using Compl-eat ${ }^{\mathrm{TM}}$ the participant first filled out the Quick list indicating which food groups were consumed at what occasion and time of the day without giving details. The next step was to specify all food groups of the quick list meal by meal in chronological order during the day. The participant was allowed to continue with the next meal if all food groups of a meal had been specified and the amounts had been added. The participant was offered the possibility to split up food groups into subgroups, by a search tool and scroll down menus. In this way, the tool enables to select single foods and standard recipes commonly used in the Dutch population. The program also contains a recipe module in which the participants could adapt standard recipes or fill out all ingredients of their own recipe and the part of the recipe they consumed. Yield and retention factors were automatically taken into account when appropriate. Participants could include notes for clarifications when needed. Compleat $^{\mathrm{TM}}$ reminded the participants to fill out often forgotten foods such as sugar in coffee, snacks, fruit, and cooking fat.

Trained dieticians checked all Web-based 24-hour recalls for their completeness and unusual portion sizes and processed all notes made by the participants. Adjustments of errors and notes were made in a standardised way using standard portion sizes and recipes according to a protocol. ${ }^{23}$

The program included a wide selection of foods commonly used in a Dutch food pattern (Stichting NEVO, 2010) but no dietary supplements or sport nutrition products, which were questioned separately.

\section{Nutritional supplement intake questionnaires}

The Web-based questionnaires regarding training load (total minutes of exercise per day) and dietary supplement and sports nutrition product use as part of each separate 24-hour recall were collected with the "vitality portal" built by the HAN University of Applied Sciences. Subjects were asked if they had used any dietary supplements and/ or sports nutrition products. If so, they were asked to select the specific brand, type and name of the supplement from a pre-specified list with more than 3400 products. Product information was largely based on the Dutch database for dietary Supplements (RIVM, 2015). Next, subjects were asked to specify the total dose of the product used 
on that day based on unit dose and type of formulation (capsule, tablet, drops etc.) in case of dietary supplements, or grams and/or millilitres in case of sport nutrition products. If a product was missing in the list, subjects were able to fill out all specifications as described before. We were able to retrieve the protein composition of all dietary supplements and sport nutrition products used based on label information given by manufacturers. Data was checked for unusual values, unspecified dietary supplements and sports nutrition products. If necessary, participants were contacted and asked for additional information. If information was missing, the composition of dietary supplements and sports nutrition products was retrieved from the internet or through local shops.

\section{Combining 24-hour recalls and questionnaires}

To calculate the mean total energy and protein intakes, results of all 24-hour recalls with questionnaire of the same day were summed and divided by the total number of days collected per person. For conversion of products into energy and nutrients the Dutch food composition database of 2010 was used (Stichting NEVO, 2010) in combination with the Dutch database for dietary Supplements (NES). ${ }^{24,25}$

Total reported dietary intake per person was converted into total protein (g and $\mathrm{g} / \mathrm{kg}$ ), and total energy (MJ). Food intake level (FIL) was calculated by dividing estimated energy intake (EI) through basal metabolic rate (BMR) based on the formula of Schofield. ${ }^{26}$ The FIL was used as an indication of the quality of reporting in comparison to expected PAL values for athletes. Based on studies using DLW, PAL values are expected to be between 1.75 and 2.0 for these young adult athletes. ${ }^{27}$ We compared the protein intake of the group above and below the median value for FIL to evaluate the influence of reporting quality.

\section{Urine collection}

Each subject received labelled containers (at least two), one funnel to help the collection, one safety pin to be fixed in the underwear as a reminder for collection and a diary scheme booklet to register the timing, observations (e.g., use of medication and supplements) and possible deviations (e.g., missing urine) of the urine collection protocol. Subjects were instructed to keep the urine samples at approximately $4^{\circ} \mathrm{C}$ at all times. Boric acid ( $3 \mathrm{~g} / 2$ litre bottle) was used as preservative.

The evening before the collection, subjects received a short text message between 10:00-11:00 PM as a reminder. The collection of the 24-hour urine started with sampling and discarding the first urine in the morning after waking up. Subsequently, the urine produced during the next 24 hours, up to and including the first sampling of the following day, was collected. The subjects handed in their urine samples at their training facilities, at maximum five hours after the end of the collection. 
To check completeness of urinary collections, subjects took three tablets of $80 \mathrm{mg}$ PABA (PABAcheck, Laboratories for Applied Biology, London, UK) on the day of the urine collection, one during each of their main meals. The total amount of $240 \mathrm{mg}$ of PABA is expected to be almost completely excreted in 24 hours. $^{28,29}$

\section{Analysis of urine samples}

In our laboratory, urine fractions of the same person and 24-hour period were mixed, weighed and aliquoted. Each sample of 24-hour urine was measured to the nearest $1.0 \mathrm{~g}$ on a digital scale. The urine was homogenised and two samples of $4.5 \mathrm{ml}$ were taken. Samples were stored at $-20{ }^{\circ} \mathrm{C}$ until further analysis could take place. Total nitrogen was analysed using the automated Kjeldahl method. ${ }^{30}$ Total urinary nitrogen was calculated by relating nitrogen levels to the volume of the 24-hour collections. The assumption was made that excreted nitrogen accounts for $81 \%$ of ingested protein due to extra-renal nitrogen losses. ${ }^{15,31}$ Daily dietary protein was calculated based on the assumption that all proteins on average contain $16 \%$ nitrogen. ${ }^{14,32}$ Thus, excreted $\mathrm{N}(\mathrm{mg} / \mathrm{d})$ was converted to g protein/d (protein $\mathrm{g} / \mathrm{d}=(\mathrm{N} \mathrm{mg} / \mathrm{d} \times 6.25) / 1000)$ and then divided by $0.81 .^{33}$

A high-performance liquid chromatography (HPLC) method was used for the determination of PABA. This method includes alkaline hydrolysis for conversion of PABA metabolites in the urine samples to PABA, followed by separation on a reverse phase column, detection at $290 \mathrm{~nm}$ and quantification using an internal standard. Total urinary PABA was calculated by relating PABA concentration of the samples, to the volume of the 24-hour collections.

Using a minimum PABA recovery of $78 \%$ proposed by literature as cut-off point for complete urine collection, ${ }^{34} 13 \%$ of the urine samples were considered incomplete. A sensitivity analysis was performed comparing the results from the complete urine dataset with the results after exclusion of the urine samples $<78 \%$ PABA recovery.

The mean protein intakes based on recalls and questionnaires was 10 grams lower if subjects with PABA recovery below $78 \%$ were excluded as compared to the total dataset. However, excluding subjects based on PABA recovery did not affect estimates for protein intake based on 24-hour urine excretions or the association between protein intake derived from recalls and urines. Therefore, we decided to report the results on the complete dataset.

\section{Other measurements}

To check whether the assumption of nitrogen balance was justified, self-reported bodyweight on each day was recorded as an indicator for stable bodyweight over the total period.

Also, creatinine levels were analysed in a small subgroup ( $n=19$ with 2-3 samples within each person) to estimate protein muscle balance as an indicator for nitrogen 
balance. Urinary creatinine was analysed by SHO (Velp, the Netherlands) using a spectrometric chemical analyser (Modular P800, Roche, US). All samples were measured in duplicate and each run contained two control samples. Analyses were valid if duplicates differed by less than $5 \%$ and control samples were within the expected range. Total daily urinary creatinine content was calculated for the total urine collected over 24 hours.

\section{Statistical analyses}

Statistical analysis was carried out on data of all subjects delivering 2-3 complete data sets using the statistical software program SPSS (version 19). Values for protein and energy were presented as continuous variables, expressed as mean \pm SD or $95 \% \mathrm{Cl}$. Log transformations (In) were used, if necessary, to obtain a normal distribution for additional statistical analysis. Protein ratio was calculated by dividing estimated mean protein intake based on 24-hour recalls by protein based on 24-hour nitrogen excretions. To assess whether athletes were in nitrogen balance, a repeated measures ANOVA (using mixed models with Bonferroni correction) was performed using values of creatinine and body weight.

Paired t-test was performed to determine the difference between total mean protein intake by 24-hour recall and 24-hour urine method with statistical significance levels set at $p \leq 0.05$. Furthermore, differences for protein intake were examined within several subgroups; gender, reporting, BMI category and recalls by use of a univariate analysis.

To investigate ranking of individuals according to their intake, Pearson correlation coefficient was calculated between nitrogen estimated by the 24-hour recall method and the 24-hour urine samples. A partial Pearson correlation coefficient ( $r$ ) was calculated for estimated crude and energy corrected protein intake and coefficients were computed using regression calibration-adjusted correlation. For all correlations, 95\% confidence intervals where calculated using Fisher's Z transformation.

For total protein intake (g/day and $\mathrm{g} / \mathrm{kg} /$ day) attenuation factors and $95 \% \mathrm{Cl}$ were calculated. These factors were estimated as the slope in the linear regression of the log transformed biomarker value plotted against the log transformed reported intake. Although no formal cut-off values exist, values less than 0.4 were considered of no use.

A Bland-Altman plot was made to evaluate the agreement of the assessment of protein intake between recalls and urinary excretions in individuals. For this plot, the mean intake of protein estimated by the methods was plotted against the difference in protein between the methods. We added $95 \%$ limits of agreement (mean \pm 2 SD) to the plot. 


\section{Results}

The vast majority of the 47 athletes delivered three 24-hour recalls, 3 questionnaires and three urine collections, except 2 subjects who delivered only 2 complete datasets.

This final study population consisted of both male (66\%) and female (34\%) athletes; participants were young adult elite athletes, with a BMI between 20 and $31 \mathrm{~kg} / \mathrm{m}^{2}$ (Table 1). Subjects practised a large variety of sports: 5 middle-distance runners, 8 track cyclists, 6 BMX cyclists, 8 Paralympic cyclists (of which 3 physically disabled, 1 having Mobius syndrome, 1 visual disabled and 3 non-disabled tandem pilots), 3 athletic sprinters, 7 archers, 7 long-distance ice-skaters, and 3 short-track skaters. Most recalls (74.5\%) were collected within 36 hours, and all recalls within 72 hours. A proportion of $78.7 \%$ of the subjects reported a FIL lower than 1.75, indicating possible underreporting of energy intake.

Table 1. Characteristics of the 47 athletes

\begin{tabular}{lcccccccccc}
\hline & Gender & Age & Height & Body weight & BMl & $\begin{array}{c}\text { BMl } \\
>25^{1}\end{array}$ & $\begin{array}{c}\text { Recall } \\
<36 h\end{array}$ & $\begin{array}{c}\mathrm{FIL}^{2} \\
\text { Reporters }\end{array}$ & $\begin{array}{c}\text { Rep } \\
<\text { PAL } 1.75^{3}\end{array}$ \\
& $\mathrm{~N}$ & $\%$ & years & $\mathrm{cm}$ & $\mathrm{kg}$ & $\mathrm{Kg} / \mathrm{m}^{2}$ & $\%$ & $\%$ & Mean & $\%$ \\
\hline Female & 16 & 34 & $20.8 \pm 4.0$ & $172.6 \pm 4.7$ & $66.3 \pm 8.1$ & $21.7 \pm 2.9$ & 18.8 & 81.3 & $1.7 \pm 0.5$ & 68.9 \\
Male & 31 & 66 & $21.4 \pm 3.9$ & $182.8 \pm 5.5$ & $78.4 \pm 8.9$ & $21.5 \pm 4.6$ & 19.4 & 71.0 & $1.5 \pm 0.3$ & 83.7 \\
Total & 47 & 100 & $21.2 \pm 3.9$ & $179.3 \pm 7.2$ & $74.3 \pm 10.3$ & $21.6 \pm 4.1$ & 19.1 & 74.5 & $1.6 \pm 0.4$ & 78.7 \\
\hline
\end{tabular}

All values are shown as number $(\mathrm{n})$ and percentages, mean and standard deviation or percentage.

${ }^{1}>25.0 \mathrm{~kg} / \mathrm{m}^{2}$ and $<31.0 \mathrm{~kg} / \mathrm{m}^{2}$.

${ }^{2} \mathrm{FIL}=\mathrm{EI} / \mathrm{BMR}$, reported values between 0.88-2.81.

${ }^{3}$ PAL 1.75 is selected as cut-off value to determine underreporting for active younger adults based on FIL.

\section{Comparison of methods}

Mean protein intake assessed by the 24-hour recalls combined with the nutritional supplement intake questionnaires was underestimated in comparison to protein estimated by the 24-hour urine nitrogen excretions. Estimated dietary mean protein intake was $109.6 \pm 33.0 \mathrm{~g} / \mathrm{d}$ or $1.49 \pm 0.35 \mathrm{~g} / \mathrm{kg} / \mathrm{d}$ by recalls versus a $141.3 \pm 38.2 \mathrm{~g} / \mathrm{d}$ or $1.90 \pm 0.39$ $\mathrm{g} / \mathrm{kg} / \mathrm{d}$ based on nitrogen excretions in urine, with a protein ratio of 0.78 . The absolute underestimation was $-31.7 \pm 30.0 \mathrm{~g} / \mathrm{d}$ reflecting an absolute significant mean difference of $25.5 \pm 21.3 \%$ between methods in $g / d(p<0.001)$ which is in line with the previously suggested underreporting of energy intake. Estimated mean energy intake was $16.9 \pm 4.2$ MJ, with a range of 8.54-26.6 MJ.

We found a rather high correlation of 0.65 (95\% Cl: 0.45 ; 0.79$)$ for crude protein intake in $\mathrm{g} / \mathrm{d}$ between the multiple 24-hour recall method and 24-hour nitrogen excretions (Table 2). If protein intake was expressed as protein per kg bodyweight correlation was slightly lower, but still reasonably good (Table 2 ). Attenuation factors were high for total protein intake and good to acceptable for protein intake in $\mathrm{g} / \mathrm{kg} / \mathrm{d}$. 
To predict true protein intake when a gold standard is not available in daily practice a calibrated regression function formula was calculated for both crude protein and energy adjusted protein as shown in Table 2.

Table 2. Associations and attenuation factors for the comparison of self-reported protein intakes to urinary nitrogen excretions for crude protein intake

\begin{tabular}{|c|c|c|c|c|c|}
\hline \multirow[t]{2}{*}{ Protein intake } & \multicolumn{2}{|c|}{ Pearson correlation } & \multicolumn{2}{|c|}{ Attenuation } & \multirow[t]{2}{*}{ Calibrated regression function } \\
\hline & $\mathrm{R}$ & $95 \% \mathrm{Cl}^{1}$ & AF & $95 \% \mathrm{Cl}$ & \\
\hline Crude intake g/day & 0.65 & $0.45-0.79$ & 0.76 & $0.49-1.02$ & $\begin{array}{l}y=58.3+0.76 * \text { g protein } 24 \mathrm{~h} \text { recall and } \\
\text { questionnaires }{ }^{2}\end{array}$ \\
\hline Crude intake g/kg/day & 0.58 & $0.35-0.74$ & 0.65 & $0.36-0.95$ & $\begin{array}{l}\mathrm{y}=0.43+0.52 * \mathrm{~g} / \mathrm{kg} \text { protein } 24 \mathrm{~h} \text { recall } \\
\text { and questionnaires }\end{array}$ \\
\hline
\end{tabular}

$r=$ pearson correlation coefficient, $\mathrm{AF}=$ attenuation factor.

${ }^{1} 95 \% \mathrm{Cl}$ computed by Fisher Z transformation.

${ }^{2} y=\beta 0+\left(\beta 1^{*}\right.$ protein $24 \mathrm{~h}$ recall).

Figure 1 depicts the agreements for difference of protein intake based on 24-hour recalls and 24-hour urine excretions against the mean of both methods, in a so-called Bland-Altman plot. The 95\% limits of agreement were between -90.4 and +27.1 gram. In addition, the Bland-Altman plot shows that results were very similar for men and women. Underestimation of protein intake was related to the amount of protein intake ( $r$ : $0.20 ; 95 \% \mathrm{Cl}-0.46 ; 0.09)$ indicating that higher protein intakes are possibly prone to higher underreporting than lower intakes.

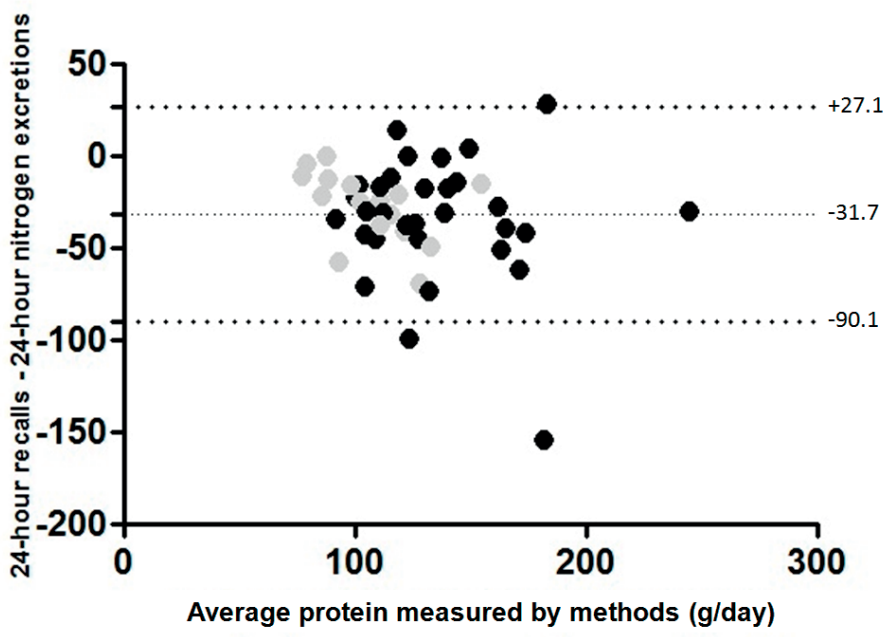

Figure 1. Difference of protein intake based on 24-hour recalls and 24-hour urine excretions against the mean of both methods

Data points for women are in grey and for men in black. 
For all categories shown in Table 3 no significant differences were found between protein intake estimated by both methods between subcategories. The p-values were 0.51 for gender, 0.58 for underreporting according to a cut-off value of $1.75,0.29$ for BMI category, 0.08 for reporting within 36 hours or more, and 0.63 for protein supplement use or not. When we splitted the population in two groups of low reporters and high reporters (below and above the median FIL of 1.52) the mean FIL was respectively $1.26 \pm 0.17$ for the group below the median and $1.76 \pm 0.29$ for the group above the median. The mean protein intake of the high reporters was significantly higher than that of the low reporters $(P=0.04)$. For ranking based on correlations some categories showed better results as the other categories within subcategories.

\section{Use of protein supplements}

Thirteen out of 47 subjects used one or more protein supplement(s). Two subjects reported the use of protein supplements on all 3 days, 3 subjects on 2 days and 8 subjects on only 1 day. For these 13 subjects mean intake of protein including supplements was $129.3 \pm 41.0 \mathrm{~g} / \mathrm{d}$ which was $27.2 \mathrm{~g} / \mathrm{d}$ higher than that of non-users of protein supplements $(n=34)$. Protein supplement users showed a slightly higher correlation $(r=0.70$, $95 \% \mathrm{Cl} 0.24-0.90$ ) but also wider $95 \% \mathrm{Cl}$ than non-users ( $r=0.65,95 \% \mathrm{Cl} 0.40-0.81$ ).

\section{Protein balance}

Total mean daily urinary creatinine in $\mathrm{mmol} / \mathrm{d}$ was $19.4 \pm 4.69$ (with a mean of $18.6 \pm 4.17$ $\mathrm{mmol} /$ day for women and $19.8 \pm 5.05 \mathrm{mmol} /$ day for men) which is within the normal range of $10-20 \mathrm{mmol} / \mathrm{d} .{ }^{35}$ Per sport category small differences were observed. Speed skaters and short-track skaters had mean creatinine levels $\sim 14.5 \mathrm{mmol} / \mathrm{d}$. The middledistance runners, Paralympic cyclist, track cycling sprinters, athletic sprinters and archers had slightly higher mean creatinine levels of $\sim 20 \mathrm{mmol} /$ day (range 13-28). In addition, $\mathrm{BMX}$ riders had the highest creatinine levels in comparison to others (average $\sim 24$ $\mathrm{mmol} /$ day, with a range of $19-32 \mathrm{mmol} / \mathrm{day}$ ). Although some of the athletes had higher creatinine levels than within normal limits, their urinary creatinine levels did not differ between single recall days $(p=1.00)$ confirming that they were in nitrogen balance. Also, according to the interviews with coaches (results not shown) none of the athletes gained or dropped weight as part of a personal intervention, and daily body weight did not differ between recall days ( $p>0.05$ ). Based on the results of these combined measurements we consider this group of subjects to be in nitrogen balance. 


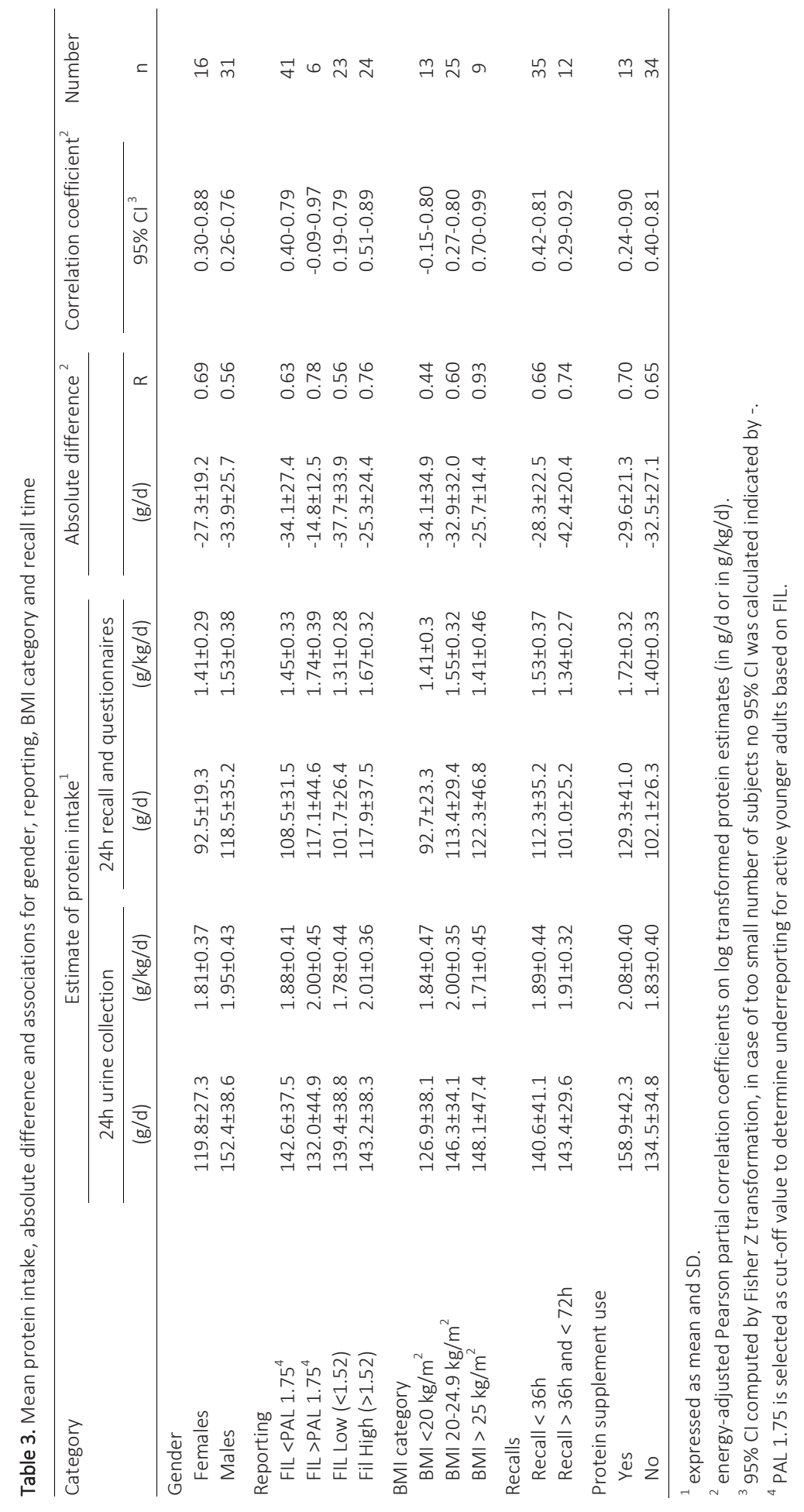




\section{Discussion}

As far as we know, this is the first validation study in elite athletes to evaluate a Webbased 24 -hour recall with questionnaires for protein intake. Mean protein intake was underestimated by $25.5 \%$. The multiple 24 -hour recalls and questionnaires proved to be suitable for ranking athletes according to their protein intake, as reflected by the reasonably high correlation coefficient. At the individual level we observed considerable underestimations of protein intake, which tended to be more pronounced in situations where intake was higher. Small differences were seen for subcategories of athletes.

\section{Quality of results}

It is difficult to compare outcomes of the tool used in the present study, the Webbased recall module Compl-eat ${ }^{\mathrm{TM}}$ and questionnaires, with those of other Web-based tools $^{36-40}$ because of different study designs. Recently, Compl-eat ${ }^{\text {TM }}$ was compared to telephone recalls performed on randomly chosen days, independent of the Web-based recalls, as part of an ongoing cohort study (NQplus, Wageningen, the Netherlands). Here, it was found that the tool underreported energy intake by $8 \%$, and protein by $9 \%$. Possible explanations for these differences included not defining serving sizes, or ignoring components such as dairy or cooking fat. Thompson et al. ${ }^{41}$ evaluated a comparable method, ASA24 against an Automated Multiple-Pass Method (AMPM) interview by telephone and found an average underreporting of $6 \%$ for reported energy. Thus, a part of our underreporting may be explained by using a Web-based tool instead of an AMPM based interview by telephone.

As no comparable studies are available for athletes using nitrogen excretion as a validation method for Web-based 24-hour recalls, we discuss our results in comparison to studies performed in other groups. A study in women using two 24-hour recalls and eight 24-hour nitrogen excretions in urine ${ }^{42}$ reported a smaller mean difference than our study. The difference found by Bingham et al. was only $7.8 \%$ between methods, which is substantial lower than in our women (24.9\%). The EFCOVAL study included data of a population in the Netherlands that may be comparable with our results because of a similar dietary pattern. ${ }^{43}$ The study included two non-consecutive 24-hour recalls and 24-hour urine collections covering the same reference day. Underreporting for protein in men was $12.4 \%$ and in women $8.2 \%$. Although total underreporting was lower in this overweight older population, gender differences are pointing in the same direction. Also, the reported protein ratio of our study of 0.78 is in line with a range of 0.54-0.99 reported as part of the EPIC study in non-athletes. ${ }^{13}$ So the extent of underreporting on a group level in the present study is fairly acceptable in comparison to others using 24-hour recalls. ${ }^{13,43,44}$

Three 24-hour recalls covering the same reference day as the biomarker appeared to be good for ranking elite athletes according to their protein intake, as indicated by a 
rather high correlation with the reference method $(r=0.65 ; 95 \% \mathrm{Cl} 0.45-0.79)$. Pooled results of 5 validation studies in non-athletes showed an average correlation for men of 0.39 (95\% Cl 0.31-0.47) and for women of 0.42 (95\% Cl 0.36-0.48). ${ }^{45}$ The Dutch data sub-set of the EFCOVAL study also resulted in lower unadjusted correlations for men: $r=0.42$ (95\% Cl 0.18-0.61) and women: $r=0.51$ (95\% Cl 0.29-0.67). ${ }^{43}$ Thus, based on the comparisons with these studies the results of our validation study for protein are comparable or better than that of others. ${ }^{43,45}$ However, most other studies did not cover the same reference day for recall and biomarkers, as was the case in our study

The observed attenuation factors for total protein intake are almost two times as high as in most others. ${ }^{45}$ This indicates that relative risks assessed in our population will not be substantially de-attenuated because of measurement error. High correlations and attenuation factors indicate that the method is suitable for ranking athletes according to their protein intake.

On an individual level the magnitude of underestimation is quite large as shown by the levels of agreement in the Bland-Altman plots (with a range of $-105.7 \mathrm{~g}$ up to $17.3 \mathrm{~g}$ ). This is also seen in other studies. ${ }^{14}$ The higher protein intakes based on the means of the combined methods tended to be underestimated more than the lower intakes. An explanation for this finding might be that the 24-hour recalls make use of standardised portion sizes which may not be representative for athletes. ${ }^{14}$ It is not very likely that we have missed specific protein-rich foods, because our questionnaire was specifically designed to cover all dietary supplements and sports nutrition products containing protein. Nevertheless, in future studies, estimation of protein intake needs specific attention.

Athletes may register their dietary intake more carefully than non-athletes as they would represent a motivated and disciplined population. There is some evidence that motivated subjects report better than less motivated subjects, ${ }^{46}$ but not much is known about the validity of protein intake values assessed by multiple 24-hour recalls in elite athletes. Mean underreporting of $25.5 \%$ is higher than in the non-athlete literature, but these studies also differ in methodology used compared to ours. ${ }^{13,45}$ An explanation could be that underreporting was larger because of a higher true mean protein intake of athletes compared to less active people. This seems reasonable, because all other results respond within the normal range in comparison to other publications.

Protein intake values in our study are in line with those reported by other groups of athletes. However, only a few studies used multiple 24-hour recalls. ${ }^{7}{ }^{47}$ One study using three 24 -hour recalls reported an absolute mean protein intake of $1.6 \pm 0.4 \mathrm{~g} / \mathrm{kg} / \mathrm{day}{ }^{7}$ This is slightly higher than the mean protein intake found in the present study. The only Dutch study examining elite athletes, reported $1.0-3.0 \mathrm{~g} / \mathrm{kg} / \mathrm{d}$ for different types of athletes, based on 3-4 day food records. ${ }^{48}$ Mean protein intake of dietary supplement users in our study was substantially higher than that of non-users. However, as the overall number of participants using dietary supplements was small, the contribution of protein supplements to the mean protein intake was limited. 
Urinary nitrogen as marker for dietary protein as proposed by Isaksson (1980) is well accepted as a marker for actual protein intake, ${ }^{13,14,16-18,49}$ but assumes nitrogen balance. ${ }^{19}$ Especially in athletes, this assumption may not always be applicable because athletes potentially have a higher protein turnover than more sedentary subjects. ${ }^{50} \mathrm{We}$ used urinary creatinine levels as an indicator of protein turnover. Higher creatinine levels are often a sign of higher protein turnover. ${ }^{51}$ In athletes, higher urinary creatinine values supported by serum creatinine values compared to sedentary people have been found in several studies. ${ }^{52}$ In our study, urinary creatinine levels in the athletes did not differ between the recall days. Also, although mean creatinine levels were high, they were still in line with reference values $(10-20 \mathrm{mmol} / \mathrm{d})$ for the normal population. ${ }^{53}$ Athletes performing sports characterised by a high BMI, indicating a high muscle mass, have higher serum creatinine levels than endurance athletes, who generally have a lower BMI. ${ }^{54-56}$ Most athletes in the present study had pronounced muscular bodies probably resulting in higher net protein turnover and higher creatinine levels. However, we assume that our athletes were in nitrogen balance. This was also supported by stable body weights during the study period and confirmation by coaches that training schedules were stable. If nitrogen was overestimated, underreporting of protein would actually have been smaller than measured.

We used the data of all subjects, despite incomplete PABA recovery in a small number of subjects. Regarding this, our results were not completely in line with previous findings, ${ }^{57}$ because we found a difference in estimated mean protein intake of the total population as compared to that of the population excluding subjects with a low PABA recovery. However, as other results were not affected we chose to follow the recommendation of Subar et al. ${ }^{57}$ to include all subjects. This resulted in a smaller mean difference ( $11.3 \mathrm{~g} /$ day) without influencing correlation coefficients.

We found no significant differences for mean protein intake within BMI or other subcategories. However, results for these subcategories should be interpreted with care because of small sample sizes, resulting in a wide $95 \% \mathrm{Cl}$ in some, but not all cases. The higher association between protein intake and the biomarker found in athletes with a BMI $>25 \mathrm{~kg} / \mathrm{m}^{2}$ as compared to the other two subcategories is interesting because in most validation studies overweight people misreport more than their leaner counterparts. A possible explanation is that athletes with a high BMI are mostly not overweighted, but very muscular and perhaps more aware of their protein intake than others.

We chose to compare the estimated FIL with a PAL of 1.75 to distinguish between accurate reporting and underreporting. PAL for active people was estimated $\sim 1.75$, besides this no training study reported individual PAL values over 2.5, and mean PAL values in young people reaches a ceiling around 2.0. ${ }^{27}$ Although slightly conservative this PAL seems reasonable for this mixed group of active athletes. We indeed found that reports below a FIL of 1.75 were less accurate than those of 1.75 or higher suggesting underreporting of energy as well. 
Additional questionnaires were used to assess intake via supplements and/ or sport nutrition products as the Web-based 24-hour recall module was in our opinion not specific enough in this respect. Because of the ability to select out of $>3400$ preselected products we think that the inquired types of foods were rather complete and could not explain the underestimated intake. The used food composition tables and ingredient declarations of the dietary supplements and sport nutrition products can have a significant influence on reporting. The contribution of these products was based on labelling information only, which may not have been accurate. However, because of the small number of users and amounts used these are considered of minor influence on the group mean protein intake. On the other hand, estimation of the normal diet based on food composition tables is also prone to under reporting as is known from studies with duplicate portions. ${ }^{58}$

Further, the combined 24-hour recalls and questionnaires were unannounced, but followed consistently the day after the 24-hour urine collection. It cannot be excluded that subjects were aware of this, and adapted their protein intake during the second and third collection. However, this would not have affected the difference in estimated protein intake between recalls and urines. It is unlikely that delay of reporting was of great influence on total group reporting. Some of the 24-hour recalls were not collected within the requested 36 hours. Due to the strict planning of training schedules of the athletes, with different types of training days, it was not always possible to perform rescheduling. Exceptionally, a new time slot was opened and data collection took place within 72 hours from the first invitation, but mostly within 48 hours. No significant difference was seen between categories, although protein intake was substantially lower in the group reporting after 36 hours.

Although our study population did not cover all types of sports, it was a fairly good mixture of different types of elite athletes competing at an international level. The mixed exercise types and training programmes reflect a representative work load for elite level athletes. The men-women ratio was representative for elite status athletes.

The study was designed to assess current intake collecting all data within 4 weeks. We believe this gives the best insight into the actual accuracy of multiple 24-hour recalls in athletes, because athletes undergo training programmes with changing exercise load and volume throughout the year. Although the study design did not take into account all different seasons, the effect on the results is expected to be small on the population level. The study covered winter, spring and summer during a basic conditional training phase of different specific types of sport. Nevertheless, we can only draw conclusions about the validity of this method within a 4 week period.

In conclusion, the validity of assessing protein intake by three 24-hour recalls plus day questionnaires on dietary supplement intake is fairly good in comparison to the protein intake based on nitrogen excretions in three different 24-hour urine samples in elite athletes. The combined multiple 24-hour recalls with an accompanying questionnaire about dietary supplements and sport nutrition products were shown to underre- 
port protein intake in young adult elite athletes, to the same extent as in other, nonathlete, populations. The method is, however, well suitable for ranking athletes according to their protein intake as is needed in epidemiological studies. When correlation for protein intake was adjusted for total energy intake based on self-reported intake no clear improvement of results was given, indicating that protein intake is a focus of athletes regardless their total energy intake. On an individual level the magnitude of underestimation was about equal for all athletes except for those with a very high intake of protein. Other determinants related to underreporting included gender, reporting $<$ FIL of 1.75 , BMI, time to hand in recalls and using protein containing dietary supplements or not and should be taken into account in dietary assessment of athletes to obtain better insight in the estimation and monitoring of protein intake.

\section{Acknowledgments}

We like to acknowledge Mark Rothuis, Pim Huting, Coen Manders, Victor Mooren and Sjoerd Privee for helping during this study as part of their internship. 


\section{References}

1 Hawley JA, Dennis SC, Lindsay FH, Noakes TD. Nutritional practices of athletes: are they sub-optimal? J Sports Sci. 1995; 13 Spec No: S75-81.

2 Kerksick C, Harvey T, Stout J, et al. International Society of Sports Nutrition position stand: nutrient timing. J Int Soc Sports Nutr. 2008; 5: 17.

3 Jeukendrup A. The new carbohydrate intake recommendations. Nestle Nutr Inst Workshop Ser. 2013; 75: 63-71.

4 Campbell B, Kreider RB, Ziegenfuss T, et al. International Society of Sports Nutrition position stand: protein and exercise. J Int Soc Sports Nutr. 2007; 4: 8.

5 Holwerda AM, van Vliet S, Trommelen J. Refining dietary protein recommendations for the athlete. J Physiol. 2013; 591: 2967-8.

6 Magkos F, Yannakoulia M. Methodology of dietary assessment in athletes: concepts and pitfalls. Curr Opin Clin Nutr Metab Care. 2003; 6: 539-49.

7 Chaouachi A, Chamari K, Roky R, et al. Lipid profiles of judo athletes during Ramadan. Int J Sports Med. 2008; 29: 282-8.

8 Willett W. Nutritional Epidemiology. 3rd edn. New York, NY: Oxford University Press USA, 2012.

9 Moshfegh AJ, Rhodes DG, Baer DJ, et al. The US Department of Agriculture Automated Multiple-Pass Method reduces bias in the collection of energy intakes. Am J Clin Nutr. 2008; 88: 324-32.

10 Bingham SA. The use of 24-h urine samples and energy expenditure to validate dietary assessments. Am J Clin Nutr. 1994; 59: 227S-31S.

11 Van Staveren WA, Ocké, M.C. \& De Vries, J.H.M., editor Estimation of dietary intake Unkown: WileyBlackwell, 2012.

12 Livingstone MB, Black AE. Markers of the validity of reported energy intake. J Nutr. 2003; 133 Suppl 3: 895S-920S.

13 Slimani N, Bingham S, Runswick S, et al. Group level validation of protein intakes estimated by 24-hour diet recall and dietary questionnaires against 24-hour urinary nitrogen in the European Prospective Investigation into Cancer and Nutrition (EPIC) calibration study. Cancer Epidemiol Biomarkers Prev. 2003; 12: 784-95.

14 Bingham SA. Urine nitrogen as a biomarker for the validation of dietary protein intake. J Nutr. 2003; 133 Suppl 3: 921S-24S.

15 Bingham SA, Cummings JH. Urine nitrogen as an independent validatory measure of dietary intake: a study of nitrogen balance in individuals consuming their normal diet. Am J Clin Nutr. 1985; 42: 1276-89.

16 Black AE, Bingham SA, Johansson G, Coward WA. Validation of dietary intakes of protein and energy against 24 hour urinary $N$ and DLW energy expenditure in middle-aged women, retired men and postobese subjects: comparisons with validation against presumed energy requirements. Eur J Clin Nutr. 1997; 51: 405-13.

17 Bokhof B, Gunther AL, Berg-Beckhoff G, Kroke A, Buyken AE. Validation of protein intake assessed from weighed dietary records against protein estimated from $24 \mathrm{~h}$ urine samples in children, adolescents and young adults participating in the Dortmund Nutritional and Longitudinally Designed (DONALD) Study. Public Health Nutr. 2010; 13: 826-34.

18 Bokhof B, Buyken AE, Dogan C, et al. Validation of protein and potassium intakes assessed from $24 \mathrm{~h}$ recalls against levels estimated from $24 \mathrm{~h}$ urine samples in children and adolescents of Turkish descent living in Germany: results from the EVET! Study. Public Health Nutr. 2012; 15: 640-7.

19 Isaksson B. Urinary nitrogen output as a validity test in dietary surveys. Am J Clin Nutr. 1980; 33: 4-5.

20 Rehrer NJ, Hellemans IJ, Rolleston AK, Rush E, Miller BF. Energy intake and expenditure during a 6-day cycling stage race. Scand J Med Sci Sports. 2010; 20: 609-18.

21 Westerterp KR, Saris WH, van Es M, ten Hoor F. Use of the doubly labeled water technique in humans during heavy sustained exercise. J Appl Physiol (1985). 1986; 61: 2162-7. 
22 Conway JM, Ingwersen LA, Vinyard BT, Moshfegh AJ. Effectiveness of the US Department of Agriculture 5-step multiple-pass method in assessing food intake in obese and nonobese women. Am J Clin Nutr. 2003; 77: 1171-8.

23 Donders-Engelen MR, Van der Heijden, L.J.M \& Hulshof, K.F.A.M. Maten, gewichten en codenummers (Food portion sizes and coding instructions). Wageningen: Department Human Nutrition, Wageningen Agricultural University (in Dutch), 1997.

24 Buurma-Rethans E. F, H., Ghameshlou, Z., de Jong, N. Een databestand voor supplementen: behoeftes en acties (Data file for dietary supplements: needs and actions). Voeding Nu (in Dutch). 2008; 10(1).

25 RIVM. Nederlandse Voedingsmiddelentabel (Dutch Food Composition Table). In: RIVM, editor. NEVOtabel. Bilthoven2011.

26 Johansson G, Wikman A, Ahren AM, Hallmans G, Johansson I. Underreporting of energy intake in repeated 24-hour recalls related to gender, age, weight status, day of interview, educational level, reported food intake, smoking habits and area of living. Public Health Nutr. 2001; 4: 919-27.

27 Westerterp KR. Physical activity and physical activity induced energy expenditure in humans: measurement, determinants, and effects. Front Physiol. 2013; 4: 90.

28 Runswick S, Slothouber B, Boeing $\mathrm{H}$, et al. Compliance with the urine marker PABAcheck in cancer epidemiology studies. IARC Sci Publ. 2002; 156: 35-7.

29 Bingham S, Cummings JH. The use of 4-aminobenzoic acid as a marker to validate the completeness of 24 h urine collections in man. Clin Sci (Lond). 1983; 64: 629-35.

30 Hambleton LG, \& Noel, R. J. Protein analysis of feed, using a block digestion. Journal of the AOAC. 1975; 58: $143-45$.

31 Kipnis V, Midthune D, Freedman LS, et al. Empirical evidence of correlated biases in dietary assessment instruments and its implications. Am J Epidemiol. 2001; 153: 394-403.

32 Jones DB. Factors for converting percentages of nitrogen in foods and feeds into percentages of proteins. Circular (United States Department of Agriculture, Washington DC). 1941; 183

33 Gibson R. Validity of dietary assessment methods, in Principles of Nutritional Assessment. New York: Oxford University Press, 2005

34 Jakobsen J, Pedersen AN, Ovesen L. Para-aminobenzoic acid (PABA) used as a marker for completeness of 24 hour urine: effects of age and dosage scheduling. Eur J Clin Nutr. 2003; 57: 138-42.

35 Coban. Creatinine-plus. Cobas, 2008.

36 Arab L, Wesseling-Perry K, Jardack P, Henry J, Winter A. Eight self-administered 24-hour dietary recalls using the Internet are feasible in African Americans and Whites: the energetics study. J Am Diet Assoc. 2010; 110: 857-64.

37 Liu B, Young H, Crowe FL, et al. Development and evaluation of the Oxford WebQ, a low-cost, web-based method for assessment of previous $24 \mathrm{~h}$ dietary intakes in large-scale prospective studies. Public Health Nutr. 2011; 14: 1998-2005.

38 Subar AF, Kirkpatrick SI, Mittl B, et al. The Automated Self-Administered 24-hour dietary recall (ASA24): a resource for researchers, clinicians, and educators from the National Cancer Institute. J Acad Nutr Diet. 2012; 112: 1134-7.

39 Touvier M, Kesse-Guyot E, Mejean C, et al. Comparison between an interactive web-based selfadministered $24 \mathrm{~h}$ dietary record and an interview by a dietitian for large-scale epidemiological studies. Br J Nutr. 2011; 105: 1055-64.

40 Zoellner J, Anderson J, Gould SM. Comparative validation of a bilingual interactive multimedia dietary assessment tool. J Am Diet Assoc. 2005; 105: 1206-14.

41 Thompson FE, Dixit-Joshi S, Potischman N, et al. Comparison of Interviewer-Administered and Automated Self-Administered 24-Hour Dietary Recalls in 3 Diverse Integrated Health Systems. Am J Epidemiol. 2015; 181: 970-8.

42 Bingham SA, Gill C, Welch A, et al. Comparison of dietary assessment methods in nutritional epidemiology - weighed records $\vee 24-h$ recalls, food-frequency questionnaires and estimated-diet records. British Journal of Nutrition. 1994; 72: 619-43. 


\section{Chapter 2}

43 Crispim SP, de Vries JH, Geelen A, et al. Two non-consecutive $24 \mathrm{~h}$ recalls using EPIC-Soft software are sufficiently valid for comparing protein and potassium intake between five European centres--results from the European Food Consumption Validation (EFCOVAL) study. Br J Nutr. 2011; 105: 447-58.

44 Crispim SP, Geelen A, de Vries JH, et al. Bias in protein and potassium intake collected with 24-h recalls (EPIC-Soft) is rather comparable across European populations. Eur J Nutr. 2012; 51: 997-1010.

45 Freedman LS, Commins JM, Moler JE, et al. Pooled results from 5 validation studies of dietary self-report instruments using recovery biomarkers for energy and protein intake. Am J Epidemiol. 2014; 180: 172-88.

46 de Vries JH, Zock PL, Mensink RP, Katan MB. Underestimation of energy intake by 3-d records compared with energy intake to maintain body weight in 269 nonobese adults. Am J Clin Nutr. 1994; 60: 855-60.

47 Darvishi L, Rabbani Z, Goodarzy S, et al. Investigating and comparing energy and macronutrient intake in female aerobic athletes in two different socio-economic regions. J Educ Health Promot. 2012; 1: 40.

48 van Erp-Baart AM, Saris WH, Binkhorst RA, Vos JA, Elvers JW. Nationwide survey on nutritional habits in elite athletes. Part I. Energy, carbohydrate, protein, and fat intake. Int J Sports Med. 1989; 10 Suppl 1: S3-10.

49 Black AE, Bingham SA, Johansson G, Coward WA. Validation of dietary intakes of protein and energy against 24 hour urinary $N$ and DLW energy expenditure in middle-aged women, retired men and postobese subjects: Comparisons with validation against presumed energy requirements. European Journal of Clinical Nutrition. 1997; 51: 405-13.

50 Phillips SM. Protein requirements and supplementation in strength sports. Nutrition. 2004; 20: 689-95.

$51 \mathrm{Kim} \mathrm{H}$, Lee S, Choue R. Metabolic responses to high protein diet in Korean elite bodybuilders with highintensity resistance exercise. J Int Soc Sports Nutr. 2011; 8: 10.

52 Banfi G, Del Fabbro M. Serum creatinine values in elite athletes competing in 8 different sports: Comparison with sedentary people. Clinical Chemistry. 2006; 52: 330-31.

53 Cobas. Creatinine-plus. 2008.

54 Witt KA, Bush EA. College athletes with an elevated body mass index often have a high upper arm muscle area, but not elevated triceps and subscapular skinfolds. Journal of the American Dietetic Association. 2005; 105: 599-602

55 Banfi G, Del Fabbro M. Relation between serum creatinine and body mass index in elite athletes of different sport disciplines. British Journal of Sports Medicine. 2006; 40: 675-78.

56 Milic R, Banfi G, Del Fabbro M, Dopsaj M. Serum creatinine concentrations in male and female elite swimmers. Correlation with body mass index and evaluation of estimated glomerular filtration rate. Clinical Chemistry and Laboratory Medicine. 2011; 49: 285-89.

57 Subar AF, Midthune D, Tasevska N, Kipnis V, Freedman LS. Checking for completeness of 24-h urine collection using para-amino benzoic acid not necessary in the Observing Protein and Energy Nutrition study. Eur J Clin Nutr. 2013; 67: 863-7.

58 Siebelink E, De Vries JHM, Trijsburg L, Hulshof PJM. Evaluation of calculated energy and macronutrient contents of diets provided in controlled dietary intervention trials by chemical analysis of duplicate portions. Journal of Food Composition and Analysis. 2015; 11. 



\section{Macronutrient intakes in $\mathbf{5 5 3}$ \\ Dutch elite and sub-elite endurance, team}

and strength athletes: Does intake differ between sport disciplines?

Floris C. Wardenaar, Naomi Y.J. Brinkmans, Ingrid J.M. Ceelen, Bo van Rooij, Marco Mensink, Renger F. Witkamp, Jeanne H.M. de Vries.

Submitted. 


\section{Abstract}

Aim: To evaluate mean energy and macronutrient intake of well-trained athletes active in different sport disciplines in view of frequently used sport nutrition guidelines.

Methods: Web-based 24-hour dietary recalls and questionnaires were obtained within a 2-4 week period from 553 Dutch well-trained athletes. Total energy and macronutrient intake was compared for categories (endurance, team and strength) within gender, and diet quality was evaluated against reference values by applying a probability approach.

Results: On average 2.83 days per person were reported with energy intake ranging between 2566-2985 kcal and 1997-2457 kcal for men and women, respectively. Mean intake of energy and macronutrients of male endurance athletes was higher than that of team athletes but similar to that of strength athletes. Female endurance athletes reported higher mean intake compared to both team and strength athletes. Most athletes, but not all, met the Dutch (general) EAR for carbohydrate $(2.9 \mathrm{~g} / \mathrm{kg} / \mathrm{bw})$ and protein $(0.6 \mathrm{~g} / \mathrm{kg} / \mathrm{bw})$. Overall $80 \%$ of the athletes met the sport nutrition recommendation of $1.2 \mathrm{~g}$ of protein per $\mathrm{kg} / \mathrm{bw}$, but $50-80 \%$ did not met the recommendation of $5.0 \mathrm{~g}$ or more carbohydrate per $\mathrm{kg} / \mathrm{bw}$ as advised in current sports guidelines.

Conclusions: Only small differences exist in mean energy and macronutrient intake between elite endurance, strength and team sports athletes. Furthermore, the majority of the athletes was able to meet the generally accepted protein recommendation for athletes of $1.2 \mathrm{~g} / \mathrm{kg} / \mathrm{bw}$, but carbohydrate intake was low to moderate in most athletes, between $3-5 \mathrm{~g} / \mathrm{kg} / \mathrm{bw}$. 


\section{Introduction}

It is commonly acknowledged that average requirements for carbohydrate and protein in well-trained athletes are above those set for the general sedentary population. ${ }^{1,2}$ Indeed, recommendations for protein and carbohydrate intake for athletes start slightly above estimated average requirement (EAR) values for the general population (i.e. 2.9 $\mathrm{g} / \mathrm{kg}$ bodyweight in the Netherlands). ${ }^{3}$ However, current recommendations for carbohydrate and protein intake for athletes do show a considerable degree of variation, ${ }^{4}$ with carbohydrate intake recommendations ranging from 3 to $12 \mathrm{~g} / \mathrm{kg} / \mathrm{bw}$ per day, and protein recommendations from 1.2 to $2.0 \mathrm{~g} / \mathrm{kg} / \mathrm{bw} .{ }^{5,6}$ Next to these general values, tailored recommendations are set for specific sport disciplines such as endurance, team and strength sports. ${ }^{7-9}$ Although athletes are considered a disciplined and motivated population, several recent studies suggested that athletes may often not meet macronutrient recommendations. ${ }^{10-15}$ However, this viewpoint has been questioned by others. ${ }^{16,17}$ Only a few studies have compared dietary intake between elite athletes from different disciplines such as endurance, team and strength athletes. ${ }^{16,17}$ Usually endurance athletes had a higher energy intake and reported substantially higher intakes of carbohydrate and protein than others. Thus the idea that strength athletes would have a higher protein intake than other athletes was not confirmed. ${ }^{16-18}$ Given the advancing insights into training methods, resulting in mixed training programs, i.e. including both endurance and strength training, especially in high level athletes, the question rises whether this differentiation for dietary intake between sport disciplines is still common practice.

The objective of the present study was to evaluate nutrition intake against generally accepted sport nutrition guidelines for carbohydrate and protein, and investigate whether differences exist in macronutrient and energy intake between endurance, team and strength athletes. This was assessed in a conditioning phase during a training period using a web-based 24-hour recall method with additional nutrient supplement questionnaires.

\section{Methods}

\section{Study design}

The study was performed between February 2012 and June 2015. After enrolment, participants were asked to complete three or four unannounced web-based, 24-hour dietary recalls, and an equal number of accompanying questionnaires about nutritional supplement use. All recalls were scheduled during a 2-4 week period on three nonconsecutive days, randomly selected by the researchers. At least two week days and one weekend day were included, with a minimum of four days apart. If the collection 
(24-hour recall and/or daily questionnaire) was not complete, an additional day was scheduled at the end of the research period. This gave athletes four opportunities to deliver at least two completed dietary assessments. Data was mainly collected during a conditioning training phase.

\section{Study population}

Dutch elite and sub-elite athletes were recruited based on their level of exercise and minimum average exercise duration of at least 9 hours a week. Participants were eligible for selection when they: 1). were granted an elite athlete status by the Dutch Olympic Committee (NOC*NSF) and/ or; 2). had participated in a European or World Championship; and/or 3). had proven to be top level in their discipline or age group on a national level. Elite athletes were first recruited by direct mailing through the Dutch Olympic Committee (NOC*NSF) and secondly by sports dieticians working with this group of athletes.

Written informed consent to participate was provided by all participants. For participants under the age of eighteen, informed consent was also obtained from their parents or guardian. No incentive was given for participation in the study. The survey was conducted according to the Declaration of Helsinki, as revised in 1983, and approved by the Medical Ethics Committee of Wageningen University.

\section{4-hour recalls and questionnaires}

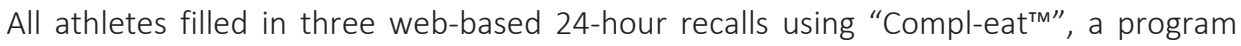
built by the Division of Human Nutrition of Wageningen University, except for a small group of male soccer players $(n=28)$ in whom four 24-hour recalls and questionnaires were conducted face to face by a trained dietician who exactly followed the web-based program. The Compl-eat ${ }^{\mathrm{TM}}$ program, based on the USDA five-step multiple-pass method $^{19}$ included a wide selection of foods commonly used in a Dutch food pattern ${ }^{20}$ but no dietary supplements or sport nutrition products, which were therefore questioned separately with a web-based questionnaire.

The web-based questionnaire regarding training load (total minutes of exercise per day) and nutritional supplement use was filled out by the participants using the "Vitality portal" a web-based questionnaire module built by the HAN University of Applied Sciences.

Nutritional supplements were categorised as dietary supplements (i.e. micronutrients and essential fatty acids), sport nutrition products (i.e. carbohydrate and protein based products) and ergogenic supplements (for example creatine, beta-alanine and other products with ergogenic claims). Based on the question: "Did you use any dietary supplements, sport nutrition products or ergogenic supplements yesterday?" athletes were asked to provide details about all supplements they had used during the previous day. They were able to select products and dosages out of a pre-specified list of more 
than 3400 dietary supplements based on the Dutch database of dietary Supplements $(\mathrm{NES})^{21}$ and additional sports specific dietary supplements and sport nutrition products. If a specific brand or product was missing athletes were able to add this as a new product to the list. For each product that the athlete added, the specific brand, amount and unit (dosage) was questioned. Based on this input, macronutrient composition and energy content was calculated by using the NES database.

Since response rates based on this questionnaire were considered too low, from 2013 onwards they were completed via telephone interview by a trained dietician who followed the same steps as the original web-based questionnaire. Trained dieticians checked all web-based 24-hour recalls and questionnaires for their completeness and unusual portion sizes, and processed all notes made by the participants. If information on foods was missing, this was retrieved by contacting subjects. Adjustment of missing data, errors and relevant notes were made in a standardised way using standard portion sizes and recipes according to a protocol. ${ }^{22}$ We were able to retrieve the composition of almost all (>99\%) added dietary supplements and sport nutrition products used based on label information given by manufacturers. If not, a product with a similar nutritional composition was selected.

\section{Combining 24-hour recalls and questionnaires}

Data analysis was separated to calculate both macro-nutrient and micro-nutrient intake to fully address both parts of dietary intake. Therefore micronutrient intake of this population will be addressed in chapter $3 \mathrm{~b}$ of this thesis.

Reported food consumption was converted into energy and macronutrient intake using the Dutch food composition database of 2010 (Stichting NEVO, 2010), the Dutch database for dietary Supplements (NES), and ingredient declarations of individual foods. After combining results of both the 24 hour recall and questionnaire per person per day energy (MJ and kcal) and macronutrient intake ( $\mathrm{g} / \mathrm{d}, \mathrm{g} / \mathrm{kg} / \mathrm{bw}$ and en\%) were calculated.

\section{Statistical analyses}

Statistical analysis (SPPS version 23) was carried out in participants with at least 2 day dietary assessments. Results were checked for normal distribution using histograms for curve, skewness and kurtosis. No log transformation was needed. The intake distribution was adjusted for day to day variation using the formula $\mathrm{SD}_{\text {corrected }}=\mathrm{SD}_{\text {observed }} * V \mathrm{r}_{\mathrm{ic}}$, where $r_{i c}$ is the intra class correlation coefficient $\left({ }^{p}={ }_{s}{ }_{s} / \delta_{s}{ }_{s}+{ }_{e}{ }_{e}\right)$. Mean $\pm S D_{\text {corrected }}$ of dietary intake was reported for the different subgroups. Within and between subject coefficients of variation $\left(\mathrm{CV}_{\mathrm{W}}\right.$ and $\mathrm{CV}_{\mathrm{b}}$ ) for energy and macronutrients were similar to those earlier found. ${ }^{22,23}$ Precision of the mean estimate $\left(D_{t}\right)$ were below $12.5 \%$ for all macronutrients. ${ }^{24}$ 
One-way ANOVA was performed to determine the difference within gender for energy, macronutrients, dietary fibre, and fluid intake. Statistical significance was set at $\mathrm{P} \leq 0.05$ and the main effect was subsequently analyzed using a Bonferroni corrected post-hoc test.

The proportion (\%) of athletes at risk of inadequate intake was estimated using the probability approach. The probability approach accounts for the probability of inadequacy $P\left(r_{i}\right)$ for each individual, and the distribution of the nutrient intake (exposure) i.e. the probability of exposure $\mathrm{P}\left(\mathrm{x}_{\mathrm{i}}\right)$ for each level of exposure. The $\mathrm{P}\left(\mathrm{r}_{\mathrm{i}}\right)$ is obtained by filling in the $z$-scores $\left(z_{i}\right)$ for the usual intake minus the EAR or sport nutrition recommendation, divided by the SD of the requirement, e.g. $\left.\left(x_{i}-E A R\right) / S d_{\text {req }}\right)$. The $P\left(x_{i}\right)$ is provided by the frequency distribution of nutrient intake of the population assuming a normal distribution. The prevalence of inadequacy is than calculated as $P_{\text {inadequacy }}=\sum P(x) * P\left(r_{i}\right)$. The estimated average requirements (EAR) used were $0.6 \mathrm{~g} / \mathrm{kg} / \mathrm{bw}$ for protein and $2.9 \mathrm{~g} / \mathrm{kg} / \mathrm{bw}$ for carbohydrate. ${ }^{3}$ Furthermore, the generally accepted sport nutrition recommendation for protein of $1.2 \mathrm{~g} / \mathrm{kg} / \mathrm{bw}^{23}$ and for carbohydrates of $5.0 \mathrm{~g} / \mathrm{kg} / \mathrm{bw}$ were considered. ${ }^{5}$

The ratio of calculated energy intake/BMR using Schofield's formula, ${ }^{24}$ may be referred to as the food intake level (FIL) value. Compared with the physical activity level (PAL) the ratio FIL/PAL should equal 1.0 if there is no bias in estimation of the energy intake. We used a lower limit Physical Activity Level (PAL) of 1.55 as was previously done in our validation study. ${ }^{25}$

\section{Results}

A total of 759 Dutch elite and sub-elite competitive athletes fulfilled the inclusion criteria and were included in the study. Due to incomplete 24-h dietary recalls or dietary questionnaires, 206 athletes were excluded, and only data of the remaining 553 athletes were analyzed (Table 1). Athletes held an elite athlete status of the Dutch Olympic Committee (NOC*NSF) ( $n=195$ ); or had participated in a European League (soccer) or European/World Championship ( $n=60$ ); or had proven to be top level in their discipline or age group on a (inter)national level $(n=298)$. The study population consisted of both male (59\%) and female (41\%) athletes representing 20 different sports. They were mostly young-adult elite athletes (mean \pm SD: $20.5 \pm 4.5$ y for men and $20.7 \pm 5.4$ y for women). Athletes were categorized in three disciplines, i.e. endurance, team and strength sports. On average, strength athletes reported the highest number of training hours, followed by endurance athletes and lowest for team athletes in both men and women (see Table 1). Participants reported on average 2.83 days per person, 2.89 days for men and 2.75 days for women. 


\section{Energy intake}

For men, as shown in Table 2, mean estimated energy intake including nutritional supplements ranged between 2561-2994 kcal per day. For women mean energy intake ranged between 1997 and $2457 \mathrm{kcal}$ per day (Table 3). The inclusion of nutritional supplements to the basic dietary intake added on average $~ 70 \mathrm{kcal}$ to the energy intake of both men and women. This mean difference between including or excluding nutritional supplements was small but significant for both men and women within all sports categories $(P<0.01)$.

For men, median food intake level (FIL) values, as an indicator of misreporting, was 1.60 for endurance athletes, which was above the estimated minimum cut-off limit for PAL of 1.55. However, both team and strength male athletes reported below this level (FIL of 1.4). For women, median FIL values of the endurance athletes (1.57) was also above a PAL of 1.55, but both team (1.31) and strength athletes (1.39) scored below this cut-off limit.

\section{Differences between endurance, team, and strength athletes}

In the group of male athletes endurance athletes reported a significantly higher level of intake of energy and all macronutrients compared to team sports athletes (Table 2). Strength athletes consumed higher amounts of protein and dietary fibre than athletes active in team sports. No differences were seen between endurance and strength athletes.

Similar as in men, female endurance athletes reported a significantly higher intake of energy and macronutrients compared to team sports athletes, but female endurance athletes also consumed more energy, carbohydrate and fibre than strength athletes (Table 3). In females no differences were seen between team and strength athletes.

With regard to the contribution of macronutrients to total energy intake (en\%) no differences were seen for carbohydrate and fat between sport disciplines in both men and women (Tables 2 and 3). In females the contribution of protein to total energy was higher in both strength (18.4 en\%) and team sports athletes (17.8 en\%) compared to endurance athletes (16.4 en\%), while in men only strength athletes and endurance athletes significantly differed: 18.0 and $16.1 \mathrm{En} \%$ protein intake respectively (Table 2). 


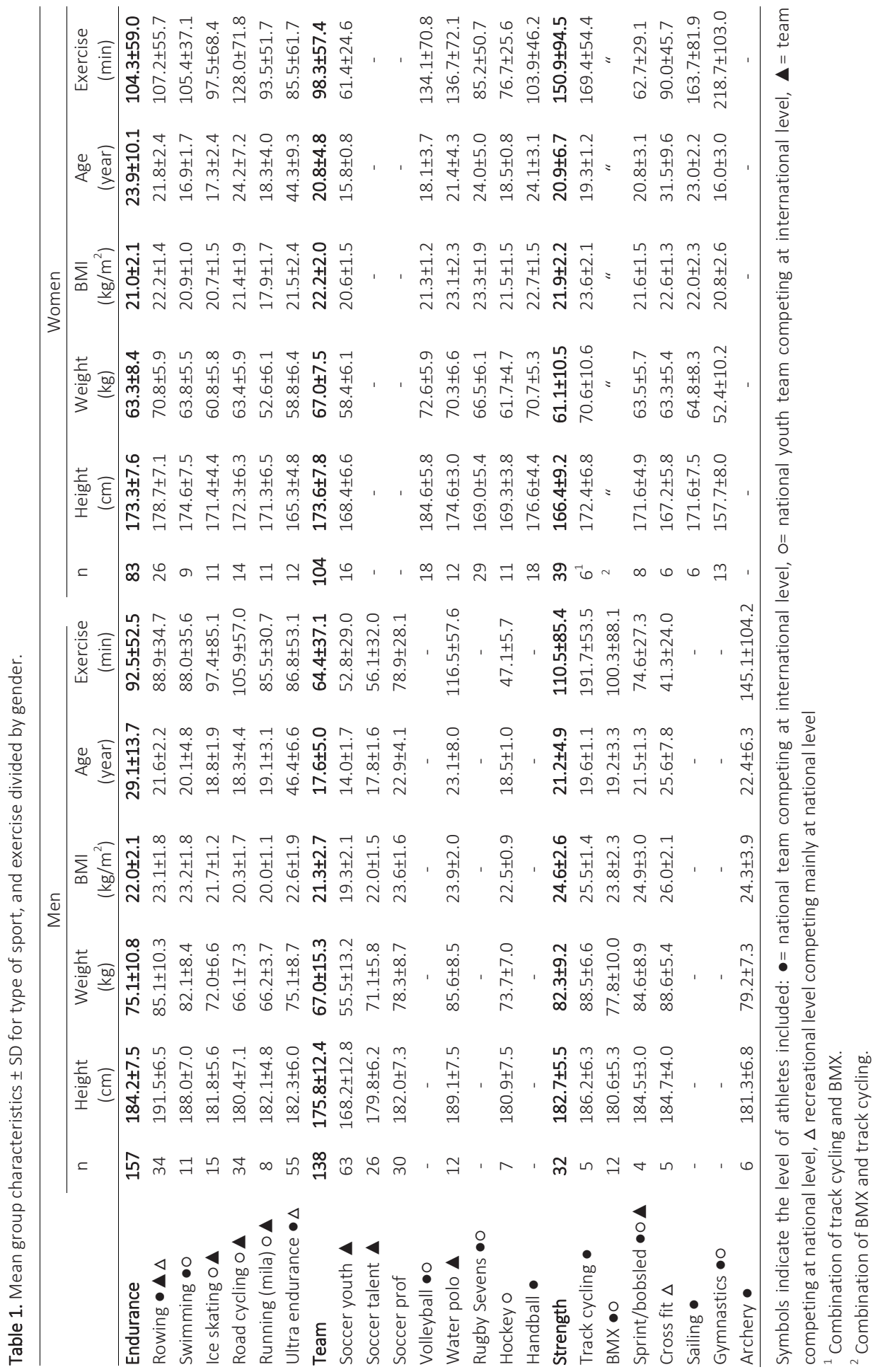




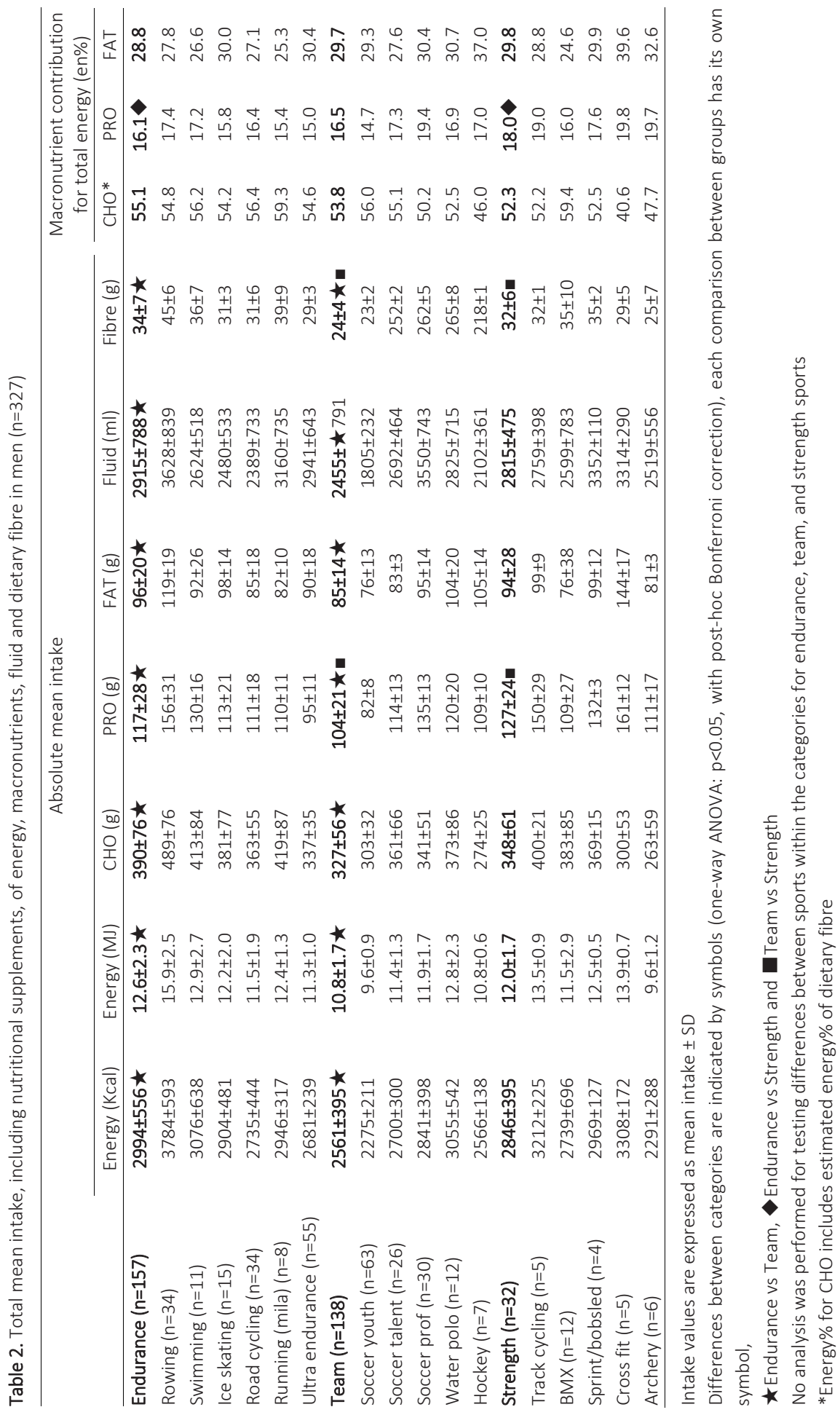




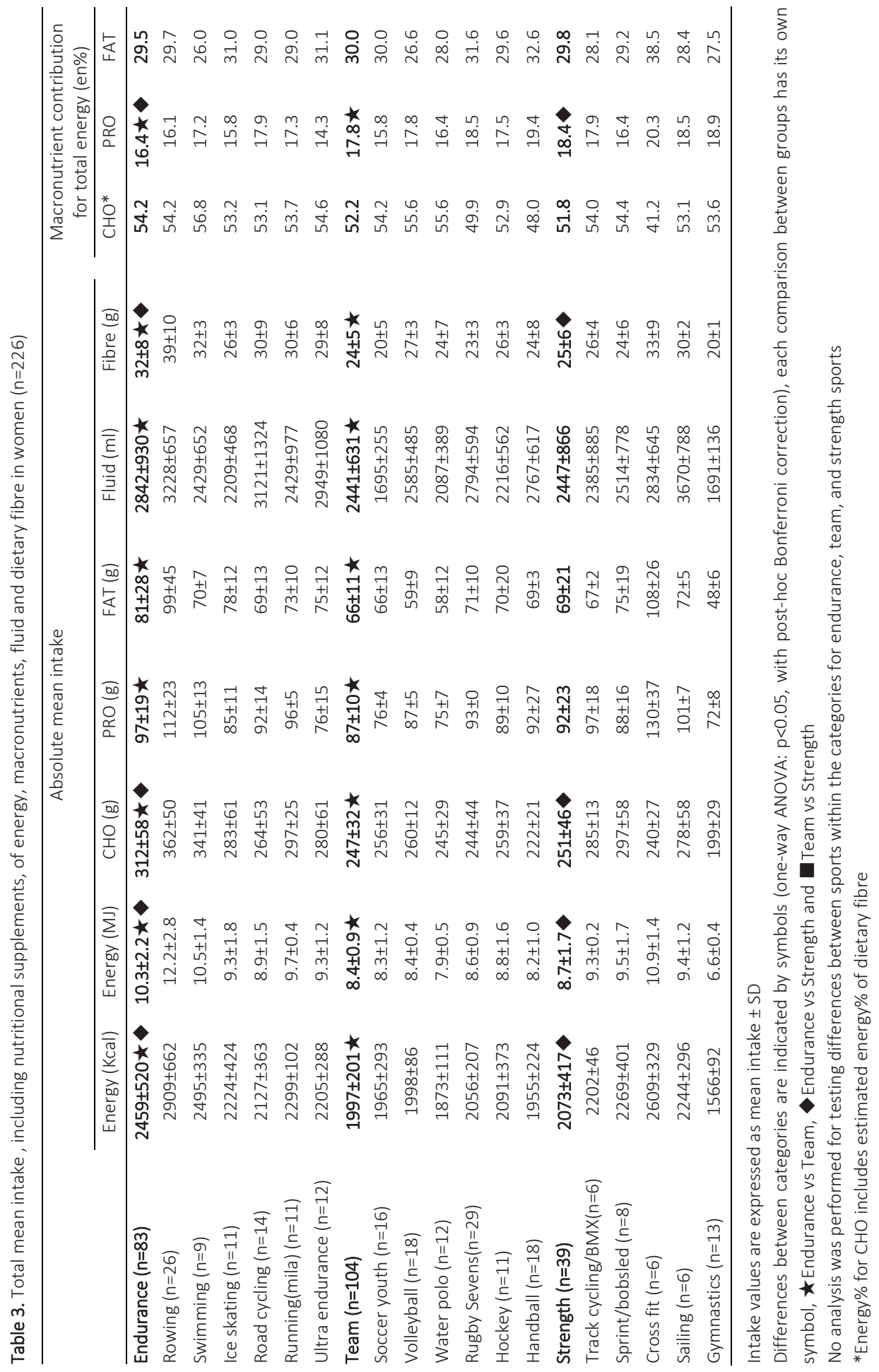


Differences, for both men and women, were also seen when carbohydrate and protein intake were expressed as $\mathrm{g} / \mathrm{kg} / \mathrm{bw}$ (Table 4). In men, endurance and team athletes consumed more carbohydrates than strength athletes, while in women, the endurance athletes consumed more carbohydrates than both strength and team athletes, with no differences in carbohydrate intake between strength and team athletes.

In women, team athletes consumed less protein per kg bodyweight than endurance and strength athletes (Table 5); in men, no differences were seen.

\section{Carbohydrate and protein intake as compared to reference values}

When sport nutrition products were included in the analysis not all athletes met the EAR for carbohydrate $(2.9 \mathrm{~g} / \mathrm{kg} / \mathrm{bw})$. For men prevalences of intake below the EAR were $5.5 \%, 8.0 \%$ and $13.6 \%$ for endurance, team and strength athletes respectively. For women higher prevalences of low intake were seen of $6.1 \%, 26.0 \%$ and $17.4 \%$ for endurance, team and strength athletes, respectively. When carbohydrate intake was compared with a moderate sports nutrition recommendation of $5 \mathrm{~g}$ carbohydrate per $\mathrm{kg} / \mathrm{bw}$ per day (Table 4), the prevalence of inadequacy for carbohydrates among men was $48.3 \%$ for endurance athletes, compared to $50.5 \%$ for team athletes and $96.2 \%$ for strength athletes. In women, the prevalence of inadequate intake of carbohydrates was $54.4 \%$ for endurance sports, $80.5 \%$ for team sports and $73.0 \%$ for strength sports when compared to the sports nutrition recommendation of $5 \mathrm{~g} / \mathrm{kg} / \mathrm{bw}$ per day. Including sport nutrition products in the analysis resulted in somewhat lower prevalences of intake below the recommendations.

For protein, our results confirmed that all athletes (>98\%) met the estimated average requirement $(E A R)$ for protein $(0.6 \mathrm{~g} / \mathrm{kg} / \mathrm{bw})$ when sport nutrition products were included. When protein intake was compared with the sports nutrition recommendation about $20-30 \%$ prevalences of intakes below $1.2 \mathrm{~g}$ protein per $\mathrm{kg} / \mathrm{bw}$ were seen in all disciplines for both men and women (Table 5). The only exception was the female team athletes group, showing a prevalence of inadequate intake of $41.8 \%$ even when nutritional supplements were included. 


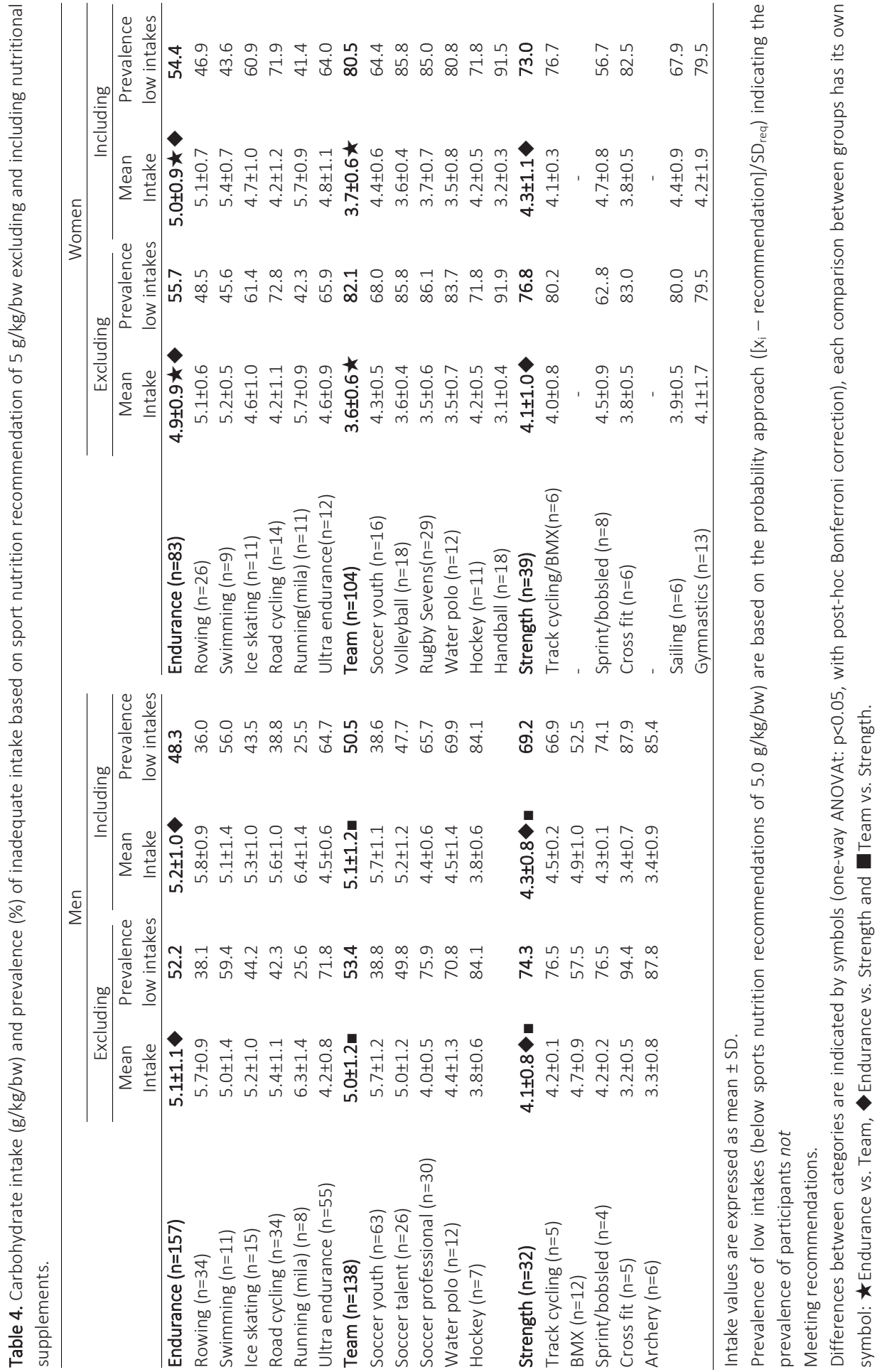




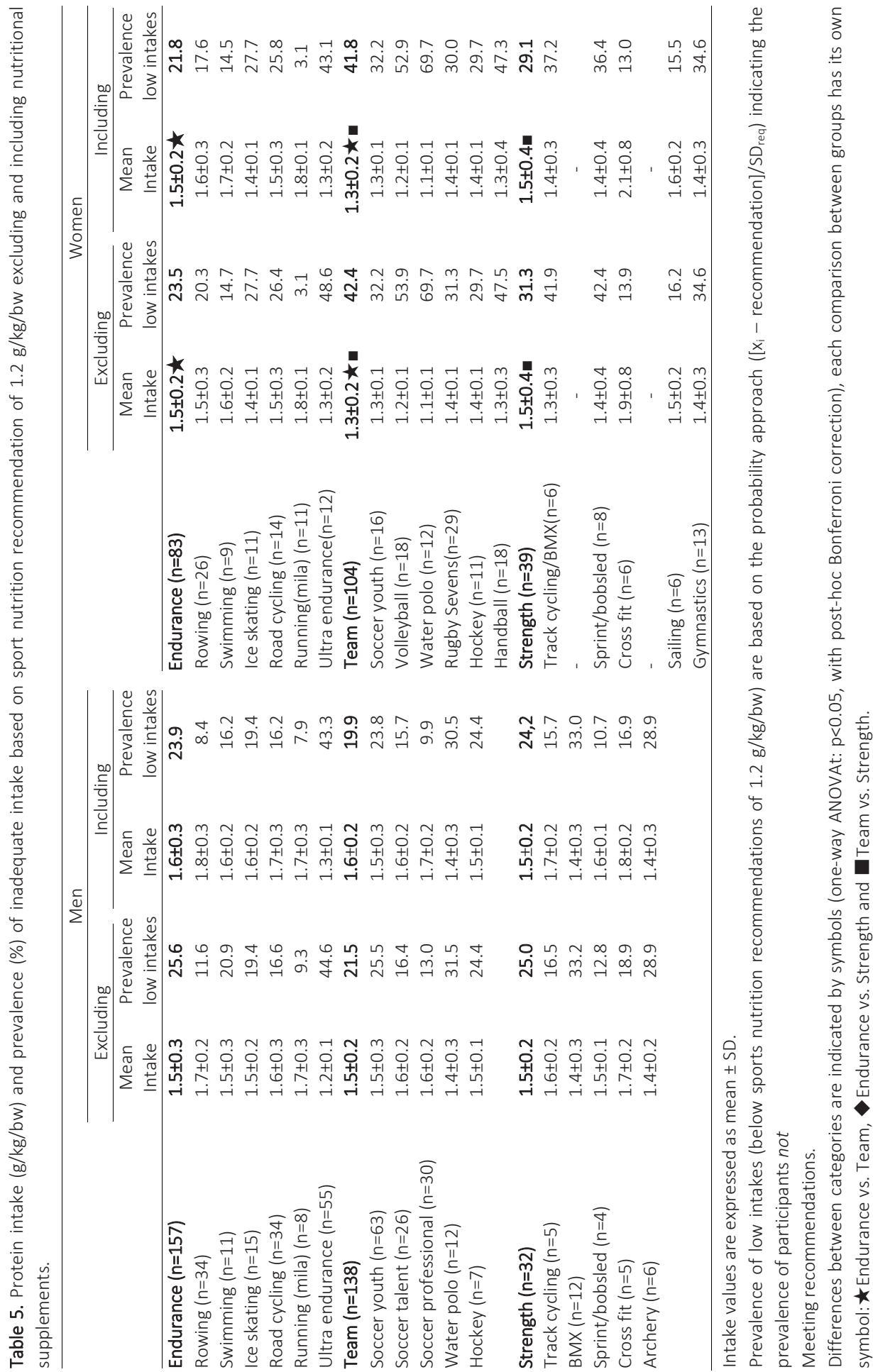




\section{Discussion}

This study provides a good insight into the nutritional intake of a unique, large cohort of elite and sub-elite athletes ( $n=553,327$ men and 226 women) practicing a wide variation of sports. Small differences were found in mean energy and macronutrient intake between athletes practising different sports disciplines. In general, intake of energy, $\mathrm{CHO}$ and protein was higher in endurance athletes compared to team athletes and to some extent also to strength athletes. Almost all athletes met the EAR for protein, but a substantial number of athletes (20-30\%) reported carbohydrate intakes below the EAR. Except for female team athletes, all other disciplines reported a protein intake of $\sim 20 \%$ below the generally accepted sport nutrition recommendation of $1.2 \mathrm{~g}$ protein per kilogram bodyweight per day. Additionally more than half of the athletes did not reach the generally accepted sport nutrition recommendation for carbohydrate intake of $5.0 \mathrm{~g}$ per kilogram bodyweight per day.

Regarding carbohydrate intake of athletes, recent literature data are scarce and they give a diverse picture. Moreover the number of large surveys comparing dietary intake and adequacy in different sports disciplines is limited. ${ }^{16,17,26-28}$ Of these, only two recent studies categorized athletes in a manner comparable to our study. ${ }^{16,17}$ In line with our data, both studies reported higher carbohydrate intake levels for endurance athletes compared to other types of athletes. However, absolute levels, as reported by Burke et al. ${ }^{16}$ for endurance athletes were higher $(6.8 \mathrm{~g} / \mathrm{kg}$, mix of men and women) in comparison to the 5.2 and $5.0 \mathrm{~g} / \mathrm{kg}$ for men and women that we observed. At the same time, some other studies reported more or less equal levels for carbohydrate to those in our study. ${ }^{10-12}$ Although differences in dietary intake between subgroups of athletes were small in the present study, absolute amounts of intakes especially of carbohydrate intake were higher in endurance athletes. Despite higher carbohydrate intake in endurance athletes, it can be questioned whether endurance athletes meet their personal requirements. It can be expected that as a result of the total amount of training hours the requirement of endurance athletes is substantial higher than for example in team or strength athletes. Despite the fact that most athletes do not meet the sport nutrition recommendation of $5 \mathrm{~g} / \mathrm{kg} / \mathrm{bw}$, team and strength athletes may be closer to meeting their personal carbohydrate needs than endurance athletes.

Our finding that carbohydrate intake levels were lower than expected, and lower than previously reported in literature, ${ }^{16,17}$ deserves some attention. The large number of participants practicing different sports and the fact that we collected data for on average 2.83 reporting days in our view resulted in a representative picture of this population. Also, information on daily variation in intake can be extracted from our data. Our results suggest that peaks in carbohydrate intake on individual days were limited in most of our athletes. We expected athletes to differentiate in carbohydrate intake resulting low, moderate and high intakes as part of the data collected but high single daily carbohydrate intakes above $8 \mathrm{~g} / \mathrm{kg}$ per athlete were exceptional $(<6 \%$ of all days col- 
lected). However, some degree of underreporting may have affected our data. The combined method of web-based 24-hour recalls and questionnaires was previously validated by our research group in a sub-sample of this population. ${ }^{25}$ Based on this study it was concluded that the method was suitable for the ranking of athletes to their intake ( $r=0.65$ [95\% $\mathrm{Cl}$ : 0.45-0.79]) with an acceptable amount of underreporting of $25.5 \%{ }^{25}$ To further investigate this possibility of under-reporting in the current population we compared the food intake level (FIL) to the, estimated lower limit PAL for this population of around 1.55; equal to our previous published validation study. ${ }^{25}$ The median FIL found in the present study was 1.53 for men and 1.43 for women which indicates possible energy under-reporting as in line with our previously reported validation study (FIL of 1.52). ${ }^{25}$ These median FIL values were improved by the higher FIL values of endurance athletes, as other categories for both men and women reported much lower values. The relative higher under-reporting by team and strength athletes in comparison to endurance athletes may have affected our results. If we assume that nutrient intake was not biased by selective under-reporting and that their energy requirements were more or less comparable, we can estimate the degree of under-reporting for $\mathrm{CHO}$ and PRO to be equal to energy under-reporting. If this is taken into account, our data indicate that no differences in mean are present between sport disciplines, for both men and women. Confirming the idea that due to advancing insights into training methods, resulting in mixed training programs, i.e. including both endurance and strength training, especially in high level athletes, differences in dietary intake between sport disciplines are, in practice, not present.

Finally, the inclusion of athletes and the way they were classified into endurance, team and strength sports could be discussed. As study participation was voluntary the number of strength athletes taking part in the study was less than of the other categories in both men and women. Also, the strength athletes included in the study do not represent the full scope of strength sports. The participating strength athletes mostly performed sports that required speed in combination with strength or static strength. Therefore the generalizability of the results, especially in relation to strength athletes, should be done with care.

Although the contribution of carbohydrate to total energy intake was $>50$ energy $\%$ in all sports disciplines, the absolute carbohydrate intake was still not very high in our population even if possible under-reporting is taken into account. These findings raise the important question whether $\mathrm{CHO}$ intake levels are actually sub-optimal in the light of current recommendations. In our population, a basic diet was the main source of carbohydrates as intake through sport nutrition products was limited. From a physiological perspective, it seems advantageous to consume over 5-10 grams of carbohydrates per kg of body weight for most of these athletes. Especially athletes exercising $>90$ min a day or performing intermittent exercise benefit from sufficient carbohydrate intake. These carbohydrates from the diet are mainly used to restore muscle and liver glycogen enhancing recovery between (multiple) training sessions or competitive events. ${ }^{5}$ From 
this it could be concluded that their carbohydrate intake needs to be improved. ${ }^{29} \mathrm{How}$ ever, whether a low carbohydrate intake, both basal and during exercise, negatively affects direct and long term athletic performance is currently under debate..$^{30,31}$

The question is raised whether athletes, for example involved in prolonged sub maximal exercise, should always consume a high carbohydrate diet. ${ }^{30}$ Moreover, it has been proposed that athletes can adapt to lower muscle glycogen stores. ${ }^{32}$ This can be already achieved with moderate carbohydrate intake (3-5 g/kg per day, such that it does not necessarily impair training or competition outcomes. ${ }^{32}$ If this is the case, athletes with a moderate carbohydrate intake in the present study, are not necessarily at risk of impaired performance capacity. On the other hand as daily carbohydrate intake is not static, a low to moderate average carbohydrate intake is still giving the ability to consume high amounts of carbohydrate, tailored according to fuel cost of training load and carbohydrate requirements, when needed. ${ }^{5}$

Reported protein intake in our athletes was comparable to previously reported data from Burke et al. (2003), ${ }^{16}$ and slightly lower than those reported by De Sousa et al (2008). ${ }^{17}$ It remains difficult to compare the quality of protein intake relative to recommendations with previous reports, due to the fact that different recommendations, between 1.2 up to 1.4 or $1.5 \mathrm{~g} / \mathrm{kg}$, were used. ${ }^{10,12}$ Although some differences were seen for protein intake between sport disciplines in our study, most athletes ( $70 \%$ ) had a daily protein intake above $1.2 \mathrm{~g} / \mathrm{kg}$. As recommendations were mostly met, the observed differences between groups of athletes may be of less relevance. It is worth mentioning that the average protein intake of the general Dutch population is already relatively high ( $\sim 1.0$ and $\sim 1.3 \mathrm{~g} / \mathrm{kg}$ for females and males in the age of 19-30 years respectively) which probably mainly underlie our observation. ${ }^{33}$ Although the absolute protein intake seems sufficient in most athletes, a substantial sample of the athletes did not meet this recommendation. Further it is possible that protein timing over the day needs further attention in all athletes to optimize adaptation and muscle protein synthesis.(Gillen et al. accepted September 2016)

In conclusion, only small differences exist in mean energy and macronutrient intake between elite endurance, strength and team sports athletes. Confirming the idea that due to advancing insights into training methods, resulting in mixed training programs, differences in dietary intake between sport disciplines are, in practice, not present. Furthermore, the majority of the athletes was able to meet the generally accepted protein recommendation for athletes of $1.2 \mathrm{~g} / \mathrm{kg} / \mathrm{bw}$, but carbohydrate intake was low to moderate in most athletes, between $3-5 \mathrm{~g} / \mathrm{kg} / \mathrm{bw}$. Considering the existing consensus on sport nutrition carbohydrate recommendations, i.e. $\sim 5 \mathrm{~g} / \mathrm{kg} / \mathrm{bw}$ per day, our data suggest that a substantial part of athletes across all disciplines should either improve their carbohydrate intake to meet recommendations, or that re-evaluation of average carbohydrate needs and related recommendations is merited. 


\section{Acknowledgements}

We would like to thank all athletes who were willing to participate in this survey as part of the Dutch Dietary and Supplement Study (DSSS). We would also like to thank all 57 students from various universities who helped with this study as part of their internship or their bachelor's or master's thesis. 


\section{References}

1 Hawley JA, Dennis SC, Lindsay FH, Noakes TD. Nutritional practices of athletes: are they sub-optimal? J Sports Sci. 1995; 13 Spec No: S75-81.

2 Jeukendrup A. A step towards personalized sports nutrition: carbohydrate intake during exercise. Sports Med. 2014; 44 Suppl 1: S25-33.

3 Health Council of the Netherlands. Dietary Reference Intakes: energy, proteins, fats and digestible carbohydrates. The Hague, the Netherlands: Health Council of the Netherlands, , 2001.

4 Potgieter S. Sport nutrition: A review of the latest guidelines for exercise and sport nutrition from the American College of Sport Nutrition, the International Olympic Committee and the International Society for Sports Nutrition. S Afr J Clin Nutr. 2013; 26: 6-16.

5 Burke LM, Hawley JA, Wong SH, Jeukendrup AE. Carbohydrates for training and competition. J Sports Sci. 2011; 29 Suppl 1: S17-27.

6 Phillips SM, Van Loon LJ. Dietary protein for athletes: from requirements to optimum adaptation. J Sports Sci. 2011; 29 Suppl 1: S29-38.

7 Slater G, Phillips SM. Nutrition guidelines for strength sports: sprinting, weightlifting, throwing events, and bodybuilding. J Sports Sci. 2011; 29 Suppl 1: S67-77.

8 Jeukendrup AE. Nutrition for endurance sports: marathon, triathlon, and road cycling. J Sports Sci. 2011; 29 Suppl 1: S91-9.

9 Holway FE, Spriet LL. Sport-specific nutrition: practical strategies for team sports. J Sports Sci. $2011 ; 29$ Suppl 1: S115-25.

10 Julian-Almarcegui C, Gomez-Cabello A, Gonzalez-Aguero A, et al. The nutritional status in adolescent Spanish cyclists. Nutr Hosp. 2013; 28: 1184-9.

11 Molina-Lopez J, Molina JM, Chirosa LJ, et al. Implementation of a nutrition education program in a handball team; consequences on nutritional status. Nutr Hosp. 2013; 28: 1065-76.

12 Noda Y, lide K, Masuda R, et al. Nutrient intake and blood iron status of male collegiate soccer players. Asia Pac J Clin Nutr. 2009; 18: 344-50.

13 Wierniuk A, Wlodarek D. Estimation of energy and nutritional intake of young men practicing aerobic sports. Rocz Panstw Zakl Hig. 2013; 64: 143-8.

14 Heaney S, O'Connor H, Gifford J, Naughton G. Comparison of strategies for assessing nutritional adequacy in elite female athletes' dietary intake. Int J Sport Nutr Exerc Metab. 2010; 20: 245-56.

15 Wardenaar FC, Dijkhuizen R, Ceelen IJ, et al. Nutrient Intake by Ultramarathon Runners: Can They Meet Recommendations? Int J Sport Nutr Exerc Metab. 2015.

16 Burke LM, Slater G, Broad EM, Haukka J, Modulon S, Hopkins WG. Eating patterns and meal frequency of elite Australian athletes. Int J Sport Nutr Exerc Metab. 2003; 13: 521-38.

17 de Sousa EF, Da Costa TH, Nogueira JA, Vivaldi L. Assessment of nutrient and water intake among adolescents from sports federations in the Federal District, Brazil. Br J Nutr. 2008; 99: 1275-83.

18 van Erp-Baart AM, Saris WH, Binkhorst RA, Vos JA, Elvers JW. Nationwide survey on nutritional habits in elite athletes. Part I. Energy, carbohydrate, protein, and fat intake. Int J Sports Med. 1989; 10 Suppl 1: S310.

19 Conway JM, Ingwersen LA, Vinyard BT, Moshfegh AJ. Effectiveness of the US Department of Agriculture 5-step multiple-pass method in assessing food intake in obese and nonobese women. Am J Clin Nutr. 2003; 77: 1171-8.

20 RIVM. Nederlandse Voedingsmiddelentabel (Dutch Food Composition Table). NEVO-tabel. Bilthoven 2011.

21 Buurma-Rethans E, Fransen H, Ghameshlou Z, de Jong N. Een databestand voor supplementen: behoeftes en acties (Data file for dietary supplements: needs and actions). Voeding Nu (in Dutch). 2008; 10(1).

22 Donders-Engelen MR, Van der Heijden, L.J.M \& Hulshof, K.F.A.M. Maten, gewichten en codenummers (Food portion sizes and coding instructions). Wageningen: Department Human Nutrition, Wageningen Agricultural University (in Dutch), 1997. 
23 Rodriguez NR DN, Langley S. Nutrition and athletic performance. American College of Sports Medicine. 2009.

24 Johansson G, Wikman A, Ahren AM, Hallmans G, Johansson I. Underreporting of energy intake in repeated 24-hour recalls related to gender, age, weight status, day of interview, educational level, reported food intake, smoking habits and area of living. Public Health Nutr. 2001; 4: 919-27.

25 Wardenaar FC, Steennis J, Ceelen IJ, Mensink M, Witkamp R, de Vries JH. Validation of web-based, multiple 24-h recalls combined with nutritional supplement intake questionnaires against nitrogen excretions to determine protein intake in Dutch elite athletes. Br J Nutr. 2015: 1-10.

26 Chen JD, Wang JF, Li KJ, et al. Nutritional problems and measures in elite and amateur athletes. Am J Clin Nutr. 1989; 49: 1084-9.

27 Burke LM, Gollan RA, Read RS. Dietary intakes and food use of groups of elite Australian male athletes. Int J Sport Nutr. 1991; 1: 378-94.

28 Grandjean AC. Macronutrient intake of US athletes compared with the general population and recommendations made for athletes. Am J Clin Nutr. 1989; 49: 1070-6.

29 Hargreaves M, Hawley JA, Jeukendrup A. Pre-exercise carbohydrate and fat ingestion: effects on metabolism and performance. J Sports Sci. 2004; 22: 31-8.

30 Noakes TDV, J.S. and Phinney, S.D. Low-carbohydrate diets for athletes: what evidence? Br J Sports Med. 2014; 48: 1077-78.

31 Burke LM. Re-Examining High-Fat Diets for Sports Performance: Did We Call the 'Nail in the Coffin' Too Soon? Sports Med. 2015; 45 Suppl 1: S33-49.

32 Burke LM, Kiens B, Ivy JL. Carbohydrates and fat for training and recovery. J Sports Sci. 2004; 22: 15-30.

33 Rossum CTM, van Fransen HP, Verkaik-Kloosterman J, Buurma-Rethans EJM, Ocké MC. Dutch National Food Consumption Survey 2007-2010: Diet of children and adults aged 7 to 69 years. RIVM, 2011. 


\section{Micronutrient intakes in 553 Dutch elite and sub-elite athletes:}

prevalence of low and high intakes in users and non-users of nutritional supplements

Floris C. Wardenaar, Naomi Y.J. Brinkmans, Ingrid J.M. Ceelen, Bo van Rooij, Marco Mensink, Renger F. Witkamp, Jeanne H.M. de Vries.

Submitted. 


\begin{abstract}
Aim: To investigate whether athletes meet micronutrient recommendations and whether the adequacy of their intake is related to the use of dietary supplements, sport nutrition products or a combination of both. This is of importance since a micronutrient intake which is either too low or too high can affect the athletes' health and performance, especially when this is maintained for a prolonged period of time.
\end{abstract}

Methods: Micronutrient intakes of 553 Dutch well-trained (sub-) elite athletes was assessed using web-based 24-hour recalls with accompanying nutritional supplement questionnaires. Differences in intakes between users, i.e. users of dietary supplements (DS), sport nutrition products (SNP) or a combination of both (DS+SNP), and non-users were tested using non-parametric tests. The inadequacy of the diet was evaluated by estimating the prevalence of athletes below the estimated average requirement (AR) or above the Upper Level (UL).

Results: In the majority of both users and non-users vitamin D intake was below AR if supplements were not included in the analysis. Including DS improved vitamin D intake, but still a substantial part of the athletes, both men and women, reported an intake below the AR. Non-users of supplements were particularly at risk for low intakes of vitamin B1, B2 and vitamin A. They also reported low intakes of vitamin B3, vitamin C and selenium. As the use of sport nutrition products contributed slightly to micronutrient intake, users of SNP were also at risk for low intakes of vitamin B1, B2 and vitamin A. Mean iron intake was reported below the AR in a substantial group of women both users and non-users. A small prevalence of athletes using dietary supplements showed intakes of some micronutrients above the UL, especially for vitamin B3.

Conclusions: Both users and non-users of nutritional supplements reported inadequate intake of micronutrients, in particular vitamin D. For most micronutrients, use of nutritional supplements does not completely compensate for intakes below AR. Intakes above the UL were only reported by a few athletes. 


\section{Introduction}

Low micronutrient intake in athletes can result in deficiencies affecting health and performance, in particular when this occurs for longer periods of time. ${ }^{1}$ Some studies report that many athletes would not meet micronutrient recommendations, ${ }^{2-5}$ whereas others conclude the opposite. ${ }^{1,6}$ Shifts and variations in food patterns over time, ${ }^{7,8}$ increased availability of nutritional supplements, ${ }^{9}$ and changing viewpoints regarding requirements ${ }^{10,11}$ merit regular monitoring of dietary intake by athletes. At the same time, rapid developments in assessment tools, such as web-based approaches, make it easier to gain insight in the intake of large groups of athletes. ${ }^{12,13}$

No consensus exists on whether micronutrient requirements are different in athletes as compared to the general population. ${ }^{14,15}$ In practice, athletes are nowadays often advised to meet the general recommended dietary reference intakes (DRI) for all micronutrients, while paying special attention to optimal intake of iron, vitamin $D$ and calcium, and of antioxidants. ${ }^{16}$ There seems to be less attention for the intake of Bvitamins. ${ }^{16}$ Theoretically, exercise could increase the need for this group of micronutrients. ${ }^{14}$ However, if energy expenditure increases, food intake increases as well, which also results in a higher vitamin B intake. Unfortunately this is not necessarily the case, in particular when athletes make poor dietary choices, resulting in lower micronutrient intake than expected ${ }^{14}$ because of a low micronutrient density of the diet. 5, 6,17

Nutritional supplements are frequently used by athletes, ${ }^{18}$ although use can be irregular and varying over time. ${ }^{19}$ For sports purposes, nutritional supplements can be classified as dietary supplements, sport nutrition products and ergogenic supplements. Dietary supplements mainly comprise micronutrient supplements such as vitamins and minerals. These supplements may promote the athletes' general health through the prevention and treatment of nutrient deficiencies. Sport nutrition products mainly contain macronutrients, such as carbohydrates and protein, but can also contain micronutrients. These sport nutrition products include, but are not limited to, sports drinks, recovery drinks, and sports bars. Finally, the category of ergogenic supplements, such as creatine and caffeine may contain additional micronutrients although these products are also available as single bioactive substance products. ${ }^{20}$ Therefore, nutritional supplements can be an important source of micronutrient intake.

Even though many athletes use multiple nutritional supplements at a time, this does not necessarily guarantee adequate habitual dietary intake of micronutrients at an individual level. ${ }^{7}$ In addition, case reports have shown that some athletes consume very high doses of certain micronutrients exceeding the save upper level (UL), possibly resulting in reduced health and performance. ${ }^{21}$ Examples of frequently reported highly dosed micronutrient supplements used by individual athletes are antioxidants (i.e. vitamin $C$ and $E$ ), ${ }^{22}$ vitamin $D$, iron and magnesium. ${ }^{20}$ Further, practice experience and anecdotal reports suggest a substantial use of high doses of vitamin B6 among athletes. 
In the present study we aimed to evaluate the adequacy of micronutrient intake of Dutch elite athletes, using a web-based 24-hour recall method with accompanying nutritional supplement questionnaires. In addition, we aimed to assess the effect of nutritional supplements use on micronutrient intake, by making a comparison between both users and non-users of dietary supplements, sport nutrition products or a combination of both. Ultimately this should lead to better identification of athlete groups at risk of inadequate micronutrient intake, either too low or too high.

\section{Methods}

The study was performed between February 2012 and June 2015 as described in chapter 3a. A total of $n=759$ elite and sub-elite athletes were approached to participate in this study and to deliver three or four unannounced web-based, 24-hour dietary recalls and questionnaires, preferably during a conditioning training phase. Written informed consent to participate was provided by all contacted, and for participants under the age of eighteen these documents were signed by their parents or guardian. No incentive was given for participation in the study. The survey was approved by the Medical Ethics Committee of Wageningen University.

\section{4-hour recalls and questionnaires}

The web-based 24-hour recalls, based on the USDA five-step multiple-pass method, ${ }^{23,24}$ were collected with "Compl-eat ${ }^{\mathrm{TM}}$ ", a program built by the Division of Human Nutrition, Wageningen University. The web-based questionnaire, that was linked to the 24-hour recall of a specific day, was collected with the "Vitality portal", a web-based questionnaire module built by the HAN University of Applied Sciences. This questionnaire regarding training load (total minutes of exercise per day) and nutritional supplement use was filled out by the participants, or by a trained sports dietician during a face to face or telephonic interview. Nutritional supplements were defined as dietary supplements (i.e. micronutrients and essential fatty acids), sport nutrition products (i.e. carbohydrate and protein based products) or ergogenic supplements (for example creatine, b-alanine and other products with ergogenic claims). ${ }^{20}$ For this study all products containing micronutrients, classified as dietary supplements (including ergogenic supplements) and sport nutrition products, were included in the analysis.

Two trained dieticians checked all web-based 24-hour recalls and questionnaires for their completeness and unusual portion sizes, and processed all notes made by the participants. If information on foods or nutritional supplements was missing, this was retrieved by contacting subjects. Adjustments for missing data and errors and dealing with relevant notes were done in a uniform way, using standard portion sizes and recipes according to a protocol. ${ }^{25}$ Conversion of reported food consumption into energy 
and micronutrient intake was done using the Dutch food composition database of 2010 (Stichting NEVO, 2010), the Dutch database for dietary Supplements (NES), and individual product ingredient declarations. Results of the 24 hour recall and questionnaires were combined to calculate total energy (MJ) and micronutrient intake (mg or $\mu \mathrm{g}$ ).

\section{Statistical analyses}

The statistical analysis included data of all athletes handing in at least two complete datasets using the statistical software program SPSS (version 23). Prevalence of nutritional supplement use was reported as a percentage (\%). Energy intake and micronutrient intake was reported as mean \pm SD. Data was presented separately for men and women, for each of the four subgroups: non-users of nutritional supplements ('nonusers'), users of dietary supplements (DS), users of sport nutrition products (SNP) and users of a combination of both (DS+SNP).

Intake data was checked for normal distribution, by visual inspection of histograms and based on skewness and kurtosis. The intake distribution was adjusted for day to day variation using the following formula $\mathrm{SD}_{\text {corrected }}=\mathrm{SD}_{\text {observed }} * V \mathrm{r}_{\text {ic }}$ where $\mathrm{r}_{\text {ic }}$ is the intra class correlation coefficient $\left({ }^{p}=\delta_{s}{ }_{s}^{2} / \delta_{s}^{2}+\delta_{e}^{2}\right)$. Precision of the mean estimate $\left(D_{t}\right)$ of basal nutrition intake was acceptable around $10 \%$ for most micronutrients and mostly below $20 \%{ }^{24}$ Exceptions were seen only for vitamin A in women reporting SNP (22.6\%) and DS+SNP (23.9\%), for vitamin D in women reporting DS+SNP (26.4\%) and for selenium in women reporting DS (28.7\%). The ratio of calculated energy intake/BMR using Schofield's formula, ${ }^{26}$ may be referred to as the food intake level (FIL) value and was used to evaluate possible underreporting. ${ }^{13}$

The software program PC-SIDE (version 1.0), developed by the Department of Statistics and Center for Agricultural and Rural Development (CARD) at lowa State University, was used to estimate distribution of usual intake. ${ }^{27}$ This distribution was compared with the estimated average requirement (AR) based on Nordic Nutrition Recommendations ${ }^{11}$ using the cut-off approach. ${ }^{28}$ As for magnesium only the Adequate Intake (Al) was available, ${ }^{11} 75 \%$ of the $\mathrm{Al}$ was used as an estimator of average requirement.

The prevalence (\%) of athletes with an actual micronutrient intake above the upper limit $(U L)^{11}$ was calculated within each subgroup for all individuals using nutritional supplements.

Differences within and between subgroups for each gender were analysed using Wilcoxon-signed-rank-test, Kruskall-Wallis and Mann-Whitney-U-test using a Monte Carlo approach. Statistical significance was set at $\mathrm{P} \leq 0.05$, no additional corrections were done for type II errors. 


\section{Results}

A substantial part of the athletes $(n=206)$ provided incomplete dietary information, i.e. less than 2 complete days. As a consequence, in total 553 athletes, both men (59\%) and women $(41 \%)$, were included in the final analysis of this study. They recorded an average of 2.83 days by 24 -hour recalls and accompanying nutritional supplement intake questionnaires per person (Table 1 ). In total, $22.1 \%$ of the participants provided complete information on dietary intake of 2 days, $72.5 \%$ of 3 days, and $5.4 \%$ of 4 days. For men and women respectively, 157 and 83 participants were classified as endurance athletes, 138 and 104 participants as team sports athletes, and 32 and 39 participants as strength athletes as described in Chapter 3a. Mean age of the men was $23.5 \pm 11.5 \mathrm{y}$ and of the women $22.0 \pm 7.6 \mathrm{y}$, and mean exercise time was $93.5 \pm 61.3$ minutes per day.

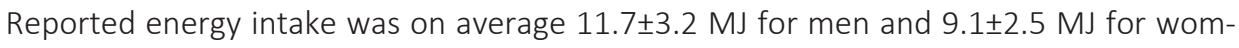
en. Mean food intake level (FIL) values, as an indicator of the quality of energy reporting, were slightly higher for men (mean \pm SD: $1.55 \pm 0.39$ ) than for women $(1.50 \pm 0.42$ ). Non-users of DS and SNP were mainly younger athletes in comparison to other categories and particular users of DS+SNP were the oldest and reported the highest exercise load.

Of the total group of athletes, $61.8 \%$ reported the use of one or more nutritional supplements; $65 \%$ in men, and $56 \%$ in women. The use of DS alone was slightly lower in men $(20 \%)$ than women $(24 \%)$, while the use of SNP's alone was more frequently reported by men (24\%) than women (17\%), as was the combined use of DS+SNP (men: $21 \%$, women:15\%). 
Micronutrient intakes in 553 Dutch elite and sub-elite athletes






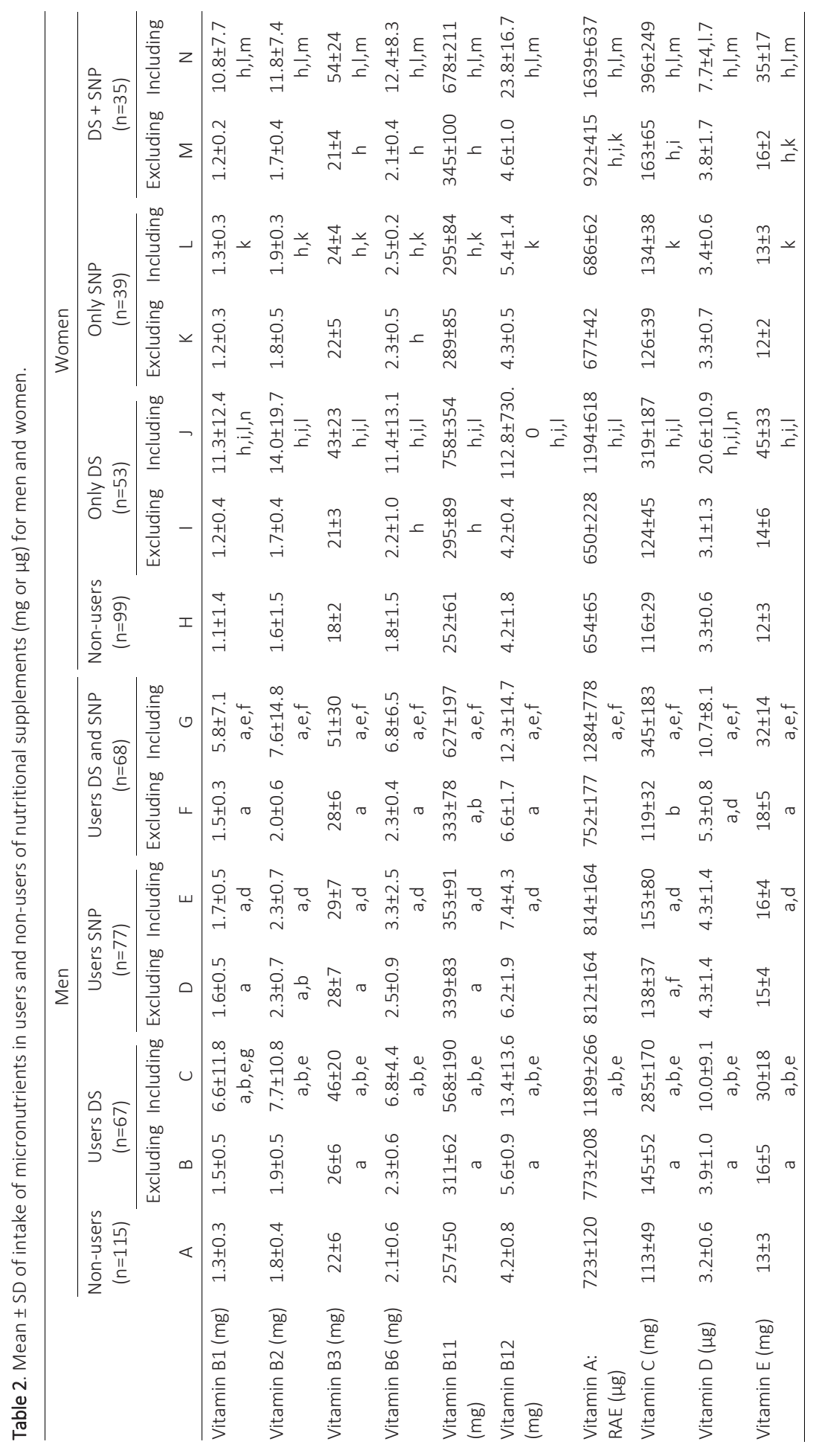




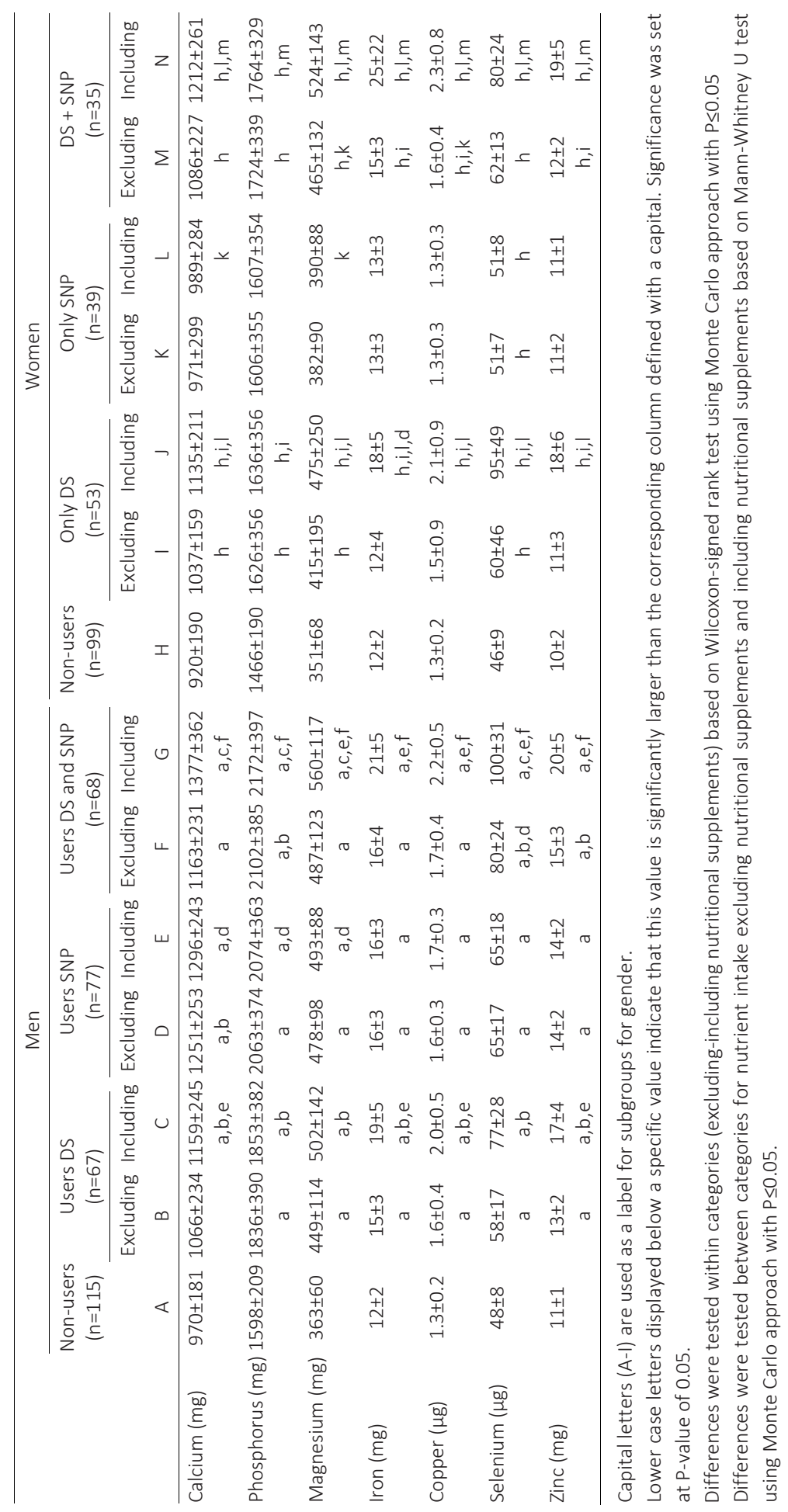




\section{Basal diet intake}

For men micronutrient intake from the basal diet, i.e. excluding nutritional supplements, was in most cases lower in non-users than in all subgroups of users (Table $2, p<$ 0.05). In women this difference was less pronounced except for the users of DS+SNP, who reported higher mean intakes than non-users, DS users and SNP users $(p<0.05)$. Nutrient density of basal dietary intake excluding supplements (not shown) did not differ for most micronutrients between users or non-users of nutritional supplements. The only exceptions were a higher nutrient density for vitamin B11, vitamin E, magnesium, iron and copper in men, and magnesium in women in the subgroups classified as DS users versus non-users ( $p \leq 0.05)$.

\section{Total micronutrient intake}

When nutritional supplements were included, users of DS and DS+SNP reported a higher total intake of all micronutrients as compared to the basal diet for both men and women ( $p \leq 0.05)$. For SNP users (both men and women) the same trend was seen, except for vitamin A, vitamin D, iron, copper, selenium and zinc, which values did not differ with the basal diet after including SNP's in the calculation ( $P>0.05)$.

Differences in mean intake existed between subgroups for almost all nutrients. Intake for most micronutrients was higher in users of DS and DS+SNP than in non-users and users of SNP's in both men and women $(P \leq 0.05)$. In men, users of SNP'S also reported higher intake of most nutrients than non-users $(P \leq 0.05)$, except for vitamin $A$ and D. Women using SNP's only reported higher intakes than non-users for vitamin B2, $B 3, B 6$, folate equivalents and selenium $(P \leq 0.05)$.

\section{Adequacy of micronutrient intake of the basal diet}

Almost all athletes (>85\%), both men and women, were not able to meet the AR of vitamin D. The basal diet was also low for vitamin A (20-48\%) and vitamin B1 (18-40\%) for both men and women. Also the intake of vitamin B2 was below the AR in some of the athletes, mainly in non-users and users of SNP in men and women (with prevalences of low intakes varying between12-17\%), except for men using DS+SNP, who showed only a prevalence of low intakes of $4 \%$. In general, non-users had the highest prevalence of micronutrient intakes below the AR. They showed low intakes of folate equivalents and selenium in both men ( $15 \%$ and $11 \%$ respectively and women ( 25 and $11 \%$ respectively) and low intakes of vitamin $\mathrm{C}$ in men (11\%). In addition, the basal diet of women, but not of men, showed within all subgroups of users and non-users, prevalences below the AR for iron. However, the overall athletes' basal diet was providing 
sufficient amounts of vitamin B3, vitamin B12, vitamin E, calcium, phosphorus, magnesium, copper and zinc.

\section{Adequacy of total micronutrient intake including nutritional supplements}

If nutritional supplements were included in the analyses, vitamin D intake of DS and DS+SNP users improved. The contribution of dietary supplements reduced the prevalence of athletes below the AR of vitamin D, but still low intakes were seen in $43 \%$ and $28 \%$ of the men and $19 \%$ and $35 \%$ of the women for DS or DS+SNP, respectively. Additionally the use of DS improved intakes of vitamin B1, B2, folate equivalents and vitamin $A$, and ensured that most intakes exceeded AR. When the use of DS was included in the analysis, iron intake improved in DS-users. Women using DS+SNP showed no prevalence of intakes below the AR for iron whereas $9 \%$ of women reporting only DS still showed an iron intake below AR. In general no beneficial effect on micronutrient intake was seen because of using SNP's. Except in women using SNP's, the prevalence of women meeting AR for vitamin B1 and vitamin A improved.

\section{Micronutrient intake exceeding UL}

If the defined upper level (UL) was available for a specific micronutrient this was shown in Table 4. The high exceedance of the UL for phosphorus in men was the result of a high intake from the basal diet. The prevalence of athletes with a micronutrient intake above the UL based on the basal diet without supplements (non-users and users of nutritional supplements excluding supplements) was in all other cases negligible.

The micronutrient intake of male users of nutritional supplements exceeded the UL for vitamin B3, in $22 \%$ and $16 \%$ using DS or DS and SNP, respectively. Of the women $17 \%$ and $34 \%$ of users of DS or DS and SNP were reporting above the UL for vitamin B3. In addition, the prevalences of high intakes of vitamin B6 (exceeding UL with $9 \%$ and $11 \%$ for DS or DS and SNP users) and vitamin A (exceeding UL with $8 \%$ and $17 \%$ ) in women is worth mentioning. All other prevalences of micronutrients exceeding UL were $\leq 4 \%$ in both men and women. 


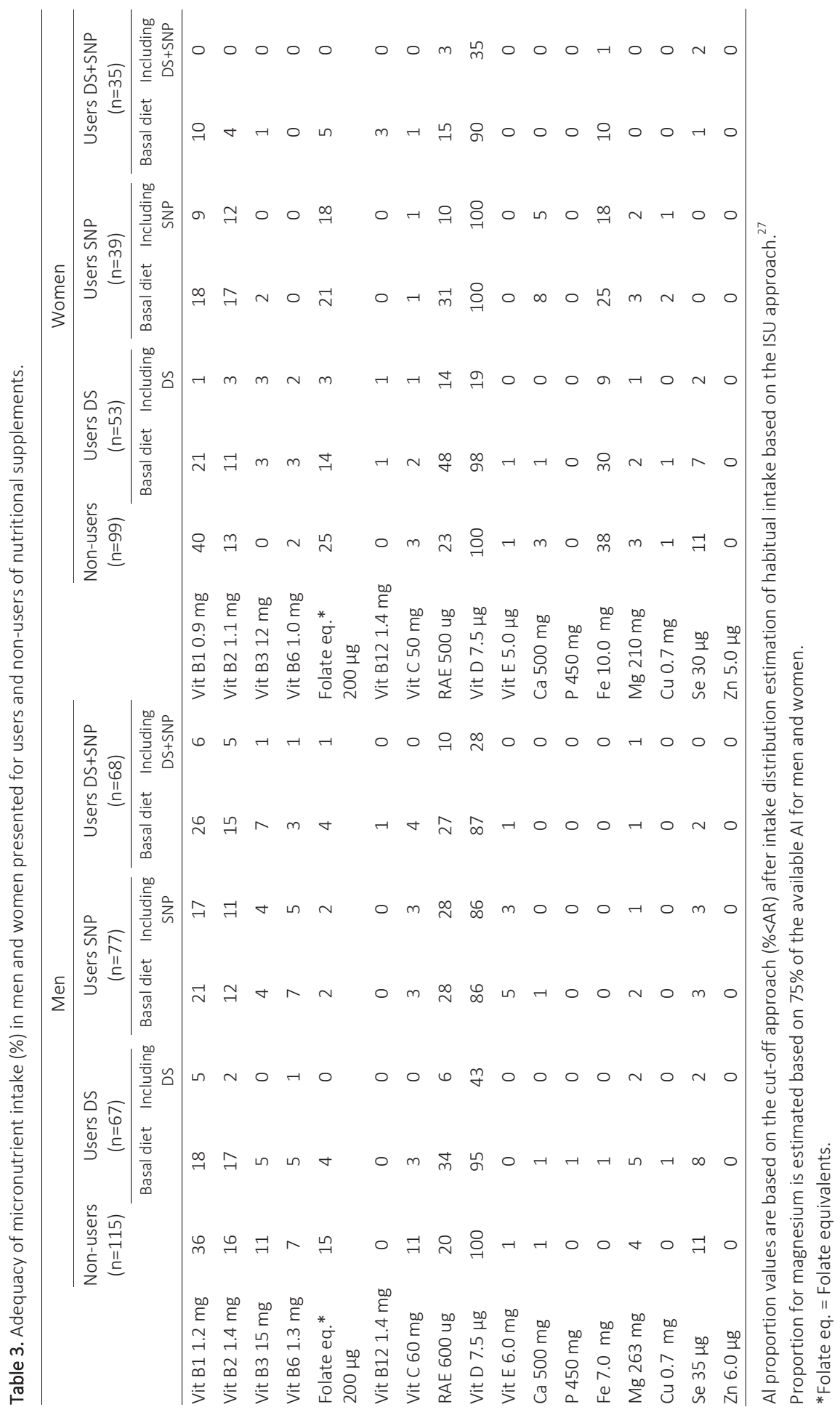


Micronutrient intakes in 553 Dutch elite and sub-elite athletes

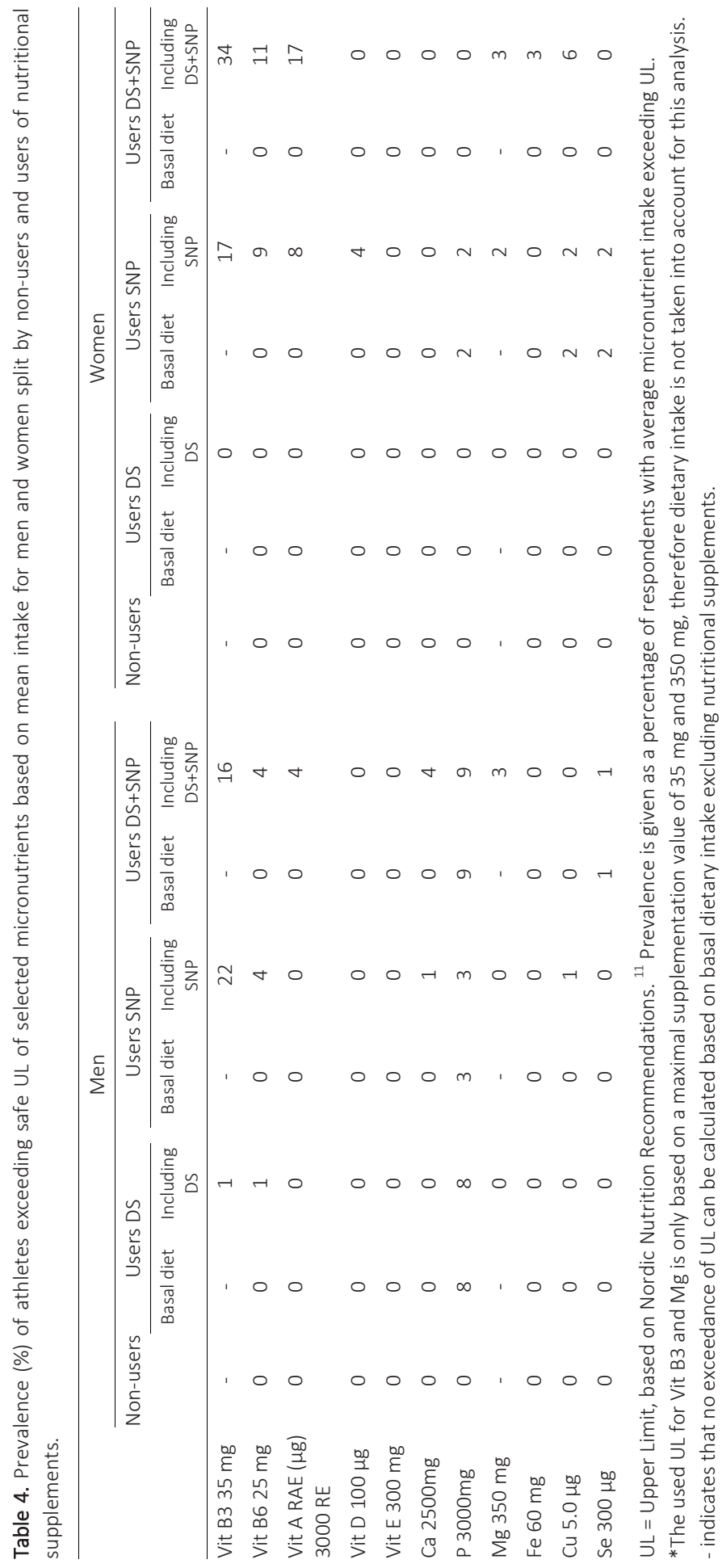




\section{Discussion}

In this survey among 553 elite and sub-elite Dutch athletes, it was shown that the basal diet alone often did not provide enough micronutrients to ensure adequate intake levels. However, when DS were included in our analyses, we saw significant differences in micronutrient intake between users and non-users of dietary supplements. Our study also revealed that vitamin $D$ intake was a problem in all athletes. In addition, non-users of supplements were particularly at risk for a low intake of vitamin B1, B2 and vitamin A. They also reported a low intake of vitamin B3, vitamin C and selenium, but this was less pronounced. As the use of SNP's hardly contributed to micronutrient intake, athletes using SNP only and no DS were also at risk for a low intake of vitamin B1, B2 and vitamin A. Iron intake was reported below the AR in female athletes only, but when dietary supplements were taken into account this appeared to be compensated. Micronutrient intake above the upper limit (UL) was only observed in those using DS, especially in case of vitamin B3.

\section{Micronutrient intake}

The majority of the athletes (62\%) involved in our study was using one or more dietary supplements, sport nutrition products or a combination of both, which is in line with a recently published meta-analysis. ${ }^{29}$ On the other hand, DS and (or) SNP's were not consistently used in the current study, and not by all athletes. Micronutrient intake from dietary supplements and sport nutrition products varied largely between days, resulting in a relatively low average contribution to the total micronutrient intake. Nevertheless, reported micronutrient intake was substantial higher in athletes using supplements compared to those not using these products, which is in line with previously published data for the general Dutch population. ${ }^{30}$

Remarkably, when nutritional supplements were not taken into account in the analysis, the intake of most micronutrients was still higher in users than in non-users. This difference in intake from the basal diet between users and non-users of dietary supplements and sport nutrition products may be a result of the higher total energy intake reported by users, because micronutrient intake correlates directly to energy intake for most micronutrients. ${ }^{7}$ This matches with the higher exercise load reported by supplement users as compared to their non-using counterparts, and the fact that nutrient density in the basal diet was not substantially different between subgroups.

The current study did not reveal problems regarding vitamin B6 and B12, vitamin C and $E$, most minerals and trace elements as suggested by other studies. ${ }^{1,5,6,31}$ This may be the result of a relatively high dairy and grain intake, which is common in the Netherlands. ${ }^{8}$ 
In all subcategories, the intake of vitamin D via the basal diet was below the AR of 7.5 $\mu \mathrm{g}$. Basal vitamin D intake was comparable to that of the Dutch general population. ${ }^{8}$ However, it was lower than previously reported for other groups of athletes, ${ }^{3-5,7}$ mainly because of the low consumption of vitamin D containing foods as butter and/or margarine and of fatty fish in our population. An adequate vitamin D status in a young healthy population is associated with improved bone health and muscle strength and function. ${ }^{11,32}$ Regarding to bone mineral density, although low vitamin D intakes were seen, the calcium intake was above the AR and exceptionally low energy intakes were not seen in the present study. ${ }^{16}$ In most people, vitamin D status throughout the year is mainly determined by seasonal exposure to sunlight in combination with vitamin $D$ intake with the diet. When the use of vitamin D containing dietary supplements was included in the analysis, a substantial improvement of vitamin D intake was seen. Unfortunately, we did not assess vitamin D status itself in our population. Therefore we can only speculate on the effect of the dietary intake of vitamin $D$ on blood status. It was previously shown in a large group of Dutch athletes that they could be at risk for developing a low 25(OH)D status especially during winter months. ${ }^{33}$ Taking this into account, it should be advised to use a dietary supplement containing 2.5-5 $\mu \mathrm{g}$ vitamin D by all athletes in order to meet at least the suggested nutrition recommendations.

Almost one third of the female athletes experienced difficulties to meet the AR for iron through their basal diet, which confirms earlier observations in athletes. ${ }^{5-7,31}$ A low iron intake increases the risk for iron deficiency or anaemia in which the oxygen-binding part of haemoglobin plays an important role. ${ }^{11}$ The development of iron deficiency is related to a higher iron loss and/or need compared to what is replaced by dietary intake. In women, iron losses are generally higher through menstrual blood loss. ${ }^{34}$ On the other hand, female athletes can suffer from amenorrhoea as a result of the high volume of exercise which could (temporarily) reduce the need for iron in the diet. ${ }^{35}$ Athletes can also suffer from exercise induced haemolysis, due to mechanically induced damage to red blood cells, which results in a higher iron loss by the body. ${ }^{36}$ A low dietary iron intake in combination with exercise induced haemolysis does not necessary lead to iron deficiency (anaemia), as for example was seen in gymnasts. ${ }^{36}$ Anyway, the AR is suggested as the lower minimal level that should be met by all athletes. Athletes should be advised to select proper sources of iron, both animal and plant-based sources and the use of a multivitamin and mineral supplement by women could add to dietary iron intake to meet recommendation.

A substantial fraction of both non-users and users of only SNP's reported an intake below the AR for vitamin B1 and B2 (thiamine and riboflavin, respectively) in both men and women and for folate equivalents in women. Theoretically, exercise increases the need for vitamin B1 and B2, as a result of a decreased absorption and (or) an increased turnover related to tissue maintenance and repair, metabolism or loss of nutrients, and 
increased mitochondrial function requiring B vitamins as cofactor. ${ }^{14}$ It is generally assumed that athletes with a poor thiamin and riboflavin status have a reduced ability to perform physical activity, especially performing maximal work. ${ }^{14}$ Previously, vitamin B1 and B2 were not seen as a particular nutritional problem for the Dutch general population based on an older study that reported higher energy intakes compared with the current study. ${ }^{7}$ Comparable prevalences for low intakes of folate were reported in 20$25 \%$ of Dutch women of the general population. ${ }^{8}$ The observed energy intake in the present study was not exceptionally high, resulting in lower B vitamin intake than recommended. Others also reported low intake of several B vitamins for both men and women, 1, 5, 6, 31 except for vitamin B2. 1, 5, 6, 31 However, subclinical vitamin B2 deficiencies were previously also identified in $20-25 \%$ of young soccer athletes, indicating inadequate vitamin B2 intakes. ${ }^{37}$ To cover the requirements of specific B vitamins, athletes should be encouraged to frequently select vitamin B1 rich foods (for example lean meat, legumes and whole grains) and vitamin B2 rich foods as eggs, lean meat and dairy products). The use of a low dosed multivitamin supplement containing both vitamin B1 and B2 may be considered.

\section{Antioxidants}

Exercise is associated with increased oxidative stress. ${ }^{38-40}$ Notwithstanding the continuing debate on the relation between their oral intake and the anti-oxidant status of the body, athletes are currently advised not to use anti-oxidant supplements as they could negatively influence protein signaling and adaptation in relation to oxidative stress. ${ }^{38-40}$ Although the bioactive anti-oxidative substances with the diet transcends the micronutrients included in this study, the basal dietary intake of vitamin C, vitamin E, selenium and zinc was in most cases above the AR in the present study. Only the basal intake of vitamin $A$, in this study reported as retinol activity equivalents (i.e. including bcarotene,) was low in a substantial part of all athletes. Therefore, consuming a wellchosen diet, rich in a large variety of fruits and vegetables containing b-carotene and retinol containing products, should be considered to optimize the antioxidant capacity of the diet. ${ }^{16,41}$

\section{Micronutrients exceeding the UL}

The prevalence of micronutrient intake exceeding the UL based on dietary supplement use was very low, i.e. a prevalence of $1-4 \%$, with the exception of users of dietary supplements containing nicotinic acid (vitamin B3), vitamin B6 and (or) vitamin A. High vitamin B intakes, as a result of the use of dietary supplements, could lead to side effects like flushing, and to more severe health problems (vitamin B3) ${ }^{11}$ and neuropathy (vitamin B6). ${ }^{42}$. Although it was not reported frequently, a combined high vitamin D and retinol intake might affect sensitivity for retinol toxicity in subjects using both high sup- 
plemental doses of retinol and vitamin $D^{11}$ even at a non-toxic dose of vitamin $D .^{43}$ In the current study eighteen athletes reported an intake of vitamin B6 above the generally accepted UL of $25 \mathrm{mg}$. ${ }^{44}$ Therefore, athletes should be advised to check their dietary supplements and avoid a combination of (highly dosed) nutritional supplements.

The UL is defined to prevent toxicity due to excessive micronutrient consumption. However, high intake levels below the UL have been associated with attenuated training adaptation and performance. It has been suggested that supplementation of high doses of vitamin $\mathrm{C}$ and $\mathrm{E}$, but below the $\mathrm{UL}$, attenuates skeletal muscle adaptations and protein signaling. ${ }^{39,45}$ A substantial number of athletes reported the use of high dosed vitamin C supplements (i.e. $1000 \mathrm{mg}$ or higher) but no high doses of vitamin E were reported. Preferably athletes should maintain an appropriate vitamin C status by selecting a large variety of fruits and vegetables as at present no consensus exists on the effect of high doses vitamin $\mathrm{C}$ on redox signaling and the implications for exercise adaptations. $^{22}$

\section{Strengths and limitations}

Inclusion of multiple non-consecutive reporting days per person ${ }^{46}$ and adjustment of dietary intake based on the method described by Nusser et al. ${ }^{27}$ resulted in a substantial correction for within-person variation, estimating habitual micronutrient intake instead of actual intake of a few days. Thanks to the use of a web-based approach for unannounced 24-hour recalls and questionnaires, we were able to include a large population of elite and sub-elite athletes.

All self-reporting methods are prone to misreporting and may not completely reflect true dietary intake. ${ }^{12,47}$ However, based on low $D_{t}$ we conclude that the effect of random errors for most nutrients was low. ${ }^{48}$ We know that our method underestimates protein intake with 25\%, ${ }^{13}$ and no clear differences were seen in that validation study between subgroups of athletes with respect to gender, BMI and use or non-use of nutritional supplements. ${ }^{13}$ In the present study, differences in calculated FIL values were found between subgroups. The average FIL level in non-users was lower than that in other groups. The FIL values of the non-users (both men and women) were on the lower end of the range of FIL values found in our validation study, ${ }^{13}$ indicating a possible higher underreporting. However, the non-users group was on average also younger, and reported the lowest exercise load in minutes per day. Thus the lower FIL could reflect, at least partly, a truly lower energy intake because of lower energy requirements .

It is hard to assess to which extent micronutrient intake was underreported in our study. If we assume that micronutrient intake was not biased by selective underreporting between groups, actual micronutrient intake was expected to be higher in all groups but also then intakes could be improved. On the other hand, when considering the use of dietary supplements, low intakes via the basal diet were mainly compensated. This 
shows the relevance of using micronutrient containing dietary supplements in meeting recommendations.

In conclusion, in this large athletic population, non-users as well as users of nutritional supplements reported an inadequate intake of some micronutrients, in particular vitamin D, iron, vitamin B1, B2 and vitamin A. The additional use of dietary supplements in general improved intake levels, but this did not always completely compensate for intakes below the average requirement. Only a small proportion of athletes was at risk for chronic consumption of high doses of single micronutrients above UL, with vitamin B3 as the most pronounced example. Our study also shows that there is often still room for improvement of an athletes' diet. Additionally, athletes should consider the option of using a daily multivitamin supplement containing $50-100 \%$ of the RDA.

\section{Acknowledgements}

We would like to thank all athletes who were willing to participate in this survey as part of the Dutch Dietary and Supplement Study (DSSS). We would also like to thank all 57 students from various universities who helped with this study as part of their internship or their bachelor's or master's thesis. Finally we like to acknowledge the help of professor Dr. Hendriek Boshuizen in applying statistical models to estimate inadequate intake. 


\section{References}

1 de Sousa EF, Da Costa TH, Nogueira JA, Vivaldi L. Assessment of nutrient and water intake among adolescents from sports federations in the Federal District, Brazil. Br J Nutr. 2008; 99: 1275-83.

2 Julian-Almarcegui C, Gomez-Cabello A, Gonzalez-Aguero A, et al. The nutritional status in adolescent Spanish cyclists. Nutr Hosp. 2013; 28: 1184-9.

3 Molina-Lopez J, Molina JM, Chirosa LJ, et al. Implementation of a nutrition education program in a handball team; consequences on nutritional status. Nutr Hosp. 2013; 28: 1065-76.

4 Wierniuk A, Wlodarek D. Estimation of energy and nutritional intake of young men practicing aerobic sports. Rocz Panstw Zakl Hig. 2013; 64: 143-8.

5 Heaney S, O'Connor H, Gifford J, Naughton G. Comparison of strategies for assessing nutritional adequacy in elite female athletes' dietary intake. Int J Sport Nutr Exerc Metab. 2010; 20: 245-56.

6 Hinton PS, Sanford TC, Davidson MM, Yakushko OF, Beck NC. Nutrient intakes and dietary behaviors of male and female collegiate athletes. Int J Sport Nutr Exerc Metab. 2004; 14: 389-405.

7 van Erp-Baart AM, Saris WM, Binkhorst RA, Vos JA, Elvers JW. Nationwide survey on nutritional habits in elite athletes. Part II. Mineral and vitamin intake. Int J Sports Med. 1989; 10 Suppl 1: S11-6.

8 Rossum CTM, van Fransen HP, Verkaik-Kloosterman J, Buurma-Rethans EJM, Ocké MC. Dutch National Food Consumption Survey 2007-2010: Diet of children and adults aged 7 to 69 years. RIVM, 2011.

9 Wardenaar FC, Ceelen IJM, Van den Dool R, Witkamp R, Mensink M. Het gebruik van voedingssupplementen en sportvoeding door meer en minder actieve Nederlanders - Een inventarisatie op basis van het Nationaal Sport Onderzoek 2012 onder de Nederlandse bevolking (Use of dietary supplements and sport nutrition products in the Dutch general population). Nederlands Tijdschrift voor Voeding en Dietetiek (in Dutch). 2014; 69: S1-S9.

10 Recommended Dietary Allowances. National Research Council: Washington, DC, USA. 1989; tenth edition.

11 Nordic Council of Ministers. Nordic Nutrition Recommendations 2012: Integrating nutrition and physical activity. 2012.

12 Baker LB, Heaton LE, Stein KW, Nuccio RP, Jeukendrup AE. Validity and relative validity of a novel digital approach for 24-h dietary recall in athletes. Nutr J. 2014; 13: 41.

13 Wardenaar FC, Steennis J, Ceelen IJ, Mensink M, Witkamp R, de Vries JH. Validation of web-based, multiple 24-h recalls combined with nutritional supplement intake questionnaires against nitrogen excretions to determine protein intake in Dutch elite athletes. Br J Nutr. 2015: 1-10.

14 Manore MM. Effect of physical activity on thiamine, riboflavin, and vitamin B-6 requirements. Am J Clin Nutr. 2000; 72: 598S-606S.

15 Potgieter S. Sport nutrition: A review of the latest guidelines for exercise and sport nutrition from the American College of Sport Nutrition, the International Olympic Committee and the International Society for Sports Nutrition. S Afr J Clin Nutr. 2013; 26: 6-16.

16 Thomas DT, Erdman KA, Burke LM. Position of the Academy of Nutrition and Dietetics, Dietitians of Canada, and the American College of Sports Medicine: Nutrition and Athletic Performance. J Acad Nutr Diet. 2016; 116: 501-28.

17 Short SH, Short WR. Four-year study of university athletes' dietary intake. J Am Diet Assoc. 1983; 82: 632-45.

18 Wardenaar FC, Dijkhuizen R, Ceelen IJ, et al. Nutrient Intake by Ultramarathon Runners: Can They Meet Recommendations? Int J Sport Nutr Exerc Metab. 2015.

19 Herbold NH, Visconti BK, Frates S, Bandini L. Traditional and nontraditional supplement use by collegiate female varsity athletes. Int J Sport Nutr Exerc Metab. 2004; 14: 586-93.

20 Wardenaar FC, Ceelen IJ, Van Dijk JW, et al. Nutritional Supplement Use by Dutch Elite and Sub-Elite Athletes: Does Receiving Dietary Counselling Make a Difference? Int J Sport Nutr Exerc Metab. 2016: 1-25.

21 Carlsohn A, Cassel M, Linne K, Mayer F. How much is too much? A case report of nutritional supplement use of a high-performance athlete. Br J Nutr. 2011; 105: 1724-8.

22 Cobley JN, McHardy H, Morton JP, Nikolaidis MG, Close GL. Influence of vitamin C and vitamin E on redox signaling: Implications for exercise adaptations. Free Radic Biol Med. 2015; 84: 65-76. 
23 Conway JM, Ingwersen LA, Moshfegh AJ. Accuracy of dietary recall using the USDA five-step multiplepass method in men: an observational validation study. J Am Diet Assoc. 2004; 104: 595-603.

24 Conway JM, Ingwersen LA, Vinyard BT, Moshfegh AJ. Effectiveness of the US Department of Agriculture 5-step multiple-pass method in assessing food intake in obese and nonobese women. Am J Clin Nutr. 2003; 77: 1171-8.

25 Donders-Engelen MR, Van der Heijden, L.J.M \& Hulshof, K.F.A.M. Maten, gewichten en codenummers (Food portion sizes and coding instructions). Wageningen: Department Human Nutrition, Wageningen Agricultural University (in Dutch), 1997.

26 Johansson G, Wikman A, Ahren AM, Hallmans G, Johansson I. Underreporting of energy intake in repeated 24-hour recalls related to gender, age, weight status, day of interview, educational level, reported food intake, smoking habits and area of living. Public Health Nutr. 2001; 4: 919-27.

27 Nusser SM CA, Dodd KW, Fuller WA, Jensen HH. A User's Guide to C-SIDE (Software for Intake Distribution Estimation). Version 1.0. Dietary Assessment Research Series Report 8. 1996.

28 Murphy SP, Barr SI. Practice paper of the American Dietetic Association: using the Dietary Reference Intakes. J Am Diet Assoc. 2011; 111: 762-70.

29 Knapik JJ, Steelman RA, Hoedebecke SS, Austin KG, Farina EK, Lieberman HR. Prevalence of Dietary Supplement Use by Athletes: Systematic Review and Meta-Analysis. Sports Med. 2015.

30 Murphy SP, White KK, Park SY, Sharma S. Multivitamin-multimineral supplements' effect on total nutrient intake. Am J Clin Nutr. 2007; 85: 280S-84S.

31 Cupisti A, D'Alessandro C, Castrogiovanni S, Barale A, Morelli E. Nutrition knowledge and dietary composition in Italian adolescent female athletes and non-athletes. Int J Sport Nutr Exerc Metab. 2002; 12: 207-19.

32 Farrokhyar F, Tabasinejad R, Dao D, et al. Prevalence of vitamin D inadequacy in athletes: a systematicreview and meta-analysis. Sports Med. 2015; 45: 365-78.

33 Backx E, van der Avoort C, Tieland M, et al. Seasonal Variation in Vitamin D Status in Elite Athletes: A Longitudinal Study. Int J Sport Nutr Exerc Metab. 2016: 1-15.

34 Hallberg L, Rossander-Hulten L. Iron requirements in menstruating women. Am J Clin Nutr. 1991; 54: 1047-58.

35 Matzkin E, Curry EJ, Whitlock K. Female Athlete Triad: Past, Present, and Future. J Am Acad Orthop Surg. 2015; 23: 424-32.

36 Sureira TM, Amancio OS, Pellegrini Braga JA. Influence of artistic gymnastics on iron nutritional status and exercise-induced hemolysis in female athletes. Int J Sport Nutr Exerc Metab. 2012; 22: 243-50.

37 Suboticanec K, Stavljenic A, Schalch W, Buzina R. Effects of pyridoxine and riboflavin supplementation on physical fitness in young adolescents. Int J Vitam Nutr Res. 1990; 60: 81-8.

38 Paulsen G, Cumming KT, Holden G, et al. Vitamin C and E supplementation hampers cellular adaptation to endurance training in humans: a double-blind, randomised, controlled trial. J Physiol. 2014; 592: 1887-901.

39 Paulsen G, Hamarsland H, Cumming KT, et al. Vitamin C and E supplementation alters protein signalling after a strength training session, but not muscle growth during 10 weeks of training. J Physiol. 2014; 592: 5391-408

40 Ristow M, Zarse K, Oberbach A, et al. Antioxidants prevent health-promoting effects of physical exercise in humans. Proc Natl Acad Sci U S A. 2009; 106: 8665-70.

41 Lamprecht M. Antioxidants in sport nutrition. Boca Raton: CRC Press Taylor \& Francis Group.

42 Katan MB. How much vitamin B6 is toxic. Ned Tijdschr Geneeskd. 2005; 149: 2545-6.

43 Rohde CM, Manatt M, Clagett-Dame M, DeLuca HF. Vitamin A antagonizes the action of vitamin D in rats. J Nutr. 1999; 129: 2246-50.

44 Buurma-Rethans E, Fransen H, Ghameshlou Z, de Jong N. Een databestand voor supplementen: behoeftes en acties (Data file for dietary supplements: needs and actions). Voeding Nu (in Dutch). 2008; 10(1).

45 Morrison D, Hughes J, Della Gatta PA, et al. Vitamin C and E supplementation prevents some of the cellular adaptations to endurance-training in humans. Free Radic Biol Med. 2015; 89: 852-62.

46 Brussaard JH, Lowik MR, Steingrimsdottir L, et al. A European food consumption survey method-conclusions and recommendations. Eur J Clin Nutr. 2002; 56 Suppl 2: S89-94. 
47 Thompson FE, Dixit-Joshi S, Potischman N, et al. Comparison of Interviewer-Administered and Automated Self-Administered 24-Hour Dietary Recalls in 3 Diverse Integrated Health Systems. Am J Epidemiol. 2015; 181: 970-8.

48 Willett W. Nutritional Epidemiology. 3rd edn. New York, NY: Oxford University Press USA, 2012. 


\section{Chapter 4}




\section{Nutrient intake by ultramarathon runners: can they meet recommendations?}

Floris C. Wardenaar, Rianne Dijkhuizen, Ingrid J.M. Ceelen, Emma Jonk, Marco Mensink, Renger F. Witkamp, Jeanne H.M. de Vries.

International Journal of Sport Nutrition and Exercise Metabolism. 2015;25:375-86. 


\section{Abstract}

Aim: The objective of this study was to investigate whether ultramarathon runners were able to meet nutrition recommendations during a training period and on a competition day.

Methods: In preparation for a 60 or $120 \mathrm{~km}$ ultramarathon covering a varied terrain, male and female ultramarathon runners ( $n=68$, age $46.5 \pm 7.1$ y) reported habitual dietary intake during three independent days using a web-based 24-hour recall and questionnaires. The diet was assessed using probability of inadequacy or by qualitative evaluation using reference dietary intakes or sports nutrition recommendations. A small group of $120 \mathrm{~km}$ runners ( $n=4)$ was observed continuously during the race. After the race, $60 \mathrm{~km}$ runners $(n=41)$ received a questionnaire to assess dietary intake and gastrointestinal (GI) distress on the race day. Spearman rank correlation coefficients ( $r$ ) were applied to investigate the association between intake and general GI distress symptoms.

Results: In men and women, habitual mean carbohydrate ( $\mathrm{CHO}$ ) intake was lower than recommended, as was mean protein intake by women. $\mathrm{CHO}$ intake during the race was $<60 \mathrm{~g} / \mathrm{h}$ in $75 \%$ of the athletes. A large variation of nutrient and fluid intake was seen. GI distress during the race was reported in $82 \%$ of the runners; severe GI distress was low. In general, moderate, mostly negative, correlations with nutrient intake were seen for GI distress.

Conclusions: Sports nutrition recommendations for the habitual diet were not achieved. During a competition day, a large variation was found in nutrient intake; this may be related to a high incidence of $\mathrm{Gl}$ distress. 


\section{Introduction}

For athletes competing in ultra-endurance activities, adequate intake (Al) of energy and nutrients during training and competition is of particular relevance to ensure optimal performance and recovery and to minimize health risks. At the same time, this population can have difficulties to meet nutrition recommendations during exercise because of a variety of reasons, in particular gastrointestinal (GI) distress. ${ }^{1,2}$

For endurance athletes, recommended amounts for the habitual diet can be substantial: up to 5-12 g of carbohydrate $(\mathrm{CHO}) / \mathrm{kg} \cdot \mathrm{bw}$ (body weight) per day, depending on training load, ${ }^{3}$ and $1.2-1.7 \mathrm{~g}$ of protein $/ \mathrm{kg} \cdot \mathrm{bw}$ per day. ${ }^{4}$ Some recent studies mention athletes meeting these recommendations. For example, Ono et al. (2012) describe soccer players with a mean $\mathrm{CHO}$ intake $>7 \mathrm{~g} / \mathrm{kg} \cdot \mathrm{bw},{ }^{5}$ and Carlsohn et al. (2012) describe a mean intake of between 7.8 and $9.0 \mathrm{~g} / \mathrm{kg} \cdot \mathrm{bw}$ by triathlon athletes. ${ }^{6}$

In addition, specific recommendations are formulated for nutritional intake during and after training or competition. ${ }^{7}$ Although there is some evidence supporting protein intake during exercise, ${ }^{8}$ most of the consensus has been built on sufficient protein intake before or after exercise, aiming to maintain nitrogen balance by an intake of $0.15-$ $0.25 \mathrm{~g}$ of protein (PRO) $/ \mathrm{kg} \cdot \mathrm{bw} .{ }^{9}$ The recommended intake of carbohydrates during exercise in intensive endurance sports lasting longer than $4 \mathrm{~h}$ currently ranges from 60 to 90 $\mathrm{g} / \mathrm{h}^{3}$ However, a great deal of variation is seen in intake. For example, Pfeiffer et al. (2012) reported an intake of $35 \pm 26 \mathrm{~g} / \mathrm{h}$ during a marathon, ${ }^{10}$ whereas Pfeiffer et al. (2009) describe runners during a $16 \mathrm{~km}$ run consuming $1.4 \mathrm{~g} / \mathrm{min}$ of $\mathrm{CHO}$, corresponding to a $\mathrm{CHO}$ intake of $84 \mathrm{~g} / \mathrm{h}^{11}$

$\mathrm{Gl}$ distress during competition is frequently experienced by runners and other endurance athletes. ${ }^{10,12}$ Such complaints have several causes, including the nutrient or fluid intake. ${ }^{2} \mathrm{Gl}$ distress, on the other hand, hampers the intake of adequate amounts of food during exercise.

To evaluate whether ultra-endurance athletes are able to reach those recommendations, dietary intake was assessed in ultramarathon runners during their preparation phase as well as before and during a 60 or $120 \mathrm{~km}$ race. The first objective of this study was to investigate whether ultramarathon runners were able to meet sport-specific dietary recommendations during a training period and on a competition day. A second objective was to assess the prevalence of Gl complaints during the race and dietary factors associated with this. 


\section{Methods}

\section{Study design}

The study design consisted of three parts as shown in Figure 1. The first part was a survey of dietary intake 2 months before the race. The second part was a questionnaire about dietary intake on a race day and GI distress during the $60 \mathrm{~km}$. The third part was a continuous observational study during the $120 \mathrm{~km}$. The study was performed in accordance with the Declaration of Helsinki and the survey was approved by the Medical Ethics Committee of Wageningen University. Informed consent in writing was obtained from all participants.

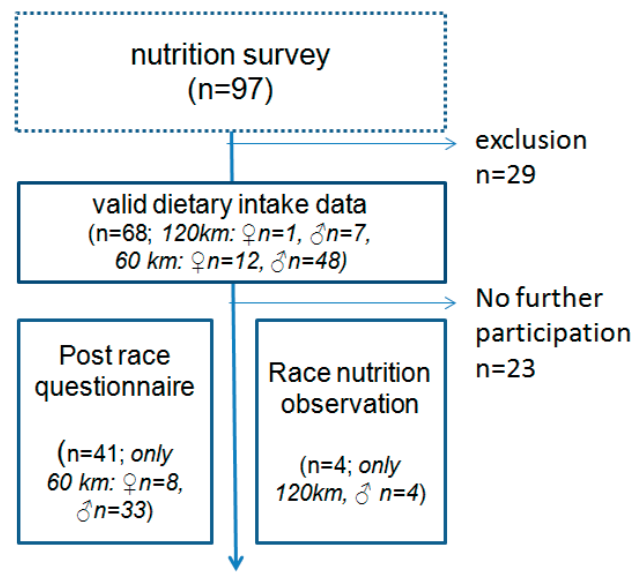

Figure 1. Study participant flow: after start of the survey 68 subjects with 2-3 complete datasets were included. For the follow up with a questionnaire only runners of the $60 \mathrm{~km}$ were included. For the continuous observation only runners of the $120 \mathrm{~km}$ were included.

\section{Study population and race information}

Runners, both male and female, were recruited through a promotional email by the organization of the Texel ultramarathon. Inclusion criteria were: preparation for the Zestig van Texel ("Sixty of Texel") race, age 16-70 years and ability to speak and understand the Dutch language.

The race took place on April 1, 2013, on the island of Texel, the Netherlands. The distance was 60 or $120 \mathrm{~km}$ on a varied track (woods, sand hills, beach, single trails and mainly flat small roads). A total of 530 athletes registered for the race (of which 31 registered for $120 \mathrm{~km}$ ). The average temperature on the day of the race was $2.2^{\circ} \mathrm{C}$, humidity was $77 \%$ and average wind speed was $6.1 \mathrm{~m} / \mathrm{s}(22.0 \mathrm{~km} / \mathrm{h})$. 


\section{Questionnaires on dietary intake and training load}

Three web-based programs were used to obtain data. Recalls of 24 hours were collected with "Compl-eat ${ }^{T M}$ " (Wageningen University), which is based on the five-step multiple-pass method, a validated technique to increase accuracy of dietary recalls. ${ }^{13}$ This program also allows participants to select, adapt or describe complete recipes by using household measures, standard portion sizes, weight in grams or volume in liters. ${ }^{14}$ The daily questionnaires regarding training load and the use of dietary supplements and sports nutrition products were collected with the "vitality portal" (HAN University of Applied Sciences). The daily questionnaire consisted of five groups of questions regarding type of day (training, race or resting), type of training (game, endurance, strength, technical, core-stability, sprint or other), total amount of exercise, perceived workload on a four-point scale (light, moderate, heavy, very heavy) and dietary supplements and/or sports nutrition products used based on a pre-specified list of more than 3400 product names. If the product was not available in the list, subjects were able to fill in this themselves.

The post-race questionnaire was obtained using "Qualtrics" (The Qualtrics Research Suite, 2013. Provo, UT). To calculate energy and nutrient intakes and assign foods to food groups, the Dutch food composition database of 2010 was used. ${ }^{15}$ For supplements and sports nutrition products the Dutch database for dietary Supplements (NES) was used for conversion of products into energy and nutrients. ${ }^{16}$

\section{Dietary assessment of habitual diet}

From February 4 to March 4, 2013, athletes were asked to complete three unannounced non-consecutive 24-h dietary recalls in combination with a daily questionnaire over a period of 3 weeks on three separate days, selected by the researchers. Each athlete registered one Monday, Wednesday or Friday, one Tuesday or Thursday, and one weekend day. Days collected were spread evenly over the whole testing period with at least four days in between each single measurement. All questionnaires were open for $36 \mathrm{~h}$ and were locked automatically afterwards. If the 24-h recall and daily questionnaire were not completed, they were rescheduled in the last week of the fourweek period. All 24-h recalls and questionnaires were checked by a dietician especially trained for this task using standardized procedures including a standardized weight and portion book. ${ }^{14}$ If information was lacking, the composition of dietary supplements and sports nutrition products was retrieved from Internet or through local shops. The reported combined intake consisted of at least two complete datasets each with a 24-h recall and one questionnaire per subject, and these were converted into the amount of total energy (MJ/kcal), carbohydrates (total $\mathrm{g}$ and $\mathrm{g} / \mathrm{kg}$ ), protein (total $\mathrm{g}$ and $\mathrm{g} / \mathrm{kg}$ ), fat (total g and en\%), alcohol (g), fluid (g), dietary fiber (g), vitamins including RAEs (retinol 
activity equivalents), B1, B2 and B6, C, D and minerals including calcium, iron, magnesi-

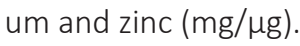

\section{Nutritional intake and GI distress before and during the $60 \mathrm{~km}$ race}

The day after the race, the $60 \mathrm{~km}$ runners received an email with a link to a post-race questionnaire asking about their food intake before and during the race and GI distress during the race. The questionnaire was a Dutch translation of the Gatorade Sport Science Institute (GSSI) questionnaire used during the 2012 Chicago Marathon. ${ }^{17}$

Breakfast, pre-race nutrition and nutritional intake during the race was calculated as total energy (MJ/kcal), protein (g), fat (g), $\mathrm{CHO}(\mathrm{g}, \mathrm{g} / \mathrm{kg}$ and $\mathrm{g} / \mathrm{h})$, fiber $(\mathrm{g})$ and fluid (ml, $\mathrm{ml} / \mathrm{h}$ and $\mathrm{ml} / \mathrm{kg}$ ) based on general sports nutrition guidelines., ${ }^{38-21} \mathrm{Gl}$ distress was measured on a nine-point scale ("no problem at all" to "the worst it has ever been") and mentioned with a score $>0$. If a complaint had a score above 5 , it was considered as serious. For vomiting and intestinal bleeding, each value above 0 was considered a serious complaint.

\section{Observation during $120 \mathrm{~km}$ race}

In a subgroup of four $120 \mathrm{~km}$ runners, nutritional intake was actively monitored during the race. Each food was uniquely labeled and listed, and pictures were taken of ingredient declarations.

Height (Cescorf stadiometer, Porto Alegre, Brazil) and body weight (Seca scale S760 mechanical) were measured the day before at the end of the afternoon and directly after the race. Each runner was accompanied by a cyclist who used a voice recorder to report the use of all products. All collected beverages or food items were checked afterwards with measuring cups and kitchen scales for remaining content $(\mathrm{ml}$ or $\mathrm{g}$ ) to calculate total consumed content as energy (total kJ/kcal and energy/hour), $\mathrm{CHO}(\mathrm{g} / \mathrm{h}$ ) and fluid ( $\mathrm{ml} / \mathrm{h})$.

\section{Statistical analysis}

All calculations were performed in Excel (2007) and SPSS (IBM SPSS Statistics, version 20). Energy and selected nutrients were checked for normal distribution based on histograms and normal curve, skewness and kurtosis. Dietary intake was expressed as mean \pm standard deviation (SD) or median with $25 \mathrm{th}^{\text {th }}-75$ th percentile. If an estimated average requirement (EAR; based on Health Council of the Netherlands ${ }^{22-25}$ or Nordic Nutrition Recommendations ${ }^{26}$ ) was available, ${ }^{27}$ group mean or log transformed mean was used to evaluate the diet based on probability of inadequacy. ${ }^{28}$ To this end, the (SD-corrected) area under normal curve (probability of inadequacy) was calculated. ${ }^{27}$ In all other cases, reference dietary intakes, Als and available sports nutrition recommen- 
dations, based on international literature or Nordic Nutrition Recommendations, were used for qualitative comparison with the group median to evaluate dietary intake.

Nutritional intake based on questionnaires during the $60 \mathrm{~km}$ race was reported as group mean \pm SD and min-max for males, females and the total group. Frequency tables were used for qualitative assessment based on sports nutrition recommendations using percentages below, equal to and above recommendations. To evaluate data on single GI symptoms, Spearman rank correlation coefficient was used, because scores on Gl symptoms were recorded mainly on the low end of the scale (score 0-9) and not normally distributed, using a P-value of $<0.05$ for significance. Data of the observational study in $120 \mathrm{~km}$ were presented per individual and as mean intake \pm SD.

\section{Results}

Complete food consumption data (records of at least 2 days) were available from 68 subjects. Nutritional intake and GI distress before and during the race was based on 41 subjects. Initially, seven subjects were followed during their $120 \mathrm{~km}$ race; however, because of drop-out $(n=2)$ and incomplete recording during the race $(n=1)$, data relating to only four male subjects were considered in this paper. Group characteristics per study part are shown in Table 1.

Table 1. Group characteristics

\begin{tabular}{|c|c|c|c|c|c|}
\hline & & \multicolumn{2}{|c|}{ Survey $(n=68)$} & \multirow{2}{*}{$\begin{array}{l}\text { Questionnaire }(\mathrm{n}=41) \\
60 \mathrm{~km}\end{array}$} & \multirow{2}{*}{$\begin{array}{c}\text { Observation }(\mathrm{n}=4) \\
120 \mathrm{~km}\end{array}$} \\
\hline & & $60 \mathrm{~km}$ & $120 \mathrm{~km}$ & & \\
\hline \multirow[t]{2}{*}{ Gender (n) } & Male & 48 & 7 & 33 & 4 \\
\hline & Female & 12 & 1 & 8 & 0 \\
\hline Age (year) & & $46.5 \pm 7.2$ & $46.6 \pm 6.3$ & $47.3 \pm 6.8$ & $46.5 \pm 6.8$ \\
\hline Weight(kg) & & $71.7 \pm 10.8$ & $73.0 \pm 7.0$ & $71.7 \pm 10.1$ & $71.8 \pm 9.6$ \\
\hline Height (cm) & & $178.4 \pm 9.5$ & $181.8 \pm 6.5$ & $171.5 \pm 27.8$ & $167.1 \pm 29.6$ \\
\hline Exercise (min/day) & & $83 \pm 52$ & $111 \pm 70$ & $48 \pm 48$ & $108 \pm 83$ \\
\hline
\end{tabular}

Food consumption survey during a training period

In total, 197 recall days were collected, of which 155 days for males and 42 for females. Total recall days consisted of $64 \%$ training days, $30 \%$ resting days and $6 \%$ competition days.

In total, 235 dietary supplements and sports nutrition products were registered in 20 different categories. Roughly one-third of the subjects did not use any of these products. Dietary intake for males and females is shown in Table 2. For both males and females, inadequate intake was highest for retinol activity equivalents and vitamin D; however, inadequate intakes were seen also for vitamin B1 and B6 (males and females) 
and for calcium, iron and zinc (females). For males, a low risk for prevalence of low intakes was shown based on the sports nutrition recommendation for PRO (1.2-1.8 $\mathrm{g} / \mathrm{kg} \cdot \mathrm{bw})$, fluid, vitamin $\mathrm{C}$, calcium, iron and zinc. For females, the low risk for prevalence was shown based on recommended daily intake for PRO $(0.8 \mathrm{~g} / \mathrm{kg} \cdot \mathrm{bw})$, fat, fluid, vitamin B2 and magnesium. No statement could be made regarding $\mathrm{CHO}(5-7 \mathrm{~g} / \mathrm{kg} \cdot \mathrm{bw})$ and PRO (1.8 g/kg.bw for males and $1.2-1.8 \mathrm{~g} / \mathrm{kg} \cdot \mathrm{bw}$ for females) based on the suggested sports nutrition recommendations or regarding fiber based on Al because median levels were below recommendations and no EAR was available. Both males and females had difficulties meeting the lower sports nutrition recommendations taken from the literature for $\mathrm{CHO}(>5 \mathrm{~g} / \mathrm{kg} \cdot \mathrm{bw})$ and partly also PRO $(>1.2 \mathrm{~g} / \mathrm{kg} \cdot \mathrm{bw})$. 
Nutrient intake by ultramarathon runners: can they meet recommendations?

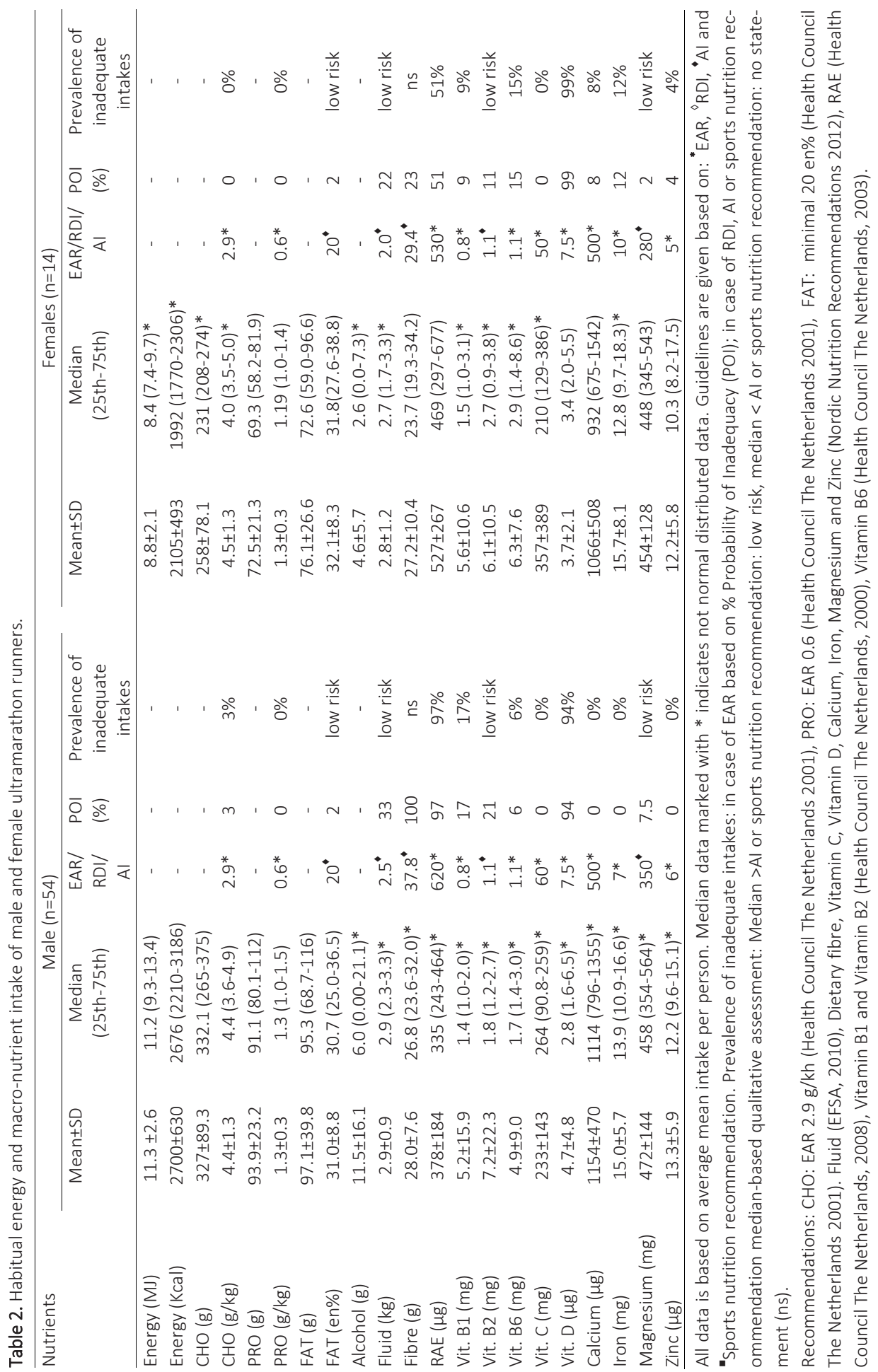


Table 3. Carbohydrate, protein and fluid intake per kg before and per hour during $60 \mathrm{~km}$ ultra-marathon based on a questionnaire.

\begin{tabular}{|c|c|c|c|c|c|c|c|c|c|c|}
\hline \multirow[t]{2}{*}{ Nutrient } & \multirow[t]{2}{*}{ Recommendation } & \multicolumn{3}{|c|}{ Total $(n=41)$} & \multicolumn{3}{|c|}{ Male $(n=33)$} & \multicolumn{3}{|c|}{ Female $(n=8)$} \\
\hline & & $\%$ equal & $\%<$ & $\%>$ & $\%$ equal & $\%<$ & $\%>$ & $\%$ equal & $\%<$ & $\%>$ \\
\hline \multicolumn{11}{|l|}{ Before race* } \\
\hline $\mathrm{CHO}(\mathrm{g} / \mathrm{kg})$ & $1-2$ & 41.5 & 12.2 & 46.3 & 36.4 & 12.1 & 51.5 & 62.5 & 12.5 & 25.0 \\
\hline PRO (g/kg) & $0.15-0.25$ & 24.4 & 7.3 & 68.3 & 21.2 & 6.1 & 72.7 & 25.0 & 12.5 & 62.5 \\
\hline Fluid (ml/kg) & $8-10$ & 14.6 & 29.3 & 56.1 & 15.1 & 27.3 & 57.6 & 12.5 & 37.5 & 50.0 \\
\hline \multicolumn{11}{|l|}{ During race } \\
\hline $\mathrm{CHO}(\mathrm{g} / \mathrm{h})$ & $60-90$ & 22.0 & 75.6 & 2.4 & 21.2 & 72.7 & 6.1 & 12.5 & 87.5 & 0 \\
\hline Fluid (ml/h) & $500-1000$ & 12.2 & 85.4 & 2.4 & 15.2 & 81.8 & 3.0 & 0 & 100 & 0 \\
\hline
\end{tabular}

Percentages of the group that corresponded equally to the recommendation and the percentages above or below this range was displayed.

*Eating moments before the race consist of total eating moments before the start of the race.

Recommendations before race: CHO: Kerksick et al. (2008), PRO: Tarnapolsky et al. (2005) and Fluid: combined guidelines proposed by Sawka et al. (2007).

Both recommendations of Sawka et al (2007) based on 3-4 hour 5-7ml/kg.bw before exercise and 2 hours before 3-5 ml/kg.bw were combined into one range of 8-10 $\mathrm{ml}$ before competition.

Recommendations during race: CHO Burke et al. (2011): and Fluid: Kreider et al. (2010).

\section{Nutritional intake and GI distress before and during the $60 \mathrm{~km}$ race}

Breakfast was consumed on average 3-4 $\mathrm{h}$ before the start of the race. Average total energy intake of the breakfast was $2.8 \pm 1.2 \mathrm{MJ}$. This consisted of PRO (21 $\pm 13 \mathrm{~g})$, fat $(17 \pm 19 \mathrm{~g}), \mathrm{CHO}(102 \pm 49 \mathrm{~g})$, dietary fiber $(7 \pm 4 \mathrm{~g})$ and fluid $(0.63 \pm 0.3 \mathrm{~L})$. In between breakfast and the start of the race, 27 runners (65.9\%) ate a snack or a small meal containing $0.9 \pm 1.0 \mathrm{MJ}$ of energy, generally consisting of PRO ( $4 \pm 5 \mathrm{~g})$ fat $(2 \pm 3 \mathrm{~g}), \mathrm{CHO}$ $(45 \pm 52 \mathrm{~g})$, fiber $(2 \pm 3 \mathrm{~g})$ and fluid $(0.23 \pm 0.39 \mathrm{~L})$. Most energy during the race was provided by carbohydrates, on average $274 \pm 133 \mathrm{~g}$, contributing to the total energy intake of 4.9 $\pm 2.3 \mathrm{MJ}$. Mean fluid intake during the race was $2.0 \pm 1.5 \mathrm{~L}$.

In Table 3, the percentage of runners who did or did not meet recommendations is specified. Of the runners, $87.8 \%$ managed to take in $>1.0 \mathrm{~g} / \mathrm{kg} \cdot \mathrm{bw}$ of $\mathrm{CHO}$ and $>0.15$ $\mathrm{g} / \mathrm{kg} \cdot \mathrm{bw}$ of PRO before the race. Furthermore, $70.6 \%$ consumed more than 8.0 $\mathrm{ml} / \mathrm{kg} \cdot \mathrm{bw}$ of fluid. During the race, $24.4 \%$ of the group achieved the recommendation to take $\geq 60$ g of $\mathrm{CHO}$ per hour and $14.6 \%$ consumed $>500 \mathrm{ml} / \mathrm{h}$ of fluid.

The percentages of self-reported complaints are shown in Table 4 . In total, $82.9 \%$ of the athletes (27 men and seven women) reported some Gl symptoms during the race. Severe GI symptoms were reported by $7.3 \%$ (two men, one woman). Men (81.8\%) and women $(87.5 \%)$ reported relatively equal amounts of discomfort. The most common complaints were an urge to urinate $(56.1 \%)$, belching $(46.3 \%)$ and flatulence $(36.6 \%)$. 
Table 4. Percentage of self reported complaints during $60 \mathrm{~km}$ based on a questionnaire $(n=43)$.

\begin{tabular}{|c|c|c|c|c|}
\hline$\%$ & & no complaints & complaints & $\begin{array}{c}\text { severe } \\
\text { complaints }\end{array}$ \\
\hline \multirow{7}{*}{$\begin{array}{l}\text { High respiratory and stomach } \\
\text { complaints }\end{array}$} & Reflux & 79.1 & 16.3 & 4.6 \\
\hline & Heartburn & 90.7 & 9.3 & 0 \\
\hline & Belching & 53.5 & 41.9 & 4.6 \\
\hline & Bloating & 81.4 & 16.3 & 2.3 \\
\hline & Stomach cramps & 81.4 & 14.0 & 4.6 \\
\hline & Vomiting & 95.4 & - & 4.6 \\
\hline & Nausea & 74.4 & 20.9 & 4.7 \\
\hline \multirow[t]{8}{*}{ Lower bowel complaints } & Intestinal cramp & 90.7 & 9.3 & 0 \\
\hline & Flatulence & 62.8 & 34.9 & 2.3 \\
\hline & Urge to defecate & 81.4 & 16.3 & 2.3 \\
\hline & Side ache & 88.4 & 11.6 & 0 \\
\hline & Abdominal pain & 88.4 & 9.3 & 2.3 \\
\hline & Loose of stool & 95.4 & 4.6 & 0 \\
\hline & Diarrhoea & 97.7 & 2.3 & 0 \\
\hline & Intestinal bleeding & 100 & - & 0 \\
\hline \multirow[t]{4}{*}{ Other } & Dizziness & 95.3 & 4.7 & 0 \\
\hline & Headache & 88.4 & 11.6 & 0 \\
\hline & Muscle cramps & 67.4 & 30.3 & 2.3 \\
\hline & Urge to urinate & 44.2 & 46.1 & 9.7 \\
\hline
\end{tabular}

All significant single-nutrient GI correlations are shown in Table 5, indicating a low to moderate relationship. All correlations are negative except for the two associations found for fiber, showing that a higher fiber intake is associated with a higher frequency of nausea and an urge to defecate.

Table 5. Significant correlations ( $r$ ) for nutrients and GI distress based on a questionnaire $(n=43)$.

\begin{tabular}{|c|c|c|c|c|c|}
\hline & & $\begin{array}{l}\text { Energy } \\
\text { intake }\end{array}$ & $\begin{array}{c}\text { Carbohydrate } \\
\text { intake }\end{array}$ & $\begin{array}{l}\text { Fiber } \\
\text { intake }\end{array}$ & $\begin{array}{l}\text { Fluid } \\
\text { intake }\end{array}$ \\
\hline \multirow{4}{*}{$\begin{array}{l}\text { High respiratory and } \\
\text { stomach complaints }\end{array}$} & Heartburn & $-0.31, p=0.04$ & $-0.33, p=0.03$ & & $-0.33, p=0.03$ \\
\hline & Belching & & & & $-0.34, p=0.03$ \\
\hline & Vomiting & $-0.40, p=0.01$ & $-0.41, p=0.01$ & & $-0.36, p=0.02$ \\
\hline & Nausea & & & $0.31, p=0.04$ & \\
\hline \multirow{6}{*}{$\begin{array}{l}\text { Lower bowel } \\
\text { complaints }\end{array}$} & Intestinal cramp & & & & $-0.36, p=0.02$ \\
\hline & Flatulence & & & & \\
\hline & Urge to defecate & & & $0.45, p=0.01$ & $-0.35, p=0.02$ \\
\hline & Side ache & & & & $-0.38, p=0.01$ \\
\hline & Loose of stool & $-0.35, p=0.02$ & $-0.34, p=0.03$ & & \\
\hline & Diarrhea & $-0.34, p=0.03$ & $-0.31, p=0.04$ & & $-0.35,0.02$ \\
\hline \multirow[t]{3}{*}{ Other } & Dizziness & $-0.34, p=0.03$ & $-0.31, p=0.05$ & & $-0.29, p=0.06$ \\
\hline & Headache & & & & $-0.39, p=0.01$ \\
\hline & Urge to urinate & $-0.40, p=0.01$ & $-0.31, p=0.05$ & & \\
\hline
\end{tabular}

Only significant $(p \leq 0.05)$ correlations are shown. No correlations for single nutrients and GI distress are shown for reflux, bloating, stomach cramps, flatulence, abdominal pain, intestinal bleeding and muscle cramps. 


\section{Observation during $120 \mathrm{~km}$ race}

Runners completed the race in 9:30:39 to 11:59:24 h. Total energy intake ranged from $1.45 \mathrm{MJ}$ to $5.51 \mathrm{MJ}$, with all runners using sport nutrition products during the race and two runners relying solely on sports nutrition products without basic food products. Lower energy intake was seen in the two fastest runners. All runners reported average $\mathrm{CHO}$ intakes $>30 \mathrm{~g} / \mathrm{h}$ and fluid intakes $>350 \mathrm{ml} / \mathrm{h}$. Body weight change after the race ranged between $-4 \%$ and $+1 \%$. The fastest runner lost the most weight and the slowest runner gained weight in comparison to the pre-race weight measured the day before in the afternoon. The energy and $\mathrm{CHO}$ and fluid intake of four runners during the $120 \mathrm{~km}$ observation are shown in Table 6.

Table 6. Mean intake and range of energy, carbohydrate and fluid per hour.

\begin{tabular}{lccccccccc}
\hline Runner Ranking & $\begin{array}{c}\text { Weight } \\
(\mathrm{kg})\end{array}$ & $\begin{array}{c}\text { Weight } \\
\text { difference } \\
(\%)\end{array}$ & $\begin{array}{c}\text { Race time } \\
\text { (hours) }\end{array}$ & $\begin{array}{c}\text { Velocity } \\
\text { (km/hour) }\end{array}$ & $\begin{array}{c}\text { Total energy } \\
\text { intake } \\
\text { MJ (Kcal) }\end{array}$ & $\begin{array}{c}\text { MJ/hour } \\
\text { (Kcal/hour) }\end{array}$ & CHO/hour (g) & Fluid/hour (ml) \\
\hline 1 & $1^{\text {st }}$ & 70.3 & $-4 \%$ & $9: 30: 39$ & 12.6 & $10.5(2496)$ & $1.1(263)$ & $61(8-114)$ & $530(130-827)$ \\
2 & $3^{\text {rd }}$ & 59.4 & $-3 \%$ & $10: 54: 26$ & 11.0 & $6.1(1457)$ & $0.6(134)$ & $31(11-57)$ & $392(178-669)$ \\
3 & $8^{\text {th }}$ & 81.1 & $0 \%$ & $11: 39: 55$ & 10.3 & $23.1(5514)$ & $1.8(428)$ & $108(39-135)$ & $609(259-805)$ \\
4 & $13^{\text {th }}$ & 81.0 & $+1 \%$ & $11: 59: 24$ & 10.0 & $15.3(3656)$ & $1.3(305)$ & $69(7-119)$ & $587(120-1230)$ \\
\hline
\end{tabular}

$\mathrm{CHO}$ and Fluid intake/hour are shown as mean intake and range per hour. Low values can be the result of incomplete hour registration due to finishing the race.

\section{Discussion}

So far, only a few studies specifically addressed dietary intake and supplement use by ultramarathon runners. ${ }^{29-32}$ The present study investigated the habitual diet including use of sport-specific products and dietary supplements during a training phase and nutrient intake before and during competition. Despite the low number of subjects, the observation of the $120 \mathrm{~km}$ run can serve as case report illustrating the practice of eating and drinking during an ultramarathon. Our general study population was relatively large compared to previous reports and consisted of 68 (training phase) and 45 (race) men and women. Their average age (around 46 y) and daily training activity (generally between 1 and $2 \mathrm{~h}$ of training per day) was in line with those reported in the literature for recreational ultra-runners. ${ }^{29-31,33}$ Quite remarkably, data on nutritional intake of women participating in ultra-endurance running appear to be limited to one case study. ${ }^{32}$

\section{Dietary intake}

We found that $\mathrm{CHO}$ intake during training periods was generally lower than the recommended $5 \mathrm{~g} / \mathrm{kg}$.bw for endurance athletes with moderate training load in both men and 
women. ${ }^{3,7}$ Although not shown, the subjects reported an average training intensity on total group level of 2.5 based on a four-point scale, indicating that they experience their total training load as being between moderate and heavy. The largest proportion of days covered consisted of endurance training days (42\%) or resting days (24\%), and $14 \%$ of days involved non-running-specific exercise. Hence, in our opinion, recommendations for moderate endurance exercise would be the most applicable for this group, corresponding to a range from 5 to $10 \mathrm{~g} / \mathrm{d}$.

For women only, PRO intake did not meet the recommendations. Daily CHO intake $\mathrm{g} / \mathrm{kg} \cdot \mathrm{bw})$ was lower in women than in men, which can be explained at least partly by their lower basal metabolic rate, and perhaps a slightly shorter average training duration per day compared to men (males: $118 \pm 78 \mathrm{~min} /$ day; females: $101 \pm 82 \mathrm{~min} /$ day).

Twenty-four hour recalls and questionnaires are known to underestimate dietary intake, ${ }^{34}$ and therefore actual dietary intake presented in Table 2 might be higher. The estimate mean intake is consequently not biased, but the precision is influenced and the distribution of measured intake is artificially widened because of random betweenperson errors and systematic and random within person errors. ${ }^{28}$ The precision of the mean estimate $\left(D_{t}\right)$ of a group can be improved by increasing the number of subjects or the number of days, ${ }^{35}$ A low percentage indicates a greater likelihood that the combination of the number of respondents and the number of replicate measurements leads to the required precision. A precision of $10-20 \%$ for single-nutrient intakes is considered to be reliable. ${ }^{36} D_{t}$ was calculated for all available nutrients. Not all estimated nutrients met the needed power based on our calculations. Except for alcohol, all nutrients shown in Table 2 met at least the proposed power of $20 \%$.

\section{Nutritional intake during the race}

Fluid intake during the race was generally low (based on questionnaires and observation). Although personal fluid needs are highly variable, ${ }^{7}$ we selected the range for fluid intake suggested by Kreider et al. (2010): 0.5-2.0 L/h of fluid. ${ }^{21}$ However, weather conditions made it almost impossible to match the selected fluid recommendations during competition and we did not manage to assess the pre- and post-race weight of all subjects to estimate fluid balance. Therefore, it is difficult to draw hard conclusions based on information found in the literature. Pre- and post-race body weight was measured in the small group of $120 \mathrm{~km}$ runners $(n=4)$. Because of practical reasons, pre-race body weight was measured the day before, at the end of the afternoon. Hence, the change in body weight observed can be influenced by all foods and fluid consumed over the time before the start of the race. On the other hand, the measurement time was close to the actual time of finishing, and therefore this possibly reflected the normal weight at this time.

The mean CHO intake $(67.2 \mathrm{~g} / \mathrm{h})$ of the $120 \mathrm{~km}$ runners was close to recommendations. ${ }^{3}$ This figure is much higher than described by Fallon et al. in 1989, who reported 
an intake of $21.2 \mathrm{~g} / \mathrm{h}$ during a $100 \mathrm{~km}$ race. They included seven subjects that were continuously observed. The large variation in intake may partly account for the difference in findings. However, in our opinion, the largest part of the relative low $\mathrm{CHO}$ intake measured by Fallon et al. resulted from differences in $\mathrm{CHO}$ recommendations between both periods (1989 vs. 2011). ${ }^{30}$

Our $60 \mathrm{~km}$ runners reported a $\mathrm{CHO}$ intake of $24.8 \mathrm{~g} / \mathrm{h}$, which was lower than previous findings using a questionnaire. ${ }^{29}$ Differences may be explained at least partly by differences in running speed, which also determines $\mathrm{CHO}$ demand. In the studies reported by Fallon et al. (1989) and Glace et al. (2002), average speed was lower than recorded in the present study; ${ }^{29,30}$ in our opinion, this makes it easier to consume higher amounts of $\mathrm{CHO}$ without resulting in a notable number of $\mathrm{Gl}$ complaints. It is also possible that the low fluid intake influenced $\mathrm{CHO}$ intake. This may be due to the fact that athletes had expected to receive $\mathrm{CHO}$ from fluids according to their planned intake schedule, which may not have been adapted to the cold circumstances.

Furthermore, the differences in our study between the $60 \mathrm{~km}$ and $120 \mathrm{~km}$ runners may have methodological causes. Questionnaires are more practical and cost effective. Individual monitoring, on the other hand, including recording of spilling and actual use, is far more accurate.

\section{Gastrointestinal distress}

GI discomfort may impact the ability to eat or drink. In our study, we used a questionnaire post-race to obtain data on $\mathrm{Gl}$ distress on the race day. All values $>0$ were included as Gl symptom. Most GI complaints were ranked "moderate." Therefore, it is questionable whether these GI complaints directly influenced performance. Severe GI symptoms were rare, maybe because of the distance and environmental conditions and, in this case, probably not having a notable impact on group results. Gl complaints are more common during races over longer distances. ${ }^{2}$

Most studies used questionnaires during the race at provision/check points ${ }^{29,32,37}$ or continuous observation. ${ }^{30}$ Linderman et al. (2003) used a 48-h recall at the end of the race day, possibly giving a better insight in dietary intake in comparison with a questionnaire taken the day after. ${ }^{38}$

Self-reported moderate GI complaints (82\%) are in the upper level compared to those from other studies. ${ }^{39}$ We categorized these complaints as moderate based on our nine-point scale. Other studies often assessed only the presence of complaints ${ }^{29}$ or mentioned only severe GI complaints. ${ }^{10}$ Therefore it is difficult to compare results. Glace et al. (2002) reported a lower incidence of GI distress (50\%) and no relation with nutrient intake during a $160 \mathrm{~km}$ race, but running speed in our study was higher $(10 \pm 1.0$ $\mathrm{km} / \mathrm{h}$ ) in comparison to that reported by Glace et al. (6.6 km/h), possibly contributing to the higher incidence of $\mathrm{Gl}$ distress. ${ }^{29}$ Although Glace et al. used a questionnaire, in the specific section of the questionnaire respondents only had to mention if symptoms 
were present. In our study, all symptoms were pre-structured. ${ }^{29}$ Therefore, it is possible that Glace found a lower incidence, because complaints were not recognized as such; on the other hand, our method did rely on memory and the method of Glace et al. did not. $^{29}$

The most common complaint found in this study was the urge to urinate, but this was not associated with fluid intake. All GI-nutrient correlations were moderate, around $0.30-0.40$, and all associations found were negative except for fiber. Therefore, higher nutrient intake, except fiber intake, was in general associated with lower frequency of $\mathrm{Gl}$ distress. Of course, the question remains if this is a result of higher nutrition intake or if those subjects experience fewer complaints and therefore can eat more.

In conclusion, men and women did not meet $\mathrm{CHO}$ recommendations during training, neither did women for PRO. CHO, PRO and fluid intake on a race day before the race was considered sufficient. $\mathrm{CHO}$ intake during the race was lower than recommended for $60 \mathrm{~km}$ runners. The small group of $120 \mathrm{~km}$ runners showed that intakes higher than the recommended range of $60-90 \mathrm{~g} / \mathrm{h}$ are possible. The present study adds to our knowledge on dietary intake by ultramarathon runners because of the relatively large number of participants included and the different methods used.

\section{Aknowledgments}

We would like to acknowledge all the runners who participated in this study and thank the organisation of the Zestig van Texel (the "Sixty of Texel" race). We would also like to thank all members of the research group involved in this study: Heleen van der Wilt, Nick ledema, Kristin Jonvik, Gert Vriend, Shiannah Danen, Sarai Pannekoek, Cindy van der Avoort, Naomi Derks, Sjoerd Privee and Ellen Schravendeel. 


\section{References}

1 Black KE, Skidmore PM, Brown RC. Energy intakes of ultraendurance cyclists during competition, an observational study. Int J Sport Nutr Exerc Metab. 2012; 22: 19-23.

2 Stuempfle KJ, Hoffman MD, Hew-Butler T. Association of gastrointestinal distress in ultramarathoners with race diet. Int J Sport Nutr Exerc Metab. 2013; 23: 103-9.

3 Burke LM, Hawley JA, Wong SH, Jeukendrup AE. Carbohydrates for training and competition. J Sports Sci. 2011; 29 Suppl 1: S17-27.

4 Burke L, \& Deakin, V. . Protein and amino acid needs for training and bulking up (chapter 5), In Clinical sports nutrition. Singapore: McGraw Hill, 2010.

5 Ono M, Kennedy, E., Reeves, S., \& Cronin, L. . Nutrition and culture in professional football. A mixed method approach. . Appetite. 2012; 58: 98-104.

6 Carlsohn A, Nippe S, Heydenreich J, Mayer F. Carbohydrate intake and food sources of junior triathletes during a moderate and an intensive training period. Int J Sport Nutr Exerc Metab. 2012; 22: 438-43.

7 Potgieter S. Sport nutrition: A review of the latest guidelines for exercise and sport nutrition from the American College of Sport Nutrition, the International Olympic Committee and the International Society for Sports Nutrition. S Afr J Clin Nutr. 2013; 26: 6-16.

8 Fink HH, Mikesky, A.E., Burgoon, L.A. . Endurance and ultra-endurance athletes (chapter 12). In Practical Applications in Sports Nutrition 3rd edition edn. Boston: MA: Jones and Bartlett Learning., 2012.

9 Phillips SM, Van Loon LJ. Dietary protein for athletes: from requirements to optimum adaptation. J Sports Sci. 2011; 29 Suppl 1: S29-38.

10 Pfeiffer B, Stellingwerff T, Hodgson AB, et al. Nutritional intake and gastrointestinal problems during competitive endurance events. Med Sci Sports Exerc. 2012; 44: 344-51.

11 Pfeiffer B, Cotterill A, Grathwohl D, Stellingwerff T, Jeukendrup AE. The effect of carbohydrate gels on gastrointestinal tolerance during a 16-km run. Int J Sport Nutr Exerc Metab. 2009; 19: 485-503.

12 Jeukendrup A, \& de Oliveira, E.P. . Nutritional recommendations to avoid gastrointestinal complaints during exercise. . Sports Science Exchange2013; 1-4.

13 Conway JM, Ingwersen LA, Vinyard BT, Moshfegh AJ. Effectiveness of the US Department of Agriculture 5-step multiple-pass method in assessing food intake in obese and nonobese women. Am J Clin Nutr. 2003; 77: 1171-8.

14 Donders-Engelen MR, Van der Heijden, L.J.M \& Hulshof, K.F.A.M. Maten, gewichten en codenummers (Food portion sizes and coding instructions). Wageningen: Department Human Nutrition, Wageningen Agricultural University (in Dutch), 1997.

15 RIVM. Nederlandse Voedingsmiddelentabel (Dutch Food Composition Table). In: RIVM, editor. NEVOtabel. Bilthoven2011.

16 Buurma-Rethans E. F, H., Ghameshlou, Z., de Jong, N. Een databestand voor supplementen: behoeftes en acties (Data file for dietary supplements: needs and actions). Voeding Nu (in Dutch). 2008; 10(1).

17 Pahnke M, Stofan, J., Del Campo. J., Nyman, L., Chiampas, G. \& Jeukendrup, A. . Factors associated with severe gastro-intestinal distress and marathon running. The 18th annual Congress of the European Collage of Sport Science. Barcelona - Spain.: ECSS, 2013.

18 American College of Sports M, Sawka MN, Burke LM, et al. American College of Sports Medicine position stand. Exercise and fluid replacement. Med Sci Sports Exerc. 2007; 39: 377-90.

19 Tarnopolsky MA, Gibala, M., Jeukendrup, A.E., \& Phillips, S.M. . Nutritional needs of elite endurance athletes. Part I: Carbohydrate and fluid requirements. European Journal of Sport Science. 2005; 5: 3-14.

20 Kerksick C, Harvey T, Stout J, et al. International Society of Sports Nutrition position stand: nutrient timing. J Int Soc Sports Nutr. 2008; 5: 17.

21 Kreider RB, Wilborn CD, Taylor L, et al. ISSN exercise \& sport nutrition review: research \& recommendations. J Int Soc Sports Nutr. 2010; 7: 7.

22 Council NR. Recommended Dietary Allowances. National Research Council: Washington, DC, USA. 1989; tenth edition. 
23 Health Council of the Netherlands. Dietary Reference Intakes: vitamin B6, folic acid, and vitamin B12. . The Hague: Health Council of the Netherlands, 2003.

24 Health Council of the Netherlands. Evaluation of the dietary reference values for vitamin D. In: Health Council of the Netherlands, editor. The Hague2012.

25 Health Council of the Netherlands. Dietary Reference Intakes: energy, proteins, fats and digestible carbohydrates. The Hague, the Netherlands: Health Council of the Netherlands, , 2001.

26 Nordic Council of Ministers. Nordic Nutrition Recommendations 2012: Integrating nutrition and physical activity. 2012.

27 Murphy SP. Using DRIs for dietary assessment. Asia Pac J Clin Nutr. 2008; 17 Suppl 1: 299-301.

28 Van Staveren WA. OM, de Vries, JHM Estimation of dietary intake (chapter 59). 10th edn. Oxford, UK: Wiley-Blackwell UK., 2012.

29 Glace B, Murphy C, McHugh M. Food and fluid intake and disturbances in gastrointestinal and mental function during an ultramarathon. Int J Sport Nutr Exerc Metab. 2002; 12: 414-27.

30 Fallon KEB, E. Thompson, M.W. Reull, P.A. . Nutritional and fluid intake in a 100-km ultramarathon. International Journal of Sport Nutrition. 1989; 8: 24-35.

31 Hoffman MD, Wegelin JA. The Western States 100-Mile Endurance Run: participation and performance trends. Med Sci Sports Exerc. 2009; 41: 2191-8.

32 Moran ST, Dziedzic CE, Cox GR. Feeding strategies of a female athlete during an ultraendurance running event. Int J Sport Nutr Exerc Metab. 2011; 21: 347-51.

33 Knechtle B, Knechtle P, Schulze I, Kohler G. Vitamins, minerals and race performance in ultra-endurance runners--Deutschlandlauf 2006. Asia Pac J Clin Nutr. 2008; 17: 194-8.

34 Freedman LS, Commins JM, Moler JE, et al. Pooled results from 5 validation studies of dietary self-report instruments using recovery biomarkers for energy and protein intake. Am J Epidemiol. 2014; 180: 172-88.

35 Beaton GH, Milner J, Corey $P$, et al. Sources of variance in 24-hour dietary recall data: implications for nutrition study design and interpretation. Am J Clin Nutr. 1979; 32: 2546-59.

36 Willett W. Nutritional Epidemiology. 3rd edn. New York, NY: Oxford University Press USA, 2012.

37 Colombani PC, Mannhart, C., Wenk, C., \& Frey, W.O. . Nutritional intake during a 244 km multisport ultra-endurance race. Pakistan Journal of Nutrition. 2002; 1: 124-26.

38 Linderman J, Demchak, T., Dallas, J., \& Buckworth, J. Ultra-endurance cycling, a field study of human performance during a 12-hour mountain bike race. JEP online. 2003; 6: 14-23.

39 Rehrer NJ, Brouns F, Beckers EJ, et al. Physiological changes and gastro-intestinal symptoms as a result of ultra-endurance running. Eur J Appl Physiol Occup Physiol. 1992; 64: 1-8. 


\section{Chapter

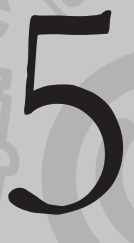

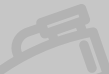




\section{Self-reported use and reasons among the general population for using sports nutrition products and dietary supplements}

Floris C. Wardenaar, Remko van den Dool, Ingrid J.M. Ceelen, Renger F. Witkamp, Marco Mensink

Sports 2016, 4(2), 33 


\section{Abstract}

Aim: Purpose of the present study was to determine the prevalence of dietary supplements (DS) and sport nutrition product (SNP) use among the general population, to identify differences for gender, age and exercise frequency, and to determine the main reasons for use.

Methods: The study was designed as a web-based questionnaire in a representative sample ( $n=1544)$ of the Dutch population.

Results: Sixty-two percent ( $\mathrm{n}=957$ ) of the respondents reported having used DS and(or) SNP in the last twelve months. Women and older people reported the highest DS use. The highest use of SNP was reported by regular exercising men and younger people with improving sporting performance as their main objective. Most frequently reported DS were multivitamins (28\%) and vitamin C (19\%) and, for SNP, energy drinks (22\%) and isotonic drinks (19\%). Health considerations were the most important motivation (DS 90\% and SNP 52\%), but also performance was substantially reported (DS 14\% and SNP $35 \%)$. A substantial group of sedentary respondents reported also the use of SNP.

Conclusions: This study confirms that DS and(or) SNP are widely used among the general population. Women and older people reported the highest DS use as regular exercising men and younger people with improving sporting performance as their main objective reported the highest use of SNP. Both health as performance are important reasons for use. It can be questioned whether the use of SNP fits all respondents' physical activity needs. 


\section{Introduction}

Nutritional supplements like dietary supplements (DS) and sports nutrition products (SNP) are commonly used by athletes to maximise their performance and to accelerate recovery, prevent nutrient deficiencies, and to maintain good general health. ${ }^{1-4}$ However, the impression exists that these arguments are also often used by physically less active people and that these products are actively promoted by suppliers aiming to reach a wider target group. ${ }^{5,6}$

The majority of literature investigating DS and SNP use does combine both as nutritional supplements or only focuses on dietary supplements, despite the fact that SNP do not only contain macronutrients but also micronutrients. Moreover, SNP are increasingly found on the shelves of supermarkets, making these types of products easily accessible for the general population. Thus, from a nutritional perspective it is necessary to include also SNP as part of dietary analysis.

Consumers of both DS and SNP may use these preparations with the intention of maintaining good health, ${ }^{5}$ often without being aware of the supporting or lacking scientific evidence. ${ }^{6}$ Further it can be questioned if they also use these type of products for performance reasons. Surveys on dietary supplement consumption by the general population generally focus on the use of multivitamins or other micro-nutrient products, but often make no distinction with sport-specific DS and SNP or not mention those at all. ${ }^{7}$ Until now, this has only been investigated in a small group of non-athletes included as controls to compare their use with the nutritional supplement use of elite athletes. ${ }^{1}$ ${ }^{6,8}$ However, two of these three studies did not provide a clear insight into the contribution of sport specific SNPS used in the non-athletes group ${ }^{1,8}$ therefore obtaining additional information in a large sample of a general population can be seen as valuable.

From an earlier pilot survey among general consumers in the Netherlands, we concluded that a typical user of sports supplements and sports nutrition products is a young ( $<35$ years) male, who regularly takes part in sports (>once/week), and is a member of a sports club. ${ }^{5}$ When subjects were asked about their reasons for using DS and SNP, we found a lower prevalence of sports-oriented use $(5.8 \%$ for DS and $21.6 \%$ for SNP) compared to other studies. 6,8

Therefore, as part of the Dutch National Sport Study (Nationaal Sport Onderzoek, NSO 2013), we investigated the self-reported use and the main reasons for use of DS and SNP. The objectives of this survey were (a) to determine the prevalence in the Dutch general population of dietary supplement and sports nutrition product use, in general and for specific DS and SNP; (b) to identify differences in use for gender, age and exercise frequency, and (c) to determine the main reasons for using DS and(or) SNP in particular for physical performance purposes in comparison to general health purposes. Knowledge about prevalence and motivation for use of DS and SNP, especially in non-athletes, is of relevance for (sports) dieticians and health professionals giving dietary advice. 


\section{Methods}

\section{Study design}

The present study was part of the Dutch Sport nutrition and Supplement Study (DSSS) which had been approved by the Ethics Board of Wageningen University. To obtain insight in nutritional supplement use of a representative sample of the general population questions were integrated in the Dutch National Sport Study (NSO). GfK Panel Services Benelux BV (GFK) conducted the survey between November 22 and December 4, 2013 using an Internet-based questionnaire (Bellview, Pulse Train, North Palm Beach USA). To reduce selection bias, the questionnaire was given a neutral title: 'Health and exercise'. Moreover, those respondents submitting a completed questionnaire were rewarded with an incentive (bonus points with a value of $€ 1.60$ that could be spent within the GfK panel rewarding system) which encouraged those respondents that were not primarily interested in health and exercise to participate. Average duration for filling out the total NSO questionnaire was 16 minutes, with 2 minutes for the specific sports nutrition questions.

\section{Study population}

Out of a panel of 10,000 representative households, 2350 participants received an invitation to fill out the questionnaire. Within thirteen days, 1544 questionnaires were returned (response percentage of 66\%) which was considered to deliver a representative sample of the population in the Netherlands for example in terms of age (15-80 years), gender(50-50\% men and women), education level (35\% lower education; $42 \%$ middle-education; 23\% higher education) and ethnicity (80\% autochthonous; $8 \%$ western-immigrant; $12 \%$ not-western immigrant).

\section{Questions}

To investigate the prevalence of dietary supplement and sports nutrition product use, in general and for specific DS and SNP sub categories, a questionnaire was developed that examined the self-reported use of DS and SNP in the last 12 months. All products questioned are shown in Table 1 . Dietary supplements were products classified as supplements that prevent or treat a perceived nutrient deficiency, i.e. vitamins, minerals, essential fatty acids. Ergogenic supplements were also included in this category, because they could be used for health purposes as well as performance improvement. Sport nutrition products were macronutrient containing beverages, i.e. sports drinks (electrolyte and carbohydrate containing drinks for rehydration and refuelling and energy drinks containing mainly carbohydrate for refuelling) and recovery drinks (containing a combination of carbohydrate and protein aiming to optimize post-exercise recov- 
ery), to provide a more convenient form of nutrients in situations where everyday foods aren't practical-particularly to address nutritional needs/goals around an exercise session. All DS that could be selected were pre-defined with the option to indicate 'no' or 'other' use and in case of SNP the option 'none of these supplements' was included.

The questions asked were: \#1 Which dietary supplements did you use during the last twelve months? (pre-selected options); \#2 Which sports nutrition products did you use during the last twelve months? (pre-selected options); \#3 and \#4 Please indicate the main reason for using these products (DS or SNP). Subjects were asked to select only one option: for health purposes, for physical performance purposes, to improve both, or for other purposes. Gender and sporting frequency were detected as part of the general questionnaire. Respondents were asked to select one or more sports out of a pre-specified list of 44 sports and an 'other' option. The exercise frequency (per year) was obtained by an open question that was part of the annual NSO questionnaire: how many times did you have exercised in the last 12 months?

\section{Statistical analysis}

After terminating the registration period results were entered into SPSS (IBM SPSS Statistics, version 20). All self-reported results are given as percentages. For each value a 95\% confidence interval was estimated and expressed as a percentage based on the following formula $v(p(1-p) / n)$ of which $p$ is the sample proportion and $n$ is the sample size. Individual (2x2) chi-square tests were used to assess whether there was a difference in the expected distribution of DS and SNP use within tied subcategories such as gender, age and sporting frequency. Results were considered significantly different at $P$ $\leq 0.05$. No correction was calculated for multiple comparisons because of the relatively small number of equations between each subcategory.

\section{Results}

The sample size was $n=1.544$ with comparable numbers of men $(n=791)$ and women $(n=753)$. The largest proportion, $76 \%$ of the sample, was aged between 21 and 65 years. Of the total study population, $26 \%$ reported that they were not engaged in any sporting activity, while $31 \%$ of the population exercised between 12 and 59 times a year. One third of the study population $(33 \%, n=512)$ indicated that they were a member of a sports club. Most of the subjects performed recreational sports without a competitive element. Table 1 contains numbers ( $n$ ) of participants in specific subgroups. 


\section{Prevalence}

The most reported DS were multivitamin/mineral supplements, vitamin C and vitamin D. The most frequently reported SNPs were energy drinks and isotonic drinks (Table 1). With regards to total prevalence of DS and SNP use in total, 62\% [95\% Cl:60-64] of the study population reported the use of DS, SNP or both. The percentage use of products categorized within DS or SNP only existed of $28 \%$ [95\% Cl: $26-30$ ] and $12 \%$ [95\% Cl: $10-$ 14] respectively. In total $38 \%$ [95\% Cl: 36-40] did not report to use any type of product (Table 2).

As shown in Table 1 Men reported to use more SNPs like energy drinks, isotonic drinks and recovery drinks than women, except for protein shakes and energy gels. Women reported a higher proportion of vitamin and mineral supplements, essential fatty acids, probiotics and other DS than men. No differences between men and women were seen for the use of ergogenic supplements, such as caffeine and creatine.

The use of dietary supplements was different between age categories as can be seen in Table 1. For example, vitamin D and calcium supplement use was higher in the oldest age category of 66-80 years. And magnesium was high in both the youngest age group of 15-20 years and the oldest age groups of 51-65 and 66-80 years. The sportspecific use of caffeine (defined as: tablet/ capsule, energy drink/ sport nutrition product, coffee or an equivalent) was especially high in the two youngest age groups of 1520 and 21-35 years old. Regarding to SNP, energy drinks, isotonic drinks and protein shakes prevalence was the highest in the two youngest age categories of 15-20 and 2135 years. The prevalence of the use recovery drinks was declining by increasing age groups. In general some differences between age groups existed, resulting in a higher prevalence of use of SNP or a combination of DS and SNP (i.e. using both) in the younger categories (15-20 years and 21-35 years) compared with the older age categories (51-65 years and 66-80 years) as shown in Table 2.

The part of the population that exercised $>60$ times a year reported the greatest consumption of SNP. This group also reported the highest percentages for single product use of multivitamin and minerals, vitamin C, isotonic drinks, energy drinks, protein drinks, recovery drinks and energy gels (Table 1). People who did not exercise or less than 11 times a year reported the highest non-use (51\%) of DS and SNP (Table 2). This percentage was significantly higher than all categories with an active participation in sports. Nevertheless, of those participants reporting not to exercise still a relatively large number indicated to use SNP (8\%, [95\% Cl: 5-11]) or a combination of DS and SNP (7\%, [95\% Cl: 5-9]). The frequency of SNP use found in those not exercising was equal to those exercising 1-11 times a year in case of those reporting only the use of SNP (8\% [95\% Cl: 5-11] vs. 9\% [95\% Cl: 4-14]. This was not the case for combined use of DS and SNP between those not active or 1-11 times a year $(7 \%$ [95\% Cl: 5-9] vs. $24 \%$ [95\% Cl: 17-31]. Overall this resulted in a relative large group of sedentary individuals using SNP. 


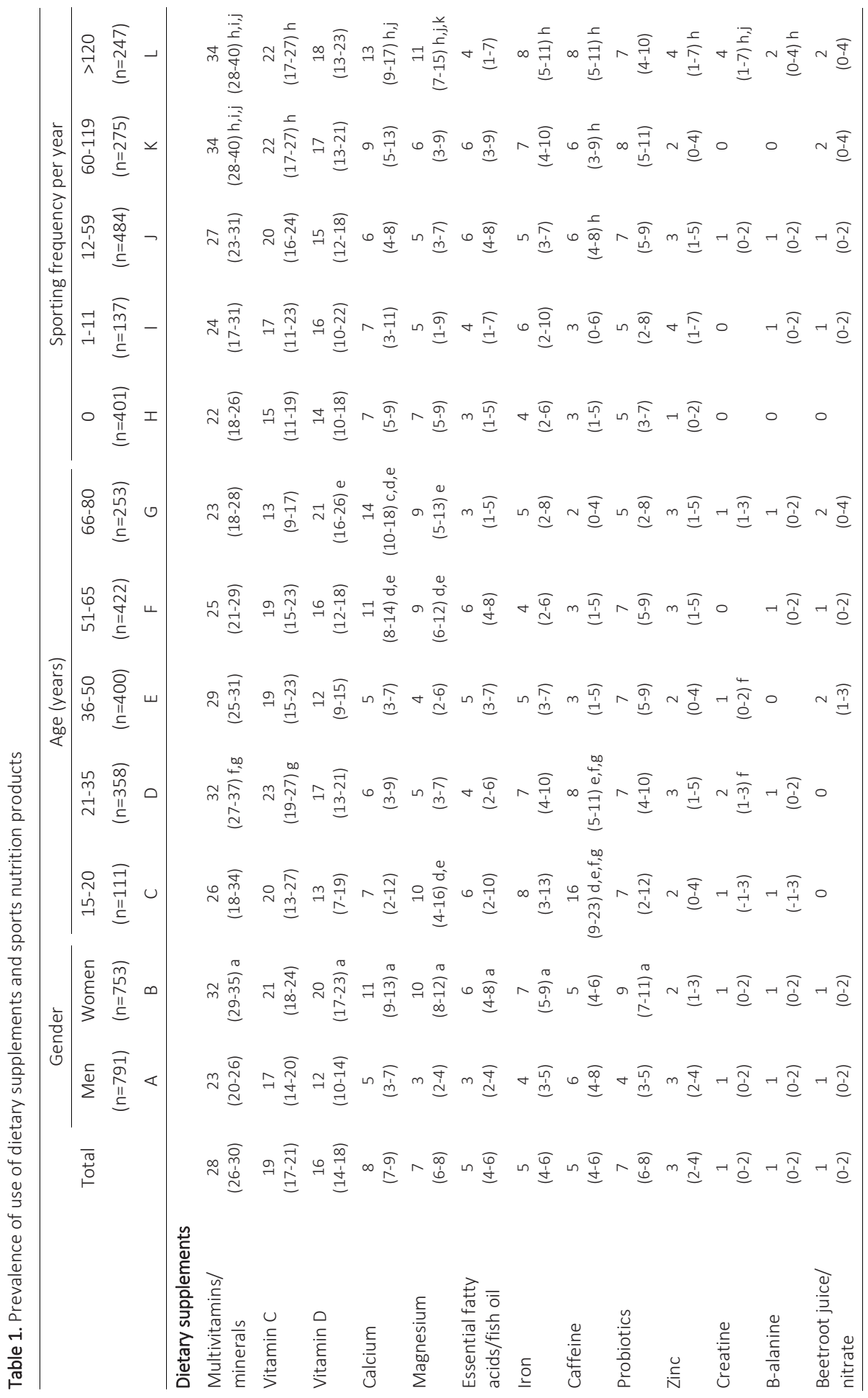




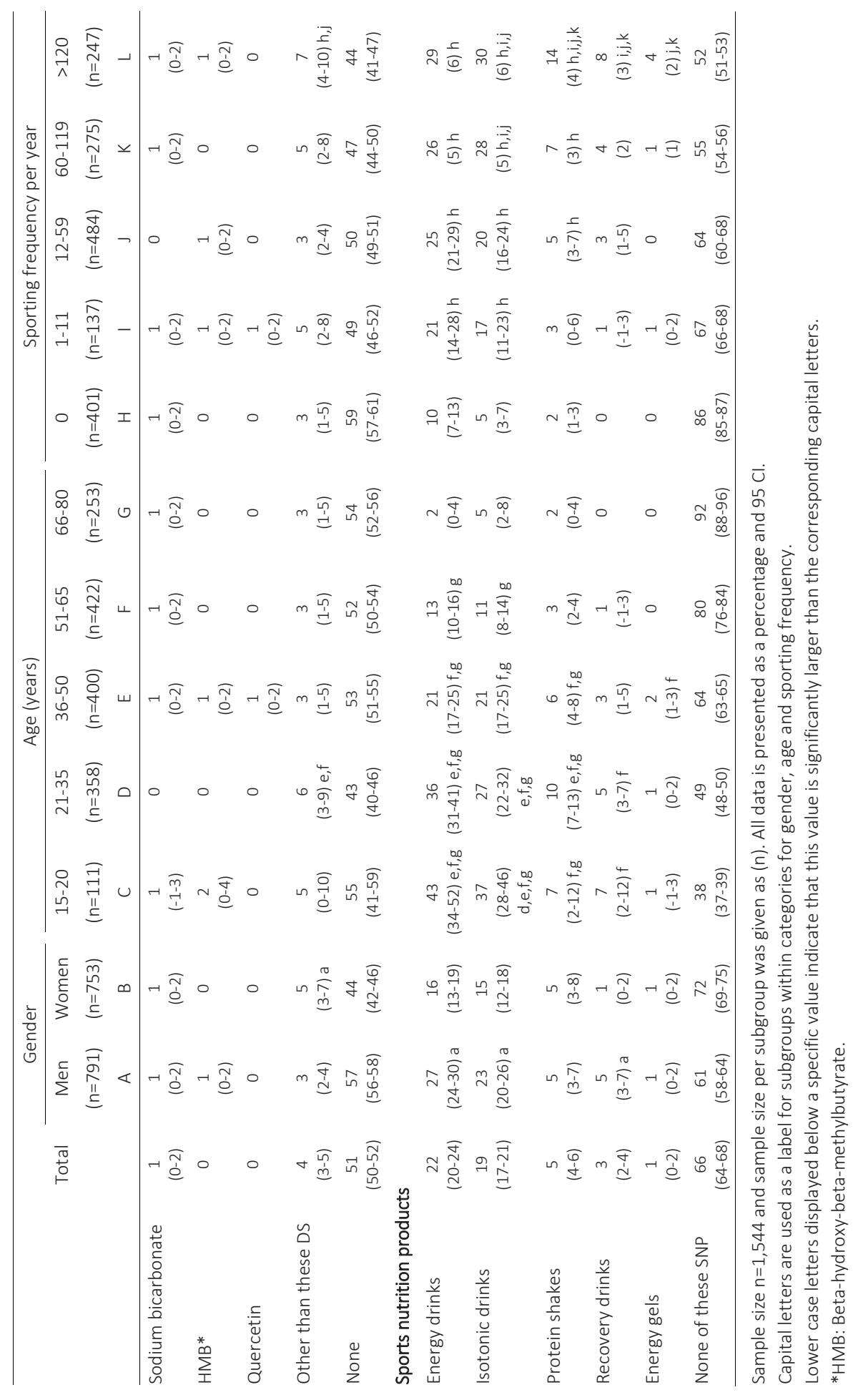


Use and reasons of nutritional supplements among the general population

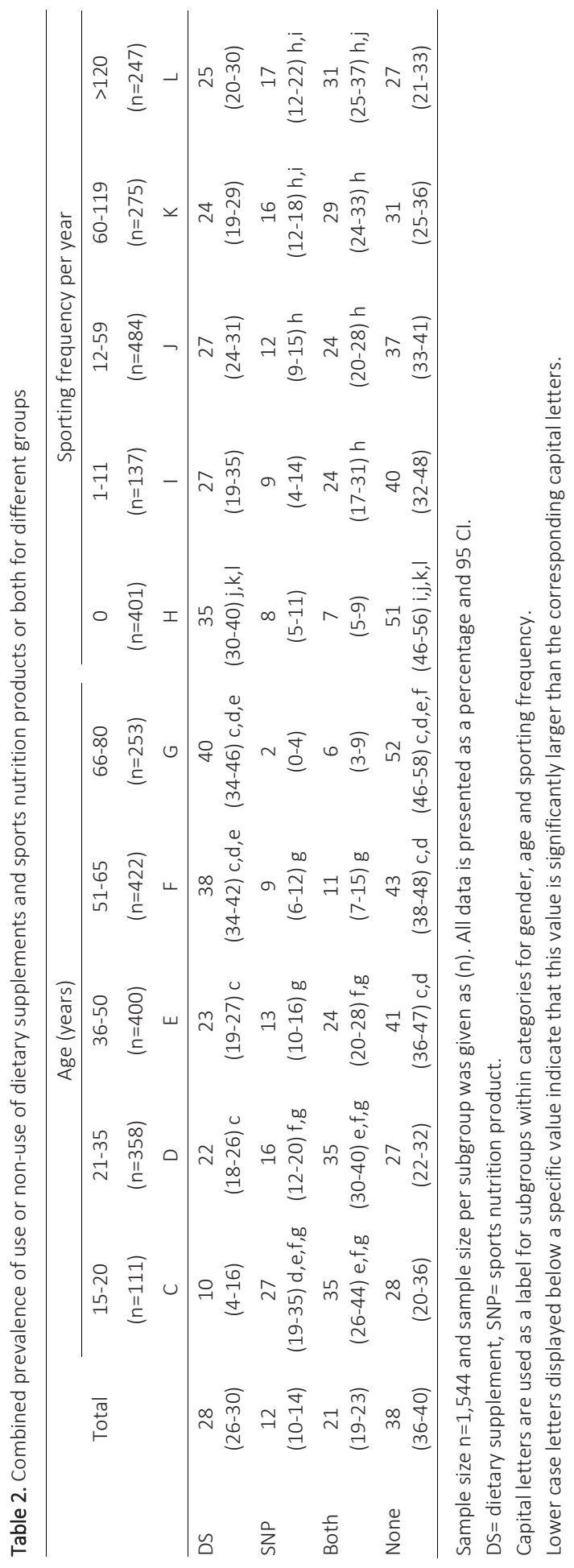




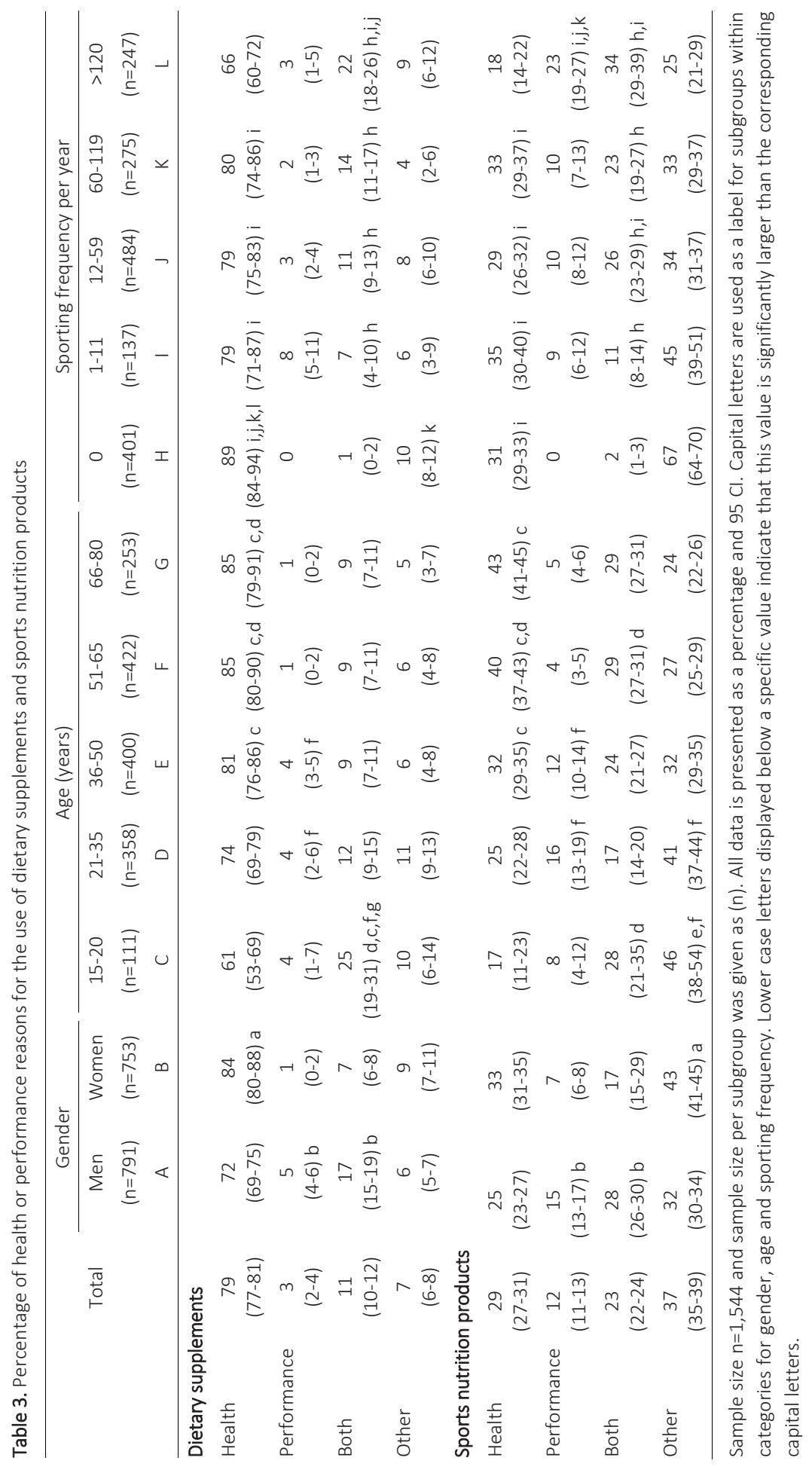


Reasons

Most subjects reported health reasons as the main motivation for using DS, with a range of $61-89 \%$ among categories (Table 3). Improvement of physical performance was not frequently selected as a single reason for use (range 1-8\% for different sub categories), although the combined reason (health and performance) was reported frequently in some but not all groups. This was most frequently seen in the age group of 15-20 years (25\% [95\% Cl: $19-31])$, and the group exercising $>120$ times a year $(22 \%$ [95\% Cl: 18-26]). Also for SNP use, health reasons were more frequently indicated than performance reasons, with, for health, a range of $17-43 \%$ among categories, Table 3), although 'other reasons' was answered more frequently (range 24-67\% ). The group exercising $>120$ times reported, in comparison with other subcategories, most frequently 'physical performance purposes' as reasons for use, $23 \%$ [95\% Cl: 19-27], indicated performance as sole reason, while 34\% [95 Cl: 29-39]) indicated the combined reason of health and performance as major argument for use.

Women more frequently reported health reasons as their motivation for DS use than men (84\% [95\% Cl: 80-88] vs. 72\% [95\% Cl: 69-75]), but not for SNP (33\% [95\% Cl: 31-35] vs. $25 \%$ [95\% Cl: 23-27]). Men reported higher percentages for physical performance purposes and a combination of health and physical performance purposes as the most important reason for DS and SNP use than women. 


\section{Discussion}

Almost two-thirds of the respondents indicated having used DS and(or) SNP during the last twelve months. DS were used more frequently than SNP, with improving health being the most important motivating factor. The most frequently reported products used were, for DS, vitamin and mineral supplements, and, for SNP, energy drinks. DS use was most frequently reported by women and older people. On the other hand, men, young people, and those exercising most frequently reported the highest use of SNP. Women tended to indicate general health considerations more frequently compared to men as their main reason, whereas men reported physical performance purposes as their main reason for use more often than women. Remarkably, even sedentary respondents reported a relatively high prevalence of SNP use.

\section{Prevalence and reasons}

Combined use of DS and SNP intake of specific groups and populations was previously reported ranging from 22 to $98 \%$ based on different methods, ${ }^{1-4,6,8-17}$ while we measured a substantial percentage of 61\% (combining both DS and SNP) in the current study. Only a few studies focused on the sport-specific use of DS and SNP in nonathletes. ${ }^{1,6,13}$ Although the combined DS and SNP use in the present study is lower than in most recent studies with athletes, ${ }^{2-4}$ it is much higher than the reported $4.8 \%$ in a small group of non-athletic controls $(n=60)$ as presented previously. ${ }^{1}$ This may be explained by geographical differences indicating the relevance of this type of study for specific regions worldwide.

Overall DS use in this Dutch sample (49\%) equals DS use of a representative sample of the US population (i.e. $52 \%)^{18}$ and data based on the latest Dutch Food Consumption Survey (VCP). ${ }^{19}$ This VCP also questioning dietary supplement use throughout the year, and showed a range of $26-36 \%$ for men and $34-54 \%$ for women across different age groups. The results of the present study are at the upper end of the results of the VCP, most likely due to including or not including specific types of DS (for example ergogenic supplements), but also reflecting some differences in our population with those of the VCP (maybe as a result of including those interested in a questionnaire about health and exercise) despite the fact that we included a representative sample of the Dutch population. As observed previously, multivitamins, vitamin C and vitamin D were most frequently reported. ${ }^{18-20}$

Gender differences found in the present study are in line with results found by Sundgot-Borgen et al. (2003), who included 1689 non-athletes as controls of an athletic population. ${ }^{8}$ These authors reported a difference in total nutritional supplement use - a combination of DS and SNP - between men (32\%) and women $(52 \%)^{8}$ We found a similar gender difference although the total prevalence of DS and SNP use was higher in our study, and the difference between both groups was much smaller: $60 \%$ vs. $64 \%$ for men 
and women respectively. Interestingly, the women in our study reported higher DS use compared to men (36 vs. 20\%), while men reported a higher prevalence of SNP. This gender difference was also previously detected by others. ${ }^{2,8,12,21}$ An explanation might be that DS are more frequently linked to health, whereas SNP are more frequently associated with physical performance. This would be in line with our observations that women reported 'health' more often as reason for use, men reported 'physical performance'. In contrast, some studies did not find a gender difference ${ }^{3}$ or in fact found the opposite, ${ }^{1,11}$ which may also depend on the definitions used for DS and(or) SNP.

It is interesting to note that younger respondents use more SNP or both SNP and DS than older respondents. This contrast some previous investigations that indicated a higher prevalence of nutritional supplement use in adult athletes compared with adolescents. ${ }^{22,23}$ It can be speculated that SNP, such as sports drinks and energy drinks, have become increasingly popular amongst younger individuals during recent years. This might be attributed to marketing strategies of companies producing these type of products that are appealing to young athletes. Resulting for example in parents buying these drinks at the supermarket for their children to replenish energy and fluid at half time during their sports in the weekend.

Our findings are also in line with the National Health and Nutrition Examination Study. As that study revealed comparable trends for those being active ( $>120$ times a year in the present study vs. vigorous in NHANES) reporting the highest percentages for total DS use, but also for the top ranked products like multivitamin/mineral and vitamin $\mathrm{C}^{18}$

\section{Strengths and limitations}

The novelty of this paper is that we examined the use of DS and SNP in a representative sample of a general population in relation to reasons for use, i.e. health purposes, physical performance purposes, both or other reasons for the total category of DS, SNP and(or) combined use of DS and SNP. To our best knowledge, this is the first study investigating the general reason for use (health, performance or both) of both DS and SNP in a general population. Besides this we used a sound sampling strategy with a strong response rate.

An important added value of the present study is that it evaluated the prevalence of intake of DS and SNP separately, as well as the different types of products used-an insight which is generally not provided in other large cohort publications. ${ }^{18-20,24,25}$ For example, there does not seem to be any nutritional substantiation for energycontaining SNP used by the majority of the non-exercising population. Combining DS and SNP will not provide this insight.

The estimated proportions with a confidence interval $(\mathrm{Cl})$ of $95 \%$ are relatively small, which increases the likelihood that the true value of the respondents will actually lay close to the reported average percentage. 
As we did not investigated frequency of use or quantity this should be investigated in the near future. As a consequence, our results reflect at least the total prevalence of respondents using a product once in this period. This may inflate the results for prevalence of use, on the other hand, others also questioned nutritional supplement use in the last 12 months, ${ }^{26}$ which can be seen as indicative for the (absolute) prevalence of type of products and the difference in proportion between products and categories.

As we were limited by the number of questions that could be included in the questionnaire, we chose to pre-select the most relevant types of DS and SNP. In the case of SNP, sports energy bars are missing in this category as we focused on fluid-based SNP, therefore the prevalence of SNP use in our study could be underestimated but should at least give a representative picture of fluid-based SNP use. It could be debated why for example ergogenic supplements as creatine and B-alanine were classified as DS, as others would put these in the SNP category because of their sports performance enhancing claims. On the other hand some but not all of these ergogenic supplements could be used for health purposes as well. For example there exists a relation between the nitrate in beetroot juice and blood pressure, quercitin is a polyfenol that also could be related to health and caffeine can also be taken from a healthy life style perspective, for example to stimulate energy metabolism to enhance body weight loss. As there is not a single definition, either legal or within nutritional science, of what constitutes a dietary supplement, ${ }^{27}$ we chose to combine all supplements based on tablets, capsules, drops and so on, in small doses mostly defined in $\mathrm{mg}$ or mcg. As the included sport nutrition products were defined as those delivering substantial energy, macronutrients and(or) fluid. In this case classifying ergogenics as DS could affect the prevalence of sport specific use as a reason. On the other hand, the prevalence of reason for physical performance regarding to DS is only $14 \%$ against $79 \%$ reason for prevalence of health purposes. The contribution of these ergogenic supplements on sport specific can be stated as limited. Still this can be seen as a limitation that could have been prevented if we divided these categories on forehand.

As health is the main reason for use of both DS and(or) SNP these observations suggest that the general population has the impression that both DS - and - SNP are considered a healthy choice. An obvious question is whether the majority of this population needs these products, and whether the products used actually enhanced their sporting performance or influenced their health.

To conclude, This study shows a high prevalence of DS and SNP use among a general population. Dietary supplement use was most frequently reported by women and older people, while men, young people, and those exercising most frequently reported the highest use of SNP. Next to improving health, improvement of physical performance appears to be an important objective for both DS as SNP or the combined use of these products. It can be questioned whether the use of SNP fits all respondents' physical activity needs and in particular for those classified as being sedentary. 


\section{References}

1 Giannopoulou I, Noutsos K, Apostolidis N, Bayios I, Nassis GP. Performance level affects the dietary supplement intake of both individual and team sports athletes. J Sports Sci Med. 2013; 12: 190-6.

2 Kang M, Kim DW, Baek YJ, et al. Dietary supplement use and its effect on nutrient intake in Korean adult population in the Korea National Health and Nutrition Examination Survey IV (2007-2009) data. Eur J Clin Nutr. 2014; 68: 804-10.

3 Tavani A, Colombo, P., Scarpino, V. Zuccaro, P., Pacifici, R., \& La Vecchia, C. A survey of dietary supplement use among Italian sporting club athletes. Nutrafoods. 2014; 13: 29-34.

4 Wiens K, Erdman KA, Stadnyk M, Parnell JA. Dietary supplement usage, motivation, and education in young, Canadian athletes. Int J Sport Nutr Exerc Metab. 2014.

5 Wardenaar FC, Ceelen IJM, Van den Dool R, Witkamp R, Mensink M. Het gebruik van voedingssupplementen en sportvoeding door meer en minder actieve Nederlanders - Een inventarisatie op basis van het Nationaal Sport Onderzoek 2012 onder de Nederlandse bevolking (Use of dietary supplements and sport nutrition products in the Dutch general population). Nederlands Tijdschrift voor Voeding en Dietetiek (in Dutch). 2014; 69: S1-S9.

6 Kristiansen M, Levy-Milne R, Barr S, Flint A. Dietary supplement use by varsity athletes at a Canadian university. Int J Sport Nutr Exerc Metab. 2005; 15: 195-210.

7 Sette S, Le Donne C, Piccinelli R, et al. The third Italian National Food Consumption Survey, INRAN-SCAI 2005-06--part 1: nutrient intakes in Italy. Nutr Metab Cardiovasc Dis. 2011; 21: 922-32.

8 Sundgot-Borgen J, Berglund, B., Torstveit, M.K. Nutritional Supplements in Norwegian elite athletes impact of international ranking and advisors. Scand J Med Sci Sports. 2003; 13: 138-44.

9 Chen S, Binns CW, Maycock B, Liu Y, Zhang Y. Prevalence of dietary supplement use in healthy pre-school Chinese children in Australia and China. Nutrients. 2014; 6: 815-28.

10 de Silva A, Samarasinghe Y, Senanayake D, Lanerolle P. Dietary supplement intake in national-level Sri Lankan athletes. Int J Sport Nutr Exerc Metab. 2010; 20: 15-20.

11 Evans MWJ, Ndetan H, Perko M, Williams R, Walker C. Dietary supplement use by children and adolescents in the United States to enhance sport performance: results of the National Health Interview Survey. J Prim Prev. 2012; 33: 3-12.

12 Froiland K, Koszewski W, Hingst J, Kopecky L. Nutritional supplement use among college athletes and their sources of information. Int J Sport Nutr Exerc Metab. 2004; 14: 104-20.

13 Heikkinen A, Alaranta A, Helenius I, Vasankari T. Dietary supplementation habits and perceptions of supplement use among elite Finnish athletes. Int J Sport Nutr Exerc Metab. 2011; 21: 271-9.

14 Mackay D, Wallace TC. Re: dietary supplement use by children and adolescents in the United States to enhance sport performance: results of the National Health Interview Survey. J Prim Prev. 2012; 33: 225-27.

15 Petroczi A, Naughton DP, Pearce G, Bailey R, Bloodworth A, McNamee M. Nutritional supplement use by elite young UK athletes: fallacies of advice regarding efficacy. J Int Soc Sports Nutr. 2008; 5: 22.

16 Scofield DE, Unruh S. Dietary supplement use among adolescent athletes in central Nebraska and their sources of information. J Strength Cond Res. 2006; 20: 452-5.

17 Yu SM, Kogan MD, Huang ZJ. Vitamin-mineral supplement use among US women, 2000. J Am Med Womens Assoc. 2003; 58: 157-64.

18 Radimer K, Bindewald B, Hughes J, Ervin B, Swanson C, Picciano MF. Dietary supplement use by US adults: data from the National Health and Nutrition Examination Survey, 1999-2000. Am J Epidemiol. 2004; 160: 339-49.

19 Rossum CTM, van Fransen HP, Verkaik-Kloosterman J, Buurma-Rethans EJM, Ocké MC. Dutch National Food Consumption Survey 2007-2010: Diet of children and adults aged 7 to 69 years. RIVM, 2011.

20 Timbo BB, Ross MP, McCarthy PV, Lin CT. Dietary supplements in a national survey: Prevalence of use and reports of adverse events. J Am Diet Assoc. 2006; 106: 1966-74.

21 Huang SH, Johnson K, Pipe AL. The use of dietary supplements and medications by Canadian athletes at the Atlanta and Sydney Olympic Games. Clin J Sport Med. 2006; 16: 27-33. 


\section{Chapter 5}

22 Braun H, Koehler K, Geyer H, Kleiner J, Mester J, Schanzer W. Dietary supplement use among elite young German athletes. Int J Sport Nutr Exerc Metab. 2009; 19: 97-109.

23 McDowall JA. Supplement use by Young Athletes. J Sports Sci Med. 2007; 6: 337-42.

24 Millen AE, Dodd KW, Subar AF. Use of vitamin, mineral, nonvitamin, and nonmineral supplements in the United States: The 1987, 1992, and 2000 National Health Interview Survey results. J Am Diet Assoc. 2004; 104: 942-50.

25 Schaffer DM, Gordon NP, Jensen CD, Avins AL. Nonvitamin, nonmineral supplement use over a 12-month period by adult members of a large health maintenance organization. J Am Diet Assoc. 2003; 103: 1500-5.

26 Slater G, Tan B, Teh KC. Dietary supplementation practices of Singaporean athletes. Int J Sport Nutr ExerC Metab. 2003; 13: 320-32.

27 Maughan RJ, Greenhaff PL, Hespel P. Dietary supplements for athletes: emerging trends and recurring themes. J Sports Sci. 2011; 29 Suppl 1: S57-66. 


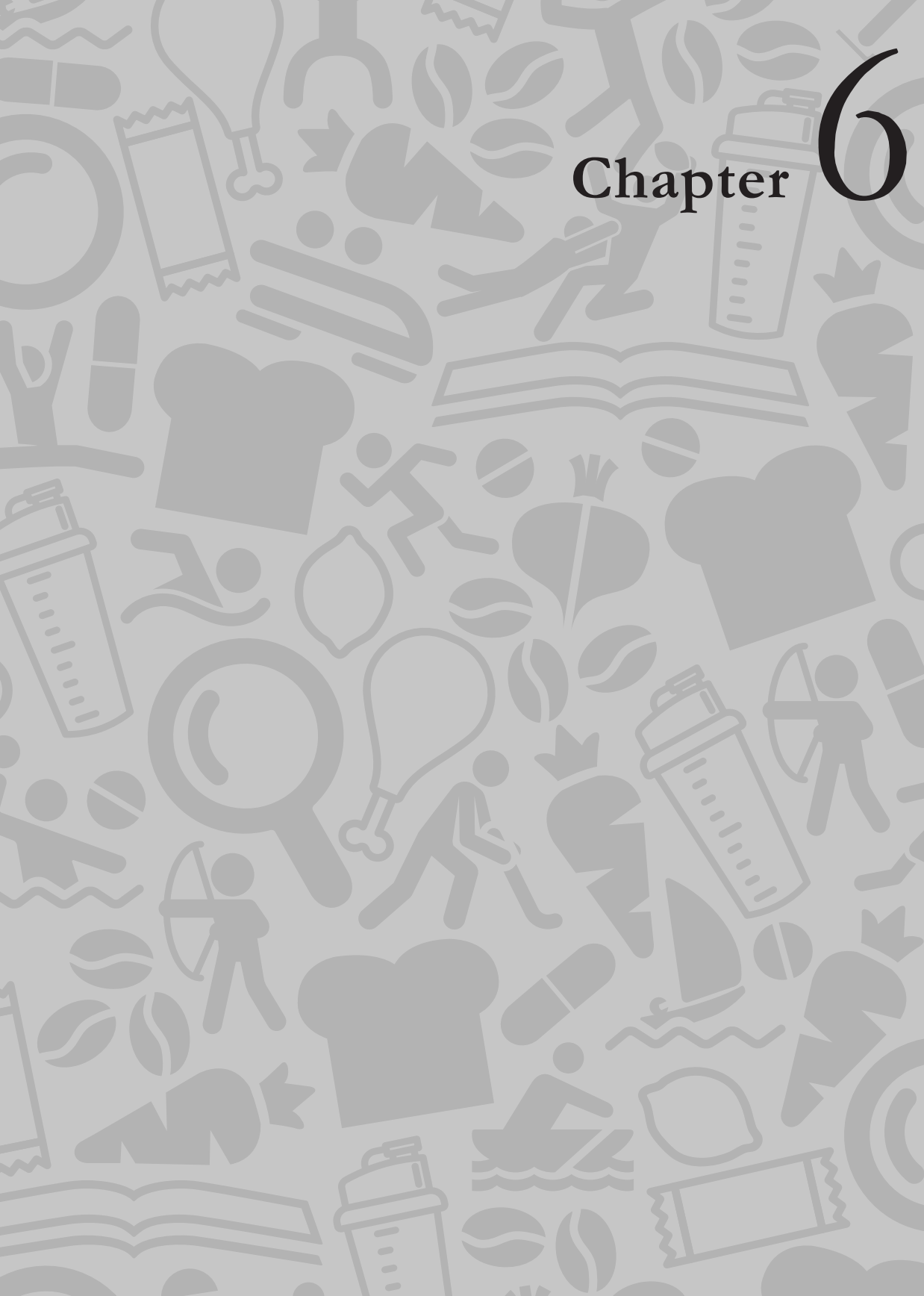


\section{Nutritional supplement use by Dutch elite and sub-elite athletes:}

Does receiving dietary counselling make a difference?

Floris C. Wardenaar, Ingrid J.M. Ceelen, Jan-Willem Van Dijk J, Roland W.J. Hangelbroek, Lore Van Roy, Britte Van der Pouw, Renger F Witkamp, Marco Mensink.

Int J Sport Nutr Exerc Metab. 2016 Sep 6:1-25. 


\section{Abstract}

Aim: The use of nutritional supplements is highly prevalent among athletes. In this cross-sectional study we assessed the prevalence of nutritional supplement use by a large group of Dutch competitive athletes in relation to dietary counselling.

Methods: A total of 778 athletes (407 males and 371 females) completed a web-based questionnaire about the use of nutritional supplements. Log-binomial regression models were applied to estimate crude and adjusted prevalence ratios (PR) for the use of individual nutritional supplements in athletes receiving dietary counselling as compared to athletes not receiving dietary counselling.

Results: Of the athletes $97.2 \%$ had used nutritional supplements at some time during their sports career, whereas $84.7 \%$ indicated having used supplements during the last 4 weeks. The top ranked supplements used over the last 4 weeks from dietary supplements, sport nutrition products and ergogenic supplements were multivitamin and mineral preparations (42.9\%), isotonic sports drinks (34.1\%) and caffeine (13.0\%). After adjustment for elite status, age, and weekly exercise duration, dietary counselling was associated with a higher prevalence of the use of vitamin D, recovery drinks, energy bars, isotonic drinks with protein, dextrose, beta-alanine, and sodium bicarbonate. In contrast, dietary counselling was inversely associated with the use of combivitamins, calcium, vitamin E, vitamin B2, retinol, energy drinks and BCAA and other amino acids.

Conclusions: Almost all athletes had used nutritional supplements at some time during their athletic career. Receiving dietary counselling seemed to result in better informed choices with respect to the use of nutritional supplements related to performance, recovery, and health. 


\section{Introduction}

Nutritional supplements are products for oral consumption that add to the nutritional value of the habitual diet. They are widely used by athletes to maximise performance and accelerate recovery, to prevent deficiencies, and/or to maintain good general health. ${ }^{1-6}$ For sports purposes, nutritional supplements can be classified as dietary supplements, sport nutrition products and ergogenic supplements. The category of dietary supplements mainly comprises micronutrient supplements such as vitamins and minerals, but also essential fatty acids. Such dietary supplements may promote the athletes' general health through the prevention and treatment of nutrient deficiencies. These supplements are not believed to enhance performance in the absence of a deficiency. Sport nutrition products mainly contain macronutrients, such as carbohydrates and protein, and form a practical and (or) convenient alternative to regular food. Such sport nutrition products include, but are not limited to, sports drinks, recovery drinks, and energy and protein bars. The category of ergogenic supplements mainly comprises products with performance enhancing claims, such as caffeine and creatine. ${ }^{7}$

The use of nutritional supplements worldwide among the general population has grown steadily during recent years. ${ }^{8,9}$ Here, health motives appear to be the most important reasons for using nutritional supplements. ${ }^{10}$ However, from the athlete's perspective, the belief that these products help to improve exercise performance is considered the main driver for their use. ${ }^{11}$ This might explain why according to a recent review (Knapik et al., 2015) the use of nutritional supplements appears to be the highest in elite athletes (up to $100 \%$ in specific groups of athletes), followed by their non-elite counterparts (up to $87 \%$ in specific groups of athletes) and by the general population (42\% in men and $54 \%$ in women).

Despite the popularity of nutritional supplements in athletes, a well-balanced diet is of prime importance in meeting the nutritional demands of training and competition. ${ }^{12}$ Athletes should therefore strive to optimize their general dietary intake, before considering nutritional supplements. However, many athletes seem to use nutritional supplements without a proper understanding of the proposed effects and the level of scientific evidence. ${ }^{11,12}$ Although specialised sports dieticians or nutritionists can be seen as the main experts in the field of sports nutrition and nutritional supplements, only a small proportion of athletes (10-14\%) considers a dietician or nutritionist as their primary source of nutritional information. ${ }^{13,14}$ Despite the fact that dietary counselling has been shown to have a beneficial effect on the food intake of athletes, ${ }^{15,16}$ many athletes decide to use nutritional supplements without consulting a specialist. ${ }^{13,17}$ Earlier studies have looked at the relationship between competition level (elite or sub-elite) and gender and the use of nutritional supplements. ${ }^{18}$ Nevertheless, it is currently unknown whether dietary counselling is related to the use of nutritional supplements in athletes.

The first objective of this study was to define the prevalence of nutritional supplement use in a representative group of elite-level Dutch athletes. The last large scale 
survey on nutritional supplement use in Dutch top athletes was conducted more than 25 years ago in a period when the use of dietary supplements was not as common, showing a prevalence of $40-60 \%$ within disciplines. ${ }^{19,20}$ Secondly, we aimed to evaluate whether supplement use differed between groups receiving dietary counselling and those not. Given the growing interest in dietary supplements by athletes, we hypothesized a higher prevalence of nutritional supplement use in the current study compared with older studies. Furthermore, we expected that those receiving dietary counselling would show a more conscientious use of nutritional supplements than those not receiving counselling.

\section{Methods}

Study Design

The study was part of the Dutch Sport Nutrition and Supplement Study that was conducted between February 2012 and May 2015. Data collection was conducted using a web-based questionnaire (The Qualtrics Research Suite, 2013. Provo, UT). The study was approved by the Medical Ethics Committee of Wageningen University. Written informed consent was obtained from all participants. For participants under the age of eighteen, informed consent was also obtained from their parents or guardian.

\section{Study population}

Athletes were recruited from February 2012 during all seasons but mainly in late winter, spring and early summer. A total of 1801 elite and sub-elite athletes with on average $17.1 \pm 10.1$ training hours per week, including 1200 athletes with elite status from the Dutch Olympic Committee (NOC*NSF), received an invitation to participate in the current study. As such, this population forms a large representative sample of Dutch elite athletes and high-level athletes competing at national and international levels. From February 2014 onwards, respondents submitting a completed questionnaire were rewarded with a book on practical sport nutrition.

\section{Questionnaire}

The questionnaire was partly based on previous questionnaires ${ }^{21,22}$ and was further expanded with questions about dietary counselling. A panel of three expert dietitians, all being members of the Dutch Association of Sports Dieticians, reviewed the first draft. The second draft was evaluated by a group $(n=10)$ of competitive runners. Feedback was specifically sought on the length, language, and content of the questionnaire. After modifying the questionnaire in accordance with their recommendations, a final draft 
was critiqued by all researchers involved in this study, including two dieticians working with elite athletes. No additional testing was done on reliability of the questionnaire. Following general questions on the athletes' characteristics (age, gender, sports discipline, NOC*NSF elite status and the presence of dietary counselling), the use of nutritional supplements was assessed based on a list of pre-specified products which included 47 specific nutritional supplements. The nutritional supplements were categorized as 1) dietary supplements, including vitamins, minerals and essential fatty acids; 2) sport nutrition products, including products with carbohydrate and/ or protein, such as sports drinks, energy drinks, recovery drinks, protein shakes and sports bars and 3) ergogenic supplements, including mainly products with health and performance enhancing claims $^{6,23}$ such as probiotics, creatine and caffeine. The ergogenic supplements may include pills, tablets, powders, solutions, or drinks that were purposely taken because of the ergogenic substance. The athletes reported the use of the pre-specified nutritional supplements at any time in the past during their sports career and over the last 4 weeks (Table 2). The presence of dietary counselling was defined as currently being under guidance of a (sports) dietician or nutritionist.

\section{Statistical analysis}

After completing the data collection, data was organized, checked and analyzed by SPSS (IBM SPSS Statistics, version 20). Athlete characteristics are reported as mean $\pm \mathrm{sd}$. The prevalence of nutritional supplement use is reported as percentage (\%). Independent ttests or Mann-Whitney $U$ tests were used to determine differences between the characteristics of subgroups.

Log-binomial regression models were applied to estimate crude and adjusted prevalence ratios (PR) for the use of individual nutritional supplements over the last four weeks in athletes receiving dietary counselling (yes/no) and additionally for gender and elite status. The PRs based on the exposure of counselling were adjusted for gender, elite status (yes/no), age (years; log-transformed) and weekly exercise duration (hours; log-transformed) and the PRs based on the exposure of gender and elite stays were adjusted for each other, counselling, age and weekly exercise duration. All results were considered significant at $\mathrm{P}<0.05$.

\section{Results}

A total of 817 questionnaires (response rate of 45.4\%) were returned. Only complete questionnaires $(n=778)$ were included in the current study, obtained from athletes practicing team sports $(26.7 \%)$, athletics $(14.3 \%)$, water sports $(12.3 \%)$, cycling $(11.4 \%)$, swimming $(8.7 \%)$ and other sports (26.6\%). The median duration for completing the total questionnaire was 22 minutes. 


\section{Chapter 6}

Table 1. Subject characteristics.

\begin{tabular}{lccc}
\hline & Total & Dietary counselling & No dietary counselling \\
\hline Respondents $(\mathrm{n})$ & 778 & 332 & 446 \\
Men $(\mathrm{n})$ & $407(52 \%)$ & $146(44 \%)$ & $261(59 \%)^{*}$ \\
Elite status & $394(51 \%)$ & $229(69 \%)$ & $103(23 \%)^{*}$ \\
Body mass index (BMI) & $22.2 \pm 2.5$ & $22.1 \pm 2.5$ & $22.2 \pm 2.6$ \\
Age (year) & $24.7 \pm 9.6$ & $22.5 \pm 6.2$ & $26.4 \pm 11.2^{+}$ \\
Exercise (hours/ week) & $17.1 \pm 10.1$ & $21.1 \pm 11.9$ & $14.1 \pm 7.1^{\dagger}$ \\
\hline
\end{tabular}

Data is reported as the number of respondents, frequencies or mean \pm sd.

* Significantly different compared with dietary counselling group based on independent $t$-test $(P<0.05)$.

${ }^{\dagger}$ Significantly different compared with dietary counselling group based on Mann-Whitney $U$ test $(P<0.01)$.

Subject characteristics are shown in Table 1. Fifty-one percent of the respondents held an elite athlete status as per the Dutch Olympic Committee (NOC*NSF). An equal percentage of men (52.3\%) and women (47.7\%) completed the questionnaire. Forty-three percent of the respondents were currently receiving dietary counselling. The groups currently receiving and not receiving dietary counselling differed with respect to gender, elite status, age and weekly exercise duration (Table 1), while those receiving counselling were more frequently female, in possession of an elite status, younger and having a higher weekly exercise volume. In the group of athletes currently not receiving dietary counselling, 86 persons received dietary counselling in the past.

\section{Prevalence of nutritional supplement use}

The prevalence of the use of any nutritional supplement was found to be $97.2 \%$ at any time in the past, and $84.7 \%$ over the last 4 weeks. Table 2 displays the use of individual nutritional supplements by athletes at any time in the past and over the last 4 weeks. The use of nutritional supplements over the last 4 weeks specified by supplement category is shown in Supplementary Table 1.

Table 2. Prevalence (\%) of nutritional supplement use ever and last four weeks $(n=778)$.

\begin{tabular}{lcc}
\hline & Any time in the past & Last four weeks \\
\hline Dietary supplements & & \\
Multivit-min & 63.4 & 42.9 \\
Vitamin C & 37.0 & 23.1 \\
Vitamin D & 29.2 & 20.2 \\
Fish oil/ essential fatty acid & 29.2 & 15.9 \\
Iron & 27.1 & 11.3 \\
Magnesium & 24.7 & 14.5 \\
Combivitamin & 22.8 & 12.9 \\
Combimineral & 13.9 & 9.3 \\
Zinc & 13.6 & 8.2 \\
\hline
\end{tabular}


Nutritional supplement use by Dutch elite and sub-elite athletes

\begin{tabular}{|c|c|c|}
\hline & Any time in the past & Last four weeks \\
\hline B-complex & 12.6 & 5.0 \\
\hline Vitamin B12 & 11.8 & 5.0 \\
\hline Calcium & 9.6 & 5.9 \\
\hline Vitamin E & 6.0 & 3.5 \\
\hline Anti-oxidants & 5.9 & 2.3 \\
\hline Vitamin B6 & 5.1 & 3.0 \\
\hline Folic acid & 4.9 & 2.8 \\
\hline Selenium & 3.7 & 2.4 \\
\hline Vitamin B1 & 3.6 & 2.1 \\
\hline Vitamin B2 & 3.0 & 1.9 \\
\hline Chromium & 2.8 & 1.5 \\
\hline Retinol & 2.4 & 1.5 \\
\hline ß-carotene & 1.8 & 0.9 \\
\hline \multicolumn{3}{|l|}{ Sport nutrition products } \\
\hline Isotonic sports drink & 46.3 & 34.1 \\
\hline Recovery drink & 46.0 & 33.5 \\
\hline Energy bar & 43.7 & 25.6 \\
\hline Protein shake & 42.3 & 29.7 \\
\hline Energy drink & 40.2 & 24.8 \\
\hline Dextrose & 37.4 & 9.5 \\
\hline Lemonade/ sirup & 28.9 & 18.3 \\
\hline Energy gel & 26.1 & 12.1 \\
\hline Protein bar & 23.7 & 12.7 \\
\hline Isotonic sports drink with protein & 17.6 & 10.9 \\
\hline Maltodextrin & 4.0 & 1.8 \\
\hline \multicolumn{3}{|l|}{ Ergogenic supplements } \\
\hline Caffeine & 22.9 & 13.0 \\
\hline Creatine & 18.8 & 9.1 \\
\hline Beetroot juice/ nitrate & 16.2 & 4.2 \\
\hline $\mathrm{BCAA} / \mathrm{AA}^{*}$ & 14.4 & 9.1 \\
\hline Probiotics & 13.0 & 6.9 \\
\hline ß-alanine & 12.3 & 4.6 \\
\hline MCT* & 6.0 & 3.7 \\
\hline Sodium bicarbonate & 4.2 & 0.8 \\
\hline L-carnitine & 3.9 & 2.1 \\
\hline Glucosamine-chondroitine & 3.2 & 1.7 \\
\hline Herbs & 1.9 & 1.2 \\
\hline Ribose & 1.9 & 0.8 \\
\hline Oil (to improve performance) & 1.0 & 0.6 \\
\hline CLA* & 0.6 & 0.4 \\
\hline
\end{tabular}

*BCAA/ AA: branched-chain amino acids/ amino acids; MCT: medium-chain triglycerides; CLA: conjugated linoleic acid. 
The top 5 ranked dietary supplements used over last 4 weeks were combined multivitamin and mineral preparations (42.9\%), vitamin C (23.1\%), vitamin D (20.2\%), essential fatty acids (15.9\%) and magnesium (14.5\%). The top 5 ranked sport nutrition products were isotonic sports drinks (34.1\%), recovery drinks (33.5\%), protein shakes (29.7\%), energy bars (25.6\%) and energy drinks (24.8\%). In the category ergogenic supplements, caffeine (13.0\%), creatine (9.1\%), BCAA/ amino acids (9.1\%) and probiotics (6.9\%) were most frequently used. Twenty-one of the total 47 pre-specified nutritional supplements were reported by less than $5 \%$ of the athletes.

\section{Dietary counselling and nutritional supplement use}

In the group of athletes receiving dietary counselling $87.0 \%$ reported the use of any nutritional supplement over the last 4 weeks compared with $83 \%$ in the group of athletes not receiving dietary counselling. The total number of supplements used over the last 4 week by athletes receiving dietary counselling (5.0 \pm 4.4 supplements) was similar to that in athletes not receiving dietary counselling (4.4 \pm 4.8 supplements; adjusted PR 0.72 [Cl 0.48-1.07]; $\mathrm{P}=0.11$ ).

The prevalence of the use of pre-defined dietary supplements (DS) in athletes with and without dietary counselling is shown in Figure 1. After adjustment for gender, elite status, age and weekly exercise duration (Table 3), dietary counselling was associated with a higher prevalence of the use of vitamin D (27.2\% vs. 15.0\%; PR 1.53 [95\% Cl: 1.13-2.08]). Conversely, dietary counselling was inversely associated the use of combined vitamin preparations (10.5\% vs. $14.6 \%$; PR 0.61 [95\% Cl: 0.39-0.94]), calcium (3.3 vs. 7.8\%; PR 0.33 [95\% Cl: 0.16-0.66]), vitamin B2 (1.2 vs. 2.5\%; PR 0.29 [95\% Cl: 0.09 $0.93])$ and retinol (0.9 vs. 2.0\%; PR 0.21 [95\% Cl: 0.05-0.95]). 


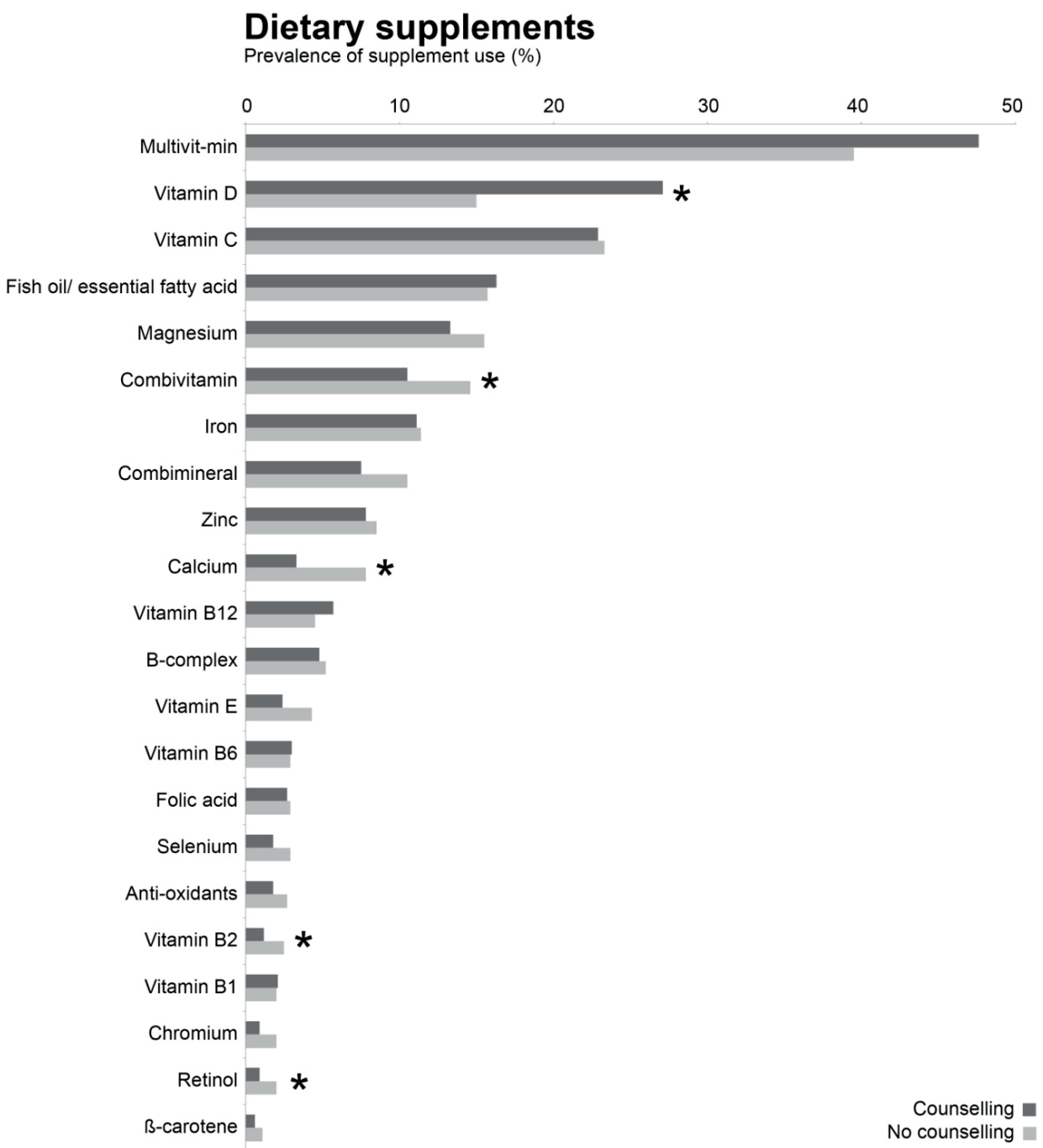

Figure 1. Prevalence of dietary supplement use during the last 4 weeks and differences between those receiving dietary counselling or not.

* Significant difference based on prevalence ratios based on log binomial regression with counselling as predictor adjusted for elite status, gender, age and weekly exercise duration.

The prevalence of the use of pre-defined sport nutrition products (SNP) in athletes with and without dietary counselling is shown in Figure 2. After adjustment for gender, elite status, age and weekly exercise duration (Table 3), dietary counselling was associated with a higher prevalence of the use of recovery drinks (43.7\% vs. 26.0\% (PR 1.35 [95\% $\mathrm{Cl}: 1.11-1.64])$, energy bars (29.8\% vs. 22.4\%; PR 1.33 [95\% Cl: $1.02-1.75]$ ), isotonic sport drinks with protein (15.7\% vs. 7.4\%; PR 1.78 [95\% Cl: 1.14-2.78]) and dextrose (12.0\% vs. 7.6\%; PR of 1.58 [95\% Cl: 1.00-2.49]). In contrast, dietary counselling was 
associated with a lower prevalence of the use of energy drinks (27.4\% vs. $21.4 \%$; PR 0.75 [95\% Cl: 0.57-0.98]).

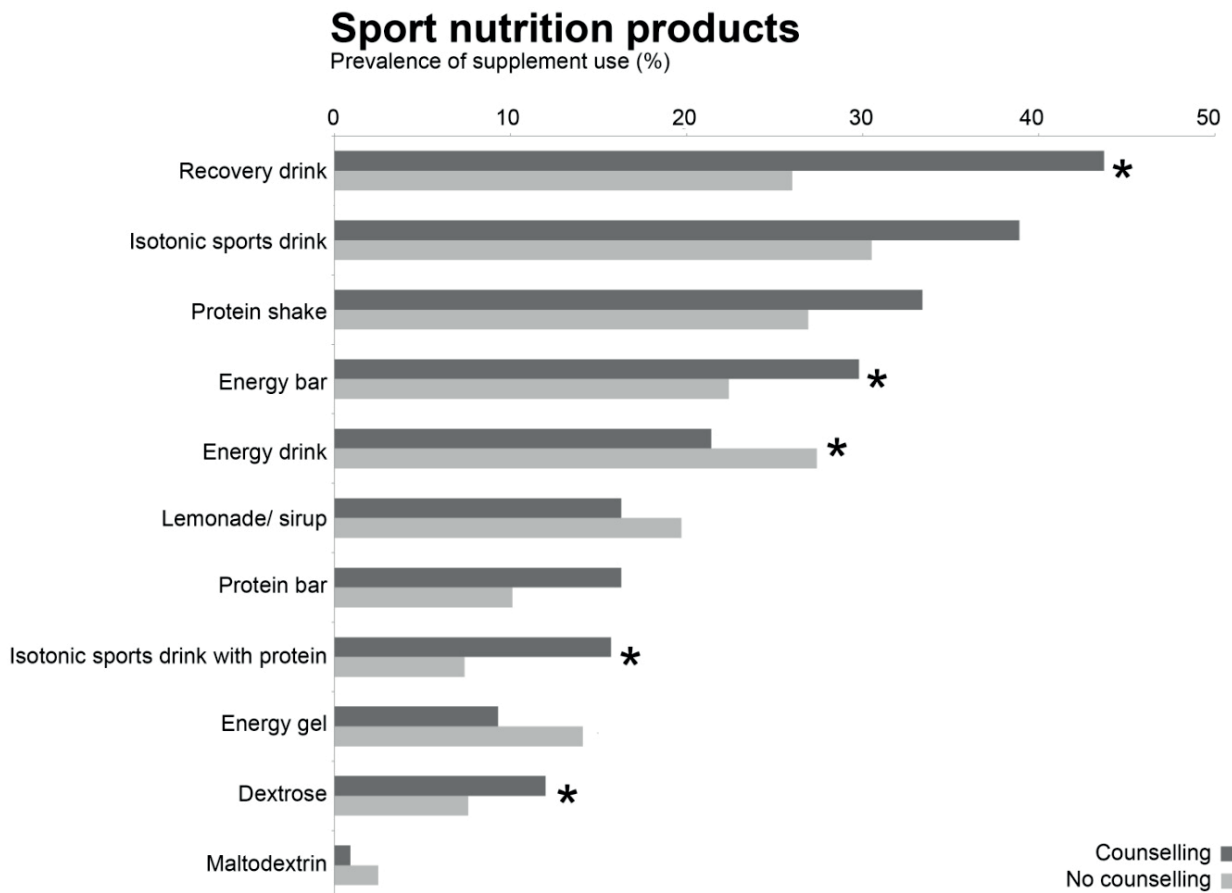

Figure 2. Prevalence of sport nutrition product use during the last 4 weeks and differences between those receiving dietary counselling or not.

* Significant difference based on prevalence ratios based on log binomial regression with counselling as predictor adjusted for elite status, gender, age and weekly exercise duration.

The prevalence of the use of pre-defined ergogenic supplements (ES) in athletes with and without dietary counselling is shown in Figure 3. After adjustment for gender, elite status, age and weekly exercise duration (Table 3 ), dietary counselling was associated with a higher prevalence of the use of beta-alanine (7.2\% vs. 2.7\%; PR 2.66 [95\% Cl: 1.37-5.14]) and sodium bicarbonate (1.8\% vs. $0.0 \%$; PR $6.53 * 10^{7}\left[95 \% \mathrm{Cl}: 2.41 * 10^{7}\right.$ $\left.1.77 * 10^{8} \mathrm{]}\right)$. In contrast, dietary counselling was associated with a lower prevalence of the use of BCAA/ amino acids (10.8\% vs.6.9\%; PR 0.50 [95\% Cl: 0.29-0.87]). 


\section{Ergogenic supplements}

Prevalence of supplement use (\%)

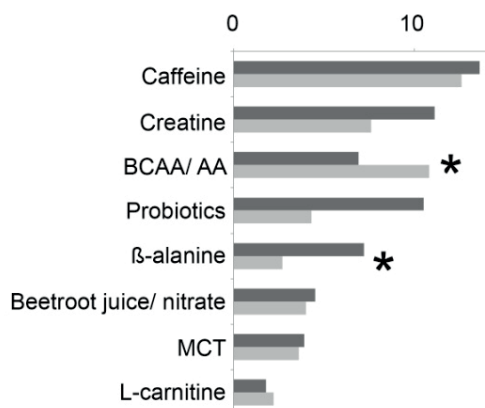

\section{Glucosamine-chondroitine \\ Sodium bicarbonate * \\ Herbs \\ Ribose}

Oil (to improve performance)

CLA I

Counselling No counselling

Figure 3. Prevalence of ergogenic supplement use during the last 4 weeks and differences between those receiving dietary counselling or not.

* Significant difference based on prevalence ratios based on log binomial regression with counselling as predictor adjusted for elite status, gender, age and weekly exercise duration.

BCAA/ AA: branched-chain amino acids/ amino acids; MCT: medium-chain triglycerides; CLA: conjugated linoleic acid.

Table 3. Crude and adjusted prevalence ratios $(95 \% \mathrm{Cl})$ for nutritional supplement use over the last four weeks according to current dietary counselling $(n=778)$.

\begin{tabular}{lll}
\hline & Crude PR & Adjusted PR \\
\hline Dietary supplements & & \\
Multivitamin-mineral & $1.11(0.96-1.28)$ & $1.08(0.92-1.26)$ \\
Vitamin D & $1.66(1.26-2.18)^{*}$ & $1.53(1.13-2.08)^{*}$ \\
Vitamin C & $0.90(0.70-1.12)$ & $0.78(0.59-1.03)$ \\
Fish oil/ essential fatty acid & $0.82(0.62-1.08)$ & $0.87(0.64-1.17)$ \\
Magnesium & $0.79(0.56-1.11)$ & $0.69(0.47-1.02)$ \\
Combivitamin & $0.66(0.46-0.97)^{*}$ & $0.61(0.39-0.94)^{*}$ \\
Iron & $0.90(0.61-1.33)$ & $0.76(0.49-1.17)$ \\
Combimineral & $0.66(0.42-1.04)$ & $0.65(0.39-1.08)$ \\
Zinc & $0.84(0.53-1.35)$ & $0.67(0.42-1.11)$ \\
Calcium & $0.39(0.20-0.75)^{*}$ & $0.33(0.16-0.66)^{*}$ \\
Vitamin B12 & $1.17(0.64-2.15)$ & $1.05(0.54-2.04)$ \\
B-complex & $0.86(0.46-1.59)$ & $0.66(0.31-1.40)$ \\
Vitamin E & $0.52(0.23-1.17)$ & $0.31(0.13-0.78)^{*}$ \\
Vitamin B6 & $0.95(0.42-2.13)$ & $0.77(0.29-2.04)$ \\
Folic acid & $0.85(0.37-1.97)$ & $0.41(0.15-1.14)$ \\
\hline
\end{tabular}


Chapter 6

\begin{tabular}{|c|c|c|}
\hline & Crude PR & Adjusted $\mathrm{PR}^{+}$ \\
\hline Selenium & $0.57(0.22-1.48)$ & $0.36(0.13-1.01)$ \\
\hline Anti-oxidants & $0.62(0.24-1.62)$ & $0.31(0.09-1.14)$ \\
\hline Vitamin B2 & $0.45(0.14-1.39)$ & $0.29(0.09-0.93)^{*}$ \\
\hline Vitamin B1 & $0.96(0.36-2.54)$ & $0.68(0.24-1.95)$ \\
\hline Chromium & $0.41(0.11-1.50)$ & $0.36(0.13-1.15)$ \\
\hline Retinol & $0.41(0.11-1.50)$ & $0.21(0.05-0.95)^{*}$ \\
\hline ß-carotene & $0.49(0.10-2.52)$ & $0.23(0.03-1.55)$ \\
\hline \multicolumn{3}{|l|}{ Sport nutrition products } \\
\hline Recovery drink & $1.35(1.14-1.60)^{*}$ & $1.35(1.11-1.64)^{*}$ \\
\hline Isotonic sports drink & $1.21(1.01-1.46)^{*}$ & $1.13(0.92-1.39)$ \\
\hline Protein shake & $0.99(0.83-1.21)$ & $1.06(0.85-1.30)$ \\
\hline Energy bar & $1.27(1.01-1.60)^{*}$ & $1.33(1.02-1.75)^{*}$ \\
\hline Energy drink & $0.75(0.58-0.95)^{*}$ & $0.75(0.57-0.98)^{*}$ \\
\hline Lemonade/ sirup & $0.79(0.58-1.06)$ & $0.85(0.59-1.23)$ \\
\hline Protein bar & $1.29(0.91-1.85)$ & $1.19(0.79-1.79)$ \\
\hline Isotonic sports drink with protein & $2.02(1.34-3.03)^{*}$ & $1.78(1.14-2.78)^{*}$ \\
\hline Energy gel & $0.63(0.42-0.94)^{*}$ & $0.76(0.49-1.17)$ \\
\hline Dextrose & $1.51(0.98-2.32)$ & $1.58(1.00-2.49)^{*}$ \\
\hline Maltodextrin & $0.35(0.98-1.24)$ & $0.41(0.07-2.28)$ \\
\hline \multicolumn{3}{|l|}{ Ergogenic supplements } \\
\hline Caffeine & $0.93(0.66-1.30)$ & $1.16(0.79-1.71)$ \\
\hline Creatine & $1.25(0.82-1.91)$ & $1.26(0.82-1.94)$ \\
\hline $\mathrm{BCAA} / \mathrm{AA^{ \S }}$ & $0.52(0.32-0.82)^{*}$ & $0.50(0.29-0.87)^{*}$ \\
\hline Probiotics & $2.12(1.26-3.58)^{*}$ & $1.48(0.79-2.77)$ \\
\hline ß-alanine & $2.30(1.19-4.48)^{*}$ & $2.66(1.37-5.14)^{*}$ \\
\hline Beetroot juice/ nitrate & $0.96(0.50-1.85)$ & $1.41(0.67-2.98)$ \\
\hline $\mathrm{MCT}^{\S}$ & $0.86(0.43-1.73)$ & $0.82(0.41-1.67)$ \\
\hline L-carnitine & $0.69(0.26-1.87)$ & $0.96(0.35-2.61)$ \\
\hline Glucosamine-chondroitine & $0.72(0.24-2.16)$ & $0.80(0.29-2.21)$ \\
\hline Sodium bicarbonate & 1.69E-9 (7.68E-8-3.70E-9)* & $6.53 \mathrm{E}-7(2.41 \mathrm{E}-7-1.77 \mathrm{E}-8)^{*}$ \\
\hline Herbs & $0.58(0.16-2.27)$ & $0.18(0.03-1.25)$ \\
\hline Ribose & $2.56(0.47-13.88)$ & $2.84(0.30-26.63)$ \\
\hline Oil (to improve performance) & $1.59(0.27-9.37)$ & $2.88(0.40-20.87)$ \\
\hline $\mathrm{CLA}^{\S}$ & $0.53(0.05-5.77)$ & $0.64(0.07-6.16)$ \\
\hline
\end{tabular}

Prevalence ratios were calculated based on log binomial regression with counselling as predictor.

* Significant difference based on $\mathrm{P}<0.05$.

${ }^{+}$Adjusted for elite status, gender, age and weekly exercise duration.

${ }^{\S} \mathrm{BCAA} / \mathrm{AA}$ : branched-chain amino acids/ amino acids; MCT: medium-chain triglycerides; CLA: conjugated linoleic acid. 


\section{Elite athletic status and gender}

Regardless of dietary counselling, various significant differences in the prevalence of nutritional supplement use were observed between athletes with and without an elite status. After adjustment for dietary counselling, gender, age and weekly exercise duration, athletes with an elite status reported a higher prevalence of the use of zinc $(11.2 \%$ vs. 5.2\%; PR 2.28 [95\% Cl: 1.36-3.81]), vitamin E (4.1\% vs. 2.9\%; PR 2.44 [95\% Cl: $1.08-$ 5.50]), folic acid (4.3\% vs. 1.3\%; PR 4.74 [95\% Cl: 1.50-14.98]), isotonic sports drinks (39.1\% vs. 28.9\%; PR of 1.33 [95\% Cl: 1.09-1.61]), protein bars (17.0\% vs. 8.3\%; PR 1.54 [95\% Cl: 1.01-2.36]), isotonic sports drink with protein (13.2\% vs. 8.6\%; PR 1.62 [95\% Cl: 1.04-2.53]) and probiotics (10.7\% vs. 3.1\%; PR 2.01 [95\% Cl: 1.01-4.01]). In contrast, a lower prevalence of the use of lemonade/sirup (14.0 vs. 22.7\%; PR of $0.62[95 \% \mathrm{Cl}$ : $0.43-0.89]$ ) and energy gels (8.4 vs. 15.9\%; PR 0.62 [95\% Cl: 0.41-0.93]) was observed in athletes with an elite status.

Besides dietary counselling and elite status, also gender affected the use of several dietary supplements. After adjustment for dietary counselling, elite status, and weekly exercise duration, male athletes reported a lower prevalence of the use of iron supplements compared with female athletes (7.9 vs. 15.1\%; PR 0.55 [95\% Cl: 0.35-0.87]). In, contrast, male athletes reported a higher prevalence of the use of vitamin B-complex (6.4\% vs. 3.5\%; PR 2.25 [95\% Cl: 1.04-4.88]), recovery drinks (36.1\% vs. 30.7\%; PR 1.27 [95\% Cl: 1.07-1.51]), energy bars (27.8\% vs. 23.2\%; PR 1.33 [95\% Cl: 1.03-1.73]), energy drinks (29.2\% vs. 19.9\%; PR 1.43 [95\% Cl: 1.10-1.86]), energy gels (15.2\% vs. 8.6\%; PR 1.58 [95\% Cl: 1.02-2.43]), isotonic drinks with protein (13.0\% vs. 8.6\%; PR 2.01 [95\% Cl: 1.29-3.12]) and caffeine (16.7\% vs. 8.9\%; PR 1.77 [95\% Cl: 1.18-2.64]).

\section{Discussion}

The vast majority of the competitive athletes involved in the present study reported current or at least previous use of nutritional supplements. The top ranked dietary supplements, sport nutrition products and ergogenic supplements consisted of multivitamin and mineral preparations, isotonic sports drinks and caffeine, respectively. Interestingly, athletes receiving dietary counselling reported a higher use of vitamin $D$, recovery drinks, isotonic sports drinks, isotonic sports drinks with protein, energy bars, probiotics, beta-alanine and sodium bicarbonate. Conversely, athletes not receiving dietary counselling reported a higher use of combined vitamin preparations, calcium, energy drinks, energy gels and BCAA/ other amino acids. Besides dietary counselling, use of nutritional supplements also appeared to be affected by having an elite status and gender. 


\section{Prevalence}

The overall prevalence of nutritional supplement use observed in the current study was higher than in most, ${ }^{3,18,21}$ but not all ${ }^{6,18}$ previous studies.

The average total number of supplements reported by the athletes in our study also appeared to be higher compared with most previous findings. For example, a study in Canadian athletes reported $3.1 \pm 1.9$ supplements per athlete, ${ }^{17}$ compared with $4.7 \pm$ 4.6 supplements in the current study. The relatively high prevalence of nutritional supplement use might be explained by the growing interest in nutrition and the increased availability of nutritional supplements. This is also reflected by the increase in nutritional supplement use in the general population both in Europe and the US. ${ }^{8,9,24}$ Furthermore, new nutritional supplements are continuously becoming available. ${ }^{12,}{ }^{25}$ For example, this is the first study that reports the prevalence of the use of the 'new' supplement beetroot juice/ nitrate amongst competitive athletes (Table 2). Another explanation for the high prevalence of nutritional supplement use in the current study might be the high number of athletes included that compete on an international level. ${ }^{17}$

In line with our hypothesis, we observed a different pattern of nutritional supplement use in athletes receiving dietary counselling compared with athletes not receiving dietary counselling. It is interesting to note that many nutritional supplements which could be listed as useful or enhancing performance, ${ }^{26}$ were more frequently used by athletes receiving dietary counselling. Such nutritional supplements include vitamin D (classified as dietary supplement), recovery drinks, energy bars, protein bars, isotonic drinks with protein and dextrose (classified as sport nutrition products) and beta-alanine and sodium bicarbonate (classified as ergogenic supplements). Vitamin D, for example, has recently regained interest in the sports community, ${ }^{27}$ as many athletes appear to be vitamin $D$ deficient. ${ }^{28}$ Other examples are the use of sodium bicarbonate and beta-alanine, which are backed by recent meta-analyses. ${ }^{29,} 30$ Some nutritional supplements were less frequently reported by athletes receiving dietary counselling, including some individual vitamins and minerals that are less likely associated with nutritional deficiencies, and health or performance benefits, such as retinol, vitamin B2, and calcium.

\section{Dietary counselling}

The group of athletes receiving dietary counselling was characterized by a higher proportion of athletes holding an elite status (69\% vs. 23\%) and a higher weekly exercise duration compared with athletes not receiving dietary counselling. After adjustment for dietary counselling, age, and weekly exercise duration, holding an elite status was associated with a higher prevalence of the use of 7 nutritional supplements (zinc, vitamin E, folic acid, isotonic sports drinks with and without additional protein, protein bars and probiotics). The higher use of zinc and probiotics by athletes with an elite status can explained by the fact that both supplements are advocated by the medical teams of Dutch elite 
athletes as part of the infection prevention program. Isotonic sport drinks are free of charge for Dutch athletes with an elite status, which might explain the higher use in elite status holders. In our opinion it is less likely that training intensity, duration or volume affect the use of nutritional supplements by elite status holders, as the athletes without a formal NOC*NSF elite status were still competing at the highest national or international level. Therefore, it can be speculated that the organization of the athletes' team staff, and financial and sponsor resources, rather than training characteristics affects the use of nutritional supplements by elite status holders. Besides dietary counselling and elite status, a small number of gender differences were found in the present study. The higher prevalence of iron supplement use in women is not surprising when considering the higher iron requirements of females. ${ }^{31}$ We observed higher prevalences of the use of recovery drink, energy drink and energy gel in male athletes compared with women, which might be explained by the higher energy requirements in males.

A strength of the current study is the large sample size and the variety of sport disciplines included in our study. Supplements were reported over two different time frames (last 4 weeks and at any time during sports career). Despite the fact that many nutritional supplements are used in a periodised way throughout the year we included questionnaires during the whole year therefore reflecting the whole year cycle.

As reporting the use of nutritional supplements over the last 4 weeks may misestimate the true prevalence of supplement use, we recommend that future questionnaires should also include a longer time frame, e.g. of one year, to better cover longterm nutritional supplement cycles. As athletes could only report the use of pre-defined nutritional supplements, the true prevalence of nutritional supplements might have been underestimated. Particularly the popularity of ergogenic supplements is changing quickly, and new ergogenic supplements are frequently introduced. Nevertheless, the pre-defined list of nutritional supplements was carefully developed and based on the input of athletes and nutritional experts working with athletes. As such, it can be argued that most relevant nutritional supplements used by Dutch athletes were present.

In conclusion, our study confirms widespread use of nutritional supplements by Dutch competitive athletes, but also underlines that dietary counselling plays a role in the choice of nutritional supplements. More specifically, athletes receiving dietary counselling seem to make better choices regarding nutritional supplement use compared to athletes that do not receive dietary counselling.

\section{Acknowledgments}

We would like to acknowledge all who participated in this part of the Dutch Sport Nutrition and Supplement Study (DSSS). We would also like to thank the students from various universities who helped with this study as part of their internship or their bachelor's or master's thesis. 
Chapter 6

Supplementary Table 1. Total nutritional supplement prevalence and use per category of supplements as \% of the total number of athletes over the last 4 weeks.

\begin{tabular}{|c|c|c|c|c|c|c|c|c|c|c|c|}
\hline & \multicolumn{3}{|c|}{ Total prevalence } & \multicolumn{8}{|c|}{ Use per category or for combined categories } \\
\hline & DS & SNP & ES & No use & Only DS & Only SNP & Only ES & $\begin{array}{c}\text { DS } \\
\text { and SNP }\end{array}$ & $\begin{array}{c}\text { DS } \\
\text { and ES }\end{array}$ & $\begin{array}{c}\text { SNP } \\
\text { and ES }\end{array}$ & $\begin{array}{l}\text { DS, SNP } \\
\text { and ES }\end{array}$ \\
\hline $\mathrm{n}$ & 458 & 574 & 246 & 119 & 65 & 163 & 5 & 185 & 15 & 33 & 193 \\
\hline$\%$ & 58.9 & 73.8 & 31.6 & 15.3 & 8.4 & 21.0 & 0.6 & 23.8 & 1.9 & 4.2 & 24.8 \\
\hline
\end{tabular}

$\mathrm{n}=$ number of respondents, \%= percentage based on total group of 778 respondents.

$\mathrm{DS}=$ dietary supplements, $\mathrm{SNP}=$ sport nutrition products, $\mathrm{ES}=$ ergogenic supplements. 


\section{References}

1 de Silva A, Samarasinghe Y, Senanayake D, Lanerolle P. Dietary supplement intake in national-level Sri Lankan athletes. Int J Sport Nutr Exerc Metab. 2010; 20: 15-20.

2 Evans MWJ, Ndetan $\mathrm{H}$, Perko M, Williams R, Walker $\mathrm{C}$. Dietary supplement use by children and adolescents in the United States to enhance sport performance: results of the National Health Interview Survey. J Prim Prev. 2012; 33: 3-12.

3 Giannopoulou I, Noutsos K, Apostolidis N, Bayios I, Nassis GP. Performance level affects the dietary supplement intake of both individual and team sports athletes. J Sports Sci Med. 2013; 12: 190-6.

4 Heikkinen A, Alaranta A, Helenius I, Vasankari T. Dietary supplementation habits and perceptions of supplement use among elite Finnish athletes. Int J Sport Nutr Exerc Metab. 2011; 21: 271-9.

5 Tavani A, Colombo, P., Scarpino, V. Zuccaro, P., Pacifici, R., \& La Vecchia, C. A survey of dietary supplement use among Italian sporting club athletes. Nutrafoods. 2014; 13: 29-34.

6 Wiens K, Erdman KA, Stadnyk M, Parnell JA. Dietary supplement usage, motivation, and education in young, Canadian athletes. Int J Sport Nutr Exerc Metab. 2014; 24: 613-22.

7 Burke LM, Castell LM, Stear SJ. BJSM reviews: A-Z of supplements: dietary supplements, sports nutrition foods and ergogenic aids for health and performance Part 1. Br J Sports Med. 2009; 43: 728-9.

8 Gahche J, Bailey R, Burt V, et al. Dietary supplement use among U.S. adults has increased since NHANES III (1988-1994). NCHS Data Brief. 2011: 1-8.

9 Kim HJ, Giovannucci E, Rosner B, Willett WC, Cho E. Longitudinal and secular trends in dietary supplement use: Nurses' Health Study and Health Professionals Follow-Up Study, 1986-2006. J Acad Nutr Diet. 2014; 114: 436-43.

10 Wardenaar FC, Van den Dool, R., Ceelen, I.J.M., Witkamp, R., Mensink, M. Self-reported use and reasons for using sports nutrition products and dietary supplements among the general population - a crosssectional explorative study in the Netherlands. Sports. 2016; 4: 11.

11 Maughan RJ, Depiesse F, Geyer H, International Association of Athletics F. The use of dietary supplements by athletes. J Sports Sci. 2007; 25 Suppl 1: S103-13.

12 Maughan RJ, Greenhaff PL, Hespel P. Dietary supplements for athletes: emerging trends and recurring themes. J Sports Sci. 2011; 29 Suppl 1: S57-66.

13 Burns RD, Schiller MR, Merrick MA, Wolf KN. Intercollegiate student athlete use of nutritional supplements and the role of athletic trainers and dietitians in nutrition counselling. J Am Diet Assoc. 2004; 104: 246-9.

14 Jacobson BH, Sobonya C, Ransone J. Nutrition practices and knowledge of college varsity athletes: a follow-up. J Strength Cond Res. 2001; 15: 63-8.

15 Valliant MW, Emplaincourt HP, Wenzel RK, Garner BH. Nutrition education by a registered dietitian improves dietary intake and nutrition knowledge of a NCAA female volleyball team. Nutrients. 2012; 4: 506-16.

16 Anderson DE. The impact of feedback on dietary intake and body composition of college women volleyball players over a competitive season. J Strength Cond Res. 2010; 24: 2220-6.

17 Erdman KA, Fung TS, Reimer RA. Influence of performance level on dietary supplementation in elite Canadian athletes. Med Sci Sports Exerc. 2006; 38: 349-56.

18 Knapik JJ, Steelman RA, Hoedebecke SS, Austin KG, Farina EK, Lieberman HR. Prevalence of Dietary Supplement Use by Athletes: Systematic Review and Meta-Analysis. Sports Med. 2015.

19 van Erp-Baart AM, Saris WH, Binkhorst RA, Vos JA, Elvers JW. Nationwide survey on nutritional habits in elite athletes. Part I. Energy, carbohydrate, protein, and fat intake. Int J Sports Med. 1989; 10 Suppl 1: S310.

20 van Erp-Baart AM, Saris WM, Binkhorst RA, Vos JA, Elvers JW. Nationwide survey on nutritional habits in elite athletes. Part II. Mineral and vitamin intake. Int J Sports Med. 1989; 10 Suppl 1: S11-6.

21 Braun H, Koehler K, Geyer H, Kleiner J, Mester J, Schanzer W. Dietary supplement use among elite young German athletes. Int J Sport Nutr Exerc Metab. 2009; 19: 97-109. 


\section{Chapter 6}

22 Kristiansen M, Levy-Milne R, Barr S, Flint A. Dietary supplement use by varsity athletes at a Canadian university. Int J Sport Nutr Exerc Metab. 2005; 15: 195-210.

23 Huang SH, Johnson K, Pipe AL. The use of dietary supplements and medications by Canadian athletes at the Atlanta and Sydney Olympic Games. Clin J Sport Med. 2006; 16: 27-33.

24 Skeie G, Braaten T, Hjartaker A, et al. Use of dietary supplements in the European Prospective Investigation into Cancer and Nutrition calibration study. Eur J Clin Nutr. 2009; 63 Suppl 4: S226-38.

25 Larson-Meyer E. Vitamin D supplementation in athletes. Nestle Nutr Inst Workshop Ser. 2013; 75: 10921.

26 Castell LM, Stear SJ, Burke L. Nutritional supplements in sport, exercise and health : an A-Z guide2015.

27 Larson-Meyer DE, Willis KS. Vitamin D and athletes. Curr Sports Med Rep. 2010; 9: 220-6.

28 Farrokhyar F, Tabasinejad R, Dao D, et al. Prevalence of vitamin D inadequacy in athletes: a systematicreview and meta-analysis. Sports Med. 2015; 45: 365-78.

29 Carr AJ, Hopkins WG, Gore CJ. Effects of acute alkalosis and acidosis on performance: a meta-analysis. Sports Med. 2011; 41: 801-14.

30 Bellinger PM, Minahan CL. The effect of beta-alanine supplementation on cycling time trials of different length. Eur J Sport Sci. 2015: 1-8.

31 Nordic Council of Ministers. Nordic Nutrition Recommendations 2012: Integrating nutrition and physical activity. 2012. 



\section{General discussion}


The research presented in this thesis focussed on the intake of nutrients, via diet, dietary supplements and sport nutrition products, of (sub-)elite athletes in the Netherlands. It is centred around the Dutch Sport Nutrition and Supplement Study (DSSS), which provided the core of the data on energy, macronutrient, and micronutrient intake in a group of 553 athletes performing in the highest level categories. These findings were further elaborated in view of the intake by specific sub-groups and existing guidelines and developments in the field. Attention was also paid to specific methodological challenges. This final chapter starts with an overview of the main outcomes, followed by a section on methodological considerations. Next, the intake data are further discussed in terms of existing recommendations. Finally, directions for further research and practical applications are described.

\subsection{General outcomes}

The results presented in this thesis add to our present knowledge by providing a most up-to-date insight in the dietary habits and nutrient intake levels of a diverse and relatively large group of well-trained athletes practicing sports at the highest competitive levels. Quite remarkably, recent surveys of a comparable size are scarce in the literature, and for example the last nationwide study in the Netherlands dates back more than 25 years. Since then training methods have changed considerably, various dietary supplements and sport nutrition products have been introduced, and nutrition has become a prominent element in the athlete's lifestyle. Our survey also adds to preceding studies by the application of validated web-based methods for dietary assessment. In addition to focusing on nutrient intake itself, the thesis addresses a number of practical issues that are characteristic of this population and some general methodological challenges in dietary assessment research. Finally, the use of dietary supplements and sport nutrition products, not only by athletes but also by the general population, was investigated.

\section{A description of the most important results per chapter follows:}

Chapter 2 commences with a comparison of combined-, multiple-, 24-hour recalls and questionnaires, with measurements of 24-hour urine nitrogen excretions. Our main conclusion is that 24-hour recalls and accompanying questionnaires underestimated protein intake in young elite athletes to the same extent as reported for non-athlete populations. The method proved to be suitable for ranking athletes according to their protein intake as needed in epidemiological studies. On an individual level, the magnitude of underestimation was approximately equal for all athletes except for those with a very high protein intake. From these findings we concluded that 24-hour recalls plus 
accompanying questionnaires are useful to estimate dietary intake at a group level and for ranking athletes according to their protein intake.

Chapter $3 a$ and chapter $3 b$ describe the results of the initial part of the Dutch Sport Nutrition and Supplement Study (DSSS) which was based on two key questions: The first question is whether there are differences in nutritional intake between categories of athletes (endurance, strength and team sports) and the second question is whether athletes who are using or not using nutritional supplements are at potential risk of too high or too low intakes of micronutrients?

Small differences in energy and macronutrient intakes were found between athletes from different disciplines, with endurance athletes mainly consuming higher amounts of energy and macronutrients. It was found that on average athletes were able to meet the estimated average requirement (EAR) for carbohydrate and protein as defined for the Dutch general population.

Most of the athletes met protein, but not carbohydrate, sports nutrition recommendations as currently in use. No substantial differences in carbohydrate and protein intake were seen between sports categories. Athletes in our study population were found to be at risk of a suboptimal intake of vitamin D, vitamins B1, B2 and vitamin A. Non-users were also at risk for low intakes of vitamin B3, vitamin C and selenium. At the same time users of supplements were not likely to exceed the upper level (UL) of certain micronutrients, except for vitamin B3.

Chapter 4 describes the nutritional intake of runners in preparation for an ultramarathon, and their nutritional intake during a competition day. Sports nutrition recommendations were in general not achieved by their habitual diets. In men and women, habitual mean carbohydrate $(\mathrm{CHO})$ intake was lower than recommended by most guidelines, the same being true for mean protein intake by women. $\mathrm{CHO}$ intake during the race was $<60 \mathrm{~g} / \mathrm{h}$ in $75 \%$ of the athletes. A large variation in nutrient and fluid intake was seen, which may be related to a high incidence of $\mathrm{Gl}$ distress during the race: $82 \%$ of the runners reported GI complaints, although the incidence of severe Gl distress was low.

Chapter 5 presents an overview of the use of dietary supplements and sport nutrition products in the general population, obtained from a web-based questionnaire as part of the Dutch National Sport Study (NSO). The study distinguished between the use of dietary supplements and that of sport nutrition products. It showed a two-third prevalence of athletes using these products combined. In conjunction with improving health, improvement of physical performance appeared to be an important objective, even amongst individuals who are not very physically active, and it can be questioned whether the use of these energy-containing sport nutrition products fits all respondents' physical activity needs.

Finally, chapter 6 further analyses the results of the general questionnaire on supplement use as part of the DSSS. It was shown that almost all athletes (97\%) taking part in our survey had used nutritional supplements at some time during their athletic ca- 
reers. When current use in the last 4 weeks was related to the question whether athletes were receiving dietary counselling or not, those receiving counselling reported better informed choices with respect to their nutritional supplement use. This was in line with available data in the literature.

\subsection{Methodological considerations}

Considering our relatively large total sample size, the diversity of sports disciplines covered and the fact that we validated our methods in a subsample of the same population $^{1}$, we believe having obtained a representative overall insight in the dietary habits and nutrient intake levels of competitive (Dutch) athletes. In our assessment we applied a probability approach and/or cut-off approach to estimate the prevalence of intake below EAR, ${ }^{2}$ which are the preferred assessment techniques at group level as proposed in the literature. An important finding was that the nutritional intake of many welltrained competitive athletes is not always in line with both general recommendations (micronutrients) or with sports nutrition recommendations (carbohydrates). In view of this, the question arises as to what extent this might affect performance and (or) general health of these athletes.

\section{Dietary assessment}

The method used in the present study was found to underestimate dietary intake to a similar extent as seen in other populations. As shown in our validation study (chapter 2) it is fairly accurate for ranking individuals. As part of dietary counselling, food records are generally used to describe individual athletes' nutritional intake. ${ }^{3}$ When web-based 24-hour recalls are becoming available these could be of additional value to the existing portfolio.

In addition to the studies described in the thesis we also conducted a small pilot study in which we examined whether a comparison could be made between our 24 hour recall plus accompanying questionnaire method, and the method used by a previous survey which collected 3 day food records of Dutch athletes in preparation for the 2004 Olympic Games in Sydney. ${ }^{4}$ To this end we compared 24-hour recall data with randomly conducted, but day to day matched, 3-day food records within a sub-sample of rowers, speed skaters and soccer players from the present Dutch Sport Nutrition and Supplement Study (9 men and 26 women). This provided us with some information about the comparability between currently and previously collected data using different methods within a sample of well-trained competitive athletes. The methods generated similar results, with a difference in energy intake of $-0.8 \%(95 \% \mathrm{Cl}:-7.7-6.2 \%)$ and in protein intake of $+1.1 \%(95 \% \mathrm{Cl}:-8.6-10.8 \%)$ in the 3-day food records compared to 24-hour recalls. The data revealed a good correlation between both methods for re- 
ported energy intake $(r=0.69)$ and protein intake $(r=0.55)$, respectively. As such, we found good agreement between 24-hour recalls and 3-day records to assess mean group intake and to rank individuals according to their intake. Thus, results from 24hour recalls and 3-day food records may be comparable although both methods may not be perfect and probably have similar systematic errors.

\section{Variability of dietary intake}

Within- and between person variation can be seen as indicators of consistency in the dietary pattern at population level and not much is known about the variation of the athletes' diet. Not described in the preceding chapters, we calculated the variation within and between subjects $\left(\mathrm{CV}_{\mathrm{w}}\right.$ and $\left.\mathrm{CV}_{\mathrm{b}}\right)$ for energy, macronutrients, fluid and dietary fibre intake within the group of 553 athletes analysed in chapters $3 a$ and $3 \mathrm{~b}$. In men, $\mathrm{CV}_{\mathrm{b}}$ was comparable for carbohydrates between disciplines in a range of 0.23 0.27 , with a slightly higher value in endurance athletes $(0.25)$ than in team sports $(0.20)$ and strength athletes (0.19). The $\mathrm{CV}_{\mathrm{w}}$ was more or less comparable for all disciplines for both carbohydrates and proteins within a range of 0.25-0.29 and 0.28-0.32, respectively. In women we calculated $\mathrm{CV}_{\mathrm{b}}$ for endurance (0.24), team sports (0.22) and strength sports (0.32). The $\mathrm{CV}_{\mathrm{b}}$ for protein was also comparable in endurance athletes $(0.20)$ and team sports athletes (0.17), but strength athletes reported a much higher $\mathrm{CV}_{\mathrm{b}}(0.32)$. The $\mathrm{CV}_{\mathrm{w}}$ was comparable for all disciplines for carbohydrate (0.28-0.30), but not for protein with a range of 0.23 in strength athletes up to 0.32 in team sports athletes. Braakhuis et al. (2003) ${ }^{5}$ reported $\mathrm{CV}_{\mathrm{w}}$ in athletes for energy and nutrients that were similar to our results. Data was also comparable to a Dutch validation study in 63 men and 59 women from the non-athlete population between 20 and 70 years of age. The comparable $\mathrm{CV}_{\mathrm{w}}$ values suggests a consistent dietary pattern. This is somewhat unexpected in view of the differences in training days and variation in recommendations matching these differences in types of training. Therefore, the question can be raised whether the differentiation in recommendations per sport category still reflects reality in today's elite athletes, who are often engaged in concurrent mixed training programs and perform multiple training sessions each day.

\section{Actual intake versus usual intake}

A method that includes at least two days of self reports in the analysis usually provides a good estimation of actual dietary intake. This can be useful for specific nutrients, for example in case of evaluating carbohydrate intake versus actual needs based on training load. On the other hand, when dietary intake is measured to investigate usual intake in relation to meeting requirements, statistical models should be applied to better take the variation in intake into account. Therefore, we used the ISU method, as proposed by Nusser et al $(1996)^{6}$, and corrected the distribution, especially for within person varia- 
tion, which made it possible to get a good estimate of the mean and distribution of usual intake. Although these types of methods are known for years in the field of nutritional epidemiology, their application in studies reporting nutrient intakes of athletes is, to our best knowledge, scarce.

To investigate nutritional supplement use and intake, different methods were applied. As part of our dietary intake survey (chapter $3 a$ and $3 b$ ) the selected recall days were random, covering a representative type and number of days during the period of data collection. Therefore we can assume that our estimation of the use of nutritional supplements based on multiple 24-hour recalls and questionnaires should closely represents the current daily intake. The other studies mainly investigated the usual prevalence of nutritional supplements (chapter 5 and 6 ). The reporting of both groups, using different methods is showing a large overlap. Still, as we were not able to compare both methods with an independent standard, we can only speculate about their accuracy. The fact that the total groups of athletes included in both studies were too different made it difficult to compare results in this light. In future research and in daily practice both methods should be combined providing a complementary perspective on nutritional supplement use. This enables sport dieticians to get insight in both actual as usual or even periodised nutritional supplement use.

\subsection{Dietary intake}

Our studies were performed to obtain insight in nutrient intake of different groups of athletes and to evaluate actual or usual intake against the most relevant recommendations. Intake of protein and most micronutrients was found to be in line with guidelines, but in general carbohydrate intake was at its best at the lower end of the available sport nutrition recommendations. Besides, intakes of some micronutrients were low, which was particular the case with some vitamins. This paragraph discusses the apparent discrepancy between carbohydrate intake and the available recommendations. It elaborates on the shortcomings of this study by not measuring blood- or urine values to assess micronutrient status and it discusses the positive role dietary counseling could have in making good (dietary) choices.

\section{Carbohydrate intake levels}

Guidelines for carbohydrates, providing direct energy during exercise, are designed to optimize performance during training and in competition. Furthermore, carbohydrate intake is recommended to restore glycogen stores after exercise. Mean carbohydrate intake in $98 \%$ of the athletes involved in the present study was found to be between 1.9 and $8.4 \mathrm{~g}$ of carbohydrate per $\mathrm{kg} / \mathrm{bw}$. However, as shown in this thesis, intake levels of the athletes were mainly below $5 \mathrm{~g} / \mathrm{kg} / \mathrm{bw}$, which is generally considered a moderate 
intake level. The ACSM proposes a range for carbohydrate intake of 6-10 g/ kg/bw, while the ISSN and IOC suggest a range from 3-5 g/ $\mathrm{kg} / \mathrm{bw}$ per day, up to $12 \mathrm{~g}$ of carbohydrate per $\mathrm{kg} / \mathrm{bw}$ per day. ${ }^{7}$ The reasoning underlying these recommendations differs between institutions. The ISSN states that the lower recommendation can be applied to those generally physically active for 30-60 minutes per day up to 3-4 times a week. The IOC only says that this range is applicable to those performing at low-intensity or during skill-based activities. ${ }^{7}$ This is in contrast to the athletes included in the present study who trained at least 9 hours a week, performing at the highest level in their discipline. Consequently, their training intensity and total work load appears to be higher than referred to by these ISSN and IOC recommendations. From that perspective it would have been expected that the athletes from our study would have consumed higher amounts of carbohydrates than mentioned in these ISSN and IOC recommendations. Although there are no indications that the athletes involved experienced any limitations in their performance that could be ascribed to an energy deficit, the question could be raised whether higher carbohydrate intake levels would have been more effective and led to a further increase in performance of these athletes. In other words; are these values optimal and do the guidelines fit the real needs of athletes?

This apparent discrepancy is fuelled by discussions that the recommendation for high carbohydrate intake levels is based on findings from only a small number of longitudinal studies. However, these studies did show clear and consistent benefits in terms of training adaptations and performance, at carbohydrate intake levels as high as those currently advised by the recommendations. ${ }^{8,9}$ Needless to say these types of studies are practically difficult to perform, and it may be questioned whether the protocols used to measure performance were always suitable for detecting small but relevant improvements. $^{10}$

By contrast, other studies suggest that athletes can adapt to lower muscle glycogen stores resulting from a more moderate carbohydrate intake such that it does not impair training or competition outcomes. ${ }^{11}$ It is also of interest to note that low carbohydrate high fat diets (LCHF) are receiving increasing attention in recent years, both outside and inside the field of sports nutrition. Although the evidence appears to be largely anecdotal thus far, it has been suggested that there may be a few scenarios where low carbohydrate diets can be of benefit, or at least are not detrimental, for sports performance or trainability. ${ }^{12}$ Notwithstanding the development of this discussion, it shows that there is a need for better recognition of current sports nutrition guidelines that promote an individualized and periodised approach to fuel availability during training and competition, resulting in optimal utilization of all muscle substrates. Because of the considerable inter-individual differences there is presently insufficient rationale for truly personalized nutrition for the majority of people. Therefore it was proposed that precision nutrition, based on the individual genetic, environmental and (or) behavioural variance ('lifestyle' ) within each person may provide a more effective basis for adjusting 
diet dynamically, with recognition of varying physiological demands and requirements over time. ${ }^{13}$

Taken together it seems that the evidence supporting the viewpoint that high carbohydrate diets are superior to a moderate carbohydrate intake in improving performance and training adaptations is scientifically sufficiently substantiated. ${ }^{11}$ On the other hand, a large variation may still exist in the athletes' personal carbohydrate needs and dietary intake. As a consequence it is conceivable that the debate on carbohydrate requirements by athletes will continue in the near future. These discussions are further fuelled by reports, be it anecdotal or based on scientific studies, suggesting positive effects of ketones, and by different viewpoints including low $\mathrm{CHO}$ training and high fat diets.

\section{Micronutrients intake levels}

A large number of individual athletes probably do not meet their micronutrient requirements with their basal diet. Most critical nutrients for all athletes were vitamin $D$, vitamin A, vitamin B1 and B2, and iron for women. This in turn leads to the question whether these low intakes might have negative physiological effects and (or) impact the general health and performance of these athletes. Considering the large number of athletes showing intakes below the $A R$, the development of certain deficiencies over time might be possible.

As with performance, general health is of great importance to athletes, and also depending on adequate nutrition. As general nutrition recommendations are based on estimates for the total population, ${ }^{14,15}$ which includes those who are very active, these could also be applied to athletes, at least as a starting point. It is important to realize that recommendations are formulated based on expert consensus and founded on the best available evidence at that moment. ${ }^{14,15}$ Furthermore, the proposed recommended dietary allowance (RDA) should result in a nutrient intake that is sufficient for $98 \%$ of the population. Therefore, it is possible that some athletes may still have higher needs than these recommended levels. However, such specific requirements are difficult to estimate a priori and should ideally be obtained by professional supervision and monitoring, taking into account a combination of health status, dietary assessment, blood and urine measurements, and performance indicators. ${ }^{3}$ Despite these considerations, we still detected a considerable number of athletes with micronutrient intake levels below the estimated average requirement (AR) that should be sufficient for $50 \%$ of the general population. As the risk of a too high intake of specific nutrients was found to be comparable to that of the general Dutch population, ${ }^{16}$ no negative effects are likely to occur if athletes were to include a low-dosed multivitamin to compensate for this. 


\section{Dietary counselling}

Taken together, our findings suggest that the dietary intake of Dutch top-athletes is suboptimal in some respects. Remarkably, a large proportion of the athletes included were already receiving some sort of dietary counselling ( $50 \%)$. Previous research has suggested that athletes have a largely positive attitude towards nutrition, but at the same time possess only limited knowledge on the subject. ${ }^{17,}{ }^{18}$ This emphasizes the importance of involving a professional sports dietician. ${ }^{18}$ Some reports have proposed that general dietary counselling and monitoring would be sufficient for most athletes. ${ }^{19}$ However, nutritional knowledge, beliefs and practices are extremely diverse in the field of sports. Within any sports organisation the dietician or nutritionist must be able to work with athletes, their families, coaches and other support staff to develop and monitor realistic and practical strategies that work best for each individual and contribute to a positive and sustained performance result. ${ }^{20}$ As described in chapter 6, self-reported use of nutritional supplements by athletes was found to be associated with receiving dietary counselling, but this is only a part of the picture. It has previously been described that athletes' nutritional knowledge and dietary practices may benefit from appropriate nutritional education. ${ }^{17,21}$ Also, this nutritional guidance, as in individual counselling by an appropriately qualified professional, ${ }^{22}$ can be effective in the long term, for example in case of weight gain in athletes. ${ }^{23}$ It can be debated whether the mainly young athletes in our study possessed enough knowledge and experience from to make proper food choices. Interestingly, the findings of Bettonviel et al. (2015) describing macronutrient distribution in a subsample of the soccer players that were part of the present study, showed, for example, relatively high carbohydrate intake in youth players, but not in professional players. ${ }^{24}$ On a population level, improvement of dietary quality is needed, which starts with the athlete making good food choices. Guiding the athlete in selecting the best products and differentiating energy and macronutrient intake in relation to training and competition should be considered a task for sports dieticians and specialised nutritionists.

\subsection{General conclusions and directions for further research}

The most important conclusions of this thesis can be summarized as follows:

- Protein intake by Dutch elite- and sub-elite athletes is in line with currently available sports nutrition recommendations.

- For carbohydrates, average intake levels appear to be lower than most guidelines recommend. This finding merits further research in order to answer the questions whether this situation is sub-optimal in terms of performance and recovery, or that the guidelines might need to be adapted to the practical situation. 
- Only small differences were seen in macronutrient intake between groups of endurance, team and strength athletes. In general, endurance athletes consumed higher amounts of energy and macronutrients than athletes from other categories, but not always.

- Intake via the basal diet of vitamin D, vitamin A, B1 and B2 in men and women, and for iron in women was found to be sub-optimal when compared with the estimated average requirements (AR).

- The use of dietary supplements, but not sport nutrition products, adds to dietary intake, but not all athletes consume these types of products. Furthermore, day to day compliance by supplement users is low.

- Dutch elite and sub-elite athletes consume higher amounts of nutritional supplements than seen in the Dutch general population. In case of the latter group it can be questioned whether there would be any need at all to use these products considering the personal goals of the individuals An example is the use of energy drinks by a substantial group of respondents with a sedentary lifestyle.

- Dietary counselling influences the selection of nutritional supplements, resulting in more considered choices by those athletes receiving dietary counselling.

At the same time, our studies leave us with a number of questions that merit further research. Initially, the comparability between methods used for dietary assessment in athletes needs additional investigation. Little information exists regarding the comparability between the results of multiple 24-hour recalls and other methods used when studying athletes. ${ }^{25-28}$ To the best of our knowledge only one study compared a webbased program to a face-to-face 24 -hour recall in athletes. ${ }^{29}$ Therefore, methods should be validated in athletes. This would make it easier to compare study results with each other. In addition, it will also enable sport dieticians to select the best available method to assess the athletes' diet.

In the studies described in this thesis, energy expenditure as part of dietary assessment in athletes was not integrated. Nevertheless, it would be very useful to gain more insight into total energy expenditure and to evaluate the amount of energy underreported for the specific dietary assessment method used in this more than active population. ${ }^{30,31}$ In view of the time the athletes already needed to report current data, we chose not to collect additional data about exercise. Although we collected information on training type, frequency, self-reported exercise time in minutes per day and a self-reported appreciation of the burden, all this gave us only an indirect and rough estimation of energy expenditure. A combination of doubly labelled water and/ or accelerometers with dietary intake could be considered for future research in this group of athletes.

Ideally, optimisation of micronutrient status would be supported by measuring blood or urinary concentrations. However, this development is still in its infancy with mainly iron (i.e. measured as haemoglobin, ferritin and/or transferrin) and vitamin $D$ 
levels being monitored in athletes frequently. A complicating factor is that there is often limited insight in the relationship between a blood (or serum, plasma) level at a particular point in time and its overall body status, as was for example recently shown for magnesium by Terink et al. (submitted).

Until now no validation studies have been performed with a focus on dietary assessment during exercise. Only a small part of our research investigated dietary intake of athletes during competition (chapter 4). ${ }^{32}$ This was done using a questionnaire and by observation. Although observation is the best method available at the moment, it is also rather time consuming and therefore expensive. For this reason validated questionnaires for this type of observational research would be useful.

The development of tools that integrate dietary assessment as part of team processes to create a continual data collection (evaluate interventions, different phases of periodisation, effect of dietary counselling over time, integrate sport nutrition science with competitive sports) is also recommended. Generally speaking, athletes and their coaches are most likely to be willing to participate when they are assured that they will receive feedback on their dietary and nutritional supplemental intake, within a limited time frame. This means that the analysis of the results should be further developed and optimized in the future. Within the time frame of this research project we already developed a number of tools that can be used in dietary counselling of athletes. Implementing research tools as a part of the daily routine of athletes would enable sports dieticians to continuously monitor processes and empowers researchers to set up large longitudinal studies. Furthermore, this makes it possible to evaluate sports nutrition recommendations over time at different phases of periodisation within the same group of athletes. Implementation of these recommendations demands for an interdisciplinary way of working within professional sports teams. Should this not yet be the case, sports associations and (or) teams should be prepared to invest in (better) sports nutrition policies, including employing sport dieticians and providing budget for sport nutrition products, dietary supplements, and menu planning for training and competition. Sports associations should encourage and enable the education of their trainers, coaches and other staff in the essentials of nutrition. Finally, sports nutrition policies and practices should be evaluated and fine-tuned at a regular basis in terms of their effectiveness and contribution to the performance of athletes. 


\section{References}

1 Wardenaar FC, Steennis J, Ceelen IJ, Mensink M, Witkamp R, de Vries JH. Validation of web-based, multiple 24-h recalls combined with nutritional supplement intake questionnaires against nitrogen excretions to determine protein intake in Dutch elite athletes. Br J Nutr. 2015: 1-10.

2 Institute of Medicine. DRI Dietary Reference Intakes: Applications in Dietary Assessment. Washington (DC)2000.

3 Wardenaar FC, Maas T, Danen S, Pannekoek S. Richtlijn Wedstrijdsport. Dieetbehandelingsrichtlijnen. Rotterdam: 2010 uitgevers, 2013.

4 Hermans JD, Z. Voedingsinname van topatleten (in Dutch). BOK-verslag. Arnhem: NOC*NSF, 2006.

5 Braakhuis AJ, Meredith K, Cox GR, Hopkins WG, Burke LM. Variability in estimation of self-reported dietary intake data from elite athletes resulting from coding by different sports dietitians. Int J Sport Nutr Exerc Metab. 2003; 13: 152-65.

6 Nusser SM CA, Dodd KW, Fuller WA, Jensen HH. A User's Guide to C-SIDE (Software for Intake Distribution Estimation). Version 1.0. Dietary Assessment Research Series Report 8. 1996.

7 Potgieter S. Sport nutrition: A review of the latest guidelines for exercise and sport nutrition from the American College of Sport Nutrition, the International Olympic Committee and the International Society for Sports Nutrition. S Afr J Clin Nutr. 2013; 26: 6-16.

8 Achten J, Jeukendrup AE. The effect of pre-exercise carbohydrate feedings on the intensity that elicits maximal fat oxidation. J Sports Sci. 2003; 21: 1017-24.

9 Simonsen JC, Sherman WM, Lamb DR, Dernbach AR, Doyle JA, Strauss R. Dietary carbohydrate, muscle glycogen, and power output during rowing training. J Appl Physiol (1985). 1991; 70: 1500-5.

10 Hopkins WG, Hawley JA, Burke LM. Design and analysis of research on sport performance enhancement. Med Sci Sports Exerc. 1999; 31: 472-85.

11 Burke LM, Kiens B, Ivy JL. Carbohydrates and fat for training and recovery. J Sports Sci. 2004; 22: 15-30.

12 Burke LM. Re-Examining High-Fat Diets for Sports Performance: Did We Call the 'Nail in the Coffin' Too Soon? Sports Med. 2015; 45 Suppl 1: S33-49.

13 Betts J, Gonzalez J. Personalised nutrition: What makes you so special? Nutrition Bulletin. 2016: 353-59.

14 Recommended Dietary Allowances. National Research Council: Washington, DC, USA. 1989; tenth edition.

15 Nordic Council of Ministers. Nordic Nutrition Recommendations 2012: Integrating nutrition and physical activity. 2012.

16 Rossum CTM, van Fransen HP, Verkaik-Kloosterman J, Buurma-Rethans EJM, Ocké MC. Dutch National Food Consumption Survey 2007-2010: Diet of children and adults aged 7 to 69 years. RIVM, 2011.

17 Walsh M, Cartwright L, Corish C, Sugrue S, Wood-Martin R. The body composition, nutritional knowledge, attitudes, behaviors, and future education needs of senior schoolboy rugby players in Ireland. Int J Sport Nutr Exerc Metab. 2011; 21: 365-76.

18 Danaher K, Curley T. Nutrition Knowledge and Practices of Varsity Coaches at a Canadian University. Can J Diet Pract Res. 2014; 75: 210-3.

19 Nattiv A, Loucks AB, Manore MM, et al. American College of Sports Medicine position stand. The female athlete triad. Med Sci Sports Exerc. 2007; 39: 1867-82.

20 Gilbert N. Conference on "Multidisciplinary approaches to nutritional problems". Symposium on "Performance, exercise and health". Practical aspects of nutrition in performance. Proc Nutr Soc. 2009; 68: 23-8.

21 Valliant MW, Emplaincourt HP, Wenzel RK, Garner BH. Nutrition education by a registered dietitian improves dietary intake and nutrition knowledge of a NCAA female volleyball team. Nutrients. 2012; 4: 506-16.

22 Beck KL, Thomson JS, Swift RJ, von Hurst PR. Role of nutrition in performance enhancement and postexercise recovery. Open Access J Sports Med. 2015; 6: 259-67.

23 Garthe I, Raastad T, Sundgot-Borgen J. Long-term effect of nutritional counselling on desired gain in body mass and lean body mass in elite athletes. Appl Physiol Nutr Metab. 2011; 36: 547-54. 
24 Bettonviel AE, Brinkmans NY, Russcher K, Wardenaar FC, Witard OC. Nutritional Status and Daytime Pattern of Protein Intake on Match, Post-Match, Rest and Training Days in Senior Professional and Youth Elite Soccer Players. Int J Sport Nutr Exerc Metab. 2015.

25 Thompson FE, Dixit-Joshi S, Potischman N, et al. Comparison of Interviewer-Administered and Automated Self-Administered 24-Hour Dietary Recalls in 3 Diverse Integrated Health Systems. Am J Epidemiol. 2015; 181: 970-8.

26 Zoellner J, Anderson J, Gould SM. Comparative validation of a bilingual interactive multimedia dietary assessment tool. J Am Diet Assoc. 2005; 105: 1206-14.

27 Touvier M, Kesse-Guyot E, Mejean C, et al. Comparison between an interactive web-based selfadministered $24 \mathrm{~h}$ dietary record and an interview by a dietitian for large-scale epidemiological studies. Br J Nutr. 2011; 105: 1055-64.

28 Liu B, Young H, Crowe FL, et al. Development and evaluation of the Oxford WebQ, a low-cost, web-based method for assessment of previous $24 \mathrm{~h}$ dietary intakes in large-scale prospective studies. Public Health Nutr. 2011; 14: 1998-2005.

29 Baker LB, Heaton LE, Stein KW, Nuccio RP, Jeukendrup AE. Validity and relative validity of a novel digital approach for 24-h dietary recall in athletes. Nutr J. 2014; 13: 41.

30 Barnard JA, Tapsell LC, Davies PS, Brenninger VL, Storlien LH. Relationship of high energy expenditure and variation in dietary intake with reporting accuracy on 7 day food records and diet histories in a group of healthy adult volunteers. Eur J Clin Nutr. 2002; 56: 358-67.

31 Goris AH, Meijer EP, Kester A, Westerterp KR. Use of a triaxial accelerometer to validate reported food intakes. Am J Clin Nutr. 2001; 73: 549-53.

32 Wardenaar FC, Dijkhuizen R, Ceelen IJ, et al. Nutrient Intake by Ultramarathon Runners: Can They Meet Recommendations? Int J Sport Nutr Exerc Metab. 2015. 


Athletes competing at the highest levels within their sports categories differ from the general population in many ways. They are considerably more physically active and their daily pattern is characterized by intensive training routines, periodisation and competition. Hence, adequate intake of energy and nutrients is of great importance for this population to ensure optimal performance and recovery during training or competition and also to minimize health risks. Several athletes experience difficulties in meeting the recommendations or their personal goals.

Current methods for dietary assessment in athletes still leave much room for improvement. The preferred five-step, multiple pass, 24-hour recall method is highly standardized and considered to produce a reliable estimation of dietary intake. Next to this, other methods are in use, i.e. those using food records, to assess the adequacy of the diet of athletes. As recommended for years, the use of estimated average requirement (EAR or AR) is preferred as a reference standard, but nevertheless the Recommended Dietary Allowance (RDA) is still most often used for assessment of the athlete's diet. Only a relatively small number of European studies have been published compared to those from the USA and Australia. The use of nutritional supplements has increased over the years, both by athletes and by the general population, but data relating to the dietary intake of-, and nutritional supplement use by athletes in the Netherlands is lacking. The same holds true for our knowledge on the current situation regarding intake levels from the basal diet of well-trained competitive Dutch athletes. The introduction of web-based dietary assessment tools makes it possible to include large samples at relatively low costs.

The main objective and starting point of this thesis was to obtain a better understanding of the current nutritional intake of (sub)elite athletes in the Netherlands and to evaluate current practices in view of the existing guidelines and developments in the field. The thesis focuses in particular on the intake of macro and micronutrients from the basal diet and the use and contribution of nutritional supplements to these figures. The Dutch Sport Nutrition and Supplement Study (DSSS) described dietary intake of a large representative group of well-trained competitive athletes belonging to the international elite, who are the best in their age group or are at least active at the highest national level in their sport disciplines. All athletes exercised for more than 9 hours a week, and in many cases multiple times a day. The novelty of this study arises from its use of properly validated dietary assessment and evaluation methods and the large sample size collected in a relatively short amount of time (3 years). Since the beginning of this century only a limited number of studies have been published with such a large sample size comparable to the present studies for, a: the dietary assessment survey described in chapters $3 a$ and $3 b \quad(n=553$, including both men and women categorized in the disciplines of endurance, team and strength sports based on 20 different types of sports) and the cross-sectional nutritional supplement questionnaires, and b: the general population ( $n=1544$, both men and women representing ages in a range of $15-80$ 
years), and c: elite athletes ( $n=778$, both men and women, of which $51 \%$ had an elite status from the Dutch Olympic committee).

Chapter 2 describes the validation of the method used, specifically focussing on protein intake. A representative group from the DSSS, consisting of 47 Dutch elite and talented athletes was included. Estimated mean dietary protein intake was $110 \pm 33.0 \mathrm{~g} / \mathrm{d}$ estimated by 24 -hour recalls and questionnaires, versus $141 \pm 38.2 \mathrm{~g} / \mathrm{d}$ based on Nitrogen excretions in urine. The difference was $25.5 \pm 21.3 \%$ between the methods $(P<0.05)$ which is comparable to results reported previously in other (more sedentary) populations. We found a reasonably good association between methods for protein intake of 0.65 (95\% Cl 0.45-0.79). On an individual level, under-reporting was greater with higher protein intake than with lower intake. In conclusion, combined, multiple, 24-hour recalls and questionnaires underestimated protein intake in these young elite athletes equal to that reported for non-athlete populations. The method proved to be suitable for ranking athletes according to their protein intake as needed in epidemiological studies. On an individual level, the magnitude of underestimation was about equal for all athletes, except for those with very high protein intake.

Chapter 3a describes the use of web-based 24-hour dietary recalls and questionnaires obtained within a 2-4 week period for 553 Dutch well trained athletes $(20.5 \pm 4.5$ years for men and $20.7 \pm 5.4$ years for women). On average 2.83 days per person were reported with energy intake ranging between 2566-2985 kcal and 1997-2457 kcal for men and women, respectively. Mean intake of energy and macronutrients of male endurance athletes was higher than that of team athletes but similar to that of strength athletes. Female endurance athletes reported higher mean intakes compared to both team and strength athletes. Most athletes, but not all, met the Dutch (general) EAR for carbohydrate $(2.9 \mathrm{~g} / \mathrm{kg} / \mathrm{bw})$ and protein $(0.6 \mathrm{~g} / \mathrm{kg} / \mathrm{bw})$. Overall, $80 \%$ of the athletes met the sport nutrition recommendation of $1.2 \mathrm{~g}$ of protein per $\mathrm{kg} / \mathrm{bw}$, but $50-80 \%$ did not meet the recommendation of $5.0 \mathrm{~g}$ or more carbohydrate per $\mathrm{kg} / \mathrm{bw}$ as advised in current sports guidelines. Overall, only small differences existed in mean energy and macronutrient intake between elite endurance, strength and team sports athletes. Furthermore, the majority of the athletes was able to meet the generally accepted recommendation for protein, but carbohydrate intake was low to moderate in most athletes, between $3-5 \mathrm{~g} / \mathrm{kg} / \mathrm{bw}$.

Chapter $3 b$ describes the adequacy of micronutrient intake of the same population as described in chapter $3 a$, using the same methods. Both users and non-users of nutritional supplements reported inadequate intakes of several micronutrients. In the majority of both users and non-users, vitamin D intake was below AR if dietary supplements (DS) were not included in the analysis. Including DS improved vitamin D intake but still a substantial part of the athletes, both men and women reported intakes below the AR. Non-users of dietary supplements were particularly at risk for low intakes of vitamin B1, B2 and vitamin A. They also reported low intakes of vitamin B3, vitamin C and selenium. As the use of sport nutrition products (SNP) only marginally contributed to micronutri- 
ent intake, users of SNP were also at risk for low intakes of vitamin B1, B2 and vitamin A. Mean basal iron intake was reported below the AR in a substantial group of women, both users and non-users. The additional iron intake from DS in women mainly compensated for low iron intakes. For most micronutrients, use of nutritional supplements does not completely compensate for intakes below AR. Intakes above the UL were only reported by a few athletes.

Chapter 4 focuses on dietary intake during exercise in competition. Male and female ultramarathon runners were included ( $n=68$, with age $46.5 \pm 7.1$ y) reporting their routine dietary intake during three independent days using a web-based $24-\mathrm{hr}$ recall and questionnaires. In both men and women, habitual mean carbohydrate $(\mathrm{CHO})$ intake was lower than recommended, as was mean protein intake by women. $\mathrm{CHO}$ intake during the race was $<60 \mathrm{~g} / \mathrm{h}$ in $75 \%$ of the athletes. A large variation in nutrient and fluid intake was seen. Gl distress during the race was reported in $82 \%$ of the runners; severe GI distress was low. In general, moderate, mostly negative, correlations with nutrient intake were seen for $\mathrm{GI}$ distress.

Chapter 5 reports that two-thirds of the respondents, individuals from the general population, reported having used DS and SNP during the last twelve months. Women and older people reported the highest DS use. The highest use of SNP was reported by regularly exercising men and younger people, who mentioned improvement of sporting performance as their main objective. The most frequently reported DS were multivitamins and vitamin C and, for SNP, energy drinks and isotonic drinks. Health considerations were the most important motivation. Remarkably, a substantial part of the more or less sedentary respondents also indicated to use SNP for improving sporting performance. It can be questioned whether the use of SNP fits all respondents' physical activity needs. The study confirms that both DS and SNP are widely used among the general population.

Chapter 6 complements the research part of the thesis by describing the association between nutritional supplement use and those receiving dietary counselling or not. Of 778 elite athletes, 97.2\% had used nutritional supplements at some time during their sports career, whereas $84.7 \%$ indicated having used supplements during the last 4 weeks. The top ranked supplements used over the last 4 weeks from dietary supplements, sport nutrition products and ergogenic supplements were multivitamin and mineral preparations (42.9\%), isotonic sports drinks (34.1\%) and caffeine (13.0\%). After adjustment for elite status, age, and weekly exercise duration, dietary counselling was found to be associated with a higher prevalence of the use of vitamin $D$, recovery drinks, energy bars, isotonic drinks with protein, dextrose, beta-alanine, and sodium bicarbonate. In contrast, dietary counselling was inversely associated with the use of the combination of 2-3 vitamins, calcium, vitamin E, vitamin B2, retinol, energy drinks, and of BCAAs (branched-chain amino acids) and other amino acids. Receiving dietary counselling seemed to result in better informed choices with respect to the use of nutritional supplements related to performance, recovery, and health. 
Finally chapter 7 discusses the results found and provides suggestions for further research and possible practical implications. A general conclusion is that protein intake was found to be sufficient in most athletes, but the average intake of carbohydrates was at the lower end of the available sport nutrition recommendations. At this stage the prevailing opinion among sports nutritionists is that moderate-high carbohydrate intake levels are to be preferred over "low-carb" for athletes, at least in competition and during periods of intensive training. However, this viewpoint is also subject to debate and some scientists call for lower or more varying carbohydrate intake strategies.

This also underlines the need to come to more individualized programmes for each athlete with new guidelines replacing generic recommendations. Based on the variation within subjects $\left(\mathrm{CV}_{\mathrm{w}}\right)$ found in our study the question can be raised as to whether athletes differentiate their dietary intake based on the specific needs for energy and macronutrients that fit with their mixed training programs and/ or multiple training sessions each day.

Micronutrient intake in the basal diet was found to be low for half of the vitamins and this is mostly, but not completely compensated by the use of DS. Given these findings, the question arises as to what extent this affects general health and performance of these athletes. Based on low micronutrient intake, particular seen in non-users of DS, the development of deficiencies over time might be possible.

It should be acknowledged that all self-reporting methods are prone to misreporting. However, in our population the degree of underreporting with our method is likely to be of the same magnitude as that of methods based on food records.

In conclusion, protein intake levels of well-trained Dutch competitive athletes appear to be in line with existing sports nutrition recommendations. Fore carbohydrates, current intake levels appeared to be lower than those described in existing recommendations.. Future research should reveal whether this practice is sub-optimal in terms of performance and recovery, or whether guidelines might need to be adapted to the practical situation. Intake via regular dietary intake of most micronutrients was found to be sub-optimal when compared with the estimated average requirements. The use of dietary supplements improved the quality of dietary intake, but not all athletes consumed these products. Including sport nutrition products in the analysis did not add much to total micronutrient intake. Therefore, athletes should make good informed choices in selecting foods with a high nutrient density. The daily use of a low dosed multivitamin (50-100\% RDA) and regular consultation of a sports dietician or a nutritionist are advised for all elite and sub-elite athletes. 



\section{Nederlandse samenvatting en praktijkadviezen}



De voedingsinname van wedstrijd atleten verschilt aanzienlijk van die van de gemiddelde bevolking. Atleten zijn lichamelijk zeer actief en hun dagindeling wordt bepaald door trainingsprogramma's en wedstrijden. Om optimale prestaties te kunnen leveren en goed te kunnen herstellen zijn een adequate energie- en voedingsinname van groot belang. Een goede basisvoeding, al dan niet aangevuld met sportvoedingsproducten en supplementen moet daarnaast ook de kans op gezondheidsproblemen verkleinen. In de praktijk blijkt dat een aanzienlijk aantal atleten er moeite mee heeft om te voldoen aan de algemene voedingsaanbevelingen en/ of hun persoonlijke doelstellingen op dit gebied.

De huidige manier van het afnemen van een voedingsanamnese bij atleten biedt vaak nog veel ruimte voor verbetering. Bij voorkeur zou er gebruik moeten worden gemaakt van de vijf-staps 24 uur recall methode. Deze methode is goed gestandaardiseerd en levert doorgaans een betrouwbare schatting van de voedingsinname op. In de sport wordt echter vooral vaak gebruik gemaakt van meerdaagse voedingsdagboeken. Door het gebruik van opschrijfmethode gedurende de dag wordt de voedingsinname beïnvloedt omdat sporters bewust of onbewust hun gedrag tijdens de registratie veranderen. Een directe opschrijfmethode geeft daardoor mogelijk een minder precies beeld van de werkelijke inname. Alhoewel er al jaren voor wordt gepleit om de gemiddelde behoefte $(G B)$ als uitgangsmaat te nemen voor het evalueren van de voedingsinname van groepen atleten, wordt in de praktijk nog bijna altijd de aanbevolen dagelijkse hoeveelheid $(A D H)$ gebruikt om de voedingsinname mee te vergelijken.

In vergelijking met Amerika en Australië bestaat er maar een klein aantal publicaties waarin de voedingsinname van sporters uit Europese landen wordt beschreven. Wereldwijd lijkt het gebruik van voedingssupplementen en sportvoedingsproducten onder atleten de afgelopen jaren te zijn toegenomen,maar Nederlandse gegevens hierover ontbreken. Daardoor en vanwege het ontbreken van gegevens over de basisvoeding bestaat er op dit moment maar een beperkt inzicht in de kwaliteit van de voedingsinname van Nederlandse wedstrijdsporters. Door het beschikbaar komen van voedingsregistratieprogramma's die werken via het Internet is het echter makkelijker en goedkoper geworden om de voedingsinname van grote groepen sporters te bepalen.

De belangrijkste doelstelling van dit proefschrift was om een beter inzicht te verkrijgen in de voedingsinname van Nederlandse topsporters en deze te vergelijken met de huidige richtlijnen en inzichten. Het onderzoek richtte zich op de inname van macro- en micronutriënten, en het gebruik van voedingssupplementen en sportvoedingsproducten. In de Dutch Sport Nutrition and Supplement Study (DSSS) is de voedingsinname van een grote groep wedstrijdsporters onderzocht. Deze sporters waren geselecteerd op basis van hun olympische status, en/of omdat ze tot de beste sporters in hun leeftijdscategorie behoorden, en/of tot de nationale- of internationale top. De deelnemers aan het onderzoek trainden meer dan 9 uur per week en vaak meerdere keren per dag. 
Een sterk punt van het onderzoek is dat de gebruikte methode voor het bepalen van de inname gedurende de looptijd werd gevalideerd door middel van een meervoudige 24-uurs metingen van de stikstofuitscheiding bij een aantal deelnemers in de urine.

Daarnaast is de inname bepaald in een relatief korte tijd, een periode van 3 jaar, en in een grote en zeer diverse groep sporters. Sinds 2000 is maar een beperkt aantal studies van vergelijkbare omvang gepubliceerd. Dit grote aantal deelnemers geldt zowel voor de studie naar voedingsinname, beschreven in hoofdstuk $3 \mathrm{a}$ en $3 \mathrm{~b}$ op basis van 553 sporters, de studie op basis van de cross-sectionele vragenlijst in een representatieve steekproef van de Nederlandse bevolking ( $n=1544$ mannen en vrouwen in de leeftijd van 15-80 jaar), en de studie met de algemene supplementen vragenlijst ( $n=778$ mannen en vrouwen, waarvan $51 \%$ met een NOC*NSF status).

Hoofdstuk 2 beschrijft een validatiestudie van de meervoudig afgenomen 24-uur recall via internet voor de eiwitinname. Deze werd uitgevoerd met een representatieve groep van 47 deelnemers die deelnamen aan de DSSS. De geschatte gemiddelde eiwitinname op basis van de 24 -uurs recalls en vragenlijsten was $110 \pm 33.0 \mathrm{~g} / \mathrm{d}$, in vergelijking met $141 \pm 38.2 \mathrm{~g} / \mathrm{d}$ gebaseerd op stikstof uitscheiding met urine. Dit betekent dat de recallmethode de eiwitinname onderschatte met $25.5 \pm 21.3 \%(P<0.05)$. Dit is vergelijkbaar met resultaten zoals eerder gevonden in andere (niet sportende-) doelgroepen. Wanneer gekeken werd naar de inname van individuele sporters werd er een redelijke correlatie gevonden (van $r=0.65,95 \% \mathrm{Cl}$ : 0.45-0.79). Op individueel niveau was de mate van onderrapportage vergelijkbaar, behalve voor sporters met een bijzonder hoge eiwitrapportage die in iets hogere mate leken te onderrapporteren. Ondanks deze onderrapportage is de methode geschikt voor het rangschikken van de eiwitinname van sporters zoals nodig in epidemiologische studies.

Hoofdstuk 3a beschrijft de energie- en macronutriënt inname van 553 Nederlandse wedstrijdsporters (mannen van gemiddeld 20,5 $\pm 4,5$ jaar en vrouwen van $20,7 \pm 5,4$ jaar) op basis van 24-uurs recalls en vragenlijsten. De mannelijke atleten rapporteerden een dagelijkse energie inname van 2566-2985 kcal en de vrouwelijke atleten van 1997-2457 kcal, op basis van gemiddeld 2,83 gerapporteerde dagen per persoon. Voor mannen was de gemiddelde inname van energie en macronutriënten hoger bij duursporters en krachtsporters dan bij teamsporters. Vrouwelijke duursporters rapporteerden een hogere inname van energie en macronutriënten dan kracht- en teamsporters. De meeste sporters rapporteerden een koolhydraat- en eiwitinname boven de gemiddelde behoefte die geldt voor de algemene bevolking (2,9 g koolhydraten per kg lichaamsgewicht en 0,6 g eiwit per kg lichaamsgewicht). Tachtig procent van de sporters realiseerde de meest gangbare sportvoedingsaanbeveling van 1,2 g eiwit/kg lichaamsgewicht, maar de koolhydraatinname van 3-5 g/kg was aan de lage kant van aanbevelingsrange van 3-12 gram per kilogram lichaamsgewicht. Van alle sporters haalde 50-80\%, afhankelijk per sportdiscipline, de sportvoedingsaanbeveling van 5,0 g/kg of meer koolhydraten niet. De absolute verschillen in energie- en macronutriënten inname waren klein tussen sportdisciplines. 
Hoofdstuk 3b beschrijft de micronutriënt inname van de 553 sporters die ook werden beschreven in hoofdstuk 3a. Zowel gebruikers als niet-gebruikers van voedingssupplementen en sportvoedingsproducten rapporteerden vaak lagere gemiddelde innames van micronutriënten dan wordt aanbevolen. Wanneer supplementen niet werden meegeteld in de berekening had het grootste deel van de sporters een vitamine D inname onder de gemiddelde behoefte. Wanneer het gebruik van voedingssupplementen wel werd meegenomen in de analyse verbeterde de vitamine D inname bij het grootste deel van de gebruikers van voedingssupplementen. Niet-gebruikers van voedingssupplementen en sportvoedingsproducten hadden ook een grote kans op een lage inname van vitamine B1, B2, B3, vitamine $C$ en vitamine $A$. Sporters die geen voedingssupplementen gebruikten, maar wel gebruik maakten van sportvoedingsproducten rapporteerden een iets hogere inname van vitamine C en vitamine B3 dan niet-gebruikers. De gemiddelde ijzerinname voor vrouwen bleek een aandachtspunt te zijn, zowel voor gebruiksters als niet gebruiksters van voedingssupplementen en sportvoedingsproducten. Suppletie compenseerde voor een lage micronutriënt inname met de basisvoeding, maar compenseerde meestal niet volledig lage innames op groepsniveau. Slechts bij een kleine groep sporters werden innames van vitamine B3, B6 en vitamine A (retinol) boven de aanvaardbare bovengrens gevonden.

Hoofdstuk 4 gaat vooral in op de voedingsinname van hardlopers tijdens inspanning. In deze studie werden 68 ultraduurlopers, zowel mannen $(n=55)$ als vrouwen $(n=13)$, geïncludeerd. De lopers hadden een gemiddelde leeftijd van 46,5 $\pm 7,1$ jaar. Vooraf rapporteerden de lopers hun basisvoedingsinname op basis van 24-uurs recalls en vragenlijsten. De gemiddelde dagelijkse koolhydraatinname was lager dan aanbevolen $(<5,0$ $\mathrm{g} / \mathrm{kg}$ ), en voor vrouwen was de eiwitinname ook lager dan aanbevolen $(<1,2 \mathrm{~g} / \mathrm{kg})$. Tijdens de race rapporteerde $75 \%$ van de lopers een inname lager dan 60 gram koolhydraten per uur. Er was een grote variatie in voedings- en vochtinname tussen personen. Tijdens de race had $82 \%$ van de lopers last van maagdarmklachten. Deze klachten waren meestal negatief gecorreleerd $(r:-0,3$ tot $-0.4, p<0.05)$ met voedingsinname (dit gold voor energie inname en koolhydraat-, vezel- en vochtinname). Een hogere voedingsinname was doorgaans geassocieerd met minder klachten.

Hoofdstuk 5 beschrijft een onderzoek naar de inname van voedingssupplementen en sportvoedingsproducten bij een representatieve steekproef van de Nederlandse bevolking bestaande uit 51\% mannen en 49\% vrouwen. Tweederde van de deelnemers rapporteerden het gebruik van één of meer productgroepen in de laatste twaalf maanden. Vrouwen en ouderen rapporteerden meer dan gemiddeld het gebruik van voedingssupplementen. Mannen die frequent sporten en jongeren die prestatieverbetering als een belangrijke motivatie zien voor gebruik van deze producten rapporteren het vaakst gebruik van sportvoedingsproducten. Vitamine $\mathrm{C}$, energiedrankjes en isotone sportdrankjes werden het vaakst gerapporteerd. De belangrijkste motivatie voor gebruik van dergelijke producten was het verbeteren van de gezondheid. Een substantieel deel van de mensen die niet (15\%) of zeer onregelmatig (33\%) aan sport deden rapporteerde wel 
het gebruik van sportvoedingsproducten, met als meest genoemd doel het verbeteren van de sportprestatie. Het is de vraag in hoeverre dergelijke producten passen binnen het energiebudget en de persoonlijke gezondheids- en prestatiedoelstellingen van deze doelgroep. De studie bevestigt het idee dat voedingssupplementen en sportvoedingsproducten veel worden gebruikt door de algemene bevolking. Toekomstig onderzoek dient onderscheid te maken tussen het gebruik van voedingssupplementen en sportvoedingsproducten omdat beiden op verschillende manieren bijdragen aan de voedingsinname van gebruikers.

Hoofdstuk 6 beschrijft het verschil in gebruik van voedingssupplementen en sportvoedingsproducten tussen sporters die wel of geen voedingsbegeleiding hebben ontvangen. Van de 778 sporters die in de studie werden geïncludeerd rapporteerden 97,2\% dat zij in hun carrière een of meer van deze producten hadden gebruikt. Over de laatste 4 weken rapporteerden $84,7 \%$ het gebruik van voedingssupplementen en/of sportvoedingsproducten. De belangrijkste producten die in de laatste 4 weken per categorie werden gerapporteerd waren multivitamine en mineralen supplementen (42,9\%), isotone sportdranken $(34,1 \%)$ en cafeïne $(13,0 \%)$. Na correctie voor NOC*NSF status, leeftijd en minuten inspanning per week bleek dat voedingsbegeleiding werd geassocieerd met een hogere rapportage van het gebruik van vitamine $D$, hersteldranken (koolhydraten-eiwit), energierepen, isotone dranken met eiwit, dextrose, Beta-alanine en natrium bicarbonaat. Sporters die voedingsbegeleiding ontvingen rapporteerden minder gebruik van combinatievitamines, calcium, vitamine $\mathrm{E}$, vitamine $\mathrm{B} 2$, retinol, energiedranken en vertakte keten aminozuren (BCAA's) en andere aminozuren. Op basis van deze gegevens lijkt het er op dat sporters die voedingsbegeleiding genieten frequenter supplementen rapporteren die een bijdrage kunnen leveren aan prestatie, herstel en gezondheid dan sporters die geen voedingsbegeleiding ontvangen.

Tot slot worden in hoofdstuk 7 de gevonden resultaten bediscussieerd. Een belangrijke eindconclusie is dat de eiwit inname van de meeste sporters voldoet aan de meest gangbare norm in de sport (1,2 gram $/ \mathrm{kg}$ ), maar dat de koolhydraatinname aan de lage kant is ten opzichte van de huidige aanbevelingen voor sporters. De basisvoeding van sporters, zonder supplementen, is voor ongeveer de helft van de bekeken vitamines lager dan aanbevolen in een deel van de sporters. In deze gevallen scoort meestal zo'n $10-40 \%$ van de sporters een vitamine inname onder de gemiddelde behoefte die werd gehanteerd als norm. Het gebruik van voedingssupplementen compenseert deze lage innames voor een deel, maar niet altijd volledig. Als gevolg van deze lage micronutriënt inname bij een deel van de sporters zouden op langere termijn tekorten in het hele lichaam kunnen optreden. Momenteel is er weinig bewijs dat een dieet met veel koolhydraten leidt tot een beter effect wat betreft trainingsadaptatie en prestatie dan een dieet met een gemiddelde hoeveelheid koolhydraten. Daarom is het van belang dat adviezen voor koolhydraten op het individu worden afgestemd op basis van de meest recente richtlijnen. Op basis van de binnen persoonsvariatie in de voedingsinname van de sporters in de huidige studie kan de vraag worden gesteld in hoeverre sporters op dit 
moment al variatie aanbrengen in hun koolhydraatinname op basis van hun persoonlijk dagverbruik aan energie en trainingsbelasting en -intensiteit. Alhoewel er reden is om aan te nemen dat de resultaten onderhevig zijn aan onderrapportage lijkt de mate van onderrapportage, qua orde van grootte vergelijkbaar met andere groepen en methoden.

Toekomstig onderzoek zal moeten uitwijzen in hoeverre de huidige koolhydraatinname suboptimaal is in relatie tot prestatie en herstel, of dat richtlijnen zouden moeten worden aangepast aan de huidige praktijk. De basisvoeding leverde vaak minder micronutriënten dan aanbevolen. De inname van voedingssupplementen verbeterde de kwaliteit van de voedingsinname, maar niet alle atleten gebruiken deze producten. Sportvoedingsproducten droegen maar weinig bij aan de micronutriëntinname. Sporters zouden meer aandacht moeten hebben voor de samenstelling van hun basisvoeding. Vooral producten met een hoge nutriëntdichtheid kunnen bijdragen aan het realiseren van een inname in overeenstemming met de aanbevelingen. Indien sporters moeite hebben om met hun basisvoeding een micronutriëntinname te realiseren die voldoet aan de aanbevelingen worden zij geadviseerd om dagelijks een laaggedoseerde multivitamine te gebruiken (50-100\% van de ADH) en een sportdiëtist of sportvoedingskundige te consulteren.

\section{Praktijkadviezen}

Dit proefschrift gaat in op de voedingsinname van wedstrijdsporters die presteren op hoog niveau. Het onderzoek heeft geleid tot meer inzicht in de huidige stand van zaken in Nederland. De inname van koolhydraten en een klein aantal micronutriënten (zoals vitamine $D$, vitamine $A$, vitamine B1 en B2 en ijzer) is voor een deel van de populatie lager dan de gemiddelde behoefte. Tegelijkertijd toont de studie aan dat 60-98\% van de sporters, afhankelijk van de gebruikte vraagstelling, gebruik maakt van voedingssupplementen en sportvoedingsproducten. Op basis van het onderzoek naar nutriëntinname kan worden geconcludeerd dat sporters vaak niet dagelijks deze producten gebruiken, waardoor het aandeel van deze producten aan de gemiddelde inname relatief beperkt is. Alhoewel het lastig is om op basis van groepsresultaat individuele uitspraken te doen, kunnen er aan de hand van de resultaten van dit onderzoek een aantal praktijkadviezen worden opgesteld.

1) De gemiddelde koolhydraatinname van de sporters in dit onderzoek lag tussen de 3$5 \mathrm{~g} / \mathrm{kg}$. Het huidige advies op basis van de beschikbare literatuur is om de koolhydraatinname af te stemmen op de individuele behoefte. Op basis van meerdere registraties per sporters hebben we kunnen vaststellen dat er maar een beperkte variatie bestaat voor de koolhydraatinname tussen dagen. Dit impliceert dat er extra nadruk zou moeten worden gelegd op het advies om, in het geval van meerdere trainingssessies per dag of op dagen waarop zeer intensief wordt ingespannen, naar 
een hogere koolhydraatinname te streven van tussen de 5 en12 g/kg lichaamsgewicht per dag.

2) Een deel van de gebruikers en niet-gebruikers van voedingssupplementen rapporteerde een lage micronutriëntinname van één of meer vitamines. Vooral bij de sporters die geen voedingssupplementen gebruikten is er geen sprake van compensatie door gebruik van een multivitamine en levert de basisvoeding in een aantal opzichten onvoldoende voedingsstoffen. Aangezien sportvoedingsproducten zoals dorstlessers en hersteldranken nauwelijks bijdragen aan de micronutriëntinname geldt voor alle sporters het advies om een laaggedoseerd multivitamine supplement te gebruiken (50-100\% van de ADH). Daarnaast dienen sporters aandacht te blijven besteden aan hun basis(sport)voedingsinname.

3) Tussen sporters bestaat er een grote variatie in koolhydraat en vochtinname tijdens inspanning. Dit is onder andere afhankelijk van persoonlijke doelstellingen, de ervaren meerwaarde van gebruik, de gevoeligheid voor maagdarmproblemen en omgevingsfactoren zoals temperatuur en luchtvochtigheid. Sporters dienen de noodzaak van voeding- en vochtinname te evalueren per type training en wedstrijd, en hier concrete geïndividualiseerde adviezen aan te koppelen. Het oefenen in het uitvoeren en realiseren van deze adviezen tijdens trainingen kan bijdragen aan de verdere optimalisering en realiseerbaarheid van de adviezen.

4) Sporters rapporteren het gebruik van een grote variëteit aan ergogene voedingssupplementen. Voor veel van deze producten ontbreekt de wetenschappelijke onderbouwing geheel. Aangezien prestatieverbetering het doel is van het gebruik van ergogene suppletie is het advies om de focus te leggen op de producten waar wel wetenschappelijke consensus over bestaat. Dit geldt momenteel voor cafeïne, creatine, Beta-alanine, natriumbicarbonat en nitraat (of nitraatrijke producten zoals bietensap). Na selectie van een supplement dient het gebruik zo goed mogelijk te worden afgestemd op het individu. Ook dient introductie een testfase te omvatten waarin intensief contact plaatsvindt tussen sporter en adviseur waarbij het advies verder wordt afgestemd op het individu.

5) De conclusies van dit proefschrift zijn relevant voor iedere professional werkzaam in de sport die bijdraagt aan het optimaliseren van sportprestaties. Voedingsinname is onlosmakelijk verbonden met kwaliteit van leven, presteren en herstel. Stafleden hebben een belangrijke functie om ongewenst of ongezond gedrag te signaleren. Daarnaast kunnen zij sporters van (aanvullend) advies voorzien en hen helpen de juiste keuzes te maken. Hiervoor is onderling overleg binnen het begeleidingsteam van een sporter over het soort advies, het gewenste gedrag en bijhorende doelstellingen essentieel. 



\section{Acknowledgments}


Although my interest in nutrition initially started during my time as a competitive cyclist, my professional sport nutrition career really began when I met Joris Hermans at the post-bachelor sports dietetics course. Instantly I felt a connection with this man who I later came to know as a great mentor. In all the years following, we kept in touch, became colleagues, developed courses and discussed sport nutrition, education and the role of research. I am very happy that I was part of this journey together with one of the world's best sports dieticians and mentors.

During the time that I was combining multiple roles within the HAN, working for both Paramedic studies and for Sport and Exercise studies, the former director of HAN Sport en Bewegen, Tjeerd de Jong supported my PhD candidacy. Tjeerd, it was a pleasure working with you. Thank you for your confidence!

My research career started in the professorship (in Dutch: lectoraat) of Victor Schreurs en Gertjan Schaafsma, who were very willing to support me in my first steps in sport nutrition science. They also introduced me to Professor Renger Witkamp and together we asked him to be my promoter during my PhD project. As Renger was interested in sports nutrition, although assessment of sports nutrition was not his specialty, our team was expended. Therefore Marco Mensink was included to give a physiological perspective and Jeanne de Vries joined the team as a specialist in measuring dietary intake. When I look back I appreciate what I have learned, and to be honest, I am not yet finished, there is so much more to learn. Renger, thank you for your positivity, your ability to see the person behind the science and your optimism. Marco, thank you for always bringing me down to earth with the simple question: "What do you want to be your message?" Thank you for showing me the structure in which a paper should be written. Finally, Jeanne, I have learned so much about the measurement of dietary intake and from a sport science perspective we can still learn a lot from the dietary assessment experience Wageningen University has to offer.

I would especially like to express my gratitude to Ingrid Ceelen, Naomi Brinkmans and Bo van Rooij and all students that participated in DSSS. I am proud that we managed to accommodate so many students within our team and that some managed to be co-author at one of my articles (Rianne, Emma, Jora, Roland, Lore and Britte). I am even more proud that Naomi and Bo where originally amongst them. You two were able to bring something extra to the project and we still embrace and use these additions to this day. My other colleagues of team SEN: Jan-Willem, Kristin, Tjieu and Cindy, thank you for always being there when I asked feedback on pieces during my writing process. Of course I would also like to thank all my other colleagues in our team Sports and Exercise Nutrition at the HAN University of Applied Sciences who are still members or were part of our team. You made my day. The fact that the team worked and that you took responsibility made my life a little bit easier as a team leader. Therefore I would like to thank you all: Heleen, Sarai, Shiannah, Nancy, Joline, Nick, Gert and, Pim. Further I also like to thank Eric Versluijs as co-director of our institute, thanks for your confidence in me as a colleague, working together is a pleasure! 
I am also grateful for the help and feedback of my nutritionist colleagues helping out including subjects in the study of the team nutrition of NOC*NSF, the CTOs and NTCS and my former colleagues of the InnoSportLab Papendal and Remko van den Dool and Koen Breedveld of the Mulier Institute. Also the critical conversations with our current Lector Prof. Dr. Luc van Loon were of help in preparation of the project and in building new ideas and plans concerning our expert team at the HAN.

I am happy to mention that some partners believed in the project from the beginning, such as Bart Coumans of the Doping Authority, the Association of Dutch Sports Dieticians represented by Anneke Palsma, Fit!vak represented by Ronald Wouters and NOC*NSF represented by Kamiel Maase.

During the last 2 years, my projects were embedded in the Eat2Move project financed by a regional grant from the province of Gelderland. This made it possible to invest a significantly higher amount of time in the PhD project resulting in delivering this booklet within 4 years after starting the process. Therefore I would like to thank all those partners who made this project possible! I also like to show my gratitude to the members of my thesis commission that were willing to judge the quality of my thesis.

Eljakim thank you for being such a good friend. Ed, you were one of the persons I always could count on during this period that also involved reconstruction of our new home. Mum, Dad, Gijs and Reinier and all those I call family, thank you for giving me a good start in life and always being there. Especially mum, Peter, Ineke and Oude Opa thank you for being there also for our children at moments that we needed to go to work. Finally, Bregje, Vlinder and Lieve you are the ones that matter the most to me. Thank you for being the most special part of my life. Let's do something fun! 


\section{List of publications}


This thesis

1. Wardenaar FC, Ceelen IJ, Van Dijk JW, Hangelbroek RW, Van Roy L, Van der Pouw B, De Vries JH, Mensink M, Witkamp RF. Nutritional supplement use by Dutch elite and sub-elite athletes: Does receiving dietary counselling make a difference? Int J Sport Nutr Exerc Metab. 2016 Sep 6:1-25.

2. Wardenaar F, van den Dool R, Ceelen I, Witkamp R, Mensink M. Self-Reported Use and Reasons among the General Population for Using Sports Nutrition Products and Dietary Supplements. Sports 2016, 4(2).

3. Wardenaar FC, Steennis J, Ceelen I, Mensink M, Witkamp R, de Vries J. Validation of multiple, web-based, 24-hour recalls against nitrogen excretions to determine protein intake in Dutch elite athletes. Br J Nutr. 2015 Dec 28;114(12):2083-92.

4. Wardenaar FC, Dijkhuizen R, Ceelen I, Jonk E, de Vries JH, Witkamp RF, Mensink M. Dietary intake of ultramarathon runners: can they meet the guidelines? Int J Sport Nutr Exerc Metab. 2015 Aug;25(4):375-86.

\section{Submitted articles this thesis}

5. Wardenaar FC, Brinkmans NYJ, Ceelen IJM, van Rooij B, Mensink M, Witkamp RF, de Vries JHM. Macronutrient intakes in 553 Dutch elite and sub-elite endurance, team and strength athletes: Does intake differ between sport disciplines?

6. Wardenaar FC, Brinkmans NYJ, Ceelen IJM, van Rooij B, Mensink M, Witkamp RF, de Vries JHM. Micronutrient intakes in 553 Dutch elite and sub-elite athletes: prevalence of low and high intakes in users and non-users of nutritional supplements

\section{Co-authored publications}

7. Jonvik K, Nyakayiru J, Van Dijk JW, Wardenaar F, Van Loon L, Verdijk L. Habitual dietary nitrate intake in highly trained athletes. J Sport Nutr Exerc Metab. 2016 Oct 21:125.

8. Wijnen A, Steennis J, Catoire M, Wardenaar F, Mensink M. Post-Exercise Rehydration: Effect of Consumption of Beer with Varying Alcohol Content on Fluid Balance after Mild Dehydration. Frontiers in nutrition. 2016 Oct 17;3-45.

9. Gillen JB, Trommelen J, Wardenaar FC, Brinkmans NY, Versteegen JJ, Jonvik KL, Kapp C, de Vries J, van den Borne JJ, Gibala MJ, van Loon LJ. Dietary Protein Intake and Distribution Patterns of Well-Trained Dutch Athletes. Int J Sport Nutr Exerc Metab. 2016 Oct 6:1-23. 


\section{Publications in Dutch}

10. Wardenaar, FC, Ceelen, IJM, Van den Dool, R, Witkamp, R, \& Mensink, M. Het gebruik van voedingssupplementen en sportvoeding door meer en minder actieve Nederlanders. Een inventarisatie op basis van het Nationaal Sport Onderzoek 2012 onder de Nederlandse bevolking. Nederlands Tijdschrift voor Voeding en Dietetiek (in Dutch) 2014;69(6):S1-S9.

11. Wardenaar FC, Maas T, Danen S, Pannekoek S. Performance nutrition guidelines (in Dutch: Richtlijn Wedstrijdsport voor diëtisten en sportvoedingskundigen), 2010 uitgevers, Rotterdam. $2^{\text {nd }}$ edition. 2014.

\section{Book in preparation}

12. Wardenaar FC, Engelen C \& van der Wilt H. Interdisciplinary cooperation in performance nutrition (in Dutch). Practical hand book for sports professionals.

\section{Voeding $N u$}

2016: Voeding bij krachttraining (togheter with Victor Mooren).

2015: Het laatste woord: Niveau van Sportvoedingsbegeleiding.

2008: Teff: feiten en cijfers onderzocht (togheter with Christel Verdonschot, Frits Matthijsen en Wim Wijers).

\section{Fietssport Magazine}

2016: Biertje; Biezza; Dipje; Route; Koolhydraten stapelen.

2015: Voedingsinname van wedstrijdrenners; Voedingsapps; Sportvoeding voor de jeugd; Trainen van voedingsinname.

2014: De reizende fietser; Recensie: sportvoedingsatlas met recept; Recensie: hardlopers kookboek met recept; De Renner Krabbe: voedingsanalyse; Recensie: alles over sportvoeding Voedingscentrum; Superfood.

2013: Koffie.

2012: Inname van koolhydraten; Buffetten; Rode bietensap; Chia.

2011: Voeding tijdens meerdaagse; Voeding voor de fietsvrouw; Eten uit de natuur; Melk de witte motor; Alcohol versus fietsen.

2010: Doping en voedingssupplementen?; Drankjes met Aloe Vera: Relatie tussen klimmen en optimaal gewicht; Alles over creatine.

2009: Voeding, de weg door je lichaam; Pasta versus brood; Poeders versus natuurlijke producten; Voedselveiligheid, Energiegels versus dorstlessers; Fietsdieet.

2008: Voedingssupplementen; Probiotica; Voeding voor, tijdens en na; Teff; Voeding tijdens fietsvakantie; Voeding en feestdagen. 
2007: Biologische voeding; Chocolade; Voeding tijdens TransAlp; Voedingtrends.

Relevant oral (scientific) presentations and posters

Invited speaker at ESPEN about sports dietetics (2014) and EFSMA workshop session about practical sport nutrition solutions (2015). Oral presentations at ECSS (2013/2014), Dutch Nutrition Science Days (2013/2014/2015/2016), Dutch Exercise Research Day (Dag van het Sport Onderzoek: DSO 2014). Poster presentations at ECSS (2013, 2014, 2016) and ESPEN (2014). Over 250 presentations for sports associations, teams and enterprises during the last 10 years. 



\section{About the author}


Floris Wardenaar was born in Amsterdam, the Netherlands, is married to Bregje van Geffen and is the father of two daughters Vlinder and Lieve. He was part of a family of five together with his parents and two brothers. Despite the fact that there was no previous history of competitive sports within the family, all the brothers were competitive in different areas of sport. At the age of fourteen Wardenaar started cycling, both on the road and the track. From that moment on his interest in performance nutrition grew. During his second year as a junior cyclist he was selected for the newly formed National track cycling team. As part of his cycling career Wardenaar collected over 30 stage places and victories. He studied nutrition and dietetics at the Hogeschool van Amsterdam (HvA, Amsterdam Applied University) with specific interest in sports nutrition. During this bachelor program he followed an internship at NOC*NSF writing the brochure: What to know about nutrition and Sydney in preparation for the Olympic Games at Sydney 2000. Together with his bachelor degree Wardenaar received his post bachelor degree of sports dietetics which was granted by NOC*NSF. Following this, Wardenaar started a master program at Wageningen University in human nutrition and physiology. During the second year at Wageningen, Wardenaar founded his own consultancy firm in sports nutrition advice and during the third year he was full-time Vice-president of the Dutch Chamber of Student Associations (LKVV). Subsequently he followed an internship at the Department of Kinesiology at the University of Texas in Austin and wrote his master's thesis on the interaction between alcohol consumption, exercise and blood glucose levels at SENECA, expert centre of HAN Sports and Exercise Studies at the HAN University of Applied Sciences at Nijmegen. He graduated in 2005 both in nutritional physiology and in nutrigenomics. At the start of 2006 Wardenaar took up the post of lecturer at the Institute of Paramedic Studies at the HAN. From that moment Wardenaar was also asked to cover the sports nutrition position of the professional TVM speed skating team as part of an agreement between this team and HAN Sports and Exercise studies. In 2007 Wardenaar was added to the Nutrition team of the Dutch Olympic Committee (NOC*NSF) and from 2010 he became a member of the research group of the professorate (in Dutch: lectoraat) Sports, Nutrition and Health. At the beginning of 2011 he moved completely from paramedic studies to Sports and Exercise studies. 2012 saw him take on a team leader role as senior lecturer of the expert team Sports and Exercise Nutrition with responsibility for education, research and consultancy within the Institute of Sport and Exercise. During this period Wardenaar was also president of the Dutch Association of Sports Dieticians. In September 2012 he commenced his PhD project in cooperation with Wageningen University, which was partly financed by a regional grant Eat2Move. At the beginning of 2013 he became program manager of work package 3 within Eat2Move and since 2014 he is team leader of the Team Nutrition of NOC*NSF. 
Het onderzoek in dit proefschrift werd financieel ondersteund door Eat2Move, gesubsidieerd door de provincie Gelderland.

Voor de financiële ondersteuning van de vermenigvuldiging van dit proefschrift gaat erkentelijkheid uit naar Wageningen University, Nutrisense en Sportsgrain.

Cover design: Britte van der Pouw

Layout: $\quad$ Floris Wardenaar and Datawyse

Printed by: Datawyse

Copyright (C): Floris Wardenaar 
